
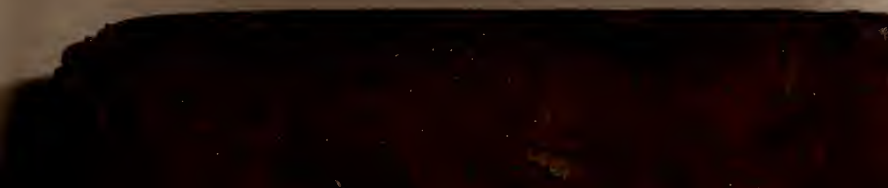

48

. 


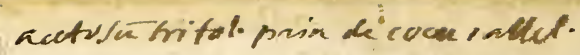

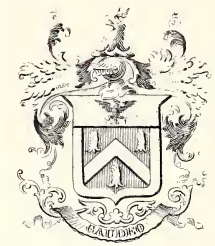

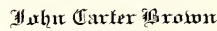
scitrarm

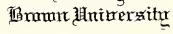

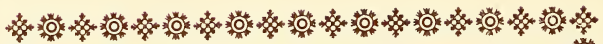
范, The John Carter Brown Library 눙 . 然 离 : \% Brown University Purchased from the Louisa D. Sharpe Metcalf Fund 然

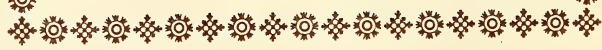




$$
1695
$$




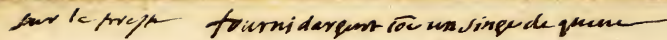

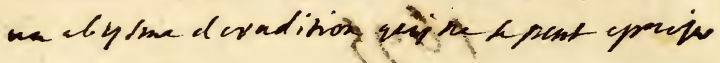
it 5 


\section{DE I A}

NAT URE,

ET DES CAUSES

D E L A

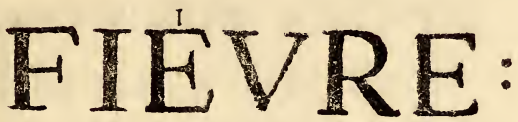

DU LEGITIME USAGE de la Saignée $\&$ des Purgatifs.

Avec des Experiences fur le Quinquina, \& drs Réfléxions Sur les effers de ce Remede.

Par M. MINOT, Docteur en Medecine.

. SECONDE EDITION, reveuë \& augmentée.

क⿻

A PARIS,

Chez La urent d'Houry tuë Saine Jacques, devant la Fontaine Saint Severin , au Saint Efprit. M. D C. X CI. Avec Privilege of Approbations. 


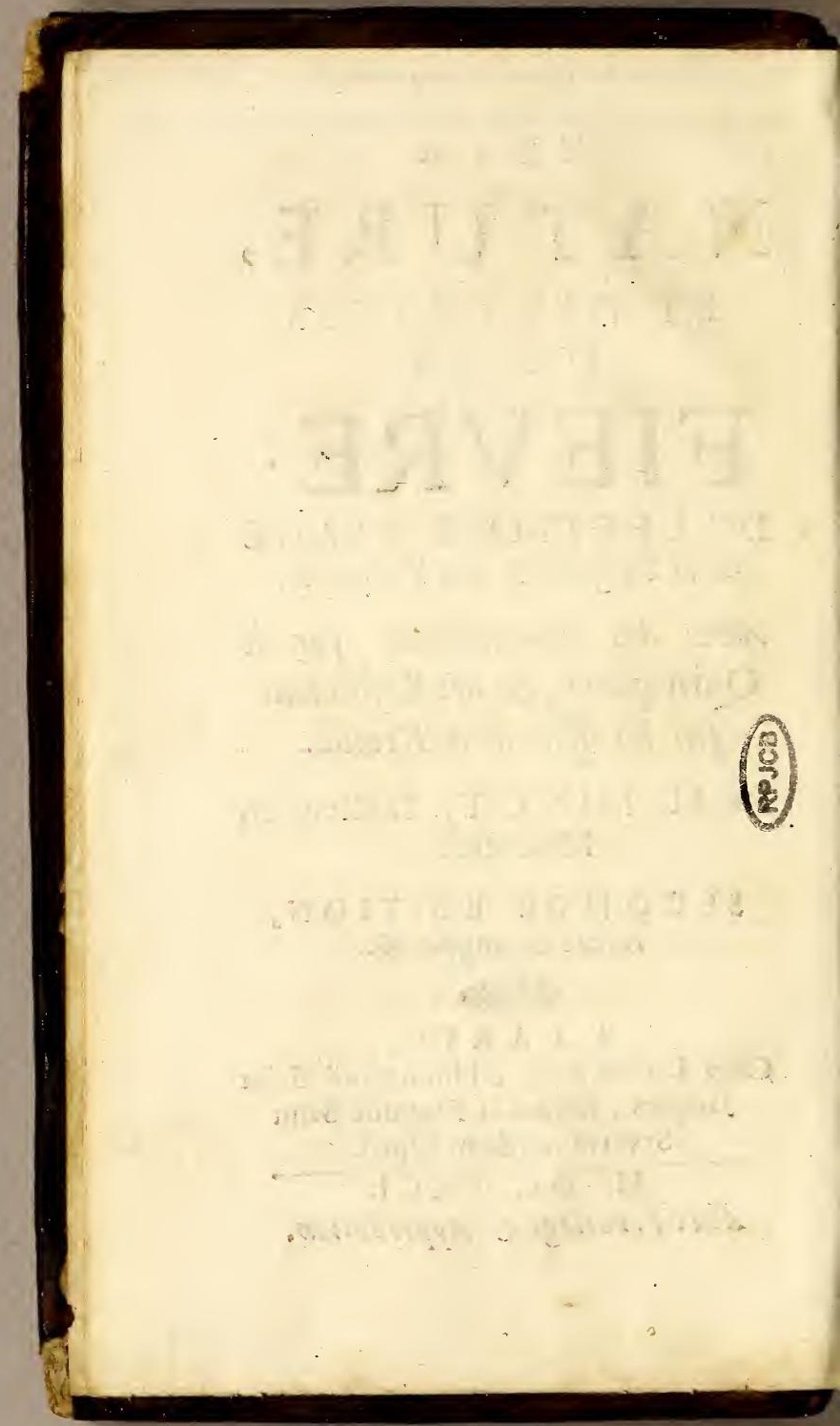




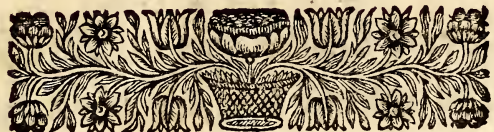

A

MONSIEUR FAGON,

PREMIER MEDECIN

de la feuë Reine.

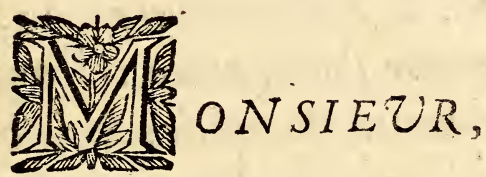

Il y a long-tems que je cherche les occafions de vous donner des marques de l'eftime finguliere que $j$ 'ay pour vous : je rien ay point trouvé qui me pa. ruft plus favorable que celle de vous dédier ce

$$
\text { a ij }
$$




\section{E P I T R E.}

petit Oworage. Mais. Monsieur, ie n'eft pas: feulement une marque d'eftime, g'eneft auffi une de reconnoifjance; $E^{2} j^{\prime} a-$ vovie quse sil y a quelque chofe de bon dans ce Traité, le Psublic vous en doit avoir l'obligation: Vous mavez dorné des lumieres pous la Pratique qui miont beureufement conduit; EF jay touijours remarqué tant de rapport des experiences avec vos raifonnemens, que jay efté convaincu quil n'y avoit qu'à vous Juivre pour fe faire une borne 


\section{E P IS T RE.}

metbode. En effet, tous ceux qui ont l'bonneur de vous connoitre demeurent d'accord, que dans la confufion étrange oì la Medecine fe trouve aujourd'buy par cette foule de Modernes, dont les uns regardent les Anciens avec mépris, El les autres s'en fervent pour autorifer leurs réveries, perfonne n'a mieux que vous démêlé le vray d'avec le faux, Ev ria fibien connu la jufte convenance quill y a entre les nousveautez $E S$ la bonne antiquité; C'eft donc avec rai-

$$
\text { a } \mathrm{ijj}
$$




\section{EPISTRE.}

fon que ciux qui veulent Sc perfectionnerdansl Art de gutrir, vous confiderent comme le plus excellent modele. Danscette penfée MONSIEuR, j'ay effayé de ne vous point perdre de vcuë; Ef flatté de l'approbation dont vous arve R bonoré mon Syftéme des Fiérores, j'ay crî que j'y pouvois ajouter une $M_{e-}$ thode de les guerir conforme àmesprincipes. Sur ce fondement, j'ayétabli des maximes, E'j'enay tiré des confeguences les plus natu ellesquilm a étépor: fible. C'eft ce que vous 


\section{E P I S T R E.}

connoitrez dans cette nous. velle Edition que je prends la liberté de vous offrir. Le goût El le difcernement que rous avezpourtontes les maticres de Pby/qque, luy procureront Sans doute une beureise deftinée, siallea l'avantage de vous plaire: ES vôtre Juffrage me fera un affuré garant de celuydu Public. Je fuis avec un profond repect

\section{MONSIEUR,}

Yôtre tres-humble \& tres: obeïflant ferviteur, MINOT. 


\section{APPROBATION.}

T'Ay fous-figné Docteur en Medecine de la Faculté de Paris, Medecin ordinaire de la feuë Reyne \& de Monfeigneur le Chancelier: Certifie avoir lû \& examiné ce Livre De la $\mathrm{Na}$ ture \& des caules des Fiévres, $\sigma$ o. dans lequel l'Auteur, non content de traiter ces matieres fur de bons principes, il y donne encore des avis pour la Pratique, qui peuvent beaucoup fervir dans la guerifon de ces maladies : \& cette Methode ne peut eftre que fort utile au $\mathrm{Pu}$ blic. FAIT à Paris ce vingtiéme Aouft 1691.

\section{BOURDELOT.}




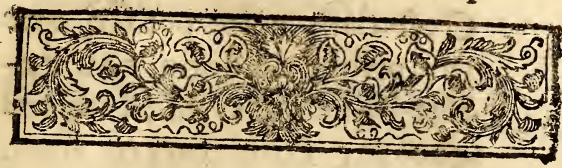

DE IA NATURE

ET DES CAUSES

DE LA

F I E VR E :

$A V E C$ QVEL $V E S$ Experiences fur le Quinquina, \& des Réfléxions Jur l'ation de ce Remede.

Uor qu'il n'y ait (1) rien dans la MeU. on ait tant écrit, que fur la Fiévre; cette macieren'eft pas fi épuif'ée, qu'elle ne puiffe encore recevoir de nouveaux éclairciffemens:

A 
2 De la Nature,

C'eft dans cette penfée que j’ay refolu de donner au $\mathrm{Pu}$ blic quelques Meditations que $j$ 'ay faites fur ce fujet.

ordre \& 8 Et afin de les expliquer avec divifion de ce ordre, j'examineray d'abord la doctrine des Anciens fur la Nature de la Fiévre ; je propoferay enfuite mon fentiment : aprés quoy je répondray aux objections quon me pourroit faire; \& dans la derniere Partie, je donneray des avis pour la Pratique. Et comme la Saignée \& la Purgation font les Remedes généraux, jeparleray du legitime ufage de la Saignée, \& jexamineray en quoy confifte la vertu \& l'action des Purgatifs ; \& enfin j'apporteray des experiences que jay faires fur le 2uinquirsa, qui confirmeront mon hypothefe. 


\section{or des caujes de lu Fićvre. 3}

月18

\section{PREMIERE PARTIE.}

Examen de la doctrine des

Anciens Jur la Fiérure.

C'Eft une chore affez é. tonnante, qu'une mala. die fi commune que la Fiévre, foit fi peu connuë, \& que tant de célébres Auteurs qui en ont écrit depuis fi long-tems, ne nous en ayent point donné de notions certaines. Ils ont définy la Fiévre, une Déf́nichaleur étrangere allamée, tion déve premierement dans le ceer, felon les o de là répanduë dans tont le corps par les arteres \& par les veines. Par cette définition qui vient des Arabes, \& que prefque tous les Medecins A ij 


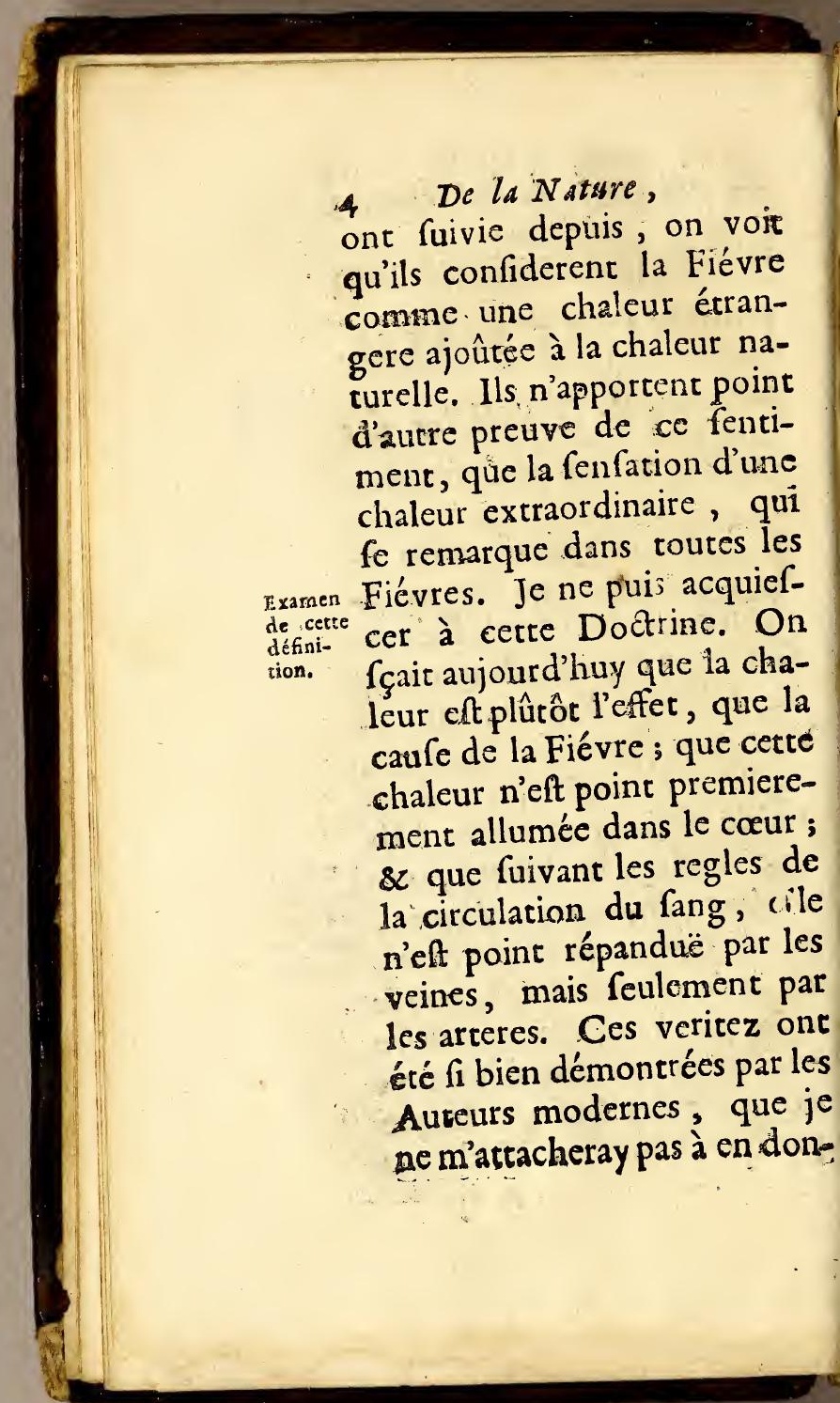


co des canges de la Fiévre. 5 ner des preuves. D'ailleurs, Que la cette chaleur étrangere que n'eft pas les Sectateurs des Arabes leur éveulent introduire, n'expli- trangere. que point les diverfes fenfations qui fe font chez nous, lors que nous avons la Fié-. vre; \& fi l'on examine dans: ce tems-là l'action de la chaleur \& des efprits, il eft impoffible d'y. rien comprendre. d'étranger.

Dans les réfléxions que jay: faites fur la chaleur, \& fur fes differens effets, je me fuis Ce qui fo arrêté plufieurs fois ̀̀ confi- parlave darer la vegetation des Plan- getation tes, \& particulierement la tes, feve, qui monte dans le tronc d'un faule avec une telle violence, qu'il en diftille de l'eau par les nouds des branches, \& par les feuilles auffi abondamment, que s'il tomboir

A iij 
6.

\section{De la Nature,}

une groffe pluie. Si alors un Paifan, qui auroit du bon fens, me demandoir raifon de cét effet, \& que je luy répondiffe qu'une chaleur étrangere fe feroit introduite dans le tronc de cét arbre, \& qu'elle en agiteroir la feve, je craindrois quil ne me dir : Comment cela fe peut - il faire? Eft-ce qu'un zutre Soleil viendroit augmenter la chaleur ordinaire qui fait que cét arbre pouffe fa feve ? Nous voyons tqus les ans arriver la même chofe, à me. fure que la chaleur du Printems fe renouvelle, \& cetre chaleur ne nous paroît pas. Ex pas étrangere.

lanalogie qu'il

y a entre

Cette penf'é m'a fait faire certe vegetation, \& cells des Ani. maux.

réfléxion fur l'analogie qui ell entre la vegetation des Plantes $\&$ celle des Animaux, 
do des canfes de la Fiévre. 7 2 fur les defordres qui peuvent arriver à l'une \& 2 à l'autre : furquoy jay formé ce raifonnement. Si le Soleil par fa chaleur. fait paffer par les tuyaux des Plantes l'humidité \& les autres principes qui fervent à leur vegetation, \& s'il eft vray qu'il fe rencontre quelquefois dans les canaux de ces Plantes, des marieres groflieres qui fon obftacle à la circulacion de la feve; alors par un mouve. ment qu'on appelle fermentation, les principes actifs agiront fur ces matieres, les rarefieront, \&cpoufferont dehors ce qui fe trouvera d'impur \& d'inurile à la nourriture de la Plante. Cela fe voit par les tubercules, par les champignons, $\&$ par les autres fuperfluitez, qui paA 
8

\section{De la Nature;}

roiffent fovvent fur les Plan. tes; \& en tout cela il n'y a rien d'etranger.

Ne peut-on pas raifonner de la même maniere à nôtre ćgard, fi l'on confidere que l'air s'introduit dans les poumons, qu'il fe mêle avec le fang, \& qu'il peut en augmenter la chaleur : tellement que s'il fe trouve dans les veines des matieres indigeftes, 2 des fucs impurs, les ef prits fe mettront en mouvement pour les digerer, \& exciteront une fermentation, qui fera forsir fur la peau des. ébullitions, \& caufera des fueurs : \& cettc fermentation peut être appellée Fiévre. Cependant comme cét air $\&$ ces fucs font des chofes qui nous font familieres \& domeftiques, il me femble 
6. des caufes de la Fiévre. qu'il n'eft pas raifonnable de dire que la Fiévre eft caufée par une chaleur écrangere, \& contre nature.

Mais il faut entrer plus avaut dans le fond de la doftrine des Anciens. Hs ont divifé les Fiévres en putrides. \& non putrides. Les Fiévres non putrides font de trois fortes, les Ephemeres ou Fiévres d'un jour, , les Continuës fimples, \& les Hecliques. Les Fiévres putrides font Continuës ou Intermit. tentes. Je ne veux pas entrer dans le d'étail de toutes les autres fubdivifions de Fiévres, it feroit trop long, \& prefque infiny.

La Fiévre Ephemere, felon que is les Anciens, eft une chaleur etrangere \& contre nature, Epheme. cauf'ee par l'inflammation des infara: 


\section{Io De la Nature,}

des efprits.

efprits, ou de la partic la plus fubtile du fang. Mais il n'eft pas facile de s'imaginer que les efprits qui font exactement mélez avec le fang, puiffent être agitez ou échauffez féparément du refte de la mafle. Les efprits font les principes actifs $\&$ dominans dans toures les fonctions des Animaux, \& leur union avec les aurres principes eft fi parfaite, qu'il eft impoffible de les féparer que par la mort : fi bien quion ne fçauroir concevoir que les efprits foient agitez dans le fang, qu'en mếme tems on ne foir perfuadé que tout le refte de la mafle eft aufi en agitation: Et fi cette agitation étoit affez violente pour enflammer les efprits, il eft certain qu'elle cauferoir plûtôt une Fiévre 
di des caufes de la Fiévre. II ardente, ou une Phrenefie, qu'une Ephemere. Il y abien plus d'apparence de croire, que dans cette Fiévre il 'ation de que dans cetce Fievre il n'y touie la 2 pas affez de mauvaifes hu- maffe du meurs, ou que le fang n'eft pas affez mal difpolé pour entretenir long-tems la fermentation : fi bien qu'on ne doir confiderer la Fiévre Ephemere, que comme une legere émotion de la maffe du fang. Je conçois bien que lors que le fang eft dans une grande agitation, les efprits font échauffez; mais je fô̂tiens qu'ils ne font point enflampez, puifque toute inflammation fuppole privation de mouvement : ce qui cauferoir neceffairement des. fymptomes, qu'on ne voit point paroître dans les Fié. vres Ephemeres. 
I2

Que ta La caufe qu'ils donnent $\partial^{2}$ continuë la Fiévre Continuë fimple, fimple, ne confifte pas. dăs l'inAammation du fang córenu däs vaífeaux. n'eft gueres mieux établie. Ils la font confifter dansl'inflammation du fang contenu. dans les grands vaiffeaux, depuis les aines jufquaux aif felles. Cette opinion ne me femble pas bien fondee: Car outre que. linflammation du fang $\&$ des efprits réparément n'elt pas foûtenable, comme je viens de le remarquer, \& quainfi cette diftinQtion ne fçauroit faire une difference effentielle entre la. Fiévre Ephemere \& celle-ci; on fçait que le fang qui eft dans la poitrine az dans le bas ventre, c'eft-à-dire, depuis les aines jufqu'aux aiffelles, coule inceffamment dans toutes les parcies du corps. De forte que par les regles de 12 
\& des caufes de la Fiévre. 13 Circulation, la fource de cetre Fiévre qui étoir bornée par les aiffelles \& par les aines, feroir bien-tốr répanduë dans tout le reite du corps. Aprés tout, je ne comprends pas ce qu'on entend par l'inflammation du fang dans les veines :- Cetre doctrine eft fi peu próbable, que je m'étonne de ce que tane d'habiles gens l'ont receuë, \& l'enfeignent encore aujourd'huy.

L'explication que les Anciens ont donnée de la Fiévre Hectique, ne fatisfera pas davantage : Ils la font confifter dans une chaleur é- tes foli: trangere, qui réfide dans les parties folides, dont elle confume toute la nourriture \& toute l'humidité. Mais ourre que cette explication ne fe pas dans les par- 
14

De la Nature,

rapporte pas à leur définition générale, qui êtablir le foyer des Fiévres précilément dans le cour; il eft conftant que cetre chaleur confumante, $\&$ inherente aux parties folides, eft mal érablie, puifque rien n'eft chaud dans nô. tre corps que par la communication du fang $\&$ des efprits. Il me femble qu'il feroit plus raifonnable de croire que la Fiévre Hectique 'Qu'elle qui fuccede ordinairement dépend aux autres Fiévres, vient de puifemét l'épuifement de ces mêmes prits.l efprits, qui ayant été prefque confumez dans les maladies précédentes, font incapables de produire une bonne fermentation, $\&$ une parfaite digeftion des fucs deftinez à la nourriture des parties. Ajoûtez ̀̀ cela, que 
Hodes caufes de la Fiévre. If dans les Maladies Chroniques les crifes \& les digeftions étant imparfaites, les humeurs impures ne font pas fuffifamment diffoutes \& $\mathrm{ra}$ refiées, pour paffer au travers des palfages étroits des vilceres \& des. routes infenfibles des perits vaifleaux : en forte qu'y faifant obltruction, el- défaut les bouchent le chemin, \& des fucs: interceptent les liqueurs ne- fiers. ceffaires à l'entretien des parties folides. Ainfi ces parties ne recevant pas les influences ordinaires de la chaleur 86 des efprits, ni les humeurs qui leur font convenables, doivent tomber dans une maigreur, \& dans une féchereffe extrême.

Quelques Modernes qui ont voulu deffendre la docerines des Anciens, ont dit, 
76 De la Nature,

que la Fiévre hectique ne confiftoit pas feulement dans une chaleur inherente aux parcies folides; mais quielle dépendoit auff de ce que le coeur ne leur envoye alors qu'une matiere impure, \& adufte, qui au lieu de les nourrir, leur imprime une chaleur f'eche \& habituelle. Mais cette exception contredit à l'efprit de l'Ecole, qui a fondé la divifion des Fiévres fur la triple fubitance de noftre corps, lors qu'elle a dit que la Fiévre Ephemere a fon fiége dans les efprits; les Fiévres humorales foit qu'elles foient fimples ou putrides, dans les humeurs, \& les heatiques dans les parties folides : d'où il eit aifé de juger, que la Doctrine des Anciens eft infoûtenable à cét égard. 
of des caufes de la Fiéure. 17 égard. Mais c'eft alfez s'arrefter fur la confideration desFiévres fimples, il faut paffer à l'examen des purrides, qui fera d'une plus longue dif́cuffion.

Les Fiévres putrides font divif'ées en conrinuës \& en intermittentes. Les continuës confiftent, felon eux, dans la corruption des humeurs conrenuës dans les grands vaiffeaux, dont la vapeur corrompuë allume continuelle-. ment au cour une chaleur qui produit la Fiévre. Et les; intermittentes font cauf'es: par une vapeur corrompü̈, qui s'éleve par intervalles de certaines minieres ou foyers où elle refide is comme de l'Eftomac, des: voutes du Eoye, de la Ratce, du Mefentere, \&c. \& qui eftans

Examen des Fié. vres puis. trides. 
8: De la Mrature,

portée au cour, y allume cette chaleur qui caufe la Fiévre.

ce que Si par ces termes de pour-

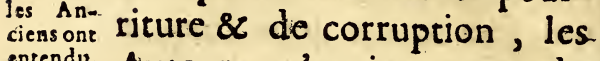
entendu: par la pourrites re du. Sang. Auteurs n'avoient entendu qu'une fimple alteration du fang, ou fi l'on veut, une difpofition à fe corrompre, on n'auroit pas de peine à s'accommoder de certe doatrine : mais cela ne paroît nulle pare dans leurs écrits, au contraire on trouve par tour les termies. de pourriture $\&$ de corruption rotale dans le fang, \& fi l'on fait reflexion fur ce qu'ils ont dit que la Fiévre continue fimple confifte dans l'infiammation du fang ${ }_{2}$ on n'aura pas de peine aे comprendre, que felon cux les Fiévres putrides qui font plus forres \& plas dang reufes que les au- 
Oo des caufes de la Fiévire. ro tres, viennent d'une veritable pourriture \& d'une rotale corruption, puifque cetre corruption doic eftre la fuite de l'inflammation. Cette docsrine eft fans contredic la doctrine de l'Ecole, \& elle eft conforme aux fencimens des plus celebres Medecins. On les voir tous les jours dans les Confultations lors qu'ils parlent diune Fiévre continuë, affurer qu'il y a de la pourriture dans les grandes veines, \& quand il s'agit d'une Fiévre intermittente, fôttenir que la pourriture eft dans les petits vaiffeaux. Mais. خे l'égard de la diftinction de la pourriture dans les grands ou dans les pecits vaiffeaux, it eft étrange que tant d'habiles gens foient dans cerce penfée, aprés que la circula B ij: 


\section{De la Nature:}

tion nous a fait voir que le. fang coule fucceflivement des. grands vaiffeaux dans les petits, \& qu'il n'eft pas aifé de concevoir qu'il y puiffe demeurer un feul moment fans paffer des uns dans les autres; de forte que s'il y a de la pourrisure ne pourricure dans les grandes. peut étre veines, elle fera bientolt dans dans les grands.

grafean les pecices, az sillye en a dans fans par- les petites, elle fera bientoft fer dans dans les grandes. 'D'où il eft aifé de conclure que la diftination des foyers de la Fié. vre continuë $\&$ de la Fiévre intermitrente eft mal-fondée, ou du moins qu'il eft impoffible que dans les Fiévres Irttermittentes ces foyers fubfiftent long-temps, ce qui feroir tres-oppol'e à leur durée:

Mais au fond commenz peur-on concevoir qu'il y aix. 
2i des caufes de la Fiévre. 2 \% dans les grands vaiffeaux des humeurs corrompuës:, qui paffent inceffamment dans le Cour, fans s'imaginer en même tems qu'elles étoufferont la chaleur naturelle, \& qu'elles cauferont une mort cer- lesa

taine? Ne voit-on pas, que lors que la Gangrene attaque quelque partie du corps, il faut neceffairement mourir, fi cette partie n'eft bien-toft guerie, ou fi elle n'eft promtement retranchée : Et puis qu'il: eft certain qu'on ne meurt alors que par la corruption, qui eft communiquée à tour le fang par les petits vaiffeaux; comment peuton concevoir que dans. les Fiévres putrides il y ait de la corruption dans les grandes veines, fans fuppofer en mếme temps que toutes ces Eié:

Si elle é: toir darrs le fang. toutes les Fiévres feroient. est.

.




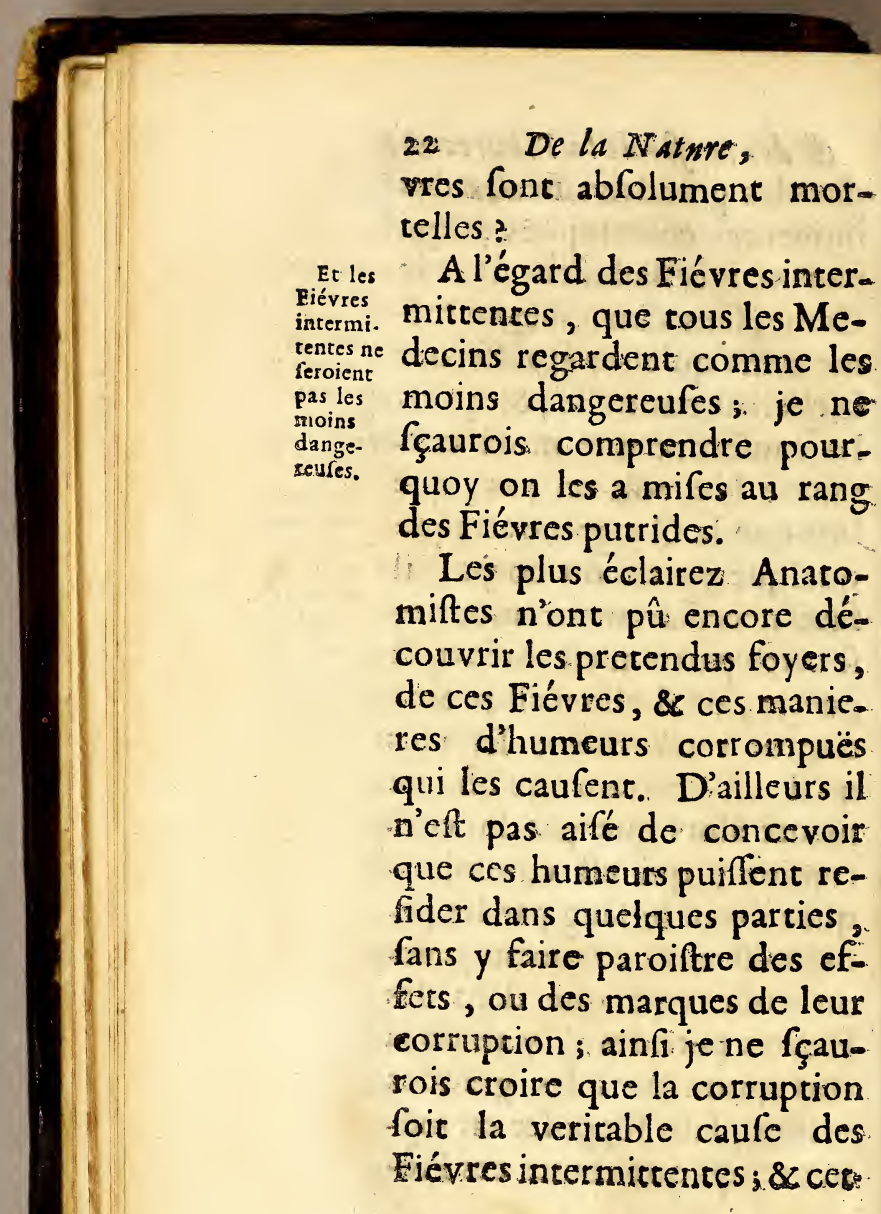


dín canfes de la Fiéure. 23 te explication des Eiévres putrides en general me paroift fi mal fondée, que je m"étonne de ce qu'on eft demeuré depuis tant de fiecles. dans cette opinion.

Il eft vray que les Anciens ane le: n'one pas connu la circula- mourerion du fang, mais ils ne laif- fang ems foient pas d'être perfuadez qu'il ne qu'il eftoit porté du centre à se corla circonference, pour la nourricure des parties : Cela fuppolé ils devoient croire que cette action ne fe pouvoit faire fans mouvement. Ils. fçavoient encore que d'abord que le fang eft extravalé, - comme il arrive fouvent dans. les inflammations, il fe corrompt aif'ement, \& fe convertit en pus, \& que cette corruption ne furvient que parce qu'il eft forci des vaiffeaux, \& qu'il a perdu fom 


\section{De la Nature,}

mouvement. Comment donc: de tout cela n'ont-ils pas conclu que le mouvement eftoir le principe de fa confervation, \& qu'il eftoit impoffible qu'il pût fe corrompre, dés-lors qu'il feroit en. quelque agitation.

Mais examinons les preuPreuves ves qu'on apporte de cette. dont on fe. fert pour éta. corrupfang. corruption du fang dans les. veines. On ditqu'elle eft demontrée par l'experience, qui nous fait voir tous les jours des Puftules \& des Abfcés dans la petite verole, $\&$. dans les Fiévres malignes, $\&$ que la caufe de ces Abfcés $\because$ Ies n'eft autre chole qu'une mapuftules \& le: Abfés qui arrivent dás les Fié. vies. tiére, qui fuppure dans. les grands vaiffeaux, d'où on conclut que le fang peut s'y corrompre, \& qu'il s'y corrompt effectivement.

$\Delta$ cette 
$\checkmark$ des caufes de la Fiévre. 25

A cette preuve on en ajoû- $2^{3} \cdot x_{2}$ te une autre tirće de la cou- couleur leur du fang des Febricitans, dus fes feleur du lequel paroift quelquefois fi corrompu dans les palettes, qu'il reffemble plûtoft à dù pus qu'à du fang. Enfin on $3^{\circ}$ Les allegue, que des Auteurs di- versqu'o des vers par l'ouverture des le fang. des vers par l'ouverture des veines, ce qui eft une preuve demonftrative de la corruption du fang. Voila ce qu'on a dit jufqu'à prefent de plus fort pour établir le fentiment * a des Anciens fur cette pourriture des humeurs: Voyons fi ces preuves fone aufi convaincantes qu'on le pretend.

Je commence par les puftules \& par les abfées de la petite verole, \&c d'abord il me femble que cét exemple 


\section{De la Nature,}

ace tes fert plutôt à prouver l'incomSuttules ne font pas une niarque de corsuption. patibilité de cette corruprion avec le fang, qu'à l'authorifer. Car par là on voit que les efprits qui font les principes dominans dans la maffe du fang, le purifient, \& chaffent hors des vaiffeaux toutes les impuretez qui y eftoient contenuës \& qu'ils n'y fouffrent foint de corruption; $\grave{z}$ quoy il faut adjoûter que ces puftules n'ont pas toutes les marques de corruption dés le monient qu'elles paroiffent ; il fe paffe encore biendu tems avant que le pus y foit for-

- mé, \& cette converfion du fang en pus, qui ne fçauroit fe faire dans les veines, \& qui depend abfolument de ce quill croupit hors des vaifceaux, eft zे mon fens un argument convaincant contre 
2 des caufes de la Fiévre. 27 eetre Doctrine de la corruption. Que fi les Anciens one dit que la matiere des puftules \& des abfés fuppuroie dans les grands vaiffeaux, ils fe font trompez, puifqu'il eft conftant que les abfcés ne fe font que par le depolt des humeurs dans les parties, $\&$ que les humeurs ne fe change en pus, que par. le fejour qu'elles font dans ces mêmes parties, \& par le re. pos qu'elles y trouvent.

A l'égard du fang qui paroît corrompu dans les palet. tes, il me femble que l'on defangs nous impole étrangement par ces apparences de couleur. Car outre qu'il n'a pas dans les palettes les veritables caracteres de corruption; eftil raifonnable de pretendre quili eft daas tes veincs de 12

$\mathbf{C}$ ij 
28 De la Nature,

même qualité qu'il paroift aprés qu'il en eft forty ? Dés que le fang eft hors des vaiffeaux, il perd fon mouvement \& fa chalcur, qui font les principes de fa confervation, fes parties fe defuniffent, $\&$ il eft aifé d'obferver qu'à mefure qu'il fe refroidit, fes efprits s'évaporent, \& fa couleur naturelle fe change; mais on ne peut pas dire que ce changement de couleur foit une marque effective de cordes dif ferentes coul urs dans le fang. jugement feroit-on du fang beau \& vermeil que l'on tire fouvent dans les Fiévres les plus malignes, de celuy qui paroift mauvais dans les Fiévres fimples $\&$ intermittentes, \& enfin de celuy des perronnes bien faines qui fe fone raigner par precaution, dont 
Oo des canfes de la Fiévre. 29 le fang n'a pas roûjonrs cette couleur rouge qui le fait juger de bonne qualité ? Seroitil jufte de conclure fur ces apparences, que le fang foir moins corrompu dans les Fiévres malignes que dans les Fiévres intermittentes, ou dans la parfaite fanté ? Il me femble qu'il n'y a perfonne de bon fens, qui voulut deferer à un fentiment fi mal fondé. Et pour faire encore reflexion fur le fang receu dans les palettes; il faut re. marquer que lors qu'on faigne un malade, le fang qui rombe fur l'affiere ou fur le bord de la palette elt toûjours d'un beau rouge, au lieu que celuy de la paletre. paroift tout corrompu : Si en confiderant celuy-cy on croit qu'il eft pourri; que dira-on

-C iij 


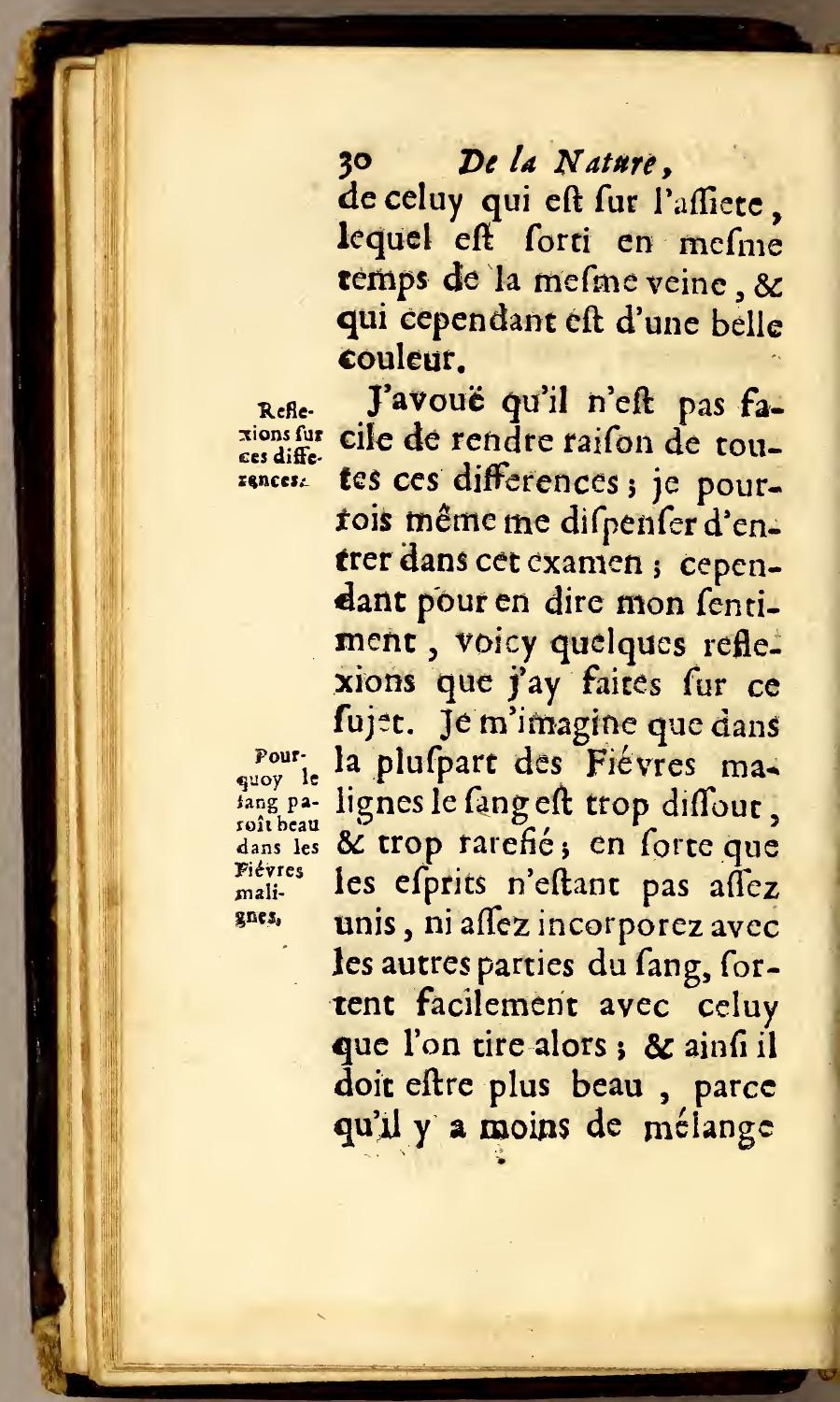


ò des caufes de la Fiévre. $3 i$ de parties groffieres, \& moins de confufion dans les principes. Ce qui me donne cetre penfée, c'eft que ces Fiévres font moins violentes que les autres, \& que le Pouls n'y eft pas fi élevé ; parce que les parries actives du fang étans moins unies, font moins d'ef. fort pour fe débarraffer des autres principes; ce qui faic que la fermentation $n^{2} e n$ eft pas fi fenfible. Ce raifonnement eft confirmé par la pra. tique ordinaire, qui fair voir que les frequentes faignées font nuifibles dans ces fortes de Fiévres, parce qu'elles épuifene les efprits, au lieu que les Acides, qui par leur qualité coagulante donnent de la confiftence au fang, \&e qui empêchent la diffipation de fes parties fpiritueufes,

C iiij 


\section{De la Natare,}

font alors d'un tres-grand ufage.

Pour- A l'égard des autres Fiéquop in paroint sorrom. pu dans tes autres Fiévies.

vres, on peur dire que les efprits font embarraffez dans des matieres indigeftes, \& que n'eftant pas dans une quantité fuffifante, ils ne fçauroient donner au fang cette belle teinture, qui le fait juger de bonne qualicé. Confiderez d'ailleurs, que toute la maffe du Sang étane alors en confufion \& dans une grande agitation, on ne doit pas efte furpris s'il paroift brouiillé , comme l'on n'auroit pas raifon de s'étonner que le vin funt troubie, fi on l'avoit tiré aprés avoir remué le tonneau.

a'ili ne Pour ce qui regarde les per-

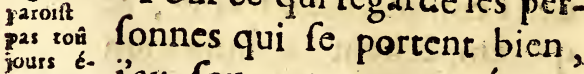
garemét jay fouvent remarqué qué 
or descaufes de la Fiévre. 33 ceux qui font d'un tempe. basu das rament chaud, qui font ceux portét d'une conftitution feiche, qui bien.

ont les veines groffes, \& le pouls élevé, \&z qui d'ailleurs fonc beaucoup d'exercice, \& vivent de regime, ont de plus beau fang que ceux qui fone d'un temperament moins chaud, qui font gras, qui ont les veines petites, \& font peu d'exercice. La raifon en eft, ce me femble, que ceux-là digerent plus aifément, que la circulation fe fait plus vite chez eux, \&z que le fang y doit eftre plus rarefié, parce qu'il y conferve plus de mouvement. Ce qui fe confirme par l'experisnce, puis qu'en Elté le fang qu'on tire aux malades, paroift plus beau qu'en Hyver, le fang eftanc alors plus rarefié. 


\section{De la Nature,}

J'ay confideré aulfi, que le fang qui retourne au coeur par la circulation, y raporte le refte des fucs que les Arteres avoient porté dans toures les parcies pour leur nourriture : si bien que fi on le tire des veines dans ce tems-là, il ne doit pas paroiftre de belle couleur, ni bien purifié, au licu qu'aptés plufieurs circulations, il fera plus épuré , \& paroiftra beau. coup plus bean, \& fur tout en ceux qui feront du temperament chaud, dont je viens de parler.

On peut encore penfer que le fang n'eft pas toûjours egalement chargé des fuperfluitez des alimens; cette circonftance dépend de la difpofition \& du befoin des parties, qui reçoivent plus ou 
¿ des caufes de la Fiéure. noins de fucs qu'il n'en faut our leur nourriture; elle lépend auffi de la qualifé de es fues, qui ne font pas toûours convenables, comme on mange trop ou trop peu, on digere $\mathrm{mal}$, fi les alinens font de mauvaife qua. ité; $\&$ enfin de ce que ce efidu des arteres, \& ces uperfluitez d'alimens ne font as inceffamment abforbez ar les veines, \& qu'ils n'y coulent que par intervalles. Et tour cela fair que le fang doit paroiltre plus beau dans un temps que dans l'autre. 'avouë pourtant que ces obcrvations, \& toutes celles que je pourrois faire à cet égard, ne fuffiroient pas pour nous donner une idée aflez jufte de routes les differences du $\int \mathrm{ng} ; \&$ je croy qu'il fau- 


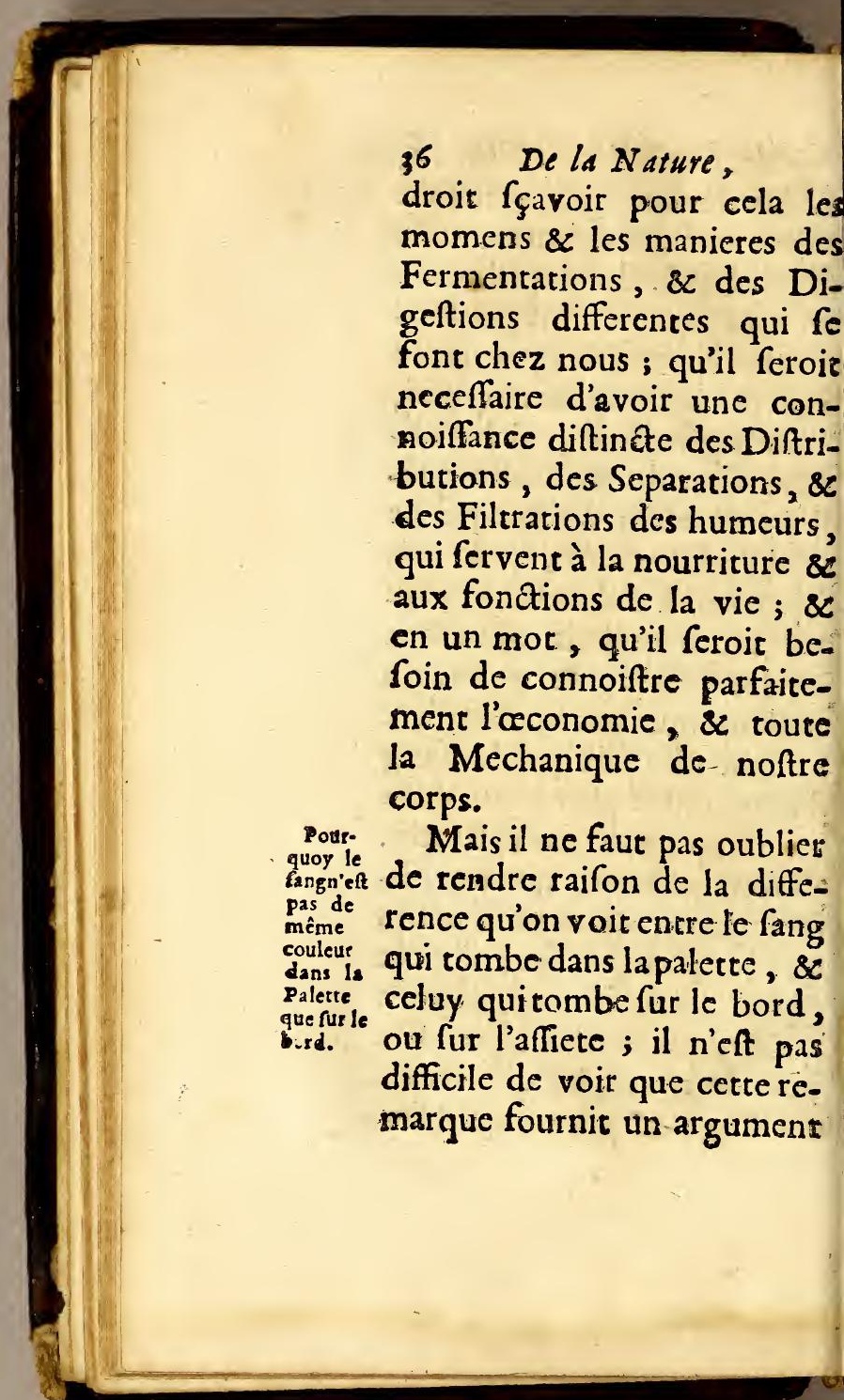


\& des caufes de la Fiévre. 37 avincible contre la corrupon pretenduë du fang dans es veines. Car fi le fang qui ombe fur l'affiete n'eft pas ourri \& corrompu, puis u'il eft bien rouge \& bien oloré; on ne peut pas dire ue celuy qui tombe dans la alette foit effed ivement corompu, puis qu'ils font fortis un \& l'autre en même temps 'une même veine, \& que cur differente policion n'étalit pas l'effence de la pouriture. Il refte donc à examier d'où vient cette diverfité le couleur qui fe remarque ntre l'un \& l'autre. Je croy que la raifon en eft, que fur e bord des palettes, ou dans es vaifleaux qui ne font pas oreux, le fang ayant plus de urface, l'air le touche, \& le enetre de tous coltez; \&z 


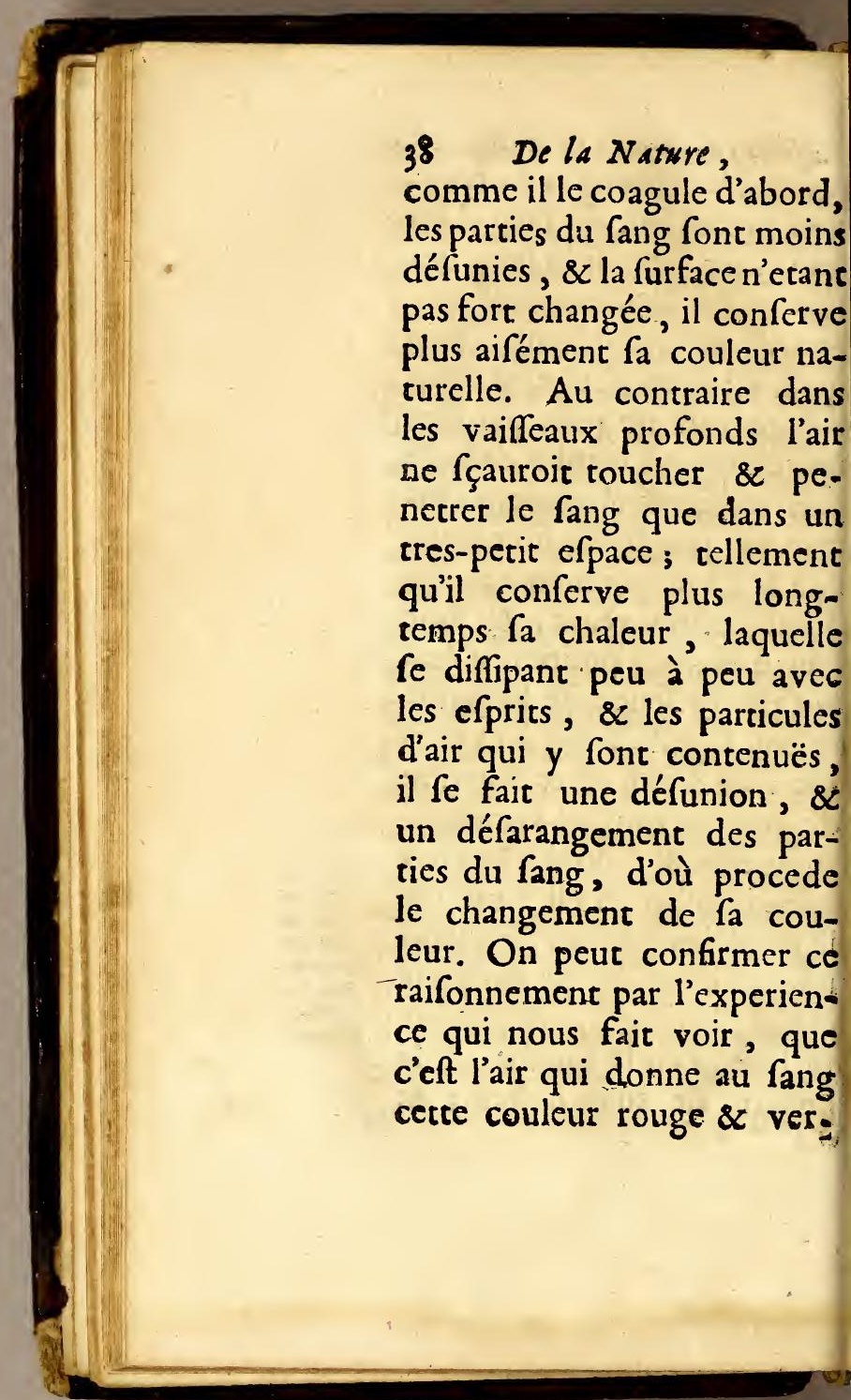




\section{or descaufes de la Fiévre. 39}

meille qu'on y remarque. On n'a qu'à ronverfer une palette de fang, \& l'on verra que celuy qui eftoit au fond, \& qui paroifloir prefque noir, devient d'un beau rouge dés qu'il eft expofé ì l'air. Cetre démonftration eft encore plus fenfible dans la Machine Pneumarique, où l'on voit que le fang devient brun tirant fur le noir dans le tems qu'on pompe l'air; au lieu que dés qu'on laiffe rentrer l'air dans la Machine, il reprend auflitoft fa couleur rouge $\&$ naturelle.

Pour répondre à la der- vers ne niere preuve de la corrup- font pas tion du fang, qu'on établit que de fur les vers qu'on a veu quel- $\mathrm{p}^{\text {tion, }}$. quefois fortir dans la Saignée, je n'ay garde de nier le fait: 


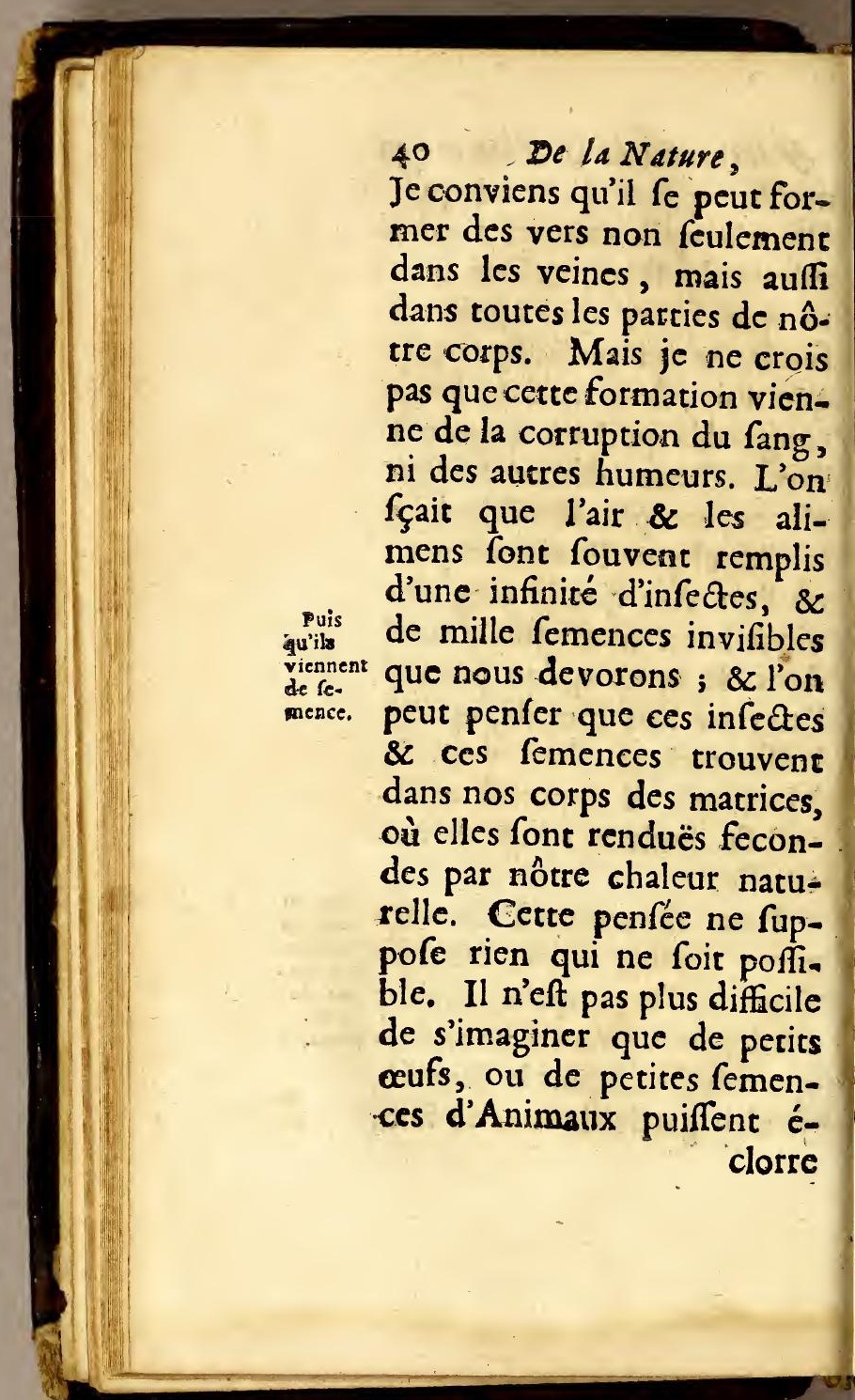


6 des canfes de la Fiéure. $4 \mathrm{I}$ clorre dans nos veines, que de voir du fray de poiffon éclorre dans les fluves les plus profonds \& lcs plus rapides : Méme je reconnois plus d'apparence \& de poffrbilité à la production des vers dans le fang, puifqu'ils y rencontrent une chateur plus analogue. On a veu des pois 8 d'autres graines qui one germé dans l'oreille, \& en d'autres parties. Un Auteur célébre rapporte qu'une fille ayant avalé un grain de bled, rendit de l'herbe qui avoit pouffé dans fon ventre : pourquoy donc ne voudra-on pas que la même chole ouiffe arriver à la femence des infectes.

On dira quaon pourroit tier d'étranges confequences. de cette hypothere, commac 
42 De la Nature,

de prétendre qu'un million de vers, de moucherons \& d'infectes qu'on voit naître en un moment fur des cadavres, vinffent de femence, \& qu'il fallût pour les produire des œufs \& des matrices : Qu'il eft bien plus raifonnable de croire qu'ils n'ont point d'autre principe de génération que la corruption, fuivant la maxime de Philofophie ; \& pour confirmer ce fentiment, on alleguera cér endroit fi célébre des Georgiques, où Virgile fait reparer la perte des mouches à miel par la corruption d'un jeune taureau : enfin on dira qu’à l'égard des.Plantes, il en croît tous les jours en mille endroits, où elles n'avoient point été femées.

On eft convaincu prefen: 
6 des canjes de la Fiévre. 43 tement que la corruption Que los n'eft pas le principe de génération dans les infeates, puifque leur génération pré- corrup. puifque leur génération pré- tion. cede la corruption : ce qu'il eft aif'e de voir tous les jours dans les cuifines, où les mouches \& les vers s'attachent aux viandes avant qu'elles ayent commencé à fe corrompre. Et l'on ne peut pas dire que c'elt parce qu'elles fe corrompent qu'on y trouve des vers, mais parce que les oufs de ces infeates y trouvét une chaleur propre à les faire éclorre, \& des fucs convenables pour leur nourriture. Et pour prouver ce que javance, on n'a qu'à mettre un morceau de viande dans une boureille de verre bien bouchée, en forte que l'air n'y entre point, la viande fe corrompra; mais

$D i j$ 


\section{De la Nature,}

il eft certain quil ne fe fera aucune génération de vers ni d'infectes : au lieu que $\mathrm{f}$ la bouteille n'ert pas bien bouchée, il s'y produira des vers Jamais cette experience n'a manqué. Virgile a re-

Expe- connu cette verité, puifqu'il rience veut qu'il y ait des fenêtres cujet. \& des ouvertures dans l'endroit où le corps du jeune taureau fera enfermé. D'où Remar- peut donc venir la naiffance ques fur des Abeilles? de 12 femence la genératoo des Abeilles. que d'autres Abeilles y ont apporcée; \& pour le montrer, Virgile a foin qu'on metre des Plantes aromatiques, \& toutes les chofes ne: ceffaires pour inviter les. Abeilles à y venir dans le tems quielles mulciplient, \& que ce foir avant la venue des Hirondelles, afin quielles $y$ 
odes gaures de la Fiévre. $4 \pi$ foient en feureté. Tour cela faic voir que Virgile eft de mon fentiment, bien loin quil foir de l'opinion contraire.

Si on demande la raifon de la production fi prompte d'une infinité d'Ánimaux qu'on voir paroître prefque en un inftanc, je crois quil tement

Doul: viét que les infeaes naifCent $f$ prompfaut la rapporter, à ce que leurs principes actifs fe trouvant alors peu embaraffez dans la matiere, une chaleur affez forte les difpofe promptenrent \& facilement, à donner la vie \&z le mouvemen à ces $p$ atits corps.

Ce grand nombre de vers qu'on voit fur les cadavres, ne nous furprendra pas, fi nous faifons réfléxion fur la quantité d'œufs que peut produire un feul infecte :

Et en $\mathbf{A}$ grand nombre: i D iij 


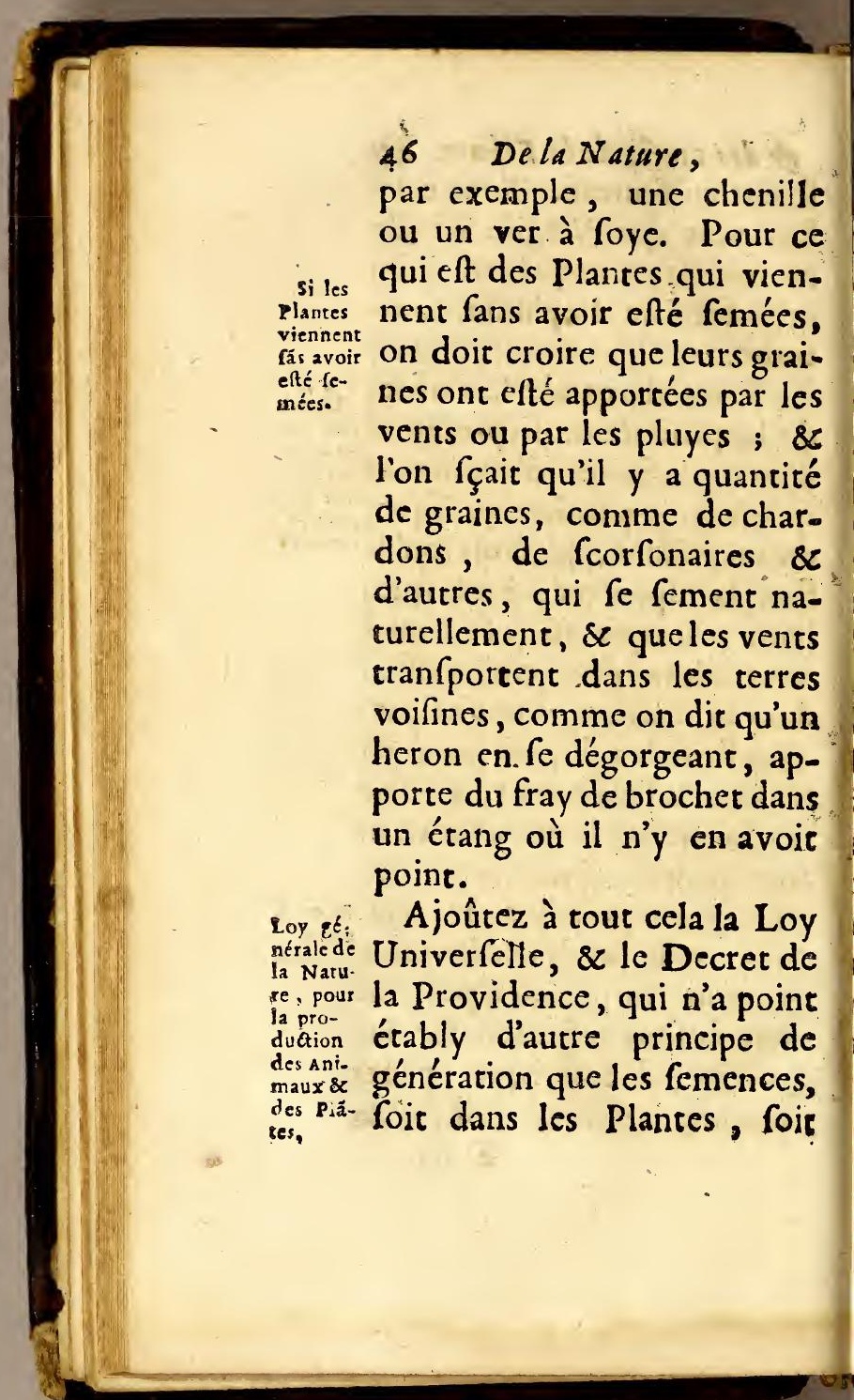


do des caufes de la Fiérure. 47 dans les Animaux ; 8 en vain Dieu les auroir-il créez mâle \& femelle, chacun felon fon efpece, fi le hazard les pouvoit faire naître tous les jours de la corruption. Car enfin comment peut-on s'imaginer que des matieres corrompuës puiffent produire des vers, des mouches, des grenouiilles, \& une infinité d'infeaes, fans préfuppofer quil y air des modéles \& des moules, par où ces matieres parfent pour recevoir tant de formes differentes? On ne s'etonne pas de voir dans un jardin le même Soleil, la même pluye, \& les mêmes terres produire des pom. mes \& des poires de differentes efpeces, parce qu'on y voir des pommiers \& des poiriers differens : Et l'on 


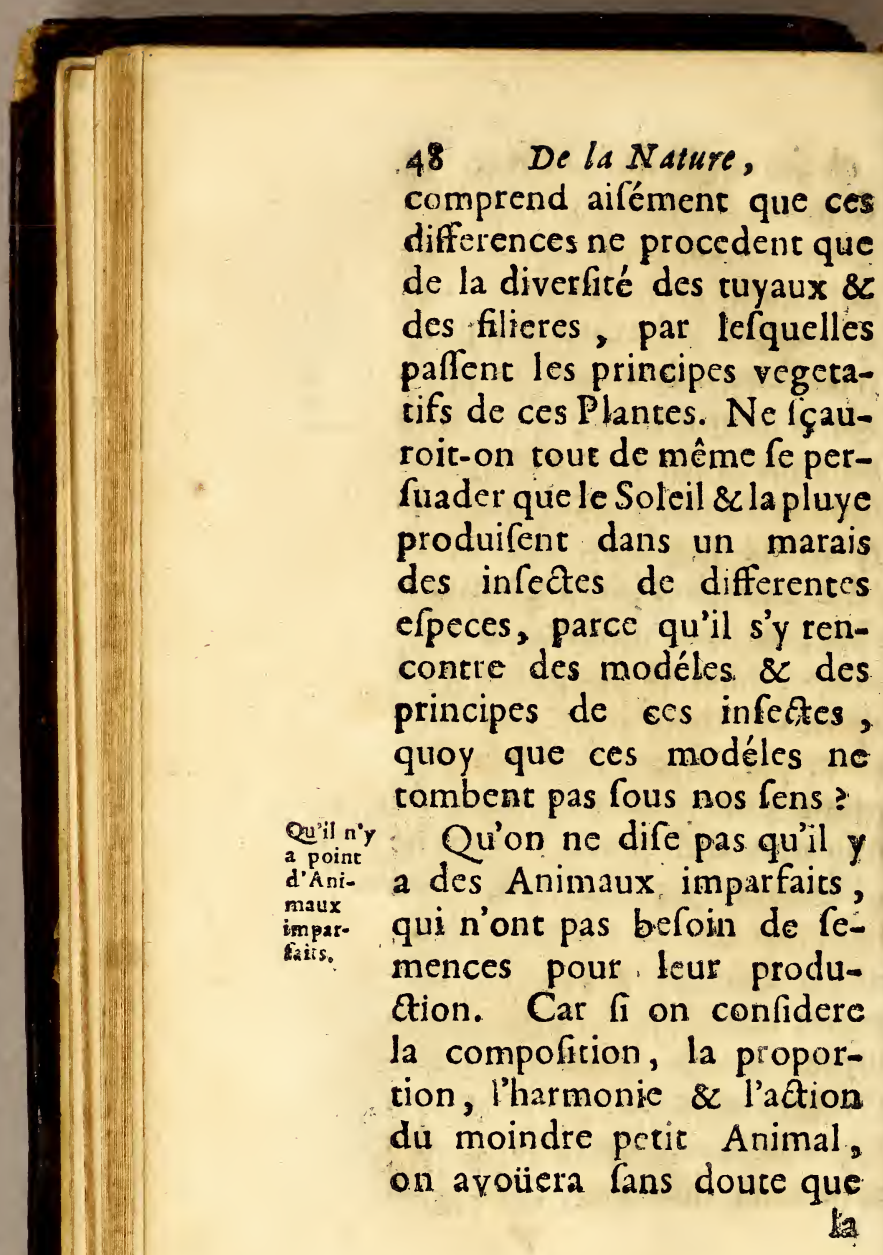


des caufes de la Fiévre. 49 ls mechanique d'un ver ou d'une fourmy eft dis moins auffi belle \&z auffi admirable, que celle d'un élephant ou d'une balaine; \&x on fera convaincu que ces Animaux ne font point redevables de leur exiftence à la corruprion $8 \&$ au hazard.

Aprés ce que je viens de dire contre la pourriture, je croy qu'il n'elt pas neceffaire d'entrer dans l'examen de roures les efpeces de Fiévres putrides : Il y a pourtant Auvifion une divifion, qui me paroît des rifé rop confiderable pour la paffer fous filence : C'eft celle qui fe fair des Fiévres coninuës putrides, en Efrentieles $S z$ en Symptomatiques. On fair confilter les Fiévres Effentielles dans la pourriure conrenuë dans les vei 


\section{0}

\section{De la Natüre,}

nes; \& l'on prétend que les Symptomatiques dépendent de l'inflammation, ou du vice de quelque vifcere.

Dans la. quelleles A etcurs prennent les cffets pour les eaufes.

On pourroit dire à cét égard, qu'une maladie qui vient de la mauvaife difpofition de quelque partie, devroit plûtôt être appellée organique, que fymptomatique : Mais on connoîtra aifément par l'explication que les Auteurs donnent de ces Fiévres Sympromatiques, qu'ils prennent les effers pour les caufes, $f i$ on confidere que les parties d'un corps bien difpof'e ne fçauroient recevoir d'ateinte ni d'alterntion dans leur fubftance, que par la mauvaife qualité des fucs $2 x$ des humeurs deftinées à leur nourriture \& à leurs fontions. Par exemple, fi un 
¿des caufes de la Fiévre. It poulmon bien fain devient enflammé, on ne peut pas douter que cette inflammation ne procede du fang 8 des humeurs mal conditionnées, qui s'embarraffent dans fa fubftance; \& il eft aifé de yoir que ce vifcere qui n'agit point par luy - même, ne fçauroit eftre la caufe de fon inflammation. Quand l'eau ne coule pas dans les tuyaux d'une fontaine, on ne dit pas que ce foit la faute des tuyaux, s'il y a des ordures qui les bouchent : le fens commun fuffic pour faire voir que les orduresfont le feul obftacle de l'é:coulement des eaux.

\section{E}


S2 De la Nature,

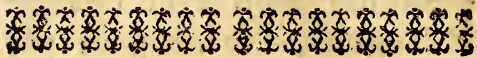

SECONDE PARTIE.

Hypotbefe fur la caufe des

Fiéures.

A Pr.E's avoir examiné A fuccinctement la Doatrine des Anciens fur la nzture des Fiévres, l'ordre que j'ay étably demande que j'explique mes fencimens fur cette matiere.

ce que cer que Jorićrie.

Je conçois done que la Fiévre n'eft autre chore qu'un mouvement, ou une fermentation extraordinaire excitée dans le fang ; que cette fer. mentation eft caufée par quel. ques matieres qui s'y mêlent, fur lefquelles les principes atifs. ou les parties fpiri- 
ó des carfes de la Fiévre. 53 tueufes du fang, agiffent pour les digerer \& les unir parfaitement à toute la maffe, ou pour les pouffer au dehors, fi elles ne peuvent y êrre unies. C'eft ce qui caufe du defordre dans l'ceconomie naturelle, \& produis tous les accidens que nous voyons dans les Fiévres, comme font la frequence dis pouls, les friffons, le chaud, Ia foif, \& tous les autres fymptomes qui les accompagnent ordinairement.

Pour expliquer tour cela ce que par ordre, il n'eft pas ne- Formenceffaire de s'étendre fur la iztion. nature de la fermentation: : On f̧̧ait que c'eft un mouvement des parties les plus fub. tiles \& les plus fpiritucufes; lefquelles eftans enveloppécs $\&$ embarraflées dans quelE iii 


\section{De la Nature,}

ques matieres épaifles \& groflieres, font effort pour les rarefier, \& pour fe mertre en liberté. Les fermentations font plus ou moins fenfibles, felon qu'il y a plus ou moins de difforde entre les principes dont les mixtes fone compofez. Nous avons dans le vin un exemple af fez familier des fermentarions fenfibles : aprés qu'on a fait vendanges, \& que les raifins font preflez, on met le mouft dans un tonncau; ce mouft qui d'abord ćtoit froid, s'échauffe peu à peu de telle forte, qu'il bouillonne, \& jette dehors l'écume \&z les impuretez qui y étoient contenuës. Cetrte aCion s'appelle Fermentation; elle fe fair par le moyen des efprits \& des principes vola. 
Oodes caufes de la Fiévre. Is tiles, qui digerent $\&$ rarefient les parties groffieres : tellement qu'il en réfulte une liqueur parfaite. On verra dans la fuite que cette idée de la fermentation fe rapporte fort bien a l'action des efprits dans la maffe du fang, \&z à tous les mouvemens qu'on obferve dans les Fiévres : Il s'agit feulement de déterminer quelles font les maticres qui fe mêlent dans le fang, qui en troublent l'œconomie, \&\& qui produifent enfin la Fiévre.

Aprés avoir fait bien des réfléxions fur ces matieres, $\begin{gathered}\text { qui exci- } \\ \text { te cerce }\end{gathered}$ jay conclu que rien n'étoit Fermenplus capable de caufer de dans les grandes alterations dans la $\begin{aligned} & \text { Fiévres } \\ & \text { et le }\end{aligned}$ maffe du fang, que le chyle, chyle ou foit qu'étant chargé d'impu- mal dif, retez, il ne foir pas propre

$E$ iij 


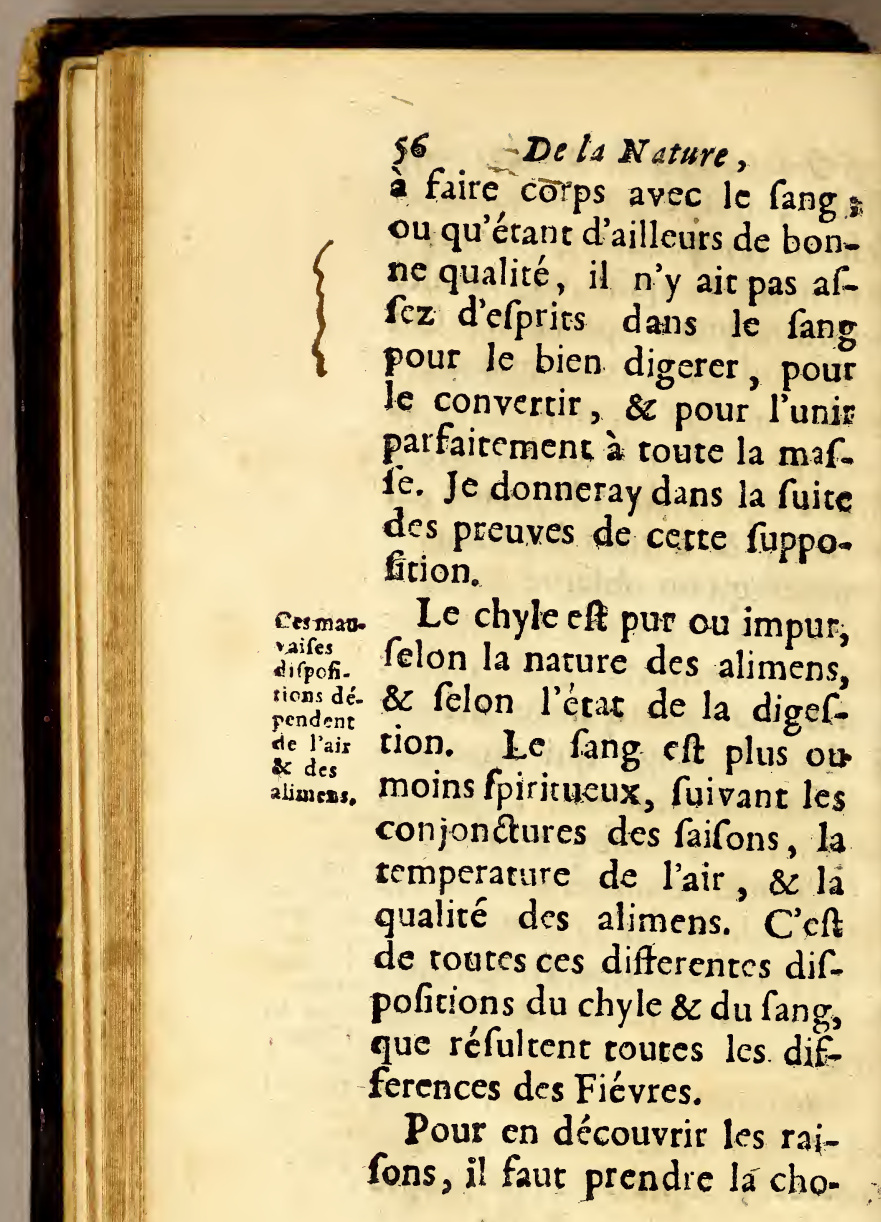


des canfes de la Fiérure: 57 e de plus loin, \& fe repreenter nôtre corps comme ne machine compolée d'une infinité de parries diffeentes, qui font fi bien arranées, qu'elles agiffent comne de concert, \& qu'elles dépendent mutuellement les anes des aurres : qu'au miieu de certe machine il y a un reffore (c'eft le cour) par le mouvement duquel oures les liqueurs neceflaires ces parties, fe diftribuent ar differens canaux : \& enfin, que nôtre fanté \& toutes les actions de nôtre vie réfultent dc $k_{2}$ jufte diftribuDont les bonnes qualitez? font la. fanté. tion de ces liqueurs, \& du bon temperament des parties.

Cette jufte diftribution des liqueurs, 82 ce bon tempesament, dépendent princi- 
98 De la Nature,

palement des bonnes qualitez de l'air \& des alimens. A l'égard des alimens, peu de gens ignorent que leur mauvaife qualité, ou leur mauvais ufage, déreglent nôtre fanté. Tane d'Auteurs one écrit fur cette matiere, De me?qu'il n'eft pas neceffaire de me que les mau. vaifesla déreglét.

s'y arréter. Mais pour ce qui eft de l'air, comme il n'eft pas facile de déterminer comment il change nôtre conftitution par fes differentes alterations, il faut donner une idée générale de ce qu'il eft, \& de quelle maniere il peut agir fur nos corps.

Par l'air, j'entens cette cee que
$e$ ect que matiere tranfparente qui nous fair. environne, \& dans laquelle nous vivons, qui ne contient pas feulement les vapeurs \& 
be des caufes de la Fiévre. 59 es exhalaifons, mais encore une infinité de petits corps inimez \& inanimez, qui naent dans toute cette étenduë. C'eft ce mélange de apeurs, d'exhalaifons \& de eetits corps, qui caufe les liverfes temperatures de l'air, clon la rarefaction, la condenfation, \&z les mouvemens differens que la chaleur leur imprime.

En effer, fi on examine cout ce qui arrive en chaque faifon de l'année, on fera convaincu que l'air eft non convaincu que lair eft non turion
leulement fufceprible de di- dans les vers remperamens, mais auf- tes faifi quil les doit communiEt com ment it change nôtre conttfons. quer à nos corps; \& caufer en nous des impreffions differentes.

En Hyver, comme le So- en Hy: leil ne fournit pas affez de 
60 De la Nature, chaleur pour échauffer tout l'Athmofphere, l'air eft chargé d'une infinité de vapeurs, qui s'uniffent fur la furface de la terre, \& forment de petits pelotons de neige, ou des parcelles de glace inuperceptibles. Ce font ces vapeurs glacées qui s'infinuane avecl'air dans nos poulmons; caufent les toux $\&$ les eatharres, \&z qui par leur mélange avec le fang, retardent fi fort fon mouvement; quil en réfulte une fenfacion de froid dans toutes les extrémitez de nôtre corps.

Antipo memps.

Dans le Printemps, au contraire, le Soleil ayane af $\mathrm{Cez}_{\mathrm{z}}$ de force pour diffiper toutes les vapeurs., \& pour les éloigner de la fuperficie de la terre, il fair fucceder en leur place les parties fpia 
6 des caufes de la Fiéure. 64 itueufes \& volatiles des planes, des.lleurs, \&\& des.autres nixtes, \& remplit l'air de aúmes \& : d'elfences qui reouvellent la maffe du fang. 2 produifent cette vigueur xtraordinaire que nous refentons toûjours dans cette Saifon.

Mais comme en Efté la en Enta haleur devient exceflive, \& lonne un mouvement trop apide aux vapeurs, $\&$ à ces etits corps dont je viens de arler, l'air eft tellementraefié que nos poulmons \& noftre coeur n'en recevane bas une quantité fuffifante, nous nous trouvons dans un ineantiffement extréme, à eu prés comme les poiffons hors de l'eau; \& le peu d'air que nous recevons eft fouyent chargé d'infectes $\&$ de 
62 De la Nature, petits corps impurs que nous devorons par la fatale necef. Gité de refpirer.

tat dans La faifon qui fuit ne re. lautom- pare pas tous ces défauts, $\&$ quoy que la chaleur foit à peu prés temperée comme au Printemps, il s'en faut beaucoup qu'elle produife les mefmes effets; car enfin fi dans le Printemps la nature paroift naiffante, parce que l'air eft rempli de ces parties fpiritueufes \& balfamiques qui s'exhalent des plantes \& des fleurs : le contraire arrive dansl'Automne, parce que l'air n'eft alors chargé que d'exhalaifons $\&$ de vapeurs malignes, qui émanent de la corruption des animaux, de celle des fruits $\& 2$ des autres mixtes; à quoy il faut ajoûter que fi au Printemps la 
\& des caufes de la Fiévre. 69 haleur augmente toûjours, lle diminuë toûjours en Auomne, \& que ces differenes produifent dans la nature \& particulierement dans no corps des effets tres-diffe. rens ; en un mor dans les diverfes faifons de l'année, la chaleur eftane plus ou moins forte, les pores plus ou moins ouverts, la tranfpiration plus ou moins libre, lair plus ou moins pur, les alimens enfin plus ou moins fpiritueux; qui peut douter que les degrez \& les combinaifons de toutes ces chofes venant à changer, noftre conftitution naturelle ne change pas auffi, foir dans la fanté, foit pendant la maladie, \& que ce'a ne contribuë aux alterations que nous reffentons tous les jours ?

Si ces rellexions fur les 
64 De la Nature, faifons font capables de petfuaderque l'air, felon fes diverfes temperatures, peut communiquer à la maffe du fang, des difpofitions diverfes, \&z que d'ailleurs on ne doure point qu'il n'en foit de mefme des alimens ; je croy qu'il ne fera pas difficile de comprendre que le chyle ot le fang fe trouvant alterez d'une certaine maniere, produiront cette fermentation que l'on appelle Fićvre, dans le temps quills fe méleront enfemble.

eft la difpofition du fangtans les Fićvress
A l'égard du fang, il n'eft pas neceffaire d'examiner toutes les alterations dont il eft fufceptible, il fuffir de démontrer celle qui convient à noftre fujet. Je fuppofe pour cela que le fang d'un homme malade de quelque Fiévre tient 
\& des caufes de la Fiévre. 65 tient de laigre, \& que 'air ou les alimens luy ont communiqué cette qualité :pour prouver cetce fuppofition, il faut premierement expliquer de quelle maniere le fang peut contracter de Yaigrcur.

Le fang devient aigre ou be quel. par la diffiparion de fes efprits, niere io oupar l'addition de quelques fang deAcides. On ne fçauroir dou - stes rer que les efprits du fang ne re dillipent quelquefois, l'épuifement ou l'on fe trouve aprés de grandes fatigues, . ou aprés de grands excés, \& laccablement dans lequel font les malades: qui ont eu: un violent accés de Fiévre; en Cont des preuves inconeftables. Mais on peur encore moins dourer que le fang: ae devienne aigre par certe: 
66 De la Nature, diflipation d'efprits, fi l'on confidere que les efprits font les principes dominans \& le frein des acides, lefquels ne fe manifeftent jamais dans le fang, qu'aprés que les efprits font diffipez; car alors les acides s'exhalent, \& en communiquant leur qualité à la tiqueur, ils la rendent aigre. On fera encore perfuadé que le fang devient acide par l'addition des acides, fi l'on fait reflexion qu'il doic neceffairement tenir des qualitez qui dominent dans les alimens, \& que commeles viandes \& les boiffoins fpiritueufes augmentent les ef prits dans la maffe du fang; il fauc aufi necefrairement que les alimens $\&$ les boif fons acides augmentent l'a. cidité du fang. 
on des caufes de la Fiéure. 67 On peur encore prouver que la diffipation des, efprits $\& 2$ l'addition des acides peuvent aigrir le fang, par l'analogie qu'il a avec le vin, la biere, le laiat, \&zc. fi on expofe au grand foleil un tonneau débouché plein de vin, le vin deviendra aigre, parce que les efprits fe diffiperit \& s'évaporent. La même chofe arrivera fi l'on $y$ ajoûte du vinaigre; il y a encore d'autres moyens de rendre les liqueurs aigres, mais de quelque maniere que l'on s'y prenne, on trouvera par tout ou addition d'acides, ou diffipation d'efprits.

A l'égard du chyle on ne corr. fçauroit douter quil ne puif- ment le fe auffi devenir aigre, foit quierr ta qu'il acquierr cetre qualité merniliţ par des alimens aigres, fois 


\section{De la Nature,}

qu'il le devienne dans l'Eftomac par le mélange des levains acides qui s'y recontrent, cela n'a point befoin de preuves.

Que le Pour appliquer tout cela à. fang li fuppofition que j'ay faite, laigre
dans les zievres. dans les Fiévres; il feroit aifé de faire voir que tout ce. qui donne occafion aux Eiévres dans toutes les faifons. de l'année, caufe ou diflipation d'efprits, ou augmentation d'acides dans le fang: maisil fuffir d'alleguer l'exemple de l'Automne, qui eft la faifon de l'année où les Fiévres regnent le plus. Peuton douter que les efprits n'ayent effé diffrpoz par les. chaleurs exceffives de liElté, \& que les acides n'ayent efté: augmentez dans le fang par. 
Or des caufes de la Fiéture. 69 es alimens \& les boiffons diont on ufe alors, lefquels participent tous plus ou moins. de l'aigrcur. Cette fuppofition êf encore conforme à l'experience, qui nous faic voir d'un cofté que le fang des febricitans donne moins d'efprits dans la diftillation que le fang de ecux qui fe portent bien; \& de l'autre, que les fueurs les plus falutaires dans les. Fiévres fentont 'aigre; ainfi que l'a remarqué l:Auteur du Trairé de la guerifon des Fiévres par le Quinquina:

Si donc le fang tient de coma. l'aigre par quelqu'une des rai- ment cetre aifons que j'ay remarquées, je greur depuis fuppofer qu'il fe fera cite la une efpece de coagulation du chyle \& du fang lors qu'ils fe mêleront dans les veines, F iij. 
70 De ta Nature;

parce que l'une \& l'autre de ces liqueurs fe coagulent comme le laid par le mélange des acides. Et d'autant que cetre coagulation épaiffra le fang, \& empêchera qu'il ne paffe dans le coeur auffi vifte que de coûtume, clle donnera lieu à une fermentation exiraordinaire, qui n'eft autre chofe que la Fiévre. Cerce fermentation fe fera par les efprits, qui fe trouvant enveloppez dans le chyle, ou plû.toft dans le fang condenfé par le mélange du chyle, agiront inceffamment jufqu'à ce qu'ils l'ayent encierement diffuus \& rarefié : Voilà l'idée que j'ay d'une Fiévre qui vient de la mauvaife difpolition du lang.

Aufi bien que

Je comprens encore que 
¿d des cares de la Fiéure. 71 a mefme difpofition acide l'aigreus Ce trouvant dans le chyle produira auffi la Fiévre; car fi un chyle de bonne qualicé excice des fermentarions fiévreuíes par fon meflange avec un fang peu fpiritueux, $\&$ qui tient de l'aigre; par la même rais:n un chyle trop rempli d'acides doit produire la Fié. vre lorfqu'il fe mélera dans le fang, quoy que le fang foic d'ailleurs de bonne qualicé. C'eft fur ces deux confiderarions que j'établis toute la doctrine des Fiévres.

Lorfque le chyle d'un euand homme fain fe convertic en onic porfang, cetre converfion fe chyle fe fait aif'ement par une fermen- conver tacion douce \& nacurelle, fang ans dont on ne s'apperçoit pas troubles. fenfiblement, parce que les mouvomens du cour \& du 
72 De la Nature, fang font bien reglez, \& quill ne s'y paffe rien d'extraordiAu lieis naire. Il n'en eft pas de mếeltantre me de la fermentation qui maldir produit la Fiévre; le fang caufen eftant condenfé par le méia fiérre lange duchyle de la maniere mélange. que je viens de l'expliquer, paffe difficilement dans le cour, \& s'il m'ett permis de parler ainfi, il caufe d'abord dans le petit monde les mêmes effets que l'Eclipfe caufe dans le grand, en arreftant linfluence des efpries , \& confiquemment la communica. tion de la chaleur à toutes les parties éloignées : C'eft-là la raifon du friffon \& de tous les accidens qui le fuivent: ce friffon ne cefle point juf qu'à ce que les efprits qui eftoient enveloppez dans cetce. matiere épaifle \& conden-

Íé 
\& des caufes de la Fiévre: 73 fée l'ayent rarefiée \& diffou-. te , \& quils fe foient mis en liberté ; alors ils fe portent avec vîtefle à toutes les parcies, \& comme ils entraînent la plus grande portion de cetre matiere, la chaleur \& la fermentation continuent jufqu'à ce que la digeftion en eftant faite, elle paffe à travers les glandes excretoires de la peau, \& finiffe l'accés par une fueur favorable, ou par une bonne tranfpiration. Voilà comme je penfe que fe fait un accés de Fiévre intermittente, lors que la maierc eft condenfée dans les veines, \& que le fang paffe entement dans le cour, c'eft e tems du frifion : aprés que es efprits fe font développez, \& qu'ils ont mis en mouvement cette matiere, c'eft le 
74 De la Nature,

tems de la chaleur; enfin lors que la matiere eft bien digerée \&z diffoute, la fucur fuccede, \& la Fiévre finit.

Explica- Que fi une Fiévre continuë tion des Fiévies continuës.

dure long - tems, cela vient de ce que le chyle qui fe méle dans le fang eft trop chargé d'impuretez, ou de ce qu'il n'y a pas affez d'efprits dans le mefme fang pour digerer \& purifier promtement le chyle, ce qui fait que la fermentation continuë plufieurs jours.

it des Fiévres
intermit- cés de Fiévre intermittente Au lieu que dans un actentes. le chyle n'eft pas affez impur pour entretenir longtems la fermentation dans le fang, ou bien les efprits y font aflez abondans pour la finir promtement.

Les Fiévres continuës dif- 
¿descaufes de la Fiérre. $7 \$$ ferent des intermittentes, en ce que les humeurs qui cau. fenc celles-là font plus abondantes \& plus en mouvement; elles font plus abondantes dans l'eftomach \& dans les premieres voyes, de forte qu'étant portées inceffamment avec le chyle dans les veines, elles y excitent les fermentations fievreufes; el. les font plus en mouvement, foit parce qu'elles font produites par des matieres capables d'exciter une promte fermentation, foit parce que l'air eft difpofé à leur imprimer ce mouvement comme en Efté; \& c'eft en cette faifon que les Fiévres continuës, ardentes \& malignes font plus en regne; les matieres promtes à fermenter font le vin, les viandes, les herbes,

G ij 
76 De la Nature,

les fruits, \&c.

$M^{5}$. d'Effe, \& prefque tous les Modernes, difenr que les parties bilieufes \& fulfurées du fang tropexhalrées font la caufe de ces Fiévres; mais je croy qu'ils fe trompent, fuivant leur principe nous aurions toûjours la Fiévre en Efté, \& les habitants des climats chauds feroient toûjours attaquezde cette maladie, puifqu'il eft conftant que par la chalcur, les parties bilieufes \& fulfurées du fang font fort exhal. tées. Cette hypothefe combat la nature des fermentations, il ne s'en fait point que par la difcorde qui fe trouve entre les principes; celles qui fe font dans le fang font toûjours caufées par des matieres qui enveloppent 86 
co des caufes de la Fiérre. 77 embarallent les parties actives, c'eft à dire les efprits \& les foulfres; $8<$ c'eft cet cmbarasaqui fait les fermentations \& la Fiévre, lefquelles ceffent dés le moment que les efprits \& les foulfres font exhalrez; lors que le vin n'eft pas meur \&z qu'il eft encore mouft, il fermente violemment, parce que les fubftances fpiritueufes font embaraflees dans les matieres groffreres; mais quand il s'aigrit par l'exhaltation \& diffipation de fes efprits, il ne s'y fait aucune fermentation : Il eft aif'e de remarquer que pendant les chaleurs exceffives de l'Efté, nous n'avons. jamais la Fiévre fi nous vi. vons fobrement, dans quelque exhaltation que foient alors les efprits \& les foulfres

G iii 
78 De la Nature, du fang, quoy que nous foyons dans un épuifement, \& dans une fòiblefie extréme; il faut donc conclure que la caufe de toures les Fié. vies vient des matieres impures \& infociables qui fe mélent dans le fang. On fera convaincu de certe verité fi on fair refléxion fur la plufpart des Fiévres malignes; on fçiit que dans ces fortes de Fiévres la férmentation eft fouvent fi foible, \& le pouls fi petit, qu'on ne s'apperçoit prefque pas que les malades ayent la Fiévre : la raifon de cela fe tire de ce que les parties volatiles \& fulfureufes du fang font trop exhaltées $\&$ fe diffipent; \& la Fiévre ne fubfifte que parce qu'il y a encore quelques efprits dans le fang qui agiffent foi- 
2 des caufes de la Fiérure. 79 blement fur les mauvais fucs qui y ont efté introduits avec le chyle : fi d'autre côté on examine les accés des Fiévres intermittentes, \& que l'on confidere quils font beaucoup plus violents, \& qu'il y a plus d'agitation \& d'élevation dans le pouls, que dans les Fiévres continuës, on fera perfuadé que tant s'en faut que les efprits \& les foulfres exhaltez foient la caufe des Fiévres, leur exhaltation au contraire eft une matque qu'elle eft finie ou diminuiée confiderablemét.

Monfieur de Bezanfon Auteur Moderne, qui a écric fur les Fiévres, dit qu'il a examiné toutes les opinions qui ont paru jufqu'icy fur la nature de ces maladies, \& qu'il s'en eft formé une idée

G iiij 
80 De la Nature,

conforme à l'experience dont il fe vante de donner des explications mechaniques. Il ajoûte que la plufpart des Auteurs ont établi la fermentation pour caufe univerfelle des Fiévres, \& qu'ils fe font trompez, puifquil $y$ en a fans fermentation, comme celles qu'il dit eftre caufées par irritation, \& qu'il fair fucceder aux gran. des douleurs, aux abfés, , \& auxinflammations; \& il affure qu'on ne fçauroit donner d'autre raifon de la caufe de ces Fiévres, qu'une violente fecouffe des nerfs qui leur fait répandre des efprits en abondance dans les vaiffeaux; je ne penfe pas que cet Auteur puiffe expliquer mechaniquement la prerenduë fecouffe des nerfs, \& 
¿ des caufes de la Fiévre. \&r cet épanchement des efprits; e croy auffi qu'il nous impoe , \& je n'ay lû nulle part que a fermentation foit la caufe aniverfelle des Fièvres.

La Fiévre n'eft point caue d'elle-même, Fernsentaion for Fievre font fynonines; Mais il faut expliquer Monfieur D. B. comment. es Fiévres qui fuccedentaux randes doutleurs, aux inflam. mations \& aux ablcés, fone des. fermentations.

Pour cela, il faut comprendre que tous ces accidens déeglentla circulation du fang, de forte que les efprits\& la ma. iere fubrile forit interceptez u troublez dans leur coure , \& cela fuffic pour juger qu'il excitent un mouvenent inteftin extraordinaie.D'ailleursil eft vraifembla. 
82 De la Nature,

ble que des matieres impures $\&$ infociables émanent des inflammarions \& des abfcés, \& qu'eftant confonduës avec le fang, elles $y$ caufent des fermentations: cette explication me paroift plus naturelle \& plus intelligible, que de faire répandre par les nerfs des efprits dans les vaiffeaux ; cer Auteur parle encore d'autres efpeces de Fiévres dont il érablit les foyers dans les inteftices de chairs, dans les détours des vifceres, dans le cerveau, \& dans les glandes.

Je n'ay pas deffein de critiquer tout l'Ouvrage de $\mathrm{M}^{\mathbf{r}}$ D. B, ni de faire voir la nullité de tous ces foyers, cela me pourroit mener trop loin, \& je ne penfe pas que 
\&o des caufes de la Fiéure. 83 e public s'en laiffe prévenir; nais je ne fçaurois m'empếher de dire quelque chole lu Syftême de $M^{2}$ Borelli, ue $M^{2}$ de Bezanfon affure ftre le plus probable de ceux quion a encore propolez. $\mathrm{M}^{\mathbf{5}}$ Borelli dit que les efrits \& le fuc nerveux étant levenus âcres, irritent le our \& les nerfs, \& font ar là les caufes productives remieres \& immediates de a chaleur de la Fiévre. Voi; fes propres termes; $s p i-$ itus of fucci nervei, folito criores redditi, nervos of cor rritantes, funt cau ầ productiva prime ó immediate excandefentia febrilis.

Il dit auffi que les levains,; Aes Fiévres font dans les" glandes, qu'il fe fait des ob- ", Reructions dans les nerfs, que, 


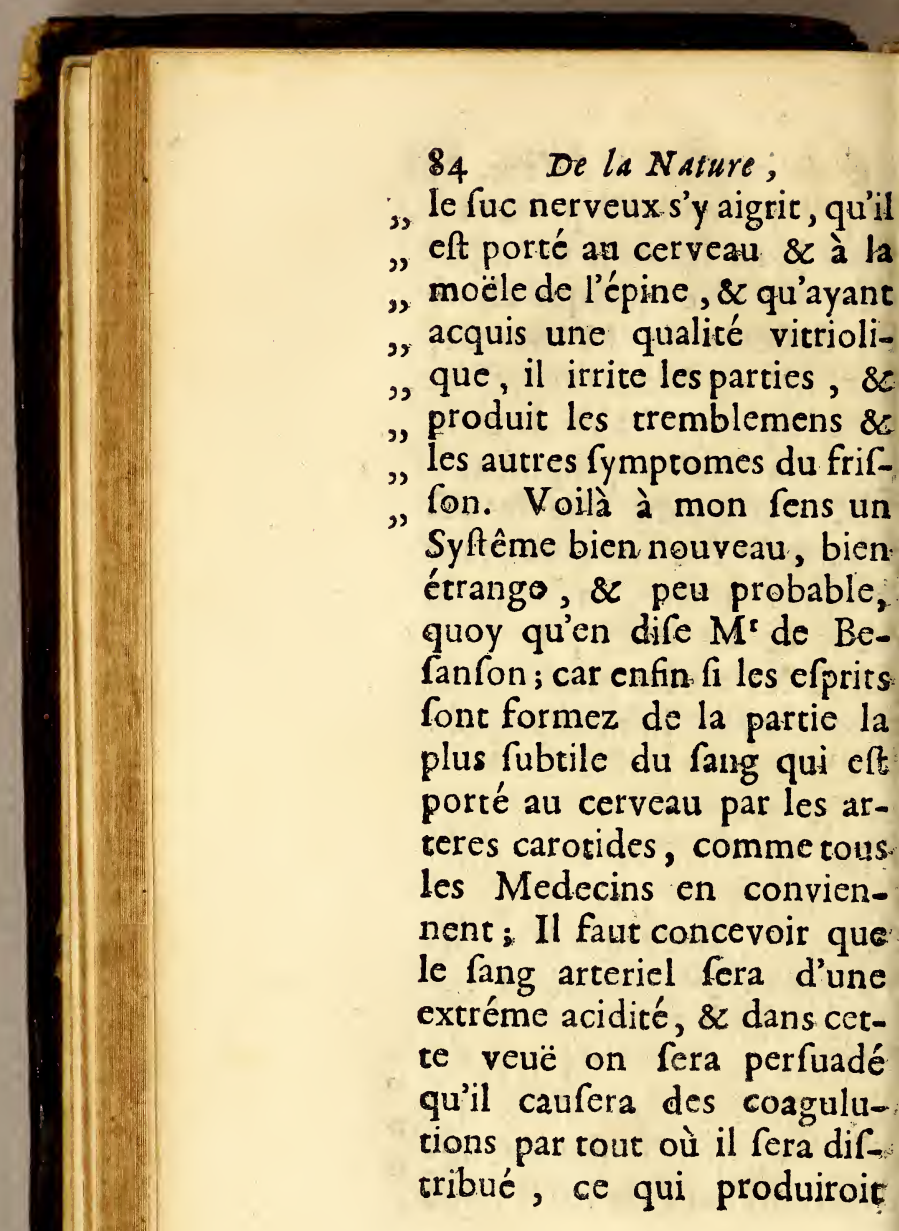


¿ des caufes de la Fiéure. 85 ine infinité d'accidents qu'on e void point paroiftre dans es Fićvres : d'ailleurs fi les fprits eftoient fufceptibles l'acidité contre l'ordre de eur nature, puifque l'Efprit le vin n'aigrit pas, il $n^{\prime} y$ uroit point de Fiévre qui le fût precedée de douleurs le tefte violentes, de conrulfions, de paralyfies, d'enyourdiffemens, \& de tous es fymptomes qui derivent lu defordre des efprits, \& de obftruction des nerfs; mais u fond comment rendraon raifon par ce Syftême d'une Fiévre qui attaque fubitement un homme qui a zrop mangé \& trop bû; cet excés de nourriture $\& z$ de boiffon aura- $t$-il établi en moins d'une heure des levains dans les glandes, 8 


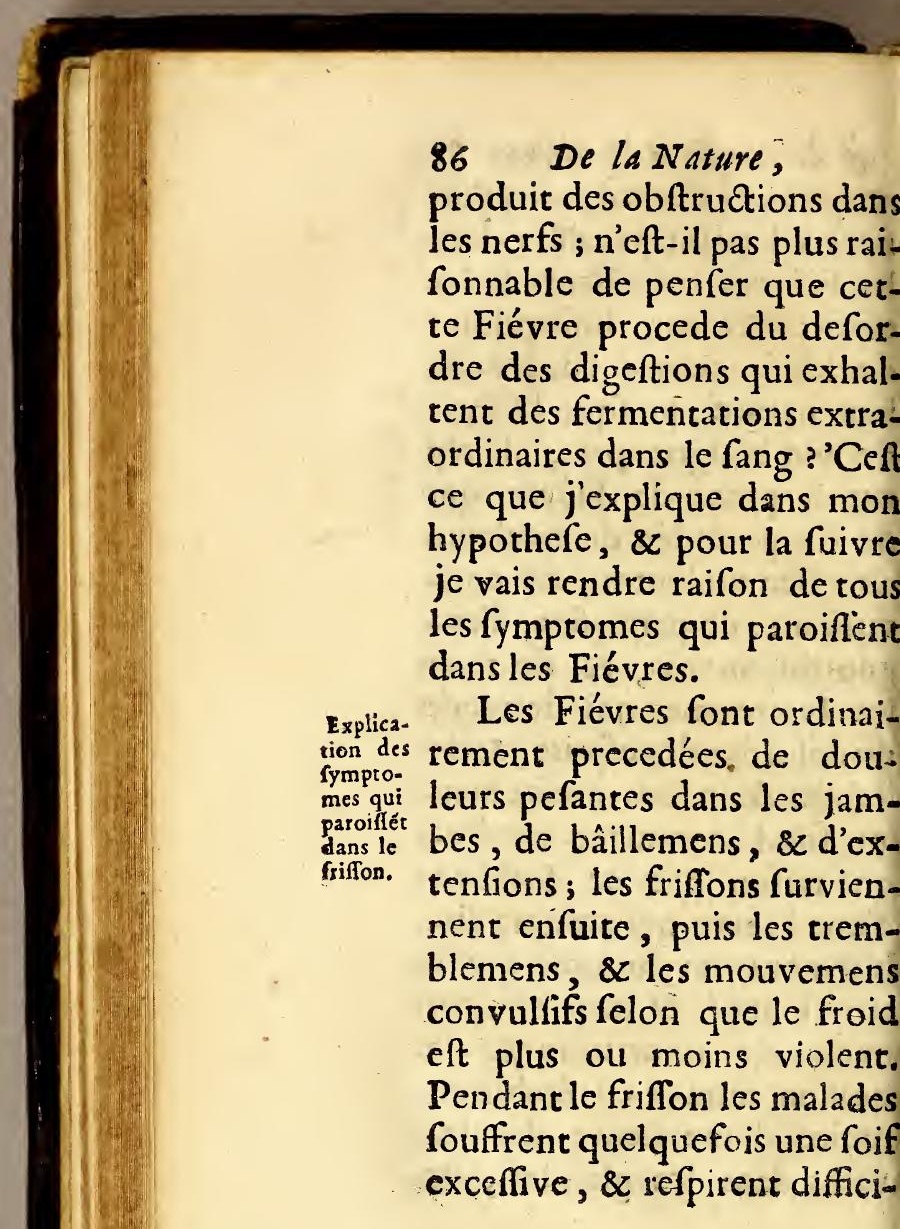


Qo des caules de la Fiéure. 87 ement; quelquefois le pouls i'elt pas fenfible, ordinairement il eft petit \& enfoncé, nais frequent, au lieu que dans la chaleur il eft grand, levé, \& frequent.

Pour bien comprendre tous pes dorr ces fymptomes, il faut fça- leurs va: roir qu'au commencement pecantes, des Fiévres, l'œconomie nacurelle fe change, $8 x$ fe déregle par le déreglement du mouvement circulaire du fang, parce qualors les humeurs \& les fucs qui eftoient portez aux parties pour leur nourriture \& pour leurs fonctions, ou font interceprez, ou coulent plus lentement. Ainfi le fang \& les efprits n'eftant pas difribuez aux parties éloignées, aux jambes par exemple, auffi regulierement, \&z auffi abondam- 


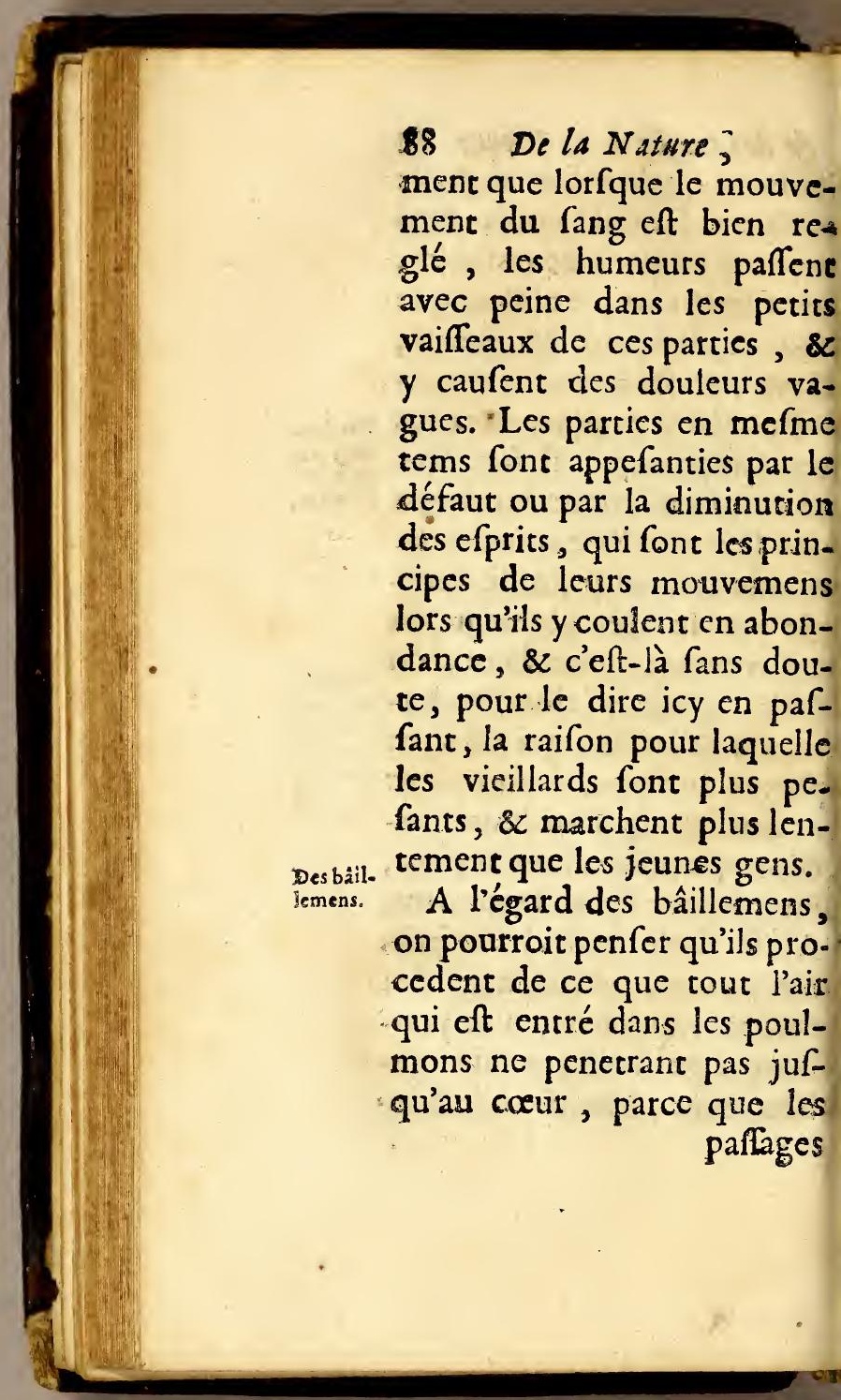


\& des caujes de la Fiévre. 89 aflages commencent à fe oucher, il fait reflux dans bouche \& la dilate. Mais y a plus d'apparence que la aefme caufe qui produit les xtenfions \& les mouvemens onvulfifs, produit auffices âillemens.

Les extenfions \& les mouDes ex: renfions $\&$ des emens convulfifs viennent e l'inégale diftribution des vulfiss, Cprits dans les fibres charuës des mufcles $\&$ des memranes; car le mouvement u coeur eftant tres-foible ans le friffon, comme je ay dit, les efprits quifont en etire quantiré coulent irreulierement dans les parties, intoft dans l'une, tantoft ans l'autre, ce qui caufe la iverfité de leurs contrations, \& l'irregularité de urs mouvemens. C'eft-lì mouve. menscồ

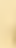


90

De la Nature,

la veritable raifon de tous

ces differens mouvemens convulfifs, qui arrivent dans le frifion, ainfi que je pourrois le prouver plus ample ment; Mais comme cét examen me meneroit trop loin, je me contenteray de confirmer ce railonnement par un exemple familier, \& qui me paroift fenfible. Voyez un pouler auquel on a coupé la gorge, \& remarquez les differens mouvemens qu'il făit à mefure qu'il perd fon fang; d'abord il bat des aîles, parce qu'il a encore beaucoup d'efprits; enfuite it a des tremblemens, parce que les efprits fe diffipent ${ }^{\prime} \&$ n'agiffent que foiblement; enfin il tombe dans des convulfions, il fe roidit $\&$ allonge fes jambes, parce que le 
ou des caufes de la Fiévre. gi mouvement du cour venant ceffer, le peu d'efprits qui luy reftent, ne coule alors que dans les mufeles qui fervent a l'extenfion, ce qui fait la roideur convulfive qu'on obCerve avant la mort.

La difficulté de refpirer que les malades fouffrent au té de ref. pirer. commencement des Fiévres, vient encore de ce que le fang paffant lentement dans les poulmons preffe \& $\mathrm{cm}$ baraffe les vaiffeaux par où l'air fe communique au cour, en forte que les paffages de l'air n'eftant pas libre, le commerce en eft interrompu, \& la refpiration déreglée. La foif procede de ce que a maffe du fang eftant con- foif denf'ee, \& toures les humcurs moins fluides, la falive ne fe fepare point dans les glan. 


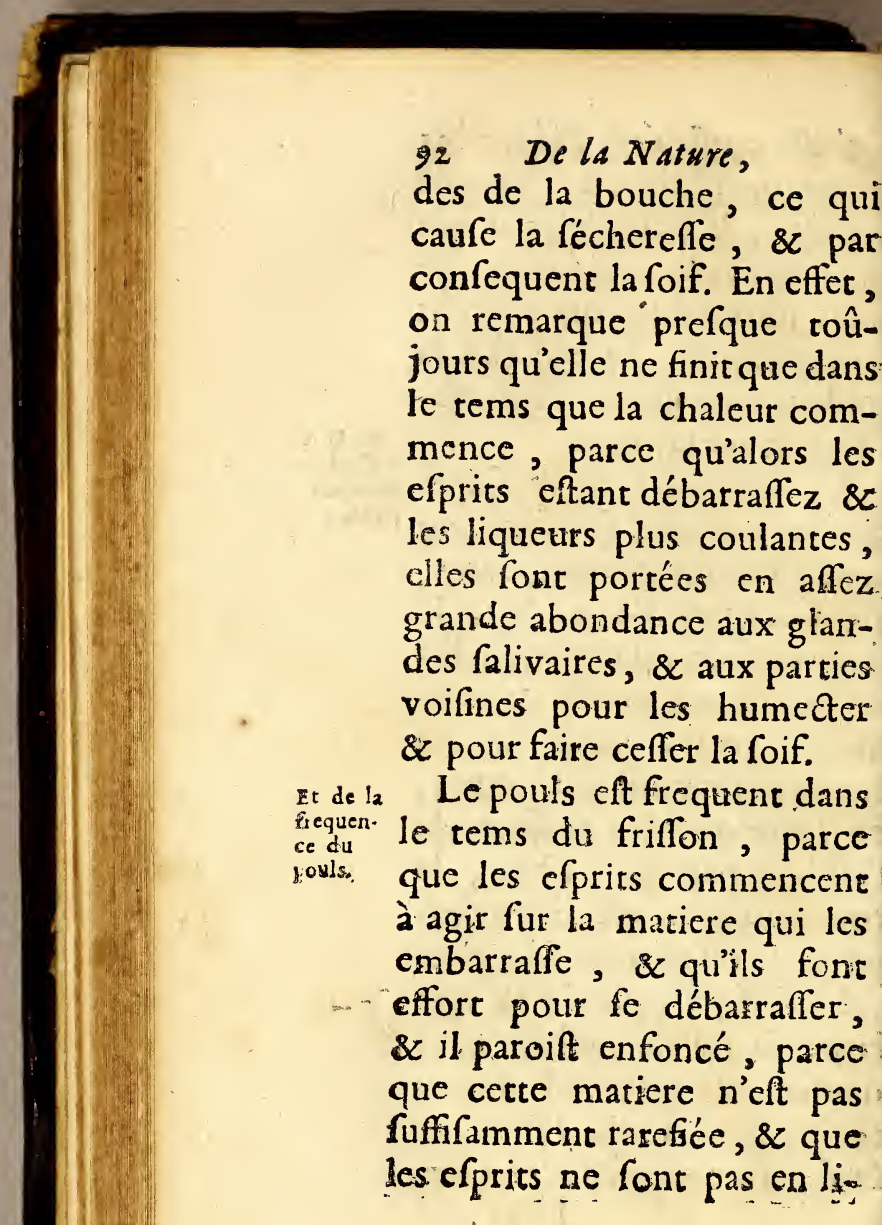


Ou des caufes de la Fiévre. 93 erté. Dans lc chaud au ontraire le pouls eft grand ¿ élevé, parce que les efrits coulent à plein canal, $\zeta$ entraînent avec rapidité ous ce qui faifoit obftacle leur mouvement.

Il y en a qui croyent que die tous ans le friffon les tremble- ces rymes: aens, les mouvemens conulfifs, \& la frequence du point de ouls viennent de l'irritation tion :des. es parties nerveufes caufée parties ar les acides; mais com. neufes.

ne j'ay fuppofé que dans froid les acides eftoient nveloppez avec les autres rincipes du fang qu'ils coaulent; il eft vray-femblale que dans ce tems-là les cides n'agiffent que fur les. umears, \& qu'ils ne fçauoient irricer les parties fenbles qu'aprés qu'ils auront $\mathrm{H}$ iij 


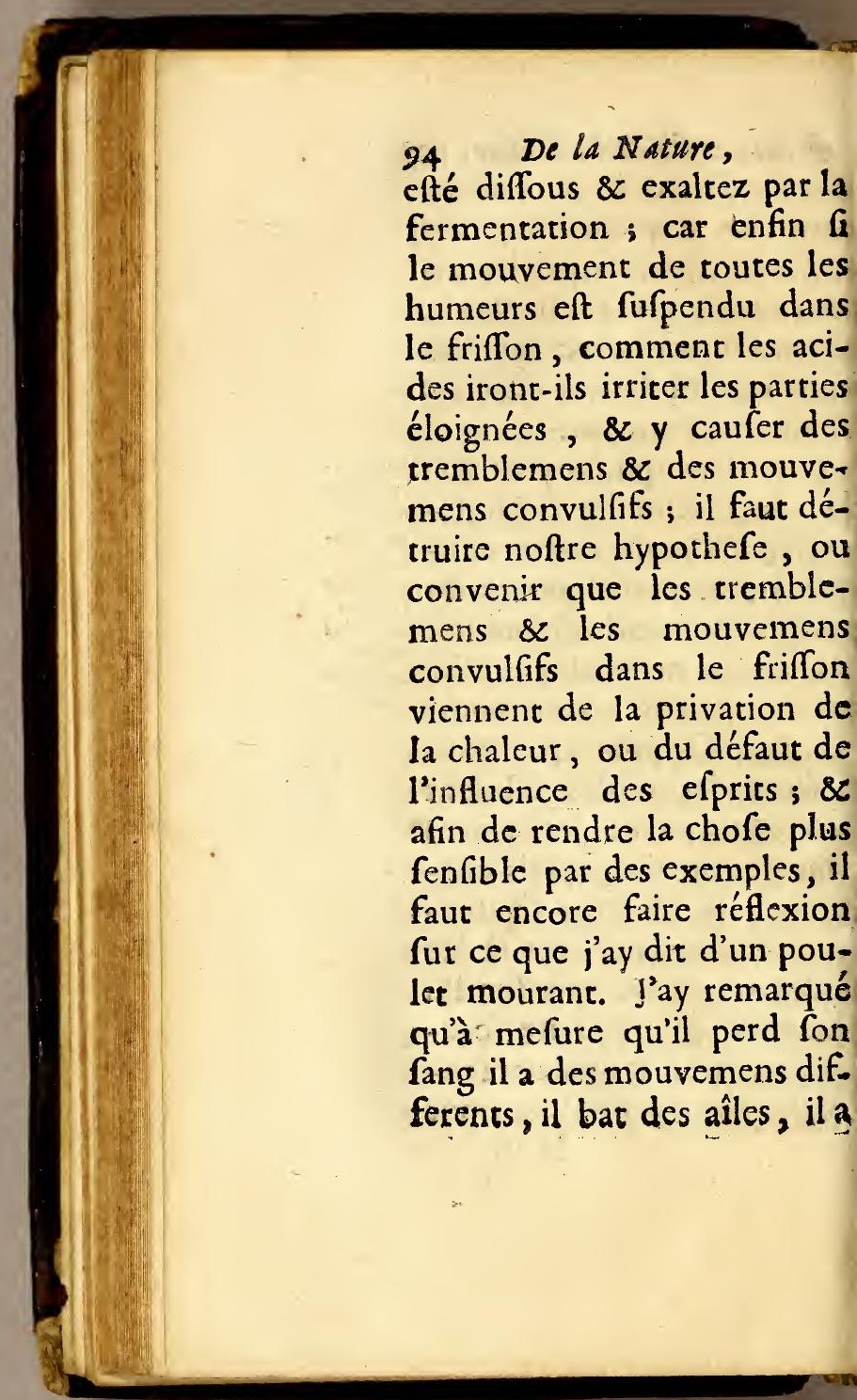


¿ des caufes de la Fiévre. of des convulfions, il fe roidir, eur-on dire que tour cela rocede d'une matiere irriante? n'y a-t-il pas plus de iijer de penfer que les conractions des nerfs, le roiliffement, \&x. viennent de ce qu'il ne coule plus d'efrits dans les nerfs $\&$ dans es mufcles de cet animal? Le friffon n'eft-il pas l'image de la mort; le mouvement du cour ne femble-il pas lors fufpendu : \& cette furenfion ne fuppofe - elle pas ieceffairement une privation de chaleur ou un défaur de diftribution des fucs necerfaires aux fonctions des paries, tellement que fi elles tombent dans des mouvemens irreguliers, doit-on en attribuer la caufe à une matiere irritante ? N'y a-t-il pas 


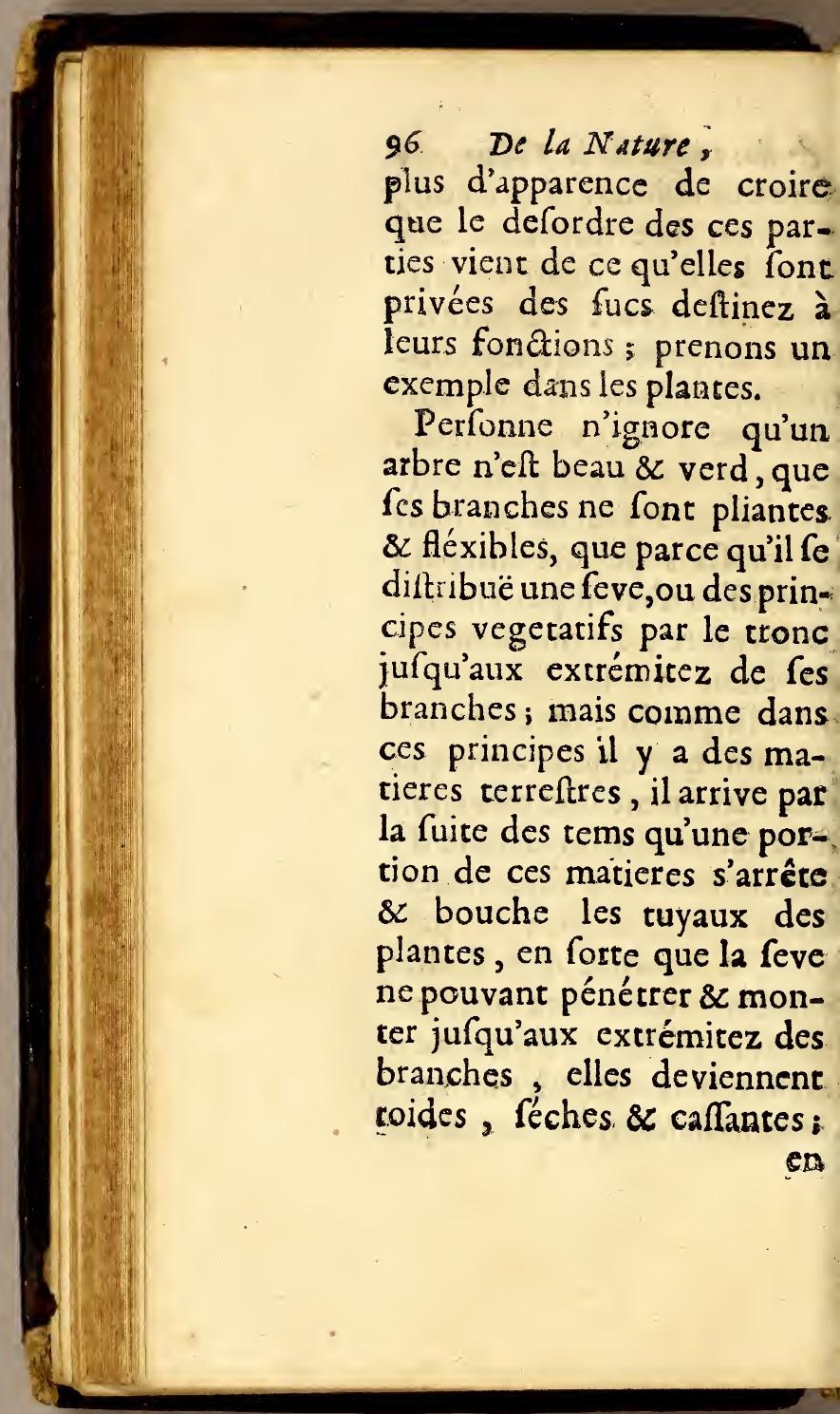


- des caufes de la Fiéure. 97 enfuice tour l'arbre perit par le défauc de diftribution de la feve; \& fi l'on prend la peine de regarder dans le ronc des vicux aibres, on trouvera fans doute des erres \& d'aucres fuperfluicz qui ont faic obft cle ̀̀ la irculation de la feve , \& qui ar confequent one caulé la nort de l'arbre.

On peur penfer que la mêne chofe fe paff: dans les nimaux, \& il cft aifé dereaarquer que dans la jeueffe les fucs nourriciers tant diftribuez abondam. aent à toutes les parties, Hles font vigourcufes, fuu-: les', \& capables de toutes ortes de mouvemrns; mais omme par les frequentes irculations de ces fucs il eft ray. femblable qu'il en refte I 
98 De la Nature,

quelque portion terreftre $\&$ groffiere dans les paffages les plus étroits, \& que même il s'en fait des incruftations contre les tuniques des vaiffeaux; les nouveaux fucs nourriciers ne fe diftribuent pas fi abondamment, ni avec la même facilité, tellement que les parties deviennent plus féches, \& par confequent moins fouples; les os fone plus durs \& plus caffants, quelques arteres font offeufes, les cheveux deviennent blancs \& fecs, parce qu'ils ne reçoivent plus tant de cette humidité on atueufe qui les nourriffoit, la peau devient ridée $\&$ féche, parce que les vaiffeaux capillaires font privez des fucs qui abreuvoien toutes les parties éloignées cour le refte devient foible \& 
dr descaujes de la Fiévre. 99 chancellart, une parrie tombe en paralyfie ; \& enfin l'on meurr par le défaut de diftribution des fucs nourriciers. aux parries éloignées; le conmerce de l'air ćrant interompu \& arrefté dans les oulmons, il y produit ce alement que l'on appelle imroprement fluxion de poirine.

Je me flateque cestraifons ces réflexions pourront aire comprendre que lirriation faite par les acides, n'eft oint la caufe des accidents ui paroiffent dans le frifton, ¿ qu'ils ne fçauroient irriter es parties fenfibles qu'en ouchant ou frapant ces $m \hat{e}-$ aes parties; il faut pour cela ue les acides foient dégagez, c mis en mouvement par les fprits: \&c c'elt alors que les

I ij 
100 De la Nature;

fymptomes qui furviennent dansle chaud de la Fiévrefe manifeftent:

Expli. eation des accidens du chaud.

Les plus ordinaires font les delires \& les douleurs de tefte, dont la caufe fera facile à comprendre, fi l'on confidere que le fang eft alors dans un grand boüillonnement, qu'il occupe plus de volume, \& qu'étant porté aut cerveau en tres-grande abonDes dou- dance, il caufe dans les mern. leurs de branes des tenfions violen-
icfle. tes, ce qui fair la douleur; $\&$ dans les efprits des mouvemens extraordinaires \& irre. et du guliers, ce qui fair le delire. delire. Ajoûtez à cela que les bumeurs âcres étant fublimées par la chaleur exceffive, elles picotent les parties fenfibles du cerveau, \& en troublent toute l'aconomie , \& ces ac- 
\&o des caufes de la Fiévre. Ió cidens ne ceflent qu'aprés que ces humeurs ont efté évacuées par les premieres voyes, ou par les fueurs, ou enfin par infenfible tranfpiration.

Aprés cette explication des fympromes, il me femble quil refte peu de chofe dans la Theorie des Fiévres, dont Raifon de la difference de tous ces $f y m$ propzes, il ne foit aifé de rendre raifon. Car l'on comprend affez que les humeurs qui en font la caufe, produiront des effets differens felon qu'elles feront en plus grande ou en plus petite quantité, felon les differens degrez de leur mouvement, \& felon les differentes parties qui en feront attaquées:

Il faut pourtant avoiier que les redans les Fiévres intermitten- Fiérses tes il y a une difficulté qui intermito I iij 


\section{$r 02$ De la Nature,}

sree dif- paroilt prefque infurmontam fociles ble, \&c qui a efté de tout dre. tems l'éciieil de la Medecine; c'eft que cette Fiévre qui fembloir eftre termincé heureufement par une fueur parfaite, ne laife pas de revenirprécifément le fecond ou le troifieme jour fuivant. Pour moy je ne prétens pas refoudre entierement cetre dufficulté, mais je croy qu'elle peur recevoir plus d'éclairciftement dans mon hypothefe que dans toutes les autres.

ces re. Voicy ceque je penfe tou-

rours

viennent de ce que

Ja maffe

du fang

n'a pas

été retablie. chant la caufe de ces retours: je croy que pendant l'accés, il s'elt fait une notable diffipation d'efprits, \& que fi la maffe du fang n'a pas efté rétablie ni par un bon air, ni. par un chyle affez fpiritueux, 
do des carefes de la Fiérure. 1og. il s'y fera neceffairement une fermentation nouvelle, lors. qu'il fera furvenu une quantité fuffifante de chyle pour l'exciter, \& cét accés fe rejrerera le deuxiéme ou le troifiéme jour felon les difpofitions du chyle ou du fang, ceft-à-dire, felon que le chyle fera plus ou moins impur ou plus ou moins acide, \& qu'il y aura plus ou moins d'efprits dans le fang pour faire une plus lente ou plus. promte fermentation. Par exemple elle fe fera plus promtement au Printems, parce qu'en certe faifon l'air eft rempli de parties fpiritueufes, quife mêlant dans le fang changent fa qualité, \& le renouvellent ; \& c'eft à mon fens la raifon pour laquelle les Fiévres font moins lon-

I iiij. 


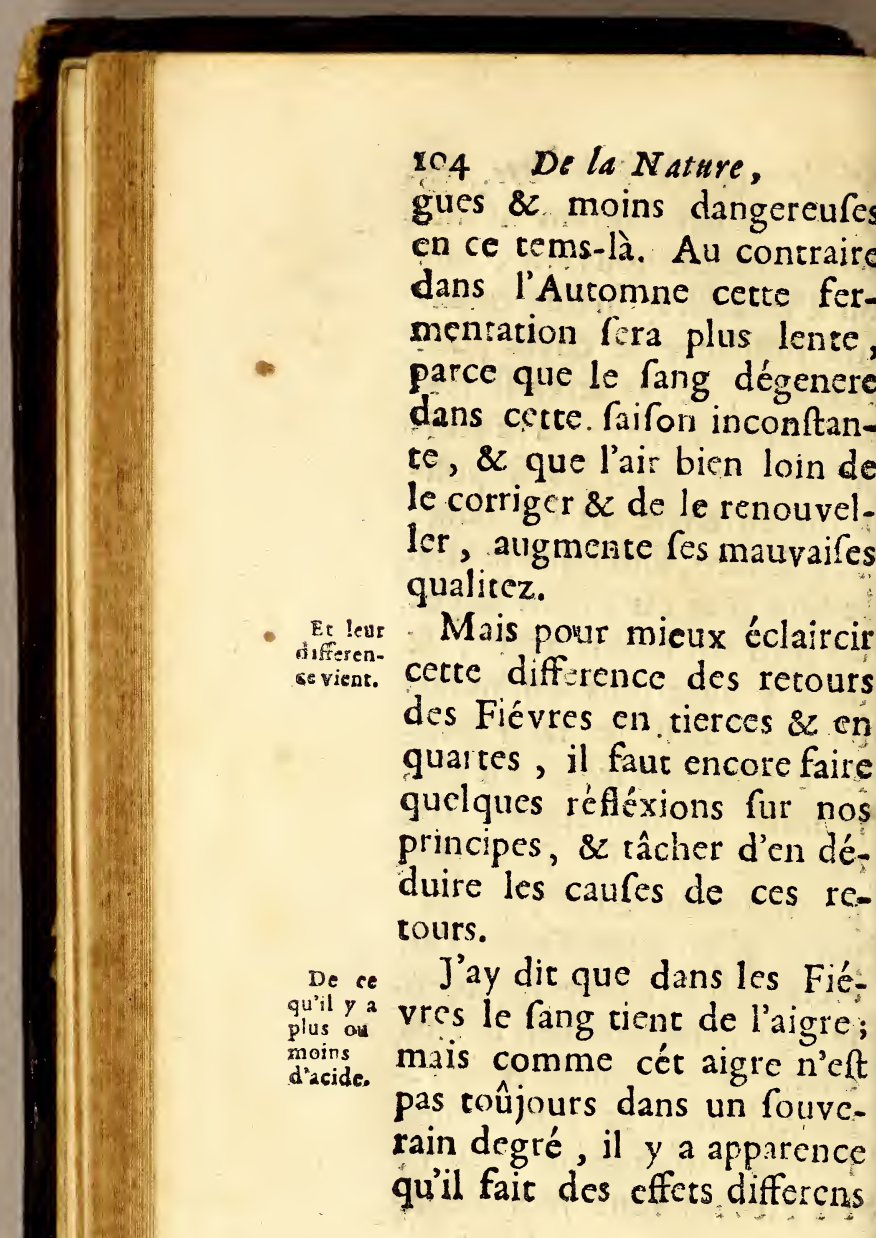


\& des caufes de la Fiévre. 105 fuivant fes differences, \& fuivant les differentes difpoitions du fujet. Il faut en- et pluj fe refouvenir que les oumoins core fe reflouvenir que les deéprits efprits font les agents dans la dans le fermentacion, qu'ils rarefient \& diffolvent la matiere qui efté coagulée par les acides, \& que la diffolution fe fair plus promtement quand il y a beaucoup d'efprits \& moins d'acides ; \& plus lentemene au contraire, quand i) y a plus d'acides \& moins d'efprits. Cela Cuppofé, i l'on peut faire voir que dans da Fiévre quarte, par ex:mple le fang contient moins d'efprits \& plus d'acide que dans la Fievre tierce : on comprendra aifément que les retours de ces Fiévres feront fort differens, \& qu²ls reviendront neceflairement plus 


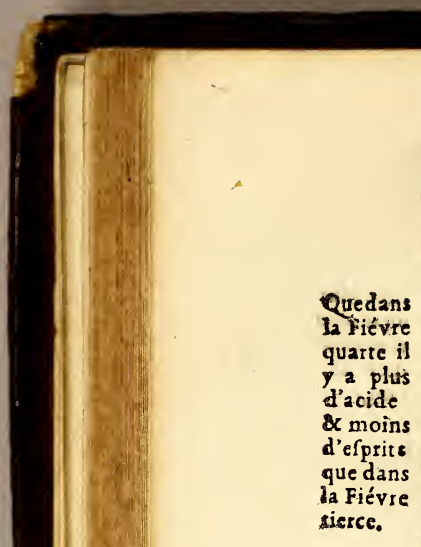

106 De la Nature;

tard dans la Fiévre quarte que dans la Fiévre tierce.

Quedans

12 Fiévire quarte il

$y$ a plus

d'acide

$\&$ moins

d'efprits

que dans tierce.

Une preuve que dans les

Firevres quartes il y a moins d'efprits \& plus d'acides que dans les Fievres tierees; c'eft que les Fiévres quartes fone les plus longues, \& qu'elles ne fe terminent guere naturellement qu'a Printems, \& qu'alors elles fe changent fouvent en tierces. La raifon de ce changement eft qu'en cette faifon $1^{2}$ air eft plus rempli d'efprits \&z d'effences, qui excitent une plus promte fermentation, \& renouvellent la maffe du fang par la defo truction des acides, \& par l'addition des parties fpiritueufes \& volatiles.

Si ce raifonnement prouve que les retours des Fiévres quartes doivent eftre 
20 des caufes de la Fiézro. 107 lus tardifs que ceux des Fiéres tierces, il fera facile de irer la même confequence our toures les aurres Fiévres atermittentes; c c'eft-à-dire, ue leurs retours feront plus. u moins frequens, à proortion qu'il y aura plus on noins d'erprits, ou plus ou noins d'acides dans les huneurs.

A l'égard des Fiévres tier- cemmo" es ou quartes, qui dégéne- les fiéent en doubles tierces, ou in doubles quartes, je com. rens que leurs accés. fe par- nét dous agene, \& que toute la ma- ces ou iere fiévreufe n'ayant pas quartes. tée confumée dans un accés, 1 en refre quelque porrion qui fert de levain à une fermentation nouvelle; \& l'on peut dire que c'eft pour cela. que les accés des Fiévres. ces. of guartes quites bles tiers. 


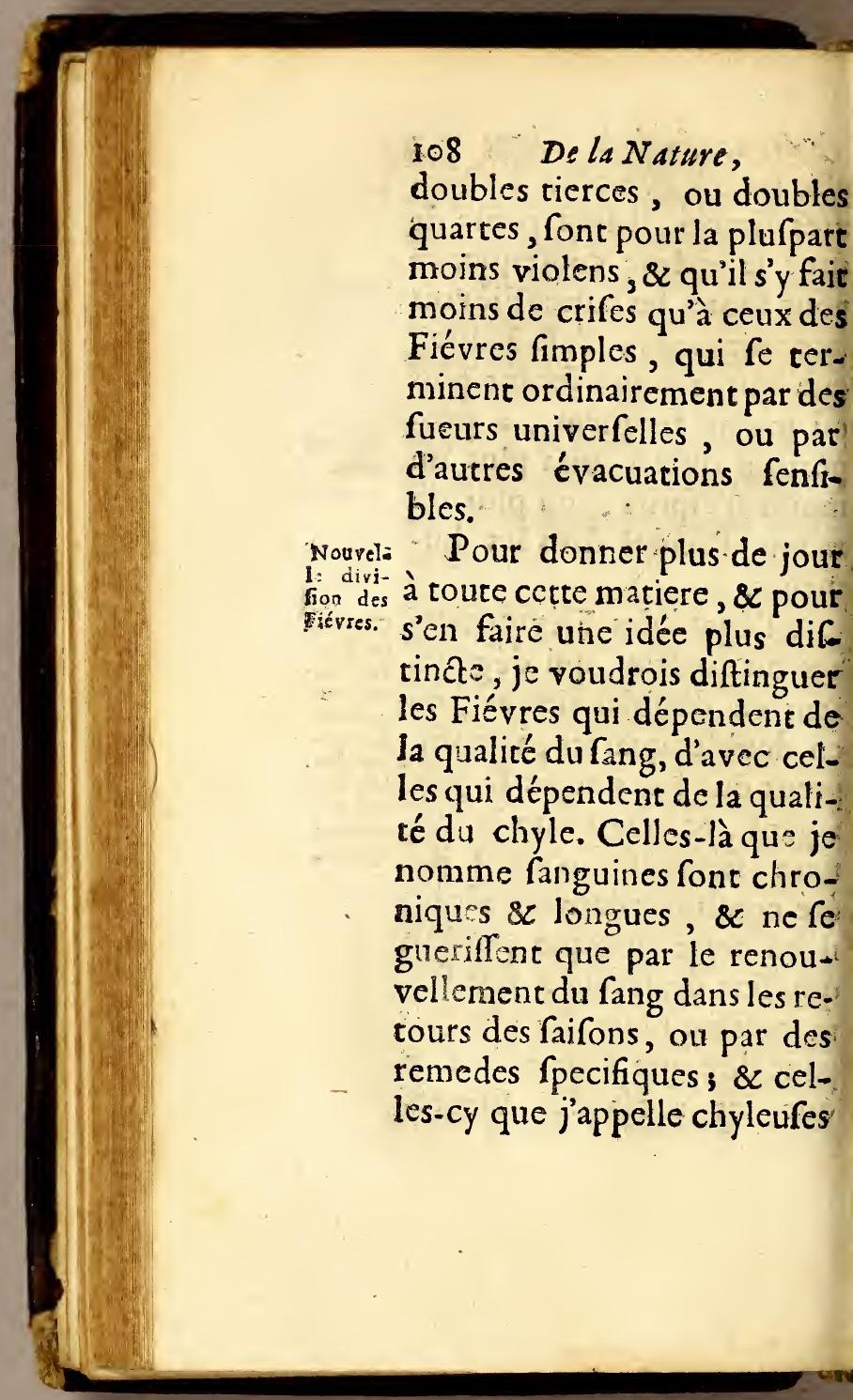


o des caufes de la Fiévre. 109 ont beaucoup moins opiniâres, \& fe gueriffent tres-fouent par des evacuations fenbles des humeurs contenuës lans l'eftomac, ou dans les arties voifines.

Les retours des Fiévres hyleufes font ordinairement En chls leufes. lus frequents, \& moins refuliers; ils. font plus frepuents, parce que le chyle jui eft porté dans les veines it fouvent chargé d'impurecez ; \& de mauvais fucs capaoles d'exciter une promte fermentation; \& ils font moins reguliers, parce que le chyle n'eft pas toûjours 'galement chargé d'impuretez, \& qu'il peut changer de nature par les alimens, ou par les medicamens que l'on met alors en ufage.

Les retours des Fiévres 


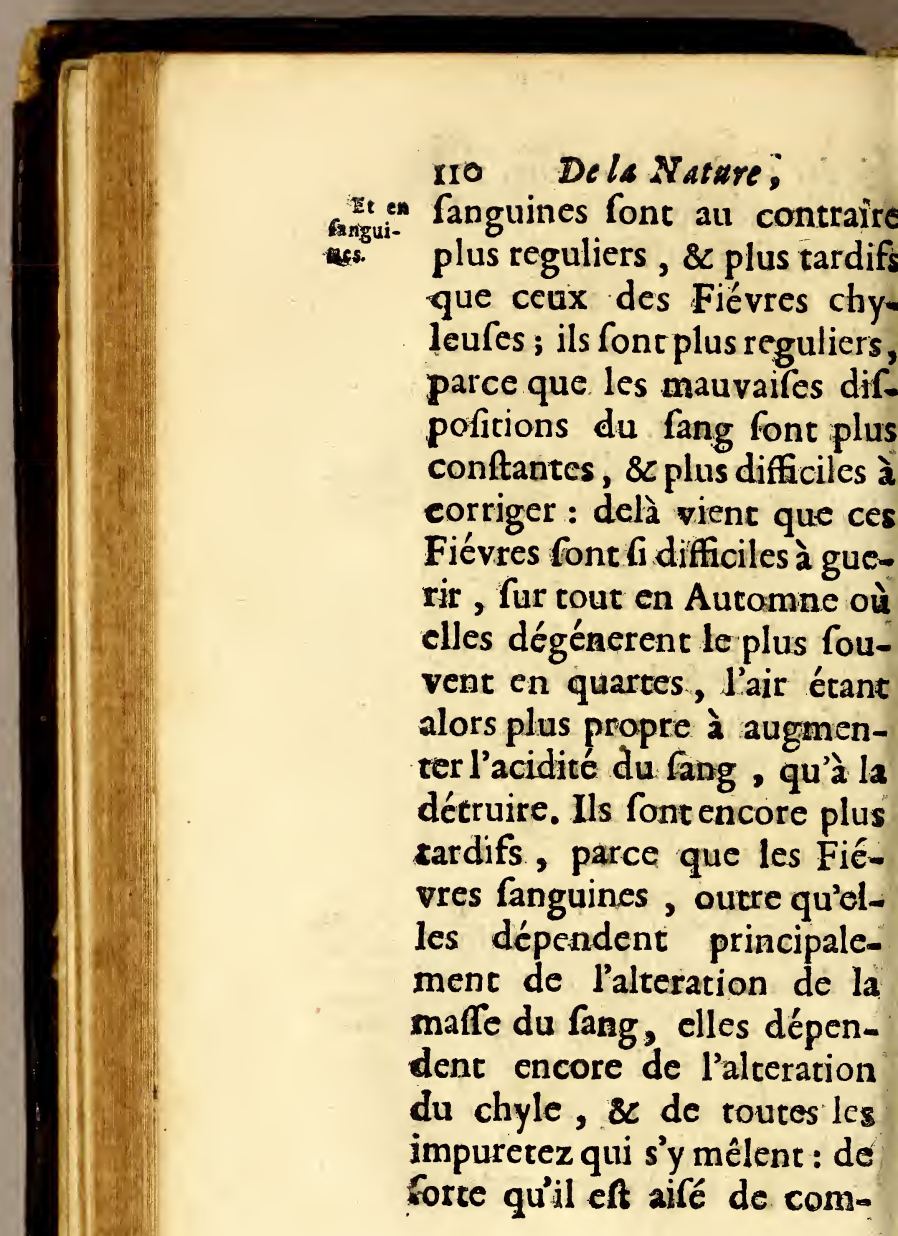


¿d descaufes de la Fiérvre. IIt rendre, que fi le fang $\&$ les ucs qu'il fournit aux parties our leur nourriture, \& pour eurs fonctions, font déja urchargez d'acides, \& que e chyle par fon mélange avee ces fucs \& ces levains, \& par es impuretez qu'il apporte ivec foy, augmente cette acidité du fang, il l'alterera $\&$ 'épaiffira davantage, \& ainf a fermentation fera plus lence $\&$ plus tardive, \& c'eft encore à mon fens une raifon pour laquelle les Fiévres fanguines font plus difficiles ì guerir.

Voilà quel eft mon rentiment fur la caufe des Fiévres; c'eft à dire qu'un fang aigri l'hppo: qui coagule le chyle, ou bien un chyle acide qui épaiffit le fang par fon mélange, font les caufes effentielles des fer- 


\section{De la Nature;}

mentations fiévreufes $\&$ de tous les accidens qui les fui vent. Je pourrois infifter davantage là-deffus, \& examiner fur ce principe toures les divifions de la Fiévre; mais je croy que cela fuffira; \& que les perfonnes éclairées en fçauront tirer, aufli bien que moy, les inductions neceffaires pour expliquer toutes les differences des Fiévres. 


\section{\& des canfes déla Fiévre. 113}

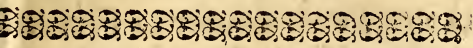

\section{TROISIE'ME PARTIE.}

Réponfés aux Objections.

E n'eft pas affez d'avoir établi mon opinion fur a Nature des Fiévres, il faut encore répondre aux $\mathrm{Ob}$ eetions qu'on me pourra faire. On me dira d'abord que $r$ ob le mélange du chyle avec le jue fit la ang n'établit pas l'effence de fiterre $_{\text {dépen- }}$ a Fiévre, puis que fi cette doit du luppofition étoit vraye, on muélange devroit avoir la Fiévre toutes \& du fág les fois que le chyle entre toûnours te chyle entre la riérre, dans les veines, cette con- $\alpha$ quoo verfion de chyle en fang ne roir par re faifant point fans fermen .2 diete tation, On ajoûtera à ocla labefi- $\begin{gathered}\text { lati } \\ \text { neacer }\end{gathered}$ que s'il faut neceffairement.

$\mathrm{K}$ 
I4 Dela Nature,

que le chyle fe mêle dans le fang pour y caufer la Fiévre, il fera aifé de la prévenir, \& de s'oppofer à fes retours en ne mangeant point, ou du: moins en faifant une diete tres-exacte.

Répon. Jay déja prévenu uné para. tic de cetre difficulté, lors. que j'ay dit que la fermenta. tion qui fe fait dans la fanguification, nieftoit pas fenfible comme in fermentation de la Fiévre. La raifon en eft que les efprits qui font en petite quantité dans le fang des febricitans, eftant enveloppez dans me matiere difficile àrarefier, font neceffairement effore pour s'en dé. barraffer; au lieu que les ef prits qui abondenc dans le fang de ceux qui fe portent: bien, eftant mêlez avec un 
od des caujes de la Fiévre. ns chyle bien preparé, le digerene \& le convertiflent en fang avec plus de facilité $\& z$ moins d'agitation. Remarquez neanmoins que cette derniere fermentation devient quelquefois fenfible : par exemple aprés de grands. repas on fue la nuir, on ne dort pas tranquillement, 8: lon voir que rous ces aocidens, qui ceffent d'ordinaire aprés la digeftion, en fone: manifeftement les effets : cependant cela ne va pas jufqu'à produire cette fermentation extraordinaire, qui n'eft autre chofe que la Fiévre. Au furplus il ne faut: point douter que le retour des Fiévres ne foit empêché: ou retardé, \& les accez di-. minuez par la diete ou pat: l'abfinence. I'experience:

K 
116

De la $N$ ature,

nous fait voir que la Fiévre avance ou retarde fouvent fuivant la differente maniere de vivre des malades; \& je comprends, qu'une Fiévre pourroic ceffer par une abftinence torale de quelques jours, files forces du malade la pouvoient permetre. Nous n'avons guere d'exemples de ces fortes d'abltinences : cependant s'il eftoit polfible qu'un febricitant fuc deux jours fans manger, \& qu'il ne laiffàt pas d'avoir un retour periodique de Fiévre, je croy qu'en ce cas-la il re trouveroit dans le fond de l'eftomac, \& dans les premie. res voyes des reftes d'alimens. mal digerez, ou des humeurs impures, qui fuivant la route \& les mêmes mouvemens du chyle fe mêler 
ir des camfes de la Fiéore. 117 oient dans le fang, \& y exiteroient une fermentation xtraordinaire, qui cauferoit n recour de Fiévre.

Mais on dira fi c'éroit la uantité des efpritsqui fic le re. our des Fiévres, \& la quantité acides plus ou moins grane; la Fiévre ne reviendroit as tout à coup, mais elle ugmenteroit à mefure que s efprits ou les acides augenteroient, ce qui n'eft pas : ailleurs il fe fair un mélange ontiniiel du chyle dans le ng, ce qui doit y produire ne fermentation continiel; \& cela elt oppof́e aux reurs reglez \& periodiques es Fiévres.

Je replique à cela que je e difconviens pas que le hyle ne fe mêle inceffament dans le fang, \& qu'il n'y $\mathrm{K}$ iij 
I:28: De la Nature, excite des fermentations; mai j’ay dit $\&$ je le repere, qu'elle e font pas fenfibles, \& qu' faut une certaine quantité d chyle impur pour y excite celles qui caufent la Fiévre deux ou trois cueillerées d vinaigre ne font pas capable d'aigrir dix ou douze pinte de vin, une chopine ou un pinte le feront : ileft donc ne ceflaire qu'il y ait une quan tité de chyle proportionné a la difpofition du fang pou y caufer une fermentatio fievreufe : J'avouë que je n fçaurois expliquer cela me chaniquement, ni détermi ner la mefure ducems, de acides, \& des efprits , je con çois feulement qu'une eerai ne quantité de chyle enve loppera la matiere fubrile \& les efprits, \& que le mouxe 
¿d des caufes de la Fiévre. Irg: ent que cette mariere 8 . es efprits feront pour fe ivelopper, caufera un accés. E Fiévre, que cet accés reendra plútoft ou plus rard, lon quil y aura plus ou: oins d'efprits dans la mafie uang. Une marmice ou un ot qui eft devantle feu, boüilra plus promtement s'il y a: eaucoup de feu; dans la Fiére quarte le fang eft moins iritueux que dans les autres. iévres, c'eft pourquoy les tours periodiques de cetce. iévre font plus tardifs come je l'ay. remarqué ; \& ce ui me perfuade que par la: ifpoficion peu fpiritueufe du ing, les accés doivent eftre zoins frequenes, e'efi que fi ans la Fiévre quat te je done des alimens chauds, $8 x$ do quenrs fpiritueufes, je di: 
120 De la Nature, minueray le firfon, \& javanceray les accés.

J'ay fouvent remarqué que - les changemens d'air $\&$ de nourriture ont changé les accés des Fiévres, ainfi leurs retours periodiques ne font pas toûjours fort reglez. Sur ce fondement je crois avoir rai. fon de pretendre que le tems des recours periodiques des Fiévres dépendra de la difpofition plus ou moins fpiritueufe du fang. Voilà mes raifons fur la caule des retours des Fiévres, je conviens qu'elles ne font pas démonftratives, mais je m'en contenteray, jufqu'à ce qu'un plus heureux que moy en ait 2. Ob. trouvé de meilleures. jection, que l'im, pureté des hualeurs eft

On dira peut-être que toue ce que j'attribuë à des humeurs impures qui fe mêlent dans 
b des caufes de la Fiérore. I2I ans le fang, fe rapporte fort $12 \mathrm{~min}$ ien à ce que les Arrciens unt huse it de la pourriture, \& qu'ain- pourrije ramene la doctrine de la orruption'que j'aycombatuë. Il me femble que je me uis affez expliqué fur les imuretez du chyle \& du fang; ay dit que j'entendois pai les alterations qu'ils receoient ou des mauvais ali. nens, ou des digeftions imarfaites, \&z je n'ay point dit u'en dégénerant de leur bonies qualitez, ils devenoient ourris \& corrompus: de fore que je ne vois pas furquoy n doit fonder cette Obje. tion. En un mot je ne nie as que dans le fang, \& que Aans le chyle il n'y alt des mpuretez; mais je n'admets oint cette pretenduë corrution du fang, que les Mé 


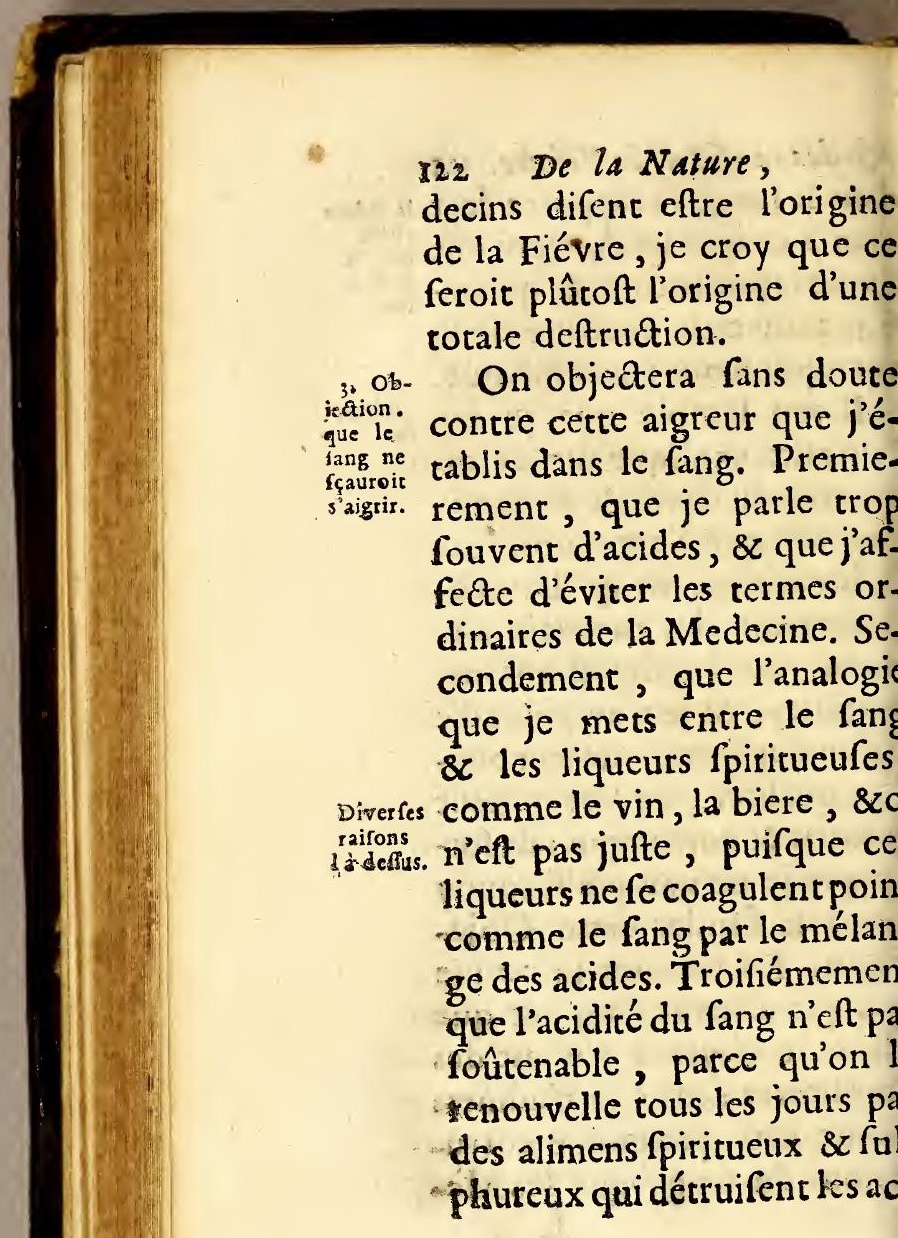


du des caules de la Fiérre. 12 des, \& enfin que ces mèmes acides ne peuvent pas fairo tane de défordre dans nos. corps, \& coaguler le fang, puifqu'ils font neceffaires à la digeftion.

Pour répondre à ces $\mathrm{Ob}$ jections, je dis ; Promicrement, qu'à la verité la façon de s'expliquer par les acides eft nouvelle, mais que la chofe ne l'eft pas; les fucs que les Medecins appellent humeur mélancolique fe rapportent fi bien avec les liqueurs acides, que pour peu qn'on y faffe de reflexion, on fera convaincu que ce n'eft qu'une même chofe ; car que peut-on dire des humeurs mélancoliques, qui ne convienne aux fucs acides; par exemple, comment expliquera-tion la caufe des Schirres. . 


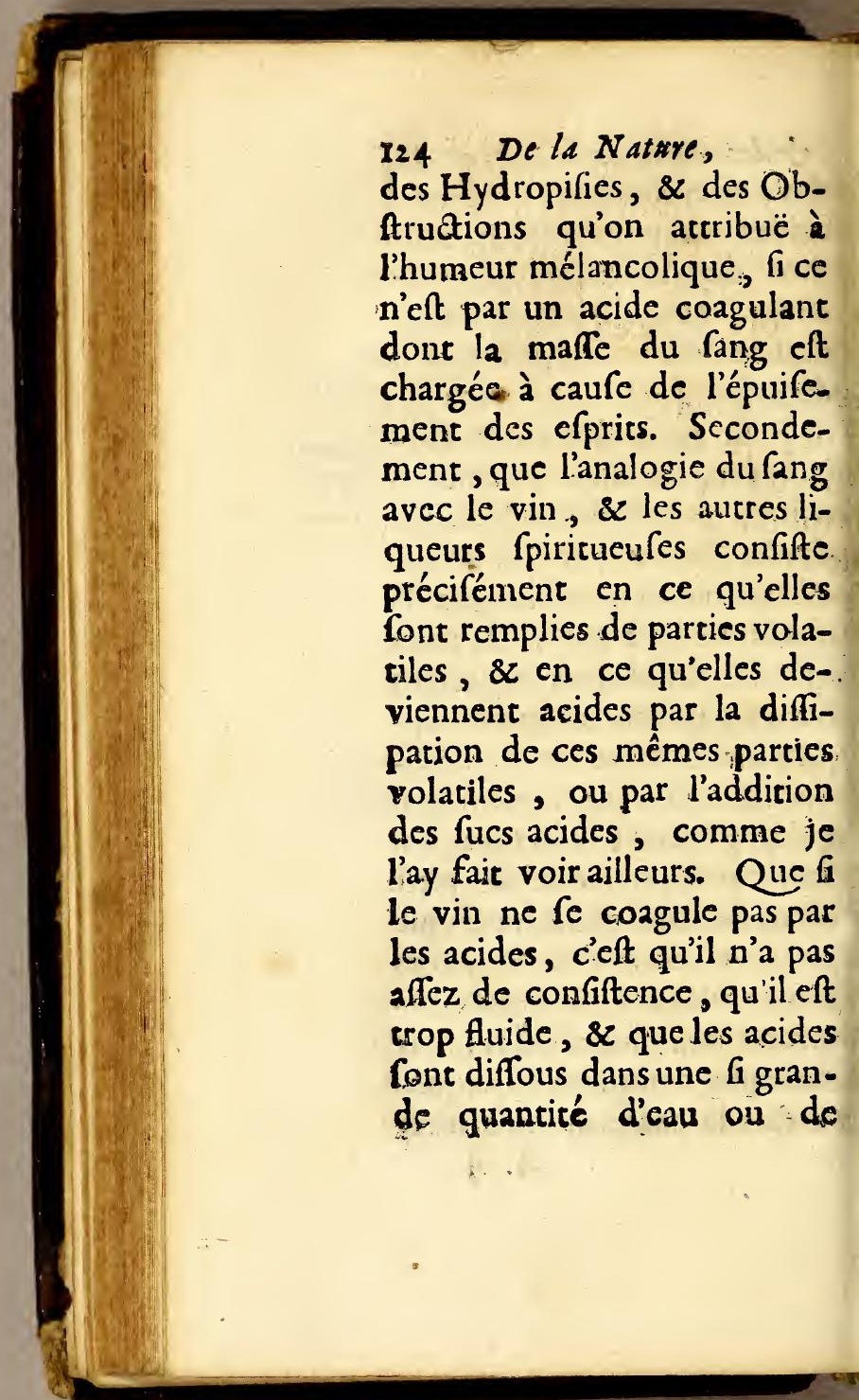


\& des: carfes de la Fiévre. 125 phlegme, qu'ils ne fçauroient s'approcher pour unir leurs forces , \& pour produire une coagulation dans cette liqueur ; mais certe circonftance n'empêche pas qu'il n'y ait une analogie tres-jufte entre le vin \& le fang.

De tour cela on peut raiConnablement conclure ce me femble, que le fang elt fufceptible d'acidité, quoiqu'on le renouvelle tous les jours par des alimens fpiritueux \& fulphureux. Dans cette veuë je confidere le fang ̀̀ peu prés comme le vin qu'on expofe fur mer dans des tonneaux fouphrez, pour empêcher que les ef prits ne fé diflipent, \& qu'il n'aigriffe; ou pluttoft comme celuy de ces grands Vaifleaux d'Allemagne, que l'on re

L iij. 


\section{De la Nature,}

nouvelle tous les ans par les vins noureaux qu'on y mer, afin de remplir la place de de celuy qu'on a ôté, de la même manicre que les alimens reparent tous les jours le fang qui a efté cmployé à la nourriture des parties, ou qui s'eft diflipé par infenfible tranfpiration. Mais comme le vin fouphré fe peut gâter fur la mer par les exceflives chaleurs qui diflipent lesefprits, \& que le vin de ces grands Vaiffeaux d'Allemagne deviendroit aigre, fi au licu de mouft on y mettoit du verjus ou du vinaigre; je dis tout de même que fe faifant dans le fang une plus grande diffipation d'efprits, qu'il n'en eft reparé par les alimens fpiritueux, ou que aes alimens au lieu d'cttre 
or des caules de la Fiévre. 127 fpiritueux \& fulphureux étant acides \& dépourveus d'efprits, le fang deviendra aigre neceffairement, ainfi que je lay expliqué.

A l'égard de ce qu'on dic que les acides font neceffaires à la digeftion, j'en conviens; j’avoue même qu'elle ne fçauroit eftre parfaire, que lors qu'il fe trouve dans les humeurs une jufte proportion d'acides \& d'efprits, \& je comprens que c'elt de cerre jufte proportion que dérivent les douces liqueurs \& les fucs nourriciers, que le fang fournit à toutes les parties du corps. Mais dés le moment que le temperament de ces liqueurs fe change, 86 que les efprits fone diffipez, ou que les acides dominent, alors les humeurs coulene

I iiij; 


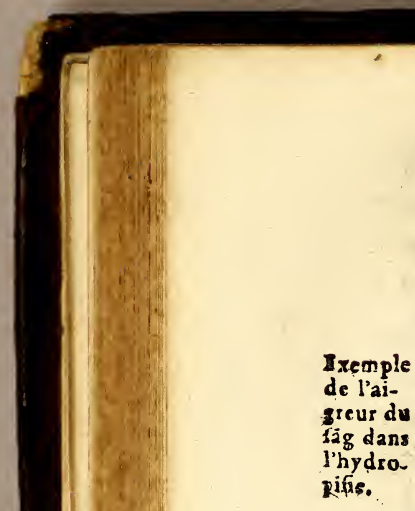

128. De la Nature,

lentement aux parties, toutes les fonctions fonc languiffantes, \& toute l'oconomie naturelle eft en defordre.

Ixemple

de lai-

L'hydropifie nous fournit un exemple remarquable de cette acidité du fang, \& des effers qu'elle peut produire. Reprefentez - vous un homme qui a efté long-tems malade d'une Fiévre quaree, pendant laquelle il n'aura gardé aucun regime, \& confiderez que s'eftane fait une grande diffipation d'cfprits dans la maffe du fang de cét homme, ce même fang a contracté une extréme acidité. Sur ce principe il faut neceffairemene qu'à proportion que le fang s'éloigne du cœur $\&$ des poulmons, ou il a été diffour par les efprits, il devienne plus froid \& plus 
\& des canfes de la Ficrure. 129 pais; que venant à paffer ans les petits vaiffeaux des arries éloignées ll s'y cinaule; \& que la ferolité s'en parant à peu prés de la mêe maniere quele petit laik - Cepare du fromage; elle répande par les orifices des aiffeaux dans le ventre, $\&$ ans les autres parties.: D'un utre côté le fang coagulé \& erenu dans la fubltance des arties mêmes (comme il eft eftitué d'efprits, \& qu’il a crdu fon mouvement ) fe orrome, \& produit les abl: és qui accompagnent le plus ouvent cetre maladie. Voila e quelle maniere l'acidicó xceflive du fang peut cauler hydropifie; \& ce raifonnenent eft confirmé par l'expeience, puifque cette malaje ne fe guerit prefque ja-. 
130 De la Nature, mais que par des remedes fpiritueux \& volatiles qui dé. truifent lcs acides.

4. ob- Mais revenons aux Objejection, Otions, en voicy une des plus acides font le remede des Fiévres $\&$ non pas
la caufe. fortes qu'on puiffe faire; les acides font fouvent le reme. de des Fiévres, comment donc en pourroient-ils eftre la caufe ?

ágonse

Pour refoudre cette difficulté, il faur fe reffouvenir qu'il y a trois tems dans la Fiévre, pendant lefquels un malade étant agité de fympromes differens, il eft évident que l'on doir avoir des indications differentes pour ra guerifon.

Premierement dans le tems. du friffon, je ne penfe pas que perfonne voulur donner des boiffons acides, \& la raifon en ef que les acides domi- 
- des canfes de la Fiéure. 13 at alors daiss la maffe du $\mathrm{g}$, \& tiennene les efprits veloppez avec les autres ncipes. Auffi eft-il évident e les boiffons froides $\&$ des augmentent le froid $8 \Sigma$ lurée du friffon, quand on affez imprudent pour s'en vir, au licu que les lieurs chaudes \& Ipiritueule diminuent.

Secondement on peut enre moins le mettre en ufapendant les fueurs, parce alors les matieres indige$s$, \& les humeurs impures. ant diffoutes \& rarefiées, auroir du peril à fe fervir cides qui pourroient en pêciner la tranfpiration , \& afer d'autres accidens plus cheux.

Il refte donc à examiner quelle utilité ils peuvent 


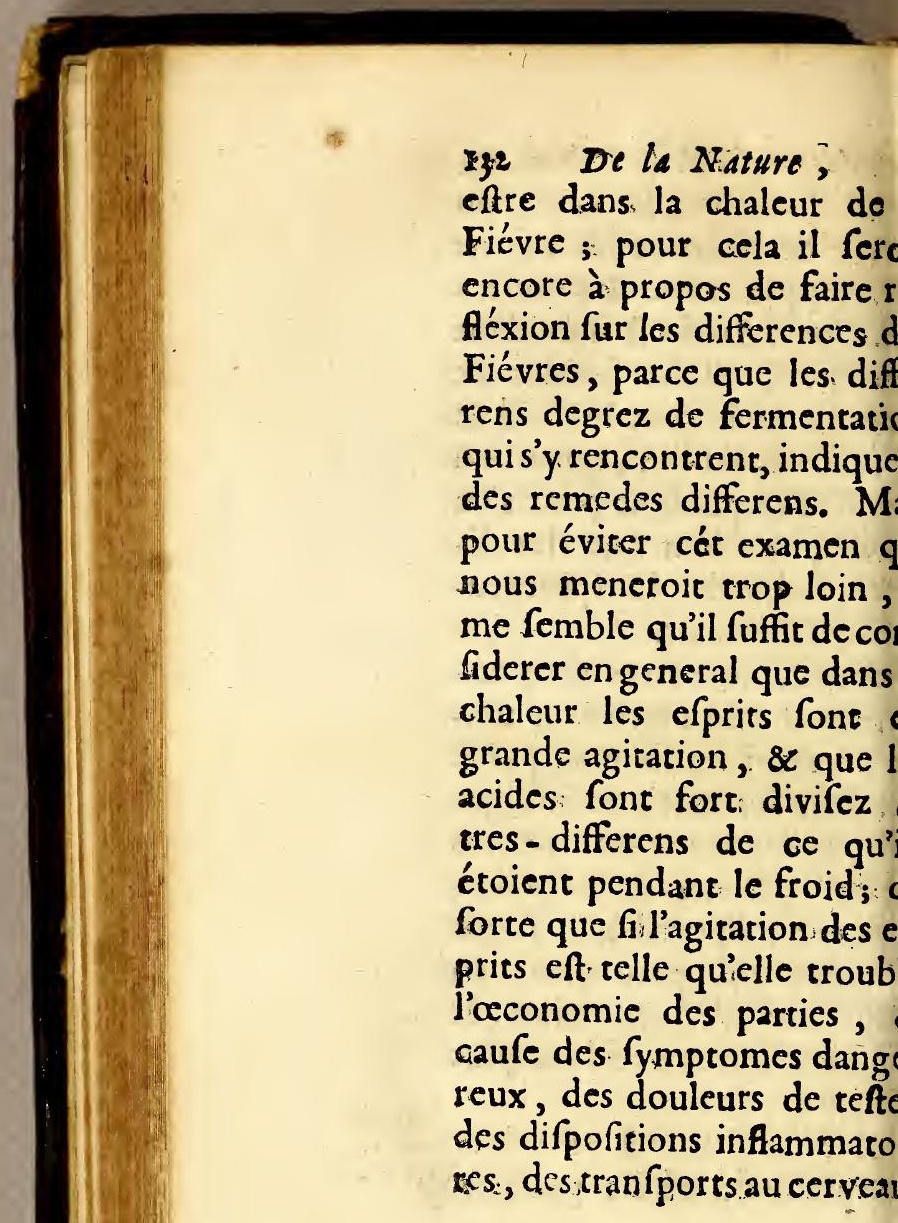


- des caufes de la Fiévré. - il femble que la vraye lication eft de calmer leur petuofité : Et comme jay voir que dans le friffon Acides embarraffent les rits; $\&$ retardent leur ouvement, il eft hors de ute que les liqueurs qui ront quelque analogie acux, doivent produire le ême effet ; \& c'eft dans tte veuë que lion employe rt à propos la limonade, les autres boiffons mêlées aigre de fouffre, ou de viol: d'autant plus, que les cides eftant fort divifez ins cét eftat de Fiévre, on it moins craindre de les llier par l'ufage des Acies, pourveu qu'il foit moeré.

C'eft ici qu'un Medecin tions fus befoin de tout fon juge- leur ufom 


\section{4 \\ De la Nature,}

ment pour faire un difcerne ment jufte de la nature do Fiévres, \& pour examiner le differens degrez du mouve mens des humeurs. Car er fin fi par un ufage indifcr des Acides, on fufpend l'a ction des efprits fur les ma tieres impures; au lieu d produire de bons effers, 0 caufe fouvent des obftry ctions : fi bien qu'il ne ré fulte de toute la fermenta tion qu'une crife imparfaic qui eft la fource d'une inf nité de maladies.

Quieft bon dans de certaines Fiévres, plûtôt que dans d'autres.

Je conclus done qu'o doit ufer de grande précau tion dans la difpenfation de Remedes acides, \& qu'i] ne fçauroient être utiles qa dans les Fiévres où les e prits font en trop grande a gitation, $\& z$ où il clt abfolu 
Ğ des caufes de la Fiévre. 135 ent neceffaire de calmer ur impetuofié. Que s'il y des Fievres où l'ufage des cides foit indifpenfable, ce e peut être que dans certai. es Fiévres malignes, qui aufent une telle fonte $\&$ ne fi grande rarefaction ans la maffe du fang, qu'il it abfolument neceffaire de condenfer, \& de luy doner plus de confiftance par le noyen des Acides : au lieu u'ils font pernicieux dans es Fiévres que j'ay appelées fanguines \& chroniques, arce que (comme j'ay fair oir cy-devant) les efprits iy eftant jamais affez agitez, i en affez grande abondane pour caufer des fymptones fâcheux, on a plûtôt befoin de Remedes volatiles qui reparent les efprics, que 


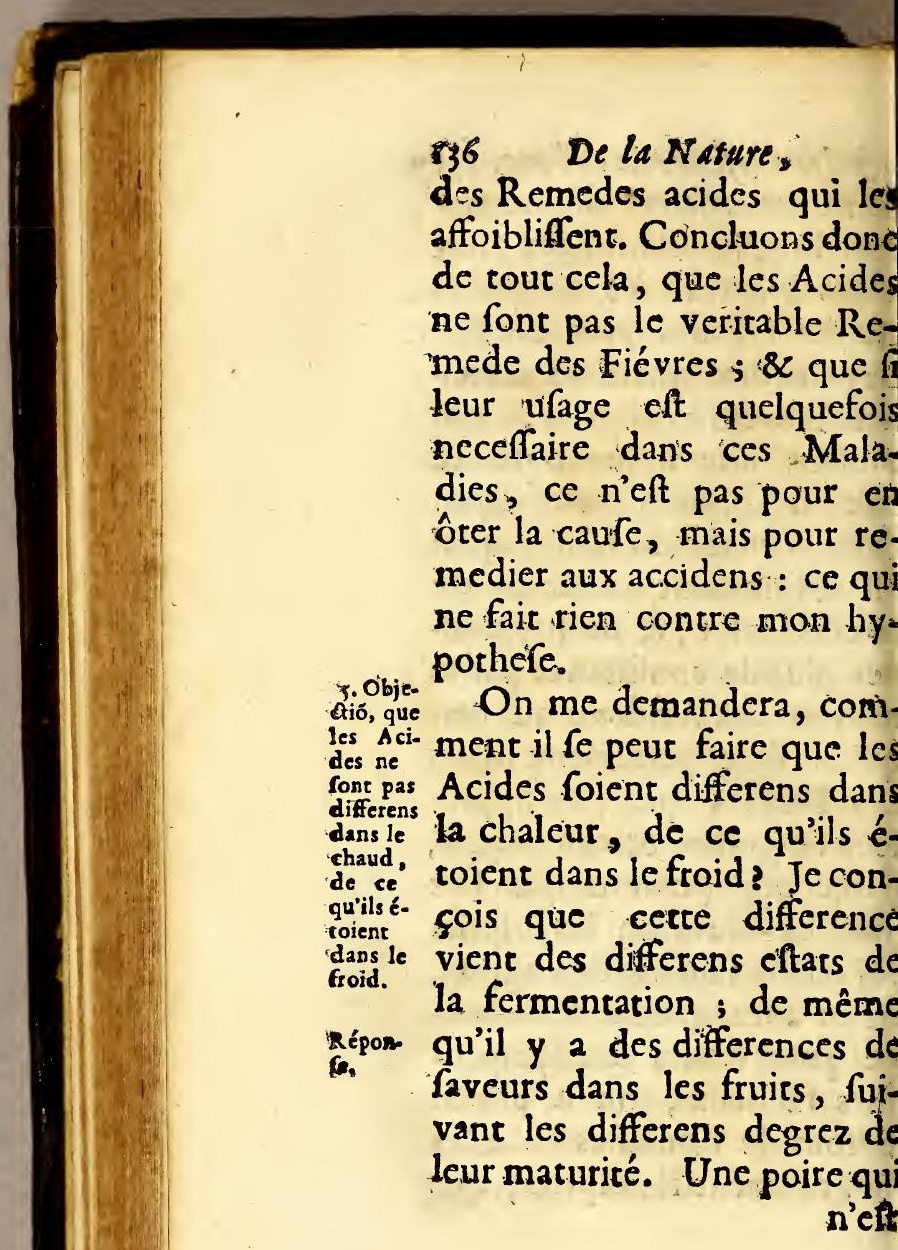


G'des caufes de la Fiévre. 137 n'eft pas meure eft acerbe parce que les Acides grofliers y dominene, \& que les parties fpiritueufes ne font pas fuffifamment exaltces :: a contraire, . lorfqu'elle eft. meure, elle a une faveur a.zreable, parce que les efprits ont adoucy les Acides dans a maturation ; mais lorfqu'elle eft trop meure, elle. ent l'aigre : la raifon en eft u'alors les Acides dominent: ar la diffipation des parties. piritueures.

La même chole arrive: lans les Fjévres : pendant le: tiffon, les Acides font grof:ers ; \& en liant les efprits $s$ caufent le froid \& les aures fynaptomes qui. font or-inaires au commencement es Fievres : pendant la clia-ur, ces mêmes Acides ayanes 
${ }_{13}^{8}$ De la Nature, efté aiguifez par une longue fermentation, deviennent plus mobiles \& moins embarafluns, \& fuivent aifément l'impetuofité des efprits. quil les entraîne; ce qui cau. fe les douleurs \& les autres accidens du chaud : \& à la fin de l'accés, les fueurs fentent fouvent l'aigre. On voit donc par là que dans les. trois tems de la Fiévre, les: Acides font differens, \& que fur ce principe, les accidens. qui arrivent au commencement ou dans le declin des. Fiévres, doivent être tresdifferens.

c.ebje- Voici encore de nouvelctiog, que
filesim- les objections. On me dira de l'air fur le. fang ét. toiet plus fe du fang, font plus fortes que cel. que celles des alimens,
tes du 
er des caufes de la Fiévre. I39 qu'au Printems le fang fe re- chyle: houvelle par les bonnes qua- on re itez de l'air, quil abonde point de pour lors en efprits. Si cela au print. eft, on me demandera d'où vient quil y a prefque toûours dans cetre Saifon des. Eiévres tierces, ou d'autres: Fiévres intermittentes? Cela. paroît manifeftement contraire à mon hypothefe, qui eft que le défaur des efprits. eft la caufe des Fiévres; 86 i l'Automne eft la Saifon: de l'année où l'on en voit: le plus, à caufe de cette diffipation d'efprits que j'ai fuppofée, il femble qu'il ne devroit point y en avoir au: Printems, ni dans les autres: Saifons, où les qualitez de: l'air font oppofées. D'ailleurs, sil eft vrai que fuivane $\begin{gathered}\text { Et atsi } \\ \text { toutesioss }\end{gathered}$ les, differentes Saifons il ar- Fiéress $\mathrm{Mij}$ 


\section{De la Nature,}

dans lesir rive des changemens confichangemens de saifons. derables dans le fang, doù vient, dira-t-on encore, qu'une Fiévre, qui felon moi, procede de la mauyaife qualité du fang, dure fouvent des années entieres ?

Néćpon. res.

Je répons à cela : premie. rement; qu'on doit attribuer la caufe des Fiévres qui vien. nent au Printems, à ce que pendant l'Hyver le fang étant épaiff \& furchargé d'A. cides; \& n'y ayant pas affez d'efprits pour exciter la fermentation, il ne fe-produifoit point de Fiévre : mais dés que les parties fpiritueufés de l'air $f$ f fort introdùtes dans les veines, alors elles agjtent ces matieres qui épaififloient-le fang; \& caufẹnc des Fiévres tierces Printannięress. Remarquez auffi; 
or des caufes de la Fiérure. 141 ue comne les efprits qui aondent dans l'air, corrigent: mauvaife qualité du fang, outes ces Fiévres font do eu de durée, \&z fe guérifene le plus fouvent fans $\mathrm{Re}$ nede. Le contraire arrive lans l'Automne, ainfi que e l'ai déja remarqué, \& tout ela s'accorde fort bien $2 v e c$ : non principe.

Je dis en fecond lieu, u'it y a peu de Fiévres qui guériflent, ou qui ne chanent par le changement des aifons. Que s'il s'en troue qui foient affez opiniâtres: our durer des années entiees, cela ne fçauroit proce-. er que du mauvais. tempeament du malade, de fon atemperance, ou de la maus aife conduite de ceux qui. uront eu foin de fa fanté. Miiij 
I42 De la Nature,

Si par exemple, au lieu de rétablir le fang dans fa qua. lité balfansique \& fpiritueufe, l'on a épuifé les veines du malade, pour les remplir de boiffons acides \& rafraîchiffantes, il eft à craindre que le benefice des Saifons ne lui foit inutile; \& à moins qu'un Remede fpecifique ne vienne au fecours de l'air, la guérifon de fa Fićvre fera difficile. On voit tous les jours des vieillards, dontl'âge a glacé le fang dans les veines; attaquez de Fiévres intermittentes, à qui des Medecins ordonnent des faignées réicerées, \&z des Remedes rafraîchiflans, pour éteindre, difent - ils, le feu devorant qui eft dans leurs entrailles : cependant l'experience fait voir rous les jours 
- des caufes de la Fiévre. 143 e certe methode eft nuifi, fur tout à desperionnes un âge avancé.

On objeatera encore que s.obje: . n n'elt plus capable do les difnner la Eiévre que la dif- pofitions. mer la Eilieufes fition bilieufe du fang, la- font la elle eft contraire à l'A cide. Fiérres, effer, ceux qui ont beu pas l'ais vins de liqueur, \& qui greur des ur úe de poivre $\&$ d'aliens chauds qui produifent bile ; ceux-là, dis-je, fonc. s.plus fujets à la Fiévre : aut u que rien n'y, eft fi oppoque l'aigreur du fang. Cela voit dans les Mélancoliues, dans les Scorburiques, dans les Hydropiques, ui n'ont jamais de Fiévre, à: aufé de l'extréme acidité ui domine dans la malle du: ing de ces Malades. Je dis à l'égard de ces répóni 
I44. De la Nature,

difpolitions bilieufes, que l'experience nous apprend que ce ne font pas les caufes principales des Fiévres, puifqu'on voit tous les jours des bilieux. \& des gens malades de la jauniffe, navoir pas la moindre émotion fiévreufe ; au contraire, ils ont prefque toûjours le pouls petit

areala

bile ne peut pas caufer la Eiévic. \&languiflant. Dans te fonds, je ne comprens pas comment la bile peut cauler la Fiévre: car fi par la bile on entend une humeur amere fans mélange d'autres fucs, telle qu'cht celle qui eft contenuë naturellement dans la veficule du fiel, . loin de pro. duire la Fiévre, elle la doir empêcher, puifque tout ce qui eft amer combat $\& z$ détruit la fermentation de la Fiévre. Cela oft manifolte danss 
on descuufes de la Fiérure. i45 lans les febrifuges les plus fitez, comme font le Quinuina, la perite Cencaurée, '́corce de Buis, d'Aune, la acine de Gentiane, \&c. \& es pierres mêmes que l'on couve dans la veficule du fiel 'un homme ou d'un bœuf, efquelles n'eftans qu'une ile épaiffie \&z condenfée, ont encore de veritables fe. rifuges. Mais fi par la bile n entend un mélange conus de fucs acides, amers, oux \& indigeftes, comme s'en rencontre fouvent ans les premieres voyes, 82 ont bien des gens fe plainent, \& difent qu'ils ont e la bile; javoüé que ces umeurs pourront caufer la iévre, lorfqu'elles feront ortées avec le chyle dans s veines, mais ce fera toû-

N 


\section{De la Niture,}

jours à caufe de l'acidité qu'elles communiquent a fang; \& tout cela confirme encore mon hypothefe.

D'où

vient que les ali'mens chauds caufent lafiévre?

$S$ il arrive que les vins de liqueur $\&$ les alimens chauds \& f piritueux produifent des Fiévres, cela ne fe fait point dans le moment quon en ufe; mais aprés qu'ils auront efté pris avec excés, \& qu'ayant caufé une trop grande rarefaction dans la maffe du fang, $\$$ donné lieu à une diffipation d'efprits, le fang aura contracté une difpofition a* pour. cide. Enfin fi les hypoconquoy les hydropiques $8 x$ les fcorbutiques n'y font pas fuiets. driaques, les fcorbutiques, \& les hydropiques, lefquels ont le fang acide, comme tout le monde en convient. ont tres-rarement la Fiévre la raifon en eft évidente; c'ef que le fang de ces fortes de 
do des caufes de la Fiévre. 147 Malades eft deftitué d'efprits, ou du moins ils y font en fir petite quantité, qu'ils font facilement abforbez \& enveloppez par les Acides qui y dominent : fi bien quil eft impoffible qu'ils puiffent exciter de grandes fermentations. Cependant on remarque prefque toújours dans ces maladies, que le pouls s'eleve aprés le repas : ce qui vient de ce que la converfion du chyle en fang ne fe fait pas tranquillement, $\&$ que les parties fpiritueufes du chyle eftant portées dans la maffe du fang, y excitent la verité une fermentation. Mais comme les Acides $\mathbf{y}$ dominent, ils lient \& enveloppent bien-tôt le peu qu'il y a d'efprits : tellement qu'il n'y paroît qu'une agitation N ij 
148 De la Nature;

legere, qui n'eft tout au plus qu'une Fiévre lente.

ร. Obje-

Mais peut-être ne fera-

ctió, que

files Fié-

vres ve-

noiêt de

l'aigreur

du fang,

elles fe-

roient

toutes

incura.

bles.

$t$ - on pas content de cette hypothefe, de l'aigreur du fang dans les veines : Si cela eftoir, dira-t-on, toutes les Fiévres feroient incurables : La raifon en eft, que pour les guérir il feroir neceffaire que le fang perdît fa qualité aigre. Or il eft certain que dés qu'une liqueur eft aigrie, elle ne fçauroit rerourner à fon premier eftat. Par exemple, fi le vin, la biere \& le lait deviennent aigres, il eft conftant que ces liqueurs ne perdent point leur aigreur, \& qu'au contraire elles la communiquent aux autres avec lefquelles on les mêle. D'ailleurs, on ne doir pas conclure que le 
ódes caufes de la Fiévre. 149 fang devienne acide par la diffipation des efprits : fouvent aprés cette diffipation, les parties fulfurées prennent le deffus, \& alors il devient rancide, à peu prés comme le vin gras.

Je n'ay pas dit abfolument Répon: que le fang fûr aigre dans les Fiévres, mais qu'il tenoir de l'aigre. Il y a bien de la difference entre l'un \& l'autre. Je conviens que lorfque le fang eft dans une extrême acidité, il eft impoffible de le rétablir dans fon premier eftat fpiritueux ; \& cent pour cette raifon que les hydropifies, les Fiévres lentes, les affections hypocondriaques \& fcorbutiques, font la plûpart incurables. Mais lorfque le fang n'a qu'une difpofition à l'aigreur, on voir

$\mathrm{N}$ iij 
150

De la Nature,

bien qu'on peut le remettre dans fon eftat naturel ; \& qu'ainf la plûpart des Fiévres font guériffables. A l'égard de ce qu'on dit, que par la diffipation des efprits. le fang peur devenir rancide, j'en demeure d'accord : ma penfée n'eft pas que le fang devienne toûjours acide, lorfque fes efprits fe dilfipent; mais feulement qu'il ne fçauroit devenir acide que par la diffipation de fes: efprits.

$\rightarrow$ ob. jection; que $\mathrm{l}_{2}$

Fiévre étant une fermensation, elle dé. pand du $m$ ilange d'un acide arec un alka$\mathrm{li}, \&$ non pas feu. jement

On dira eneore que mon hypothefe paroîr imparfaite, \& qu'elle ne répond pas à l'idée qu'on a des fermentations. Toute fermentation eft une action de deux fels. cortraires, dont l'un eft acide, \& l'autre lixivieux ou alkali. Pour expliquer done 
\& des caufes de la Fiérre. I I la Fiévre, qui eft une fer:- de ra. mentation, il faut fuppofer efpriss. dans le fang le mélange de ces deux fels ; c'eft-à-dire, ou la difpoficion acide du fang, \& la bile qui y eft entrânée des entrailles; ou ce. qui eft mieux, la difpolition: bilieufe du fang, \& les humeurs aigries qui y font por rées des entrailles à chaque accés. Or je n'ay parlé. dira-t-on, que d'un fang. aigri, \& d'un chyle impur: \& j jetribue tout le mouvement à l'action des efprits : ce qui ne paroîc pas fuffifant.

Je fçay bien que la plû- Répon part des Auteurs modernes, font dans la penfée que la fermentation ne fe peut faire que par la rencontre d'un. fel acide \& d'un fel alkali :

N iiij; 


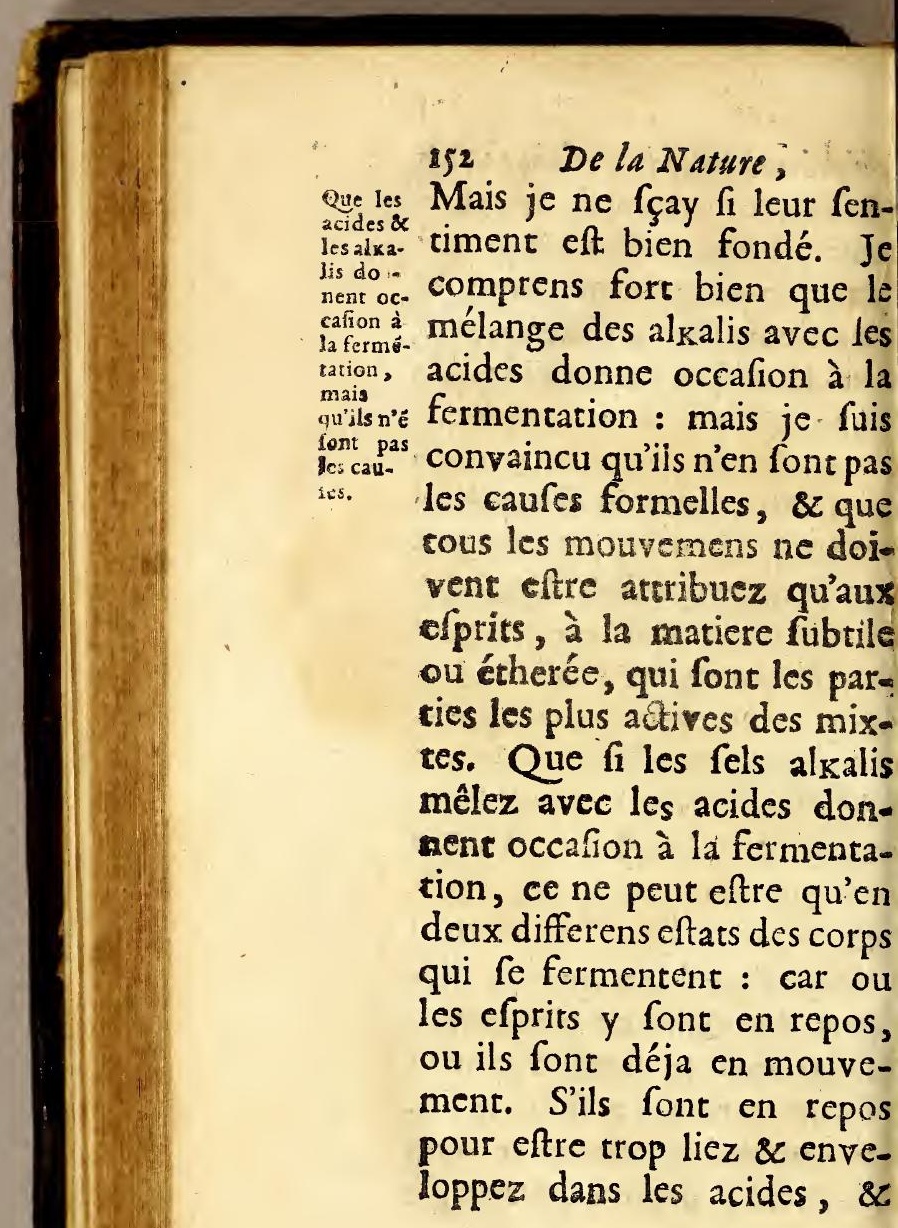


\& descaufes de la Fiévre. I53 u'alors on y ajoûte des alalis qui embaraffent les ades; on donne licu par là ax efprits de fe dégager, d'agiter les matieres qui oppofoient à leur mouveent. Mais fi au contraire s efprits font déja en mouement, \& qu'ils ne foient êlez qu'avec des alkalis; lors fi on y ajoûte des acies, ils produiront des coaulations, \& feront obftacle u mouvement des efprits : e qui leur fera faire effort our fe développer. Ainfi eft toûjours par l'action des fprits que fe fait la fermenation.

Sur ce principe on voit bien u'il n'eft pas befoin d'avoir ecours à toutes ces difpoliions bilieufes, de quelque naniere qu'on les prenne 


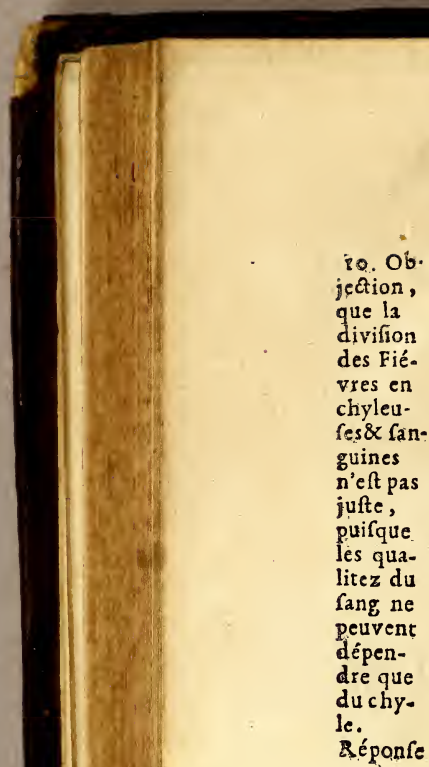

154 De la Nature, pour expliquer les ferment tions de la Fiévre.

On dira enfin que cet nouvelle divifion des Fiévie en fanguines \& en chyleufe n'eft pas bien fondée, pu que le fang ne peut avo d'autres qualitez, que cell qu'il teçoit du chyle, de m me que le chyle n'en a d'autres que celles qu'il re çoit des alimens.

Il eft vray que les bonn Réponfe \& les mauvaifes qualitez d fang procedent fouvent de nature du chyle, mais je $n$ croy pas qu'elles en dépen dent uniquement : car je tiet pour conftant que les impre fions de l'air fur la maffe d fang, font plus fortes que ce les du chyle, \& que fi le chy le fournit la matiere du fang c'ett l'air qui luy donne 
- des caufes de la Fiévre. 155 me, non feulement parqu'il eft fa premiere nourre, \& qu'il luy porte infamment les efprits, les. ences, \& les autres fubnces done il eft chargé : is encore parce qu'il eft le incipe de fon mouvement, la caufe principale de fes efactions, comme je puis démontrer.

Ce qui me perfuade que les preffions de l'air fur la mafdu fang, font plus fortes L'actios de l'ais fur le fang, de celles du chyle; c'eft que chyle ne fe mêle pas incefmment dans le fang, \& d'il reçoit beaucoup d'altetions dans les parties diffentes où il paffe avant que y parvenir; au lieu que l'air y mêle continuellement 8 nmediatement, \& luy com tunique les. fubftances pures; 
156 De la Nature, ou impures donr il eft cha gé. Pour en eftre convainc il fuffic de faire réfléxi fur nos differentes fenfatio dans les faifons differente dira-t'on que le froid \& fluxions qui nous incomm dent en Hyver, que la vigue extraordinaire que nous fe tons au Printemps, que l'a cablement \& l'épuifeme dans lefquels nous nous tro vons en Efé \& en Autom viennent des alimens. Je croy pas que cela puiffe ton ber dans l'efprit d'une pe fonne raifonnable : on vo manifeftement que ce font $\mathrm{d}$ effets des alterations de l'ai $8 z$ il eft aifé de comprend. que ce que l'air eft capable c produire dans les plantes dans les animaux qui nous fe vent de nourriture, il le pet 
des caufes de la Fiévre. 157 e auffi dans nos corps? is afin qu'il ne refte aucun apule fur cette matiere, veux faire voir que l'air le principal agent de la guification, \& le princidu mouvement inteftin fang , \& qu'ainfi il a beauap plus de part à toutes fermentations que le chypour eftre convaincu, que eft le principal agent de fanguification", il ne faut - faire réfléxion fur les alitez du fang avant qu'il Quel'air eft le
principal agent de la fan. guifica: tion, re dans les poulmons; ce g qui y eft rapporté de it le corps par les veines, dépouiillé de fes parties citueufes, qui onc efté emyées au mouvement des ffcles \& à la nourriture des ties, ou qui $f$ font diffies par infenfible tranfpira- 
158

De la $N$ ature,

tion: de plus, il eft mêlé chyle \& de lymphe, qui rendent encore plus épais plus vifqueux; de for qu'étant alteré de tant manieres, il ne fçauroit eft propre pout la nourriture d parties. Mais à mefure qu' eft pouffé dans les poulmon l'air qui fe mêle avec cet maffe confufe l'agite, la br fe \& la fubtilife; \& le fan devenant par ce moyen pl fluide $\&$ plus fpiritueux, vient par la veine du pou mon dans le ventricule gat che du cour, d'où il eft pou f'é avec rapidité dans toute les parties du corps. Cette a teration que le fang reço de l'air dans les poulmons manifefte, par la feule exp rience d'un celebre Anato mifte, qui a remarqué que 
des catifes de la Fiérure. 159 g des arteres du poulmon oit noir \& épais comme le ag qui eft dans les veines: lieu que le rang qui revient s poulmons au cour par veines du poulmon, eft btile, épuré, \& abfolument miblable au fang arteriel, rce qu'il eft mêlé d'air. On ut juftifier l'experience de

c Auteur par celle-cy.

$\mathrm{Si}$ on intercepte l'air qui tre dans les poulmons, \& ion ouvre en même tems delque artere, on verra ûjours le fang noir \&zépais; on rend le paffage à l'air, fang reprendra auffi-tôt $\hat{f}_{a}$ ouleur vermeille.

Il eft encore aifé de con- Le prind evoir que l'air eft le princi- mouvee du mouvement inteftin du ment in. ing, fi l'on fuppofe que cét fang. ir qui fe méle continuelle 
160 De la Nature, ment avec le fang, a une ver tu élaftique ou de reffort, pa laquelle il fe remet lorfqu'i eft délivré de la compreffion $\&$ du poids des parties qu l'environnent; car par là or comprend que lorfque les mufcles \& les arteres ceffen de comprimer la maffe du fang, les particules de l'air qui y font intimement mêlées fe remettent par leur ref fort , \& agitent diverfement toutes ces parties, \& c'cft cet te agitation qui produit le mouvement inteftin du fang.

Et peutêtre même qu'il eft le principe du mouvement ducours

Je ne f̧̧ay même fi on ne pourroit pas avancer que l'air eft le principe du mouvement du cour ; cette propofition eft un peu hardie, mais elle me paroift foûtr nable. Voicy de quelle maniere je penfe qu'on pourroit expliquer ce mouvement 
do des caufes de la Fiérre. I6I nouvement par l'action de air, lorfque le fang eft en'é dans les ventricules du our, l'air que ce fang conent fe dilate \& $\mathrm{fe}$ rarefie ans l'inftant mêtne, parce u'il y trouve beaucoup plus e chaleur que dans I'Áthofphere; mais comme les entricules du cour n'ont pas Tez de volume pour luy doner toute l'érenduë qu'il eft apable d'occuper, il fait efort pour fortir, \& pouffe le ing avec rapidité dans les areres; le cour fe remplic aufliof de nouveau fang mêlé air, qui renouvelle \& connuë toûjours le mouvement u coeur $\&$ du fang par fa verélaftique de la maniere que ay dit.

Ce n'eft pas que je vou. ffe rendre inutile la fruatu 


\section{De la Nature,}

re du cour, ces fibres, ces ventricules, ces valvules, $\&$ tout cét artifice admirable qui paroift dans fa conformation; je fuis perfuadé que toutes ces chofes font d'une necefficé abfoluë pour fon mouvement; mais elles ne fuffifent pas; \& quand je confidere, par exemple, que toute la mechanique d'un moulin àvent ne fert de rien dans un grand calme, \& que ces rouës, ces meules, \& tout cét attirail font fans effet, le vent ne donne le branle toute la machine, je conclus que le vent eft abfolumen neceffaire pour faire tourne ce moulin; tout de même je fais réfléxion que le cous eftant bien organifé \& rem. pli, fil'on veut, de fang pro. eluit par de bons alimens 
ou des caufes de la Fiévre: 163 ; emeurera immobile fi on luy apprime l'air ; je croy qu'on ourroit s'imaginer que l'air it le principe du mouvenent du cour.

Je fçay bien que cette ropofition n'eft pas du goult es Anatomiftes, qui veuent que les efprits animaux ui influent de la huitiéme aire des nerfs dans les fires du cour, foient la caufe mmcdiate de fon mouvenent; mais comme les efrits animaux font formez: ar la matiere fubtile, \& par a partie la plus fpiritueufe du ang contenu dans l'artere qui: nonte au cerveau, \& que ette matiere $8 z$ ces efprits. nt paffé dans le coeur avant: que d'entrer dans les nerfs' ay crîn qu'on pouvoit donaer la prerogative pour la-

$\mathrm{O}$ ij. 
164 De la Nature, mouvement du cour à l'air ou à la matiere fubtile.

Que toist cela fert 2 prouver que les im. prefilions de l'zir fur lo

Sang font plus fortes que ceiles du chyle.

Quoi qu'il en foit, cette dif culfion ne fait rien à mon fujet; il me fuffic d'avoir de. montré que l'air eft le principal agent de la fanguifica tion , \& le principe du mouvement inteftin \& des rarefactions du fang, pour pou- voir conclure que les impreffions de l'air fur le fang font plus fortes que celles du chyle.

Il ne faut pas oublier icy un fait de pratique qui eft decifif dans cette occafion; c'eft que fi au Printems ou en Efté on donne du vin de 2 uinquina pour guerir quelque Fiévre intermittente, il eft conftant qu'on fera gueri plus feurement dans l'une de ces faifons avec deux boureille; de ce vin, qu'avec fix en 
¿r des caufes de la Fiévre. 165 Hyver, quelque précaution qu'on obferve pour le regine de vivre: la raifon eft u'en Hyver l'air conferve \& 'établit aifement la difpofiion froide $\&$ acide du fang, ¿ qu'au Printems \& en Efté ces, mêmes acides font faciement diffous \& détruits par a chaleur exterieure de l'air, $x$ que cette faifon n'eft nulement proprepour en reproduire d'autres.

Par tous ces raifonnemens, Et cớfirg e veux faire comprendre merla qu'un chyle impur peut ex- des Fiéciter des fermentations ex- chyleuraordinaires dans la maffe ges \& ${ }_{\text {guness }}$

lu fang; mais que ces fernentations ne feront pas fouent reiterées, fil'on change a qualité du chyle, \& fi le ang eft d'ailleurs bien difpoé que fi au contraire ce fang

O iij. 


\section{66}

\section{De la Nature,}

reçoit de grandes alterations par celles qui arrivent à l'air par exemple, fi dans l'Autom ne aprés les grandes ardeur de l'Efté, il eft deftitué d'ef prits, \& qu'il participe dc l'aigre, comme je l'ay fup. polé, il s'y fera toûjours de fermentations extraordinaires, lors qu'il s'y mêlera une fuffifante portion de chyle pour les exciter, quelque louiable d'ailleurs que ce chy le foit, \& ces fermentation fe renouvelleront toutes les fois que cette quantite de chyle s'y introduira, jufqu'a ce que le cemperament du fang foit changé par une fai. fon nouvelle ou par un reme de Ipecifique. Voilà precilément l'id'ee que j'ay des Fié. vres fanguines \& chyleufes. \& je fuis perfuadé, qu'or 
¿des caufes de la Fiéruee. 167 ouvera cette divifion bien tablie, fi l'on fait réfléxion: II tour ce que j'ay dit fur ce jet, \& fi l'on examine. vec foin les. fymptomes des, iévres.

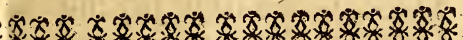

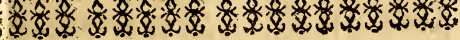

QUATRIEME PARTIE Contenant la Pratique;

Avec des Experiences Co des Reflexions fur le. Quinquina.

ARE's avoir établi mom A syltême par des raifon. aemens, il faut donner des. avis pour la Pratique qui Soient conformes à mes principes; Et comme jay remarqué que la faignée \& la purgation étaient les rems. 
168 De la Nature, des generaux, afin de fuivre lordre que je me fuis propo. f'é dés le commencement de cet Ouvrage, je parleray de la faignée, \& j'examineray quel en doit être le legitime ufage; Je tâcheray auffi de découvrir en quoy confifte

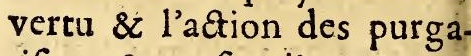
tifs, $\&$ enfin j'apporteray les experiences que j'ay faites fur le 2uinquina qui confirmeront mon hypothefe.

Comment on faifoit $\mathrm{la}_{\mathrm{a}}$ Medecine dans les premiers tems.

On debite plufieurs contes fabuleux pour prouver l'origine, l'Antiquité , \& la neceffité de la faignée : Mais il ne paroift pas qu'elle foit d'un ufage fi ancien que la Medecine, \& nous fçavons que dans les premiers tems on avoit feulement recours à la vertu des Plantes pour la guerifon de toutes les maladies 
60 des eares de la Fiévre. I69 ies; cependant il y a des uteurs qui nous affurent ue Podalirius fecond fils Efculape guerit par la fainée la fille du Roy de $\mathrm{Ca}$. e, \& que ce Roy luy donna La fai: gnée en udage
ch:z les our recompenfe cette fille Anciens.

mariage, avec la meillcure rovince de fes Erats : Si ce ir eft contant, il fert à faire oir que la faignée n'eltoit is inconnuë aux Anciens; doy quil en foit, on ne auroit difconvenir qu'elle ait toûjours efté tres-urile, ais nous n'avons point d'e mple dans toute l'Antiquide l'excés où elle a efté rrée dans ces derniers fiees : \& ce qu'il y a d'étonnt $\&$ de faral, c'eft que les us fçavants Medecins, \& i paroiffent le plus fcrupuafement attachez à la do: 


\section{i7o De la Nature;}

atrine des Anciens, ont éta bli la faignée comme un re mede univerfel $\&$ affuré cor tre toute forte de maladies \&z ont donné l'exclufion pre quà tous ceux que la Natur \& l'Art nous fourniffent plus utiles.

Le fameuxM ${ }^{x}$. Courtois éto fi prévenu pour la faignée, pour les boiffons rafrầchiffa tes, qu'il méprifoit tous les at

Methoae de Monfieur Conrtois Pçavant Medecin de Paris. Sa penfée fur les plan. tes. tres remedes; il difoit que 1 herbes n'eftoient faites qu pour les vâches, \& que Dì n'avoit pas mis des étiquett à la Scolopendre ou à l'A gremoine, pour marqu qu'elles étoient utiles au fo ou à la ratte. On a veu fo vent ce celebre Medecin o donner des faignées du pi \&z de la gorge pour des Fi - vres tierces bien caraderif'é 
des caufes de la Fiéure. I7r prés avoir épuifé les veines es bras, \& faire mettre des eaux pleins d'eau auprés du ic des malades pour éteindre es flammes de la Fiévre. Mais experience a fait voir que ette Pratique étoit fouvent unefte, scl'on a remarqué ue pluficurs malades font norts aprés des faignées reierées; l'on en a veu même xpirer fous la lancette, \& ue beaucoup d'autres foot evenus hydropiques ou heciques, \& l'on ne fçauroit ifconvenir que depuis que 2uinguina eft en ufage, n ne gueriffe plus promto nent \& plus feurement les. iévres, \& quion ne voye aoins de febricitans languir es années entieres.

Monfieur Bayle fçavane Medecin, \& Profeffeur aux

$P$ ij 


\section{De la Nature;}

Arts liberaux en l'Univerfit de Touloufe, a fait une Di fertation de la neceffité de 1 faignée pour la guerifon de Fiévres; \& comme cer Au teur eft d'une hatute repura tion, \& que le public eft for

Refura cien de la differration de Mon fieur Bayle fur la Jaignée, prévenu en $\mathrm{fa}$ faveur, il regardé cette piece comm une explication mechaniqu qui prouve évidemment l'ut lité \& la neceffité de la faigné pour la guerifon des Fiévres A mon égard je ne fçauro m'empêcher de dire que j l'ay confiderée d'une aut maniere, \&z quil me paroi que tous les raifonnemer que l'Auteur employe, que toutes les confequence qu'il tire de la machine Monfieur Papin pour prov ver la neceflité de faigne dans les Fiévres, portent 
¿ descaufes de la Fiévre. 173 aux, puifque loin d'établir ette necelfité de faigner, eles font voir au contraire que a faignée eft dangereufe, je rais en donner des preuves: Vonfieur Bayle commence differtation par un difcours aterique, $\&$ veut infinuer que es Charlatans \& les faux Melecins abufent de la foiblef e des malades pour décrier a faignée dans leur efprit, arce que ces fortes de gens, lit-il, n'ont point d'autres noyens d'établir leur repuraion qu'en ruinant celle d'auruy par des voyes indignes: Joicy comme il parle dans a page 35: La Saignée, di- , ent-ils, en ôtant une partie, iu fang, dépoüille celuy qui efte dans le corps de 12 parie fpiritueufe, l'affoiblit, \& , e rend inepte pour fervir aux P iij 
174 De la Nature,

as ufages aufquels il eft deftiné

") ces difpofitions, difent - ils

") menent infailliblement à l'hy

") dropifie : c'eft la plus fort

„objection que ces fortes di

" gens font contre la faignée.

Monfieur Bayle qui eft ut grand Philofophe, traite ave beaucoup de mépris ceux qu ne font pas de fon fentiment mais il devroit du moins rap. porter leur objection dan: toute fa force, puifqu'il con. vient dans ce même endroi que les faignées exceffive: caufent des hydropifies : Cai l'on ne dit pas qu'en ôtan une partie du fang, on dé pouiille celuy qui refte dans le

- corps de la partie fpiritueu. fe ; ce feroit mal parler, puif qu'il eft conftant que celuy qui reßte dans le corps conferve tous ces eforits, mais on ef 
Godes caufes de la Fiévre. 175 erfuadé que par les faignées requentes coute la maffe du ang eft épurifée d'efprits, \& ue fi on y fubftituë des boif ons rafraîchiffantes \& aqueues, cette pratique conduit à hydropifie.

$\mathrm{M}^{\mathrm{r}}$. Bayle fait encore icy une elle réfléxion: Au refte,dit-il, in Medcin doit avoir en veuë , le tirer fon malade du peril de a mort qui eft prefent \& cer- ") ain, au hazard qu'il tombe ," lans une autre maladie; Quele précaution plus mal-heueufe peut-on prendre pour mpêcher qu'un malade ne" levienne hydropique, que de e laiffer mourir de la Fiévre, dont il eft actuellement at- , eint, en ne faifant pas les faignées neceffaires, \& $\&$ de abandonner à un danger, evident, pour éviter une ma-

P iiij 
376 De la Nature,

i) ladie incertaine, \& qui n"el

„pas toújours incurable. Voila les propres paroles de Mon fieur Bayle.

J'avouë que je ne fçaurois affezm'étonner, qu'un Phy ficien auffi fçavant que Monfieur Bayle, n'airpoint d'autre précaution à prendre pour empêcher un homme de mou rir de la Fiévre, que de le met. tre au hazard de devenir hydropique en le faignant: Si veut bien fe donner la peine de lire cet Ouvrage, il verra que l'on peut guerir la Fiévre fans mettre les malades au hazard de devenir hydropiques par des faignées, en re compenfe il nous donnera fes belles Differtations Philofophiques; c'eft un employ qui donne un plus beau rang parmi les Sçavants , \& dans. les 
6o des caufes de la Fiévre. 177 ournaux, que de chercher les remedes pour guerir les naladies, \& d'examiner la ertu d'une feüille, d'une corce, ou d'une racine; c'eft ependant en cela que conifte principalement l'art de zuerir, mais parlons de la Difertation.

$\mathrm{M}^{2}$. Bayle conclud qu'il faut aigner pour guerir les Fiévres, arce que des chairs $\&$ des os nis dans la machine de Monieur Papin y cuifent \& s'y eduifent en gelée, fi la mahine eft expofée à un petis eu; \& il remarque que la coction des matieres fe faie dans un tems d'autant plus. ong qu'on a laiffé écouler une plus grande quantité d'eau : tellement que fi je prends droit fur la machine de Monfieur Papin, \& fur 


\section{De la Nature,}

les obfervations de $\mathrm{M}^{t}$. Bayle je tireray une confequence contraire à celle de cet Aa teur, \& je diray qu'il ne fau point faigner pour guerir les Fiévres, en voicy la raifon. Monfieur Bayle la fçait, c'eft la doctrine de tous les $\mathrm{Me}$ decins fondée fur l'autorité d'Hippocrate : Il faurqu'il fe faffe une coction des humeurs pour la guerifon des Fiévres; ces humeurs font des matieres cruës \& indigeftes qui font mêlées dans le fang, fur lefquelles la chaleur naturelle \& les efprits agiffent pour les digerer; ainfi plus il y aura de chaleur \& d"efprits; plútoft la coction fera faite, \& plûtoft fera-on gueri ; au contraire moins il y aura de chaleur \& d'efprits, plus lentement cette coation fe 
¿ des caufes de la Fiévre. 179 fera-elle : $\&$ il eft aifé de renarquer, que lorfqu'on s'oiniâtre à vouloir guerir les iévres par des faignées reite ées, \& par des boiffons raraîchiffantes, il ne fe fait oint de coction; les crifes ont imparfaites, les malades anguiffent, \& laFiévre devient labituelle. Voilà la fource les hydropifies, \& cela eft orr bien prouvé par la renarque de Monfieur Bayle, ui nous fait voir que la cocion fe fait d'autant plus lenement, qu'on a laiff'e écouer une plus grande quantité l'eau. Il eft donc neceffaire le conferver la chaleur \&z les fprits dans la maffe du fang , our faire la coction des huneurs; c'eft-à-dire qu'il ne aut point faigner.

Mais on dira, les.os fe dif. 
a des caufes de la Fiévre. x8z arrez; il ne s'y faic point de ranfpiration, \& la chaleur y it extréme en comparaifon le celle de la Fiévre.

Mais en verité, avons-nous Fiévre parce qu'il s'introuit dans nos veines une chaeur étrangere, nouvelle, ou xtraordinaire ? Ce pleuretiue eft-il malade, parce quil eft expofe au Soleil , ou pour voir bû de l'Eau-de-vie ou u Vin d'E(pagne? \& ne faine-on les pleuretiques que our diminuer leur chaleur ? Eela ne peut pas eftre, puifue pour guerir la pleurefie, on ne met en ufage que des Remedes fudorifiques, qui ont fpiritueux, fulphureux u volatiles, \& des plús hauds de la Medecine, \& que cette maladie ne fe gue. it point autrement. De tous 


\section{S82 De la Nature;}

cela il eft aifé de juger, ce m femble, que les confequen ces que Monfieur Bayle tir de la machine de Monfieu: Papin, pour prouver la ne. ceffité de la faignée dans le Fiévres, font mal fondées, \& qu'il y a lieu de s'étonner de ce que d'habiles gens les on prifes pour des démonftrations.

Mais enfin Monfieur Bayle a remarqué dans les cadavres de ceux qui font morts de pleurefie ou d'inflammation de poitrine, que la Fiévre étoit feparée des coftes, quil $y$ avoit des inflammations internes, que le coeur étoit tellement alteré, \& les parties molles des fibres fi fort diffoutes qu'elles ne tenoient point les unes aux autres, \& que tout cela venoit de l'ef- 
des daufes de la Fiéure. 18 ervefcence du fang, \& de 'excés de chaleur, parce qu'ils ivoient été peu faignez. $\mathrm{M}^{\mathbf{z}}$. Bayle ne tirera pas grand vantage de ces obfetvations, i elles fe font, comme il eft onftant, dans les corps de seux qui ont efté faignez guinze $\&$ vingt fois pour des leurefies $\&$ des inflammaions de poulmons. Il y t une autre raifon de ces phehomenes. Tous les Philofophes conviennent que le froid condenfe, \& que le chaud arefie; \&z qui ne fçait que la pleurefie eft caufée par un air frais, \& par des boiffons rafraîchiffantes chargées d'acides qui ont coagulé le fang? que ces coagulations fixent \& arreftent le fang \& les humeurs fur la plevre $\&$ furles autres parties de la poitrine, 
184 Dela Narure? où par leur rejour elles de viennent âcres \& diffolvan tes, \& caufent tous les fym ptomes remarquez par Mon. freur Bayle ; \& il eft éviden qu'ils n'arrivent point par l'ex cés de chalcur; au contrair fi elle avoit efté affez forte elle auroit empêché la coa. gulation faite par les acides elle auroit rarefié $\&$ fait tranf pirer les humeurs, \& prévenu par confequent tous les defordres qui ont efté caufez par le froid, \& par les coa. gulations; ceft un fait con( Itant dans la Pratique, que l'on guerit tous les jours des inflammations par des remedes chauds qui rarefient \& diffolvent les humeurs \& les matieres qui étoiert ta caufe de çes inflammations : ainfi la machine de Monfieur $\mathrm{Pa}$ pin, 
ơ des caufes de la Fiévre. 185 in, les obfervations de Mon. ieur Bayle, nifa Differtation ae démontrent point la ne:effité de la faignée pour la zuerifon des Fiévres; ce n'elt pas que ce remede ne foit ouvent neceffaire dans ces naladies, \& c'eft pour cela pue je me fuis propolé d'en aire connoiftre les abus, 8 l'eflayer de le reduire à un fage legitime:

La faignée eft une opera- ce que ion de Chirurgie, par la- c'eft quse ion de Chirurgie, par la- la daijuelle on tire le fang des vei- gnés, hes, ou des anterestel qu'il y ft contenu pur \& impur: G'eft le fentiment des meileurs Medecins, \& de Eerzel même, qui fe récrie con- sentimes re Avicenne de ce qu'il pre- des Au- fur endoir qu'on tirait le bon l'effer de ang, \& qu'on laiffoit le mau - gńs rais. Quelques Aureurs ont

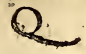


186

De la Nature,

dit que la Nature qui eft fage \& prévoyante, chaffoit dehors le mauvais, \&z retenoir le bon dans le tems de la faignée. It y en a d'autres qui difent que les Chirurgiens remarquent, que le fang vient plus vifte dansles Fiévres; que dans ce temps il fort davanta. ge d'efprits, \& qu'alors il doit eftre par confequent plus beau \&z meilleur. Mais fans nous embarrafer dans l'examen de toutes ces chofes, fuppofons ( comme il y a bien de l'apparence), que le fang force des veines ou des arteres tel qu'il y eft content, fans difinction de bon ou de mauvais, \& voyons, fuivane cette hypothefe, de quelle utilité peut eftre la faignée, \& jufqu'où elle peutaller.

Il me paroift que les Aus 
$\%$ descaufes de la Fiévure. 187 urs ont rapporté toute l'ulité \&z la neceffité de la fai- quelle née à la plethore ou à la les An: enitude : c'eft dans cette étrabsila euë qu'ils ont ordonné de fragnese igner dés le commencelent des maladies, $8 \mathrm{z}$ même e faire fouvent des faignées nples felon les occafions :effantes : mais parce que ans la fuite on a trouvé à ropos de reiterer plufieurs is ce Remede, \& que cetre ratique ne pouvoit avoir de pportà la fimple plenitude', laquelle il femble qu'on auoit fatisfait par deux, trois: u quatre faignées au plus, - par les dieres quon fait bferver aux malades. Les uteurs pour juftifier cette onduite nous ont dit qu'ir

Les $A$ u teurs ont étabii deux fortes de avoit deux fortes de ple- $p^{\prime}$ tefrat ore jil'une qu'ils ont appellée

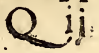




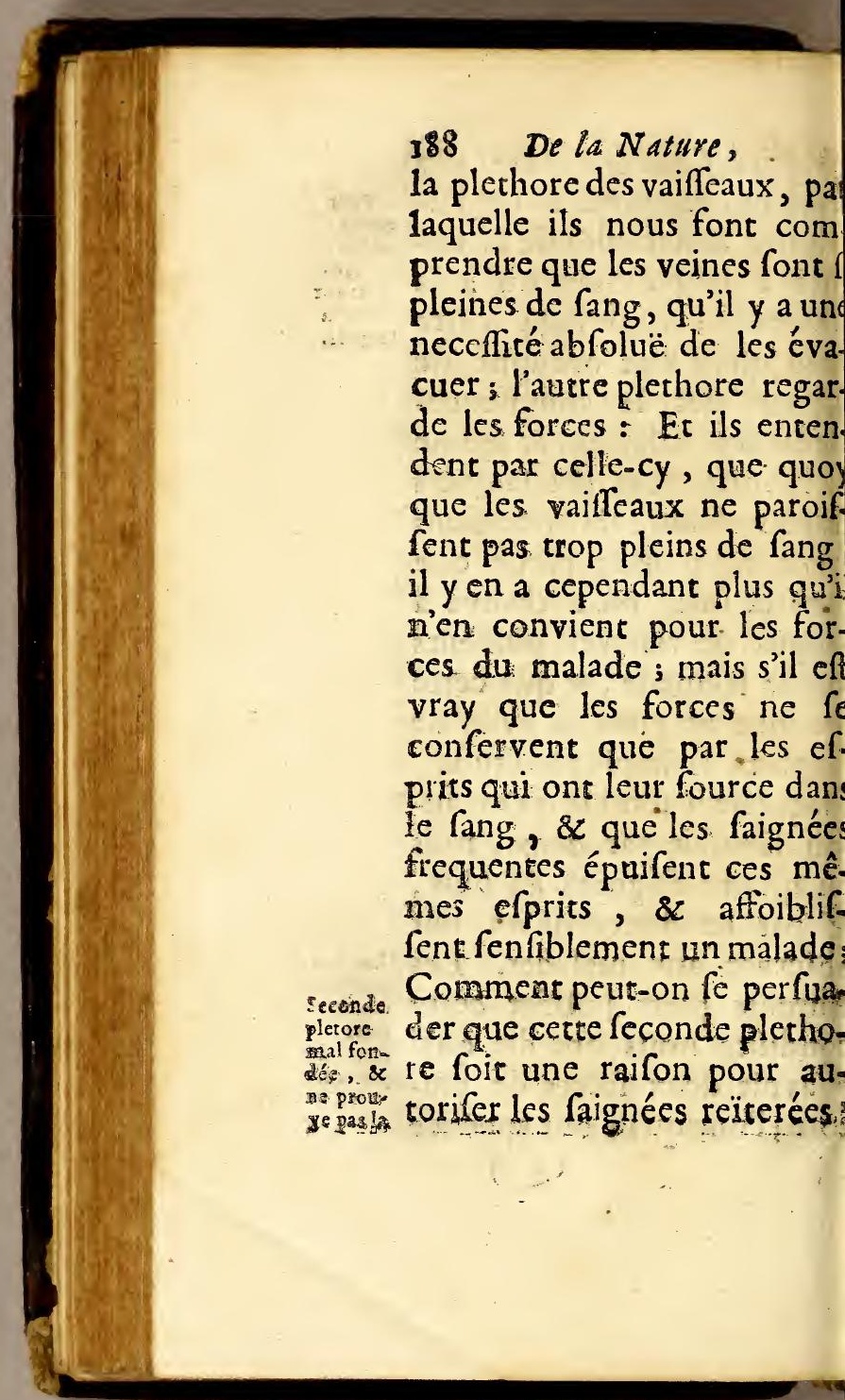


do des caules de la Fiérure. 189 1 y a bien de l'apparence fu'on ne l'a propol'ee que fur ine totale corruption du fang neceffirét de la faiti: gnée. setendü par Galien : mais omme nous avons fait voir lans la premiere Partie de ce Traité, que cette corruption: 'eft pas foûtenable, la feonde plechore paroiitra fans ondement, ainfi il fera dificlle d'en tires une confefuence folide pour prouver a neceffité de faigner, \& je enfe qu'on fera reduit à fe etrancher fur la premiere, our établir le legirime ufa. e de la faignée.

Céla fuppofé, fi on confidere la Eiévre dans la feule hotion que nous en avons lonnée, d'une fermentation, Que tà $z$ d'un mouvement extraorlinaire excité dans le fang ar des humeurs acides, cruës 


\section{rgo De la Nature,}

hament- \& indigeftes : on aura de la desfym-peine à fe perfuader que la qui les accom. Saignée en puiffe eftre le remede, parce qu'elle épuife les efprits qui font neceffaires pour perfectionner les fermentations, c'eft-à-dire pour digerer $\&$ diffoualre les hu: meurs cruës \& indigeftes; mais fi d'autre côté on fait réflexion que les Fiévres font fouvent accompagnées de grandes douleurs, d'oppreffrons, d'inflammations, de fuxions, \& de plufieurs autres accidents dont il n'eft pas facile de faire le détail, 82 quel'on peur penfer eftre des effers de l'abondance du fang dans les veines: on fera obligé d'avoir recours à la faignée pour remedier à tous ces accidents : ainfi felon ees con: fiderations differentes, ors 
du des raufes de la Fiévre: roa ura des indications diveres, \& on trouvera que s'il y des cas où la faignée n'eft as necelfaire dans les Fiéres, il y en a où elle eft inifpenfable, de forte que pour n fçavoir le legitime ufage, faut connô̂tre les caufes es fymptomes qui accomggrent les Fiévres.

Les fympromes les plus effants, \& les plus ordinai- ces mae, $s$ idans les Fiévres font à ton fens les difficultez de fpirer, les douleurs de tê, les tranfports au cerveau, $s$ inflamniations, les. fluons, les douleurs vagues, $s$ tenfrons douloureufes, \& $c_{0}$. comme tous ces fymptoes font caufez le plus fount par l'abondance du fang - parce qu'il n'a pas fon: ouvement libre, \& $q$ quil ef

Ie legi:-

timeufa:

ge de la:

faignée dépend de 12 connoir fance des fymptomes de. 


\section{2}

De la Nature,

arrefté dans fa courfe, ce q peut fe rapporter à la plen rude; la faignée en eft le plo affuré $\&$ le plus prompe ro mede, car elle dégage parties du poids des humeu qui les accablent; elle déte mine fouvent ces mêmes hi meurs à prendre une aut

to qual eas. la. faignée eft utile.

route, ou du moins elle r lentic la rapidité de leur mo vement, \& facilite la circt kation; mais elle doit eft faite promtement \& amplo ment felon les occafions comme dans tous les gran mouvemens, dans la pleur fic par exemple, on fait d'. bord de grandes faignée je n'en détermine point nombre, cela dépend de fage conduire du Medecir Réfiexio je dis feulement qu'en faifa
gue l'on dois? dans faigner un malade pour d dymp:ons 
Or des carfes de la Fiévre. 193 ymptomes preffans qui ac- lufag: ompagnent la Fiévre. On de la sajloit toûjours faire réfléxion jue cetre Fiévre eft caufée ar des humeurs cruës $\&$ inligeftes, \& qu'il faut de la haleur \& des efprits pour n faire la coction; c'eft ì ire qu'il ne faut pas telle. hent donner fon attention u fymptome de 12 maladie; u'on ne regarde principalehent la maladie même \& $z$ fes aures.

Cependant comme la plufart de ces fymptomes ont es fignes équivoques, il faut xaminer ferieufement fi la lenitude en eft la caufe, autre pent on pourroit douter que faignée en fût le remede. ouvent la difficulté de ref- Lesiym: irer eft caufée par un fang promes pais \& condenf'e, par des ves ont fes R. 


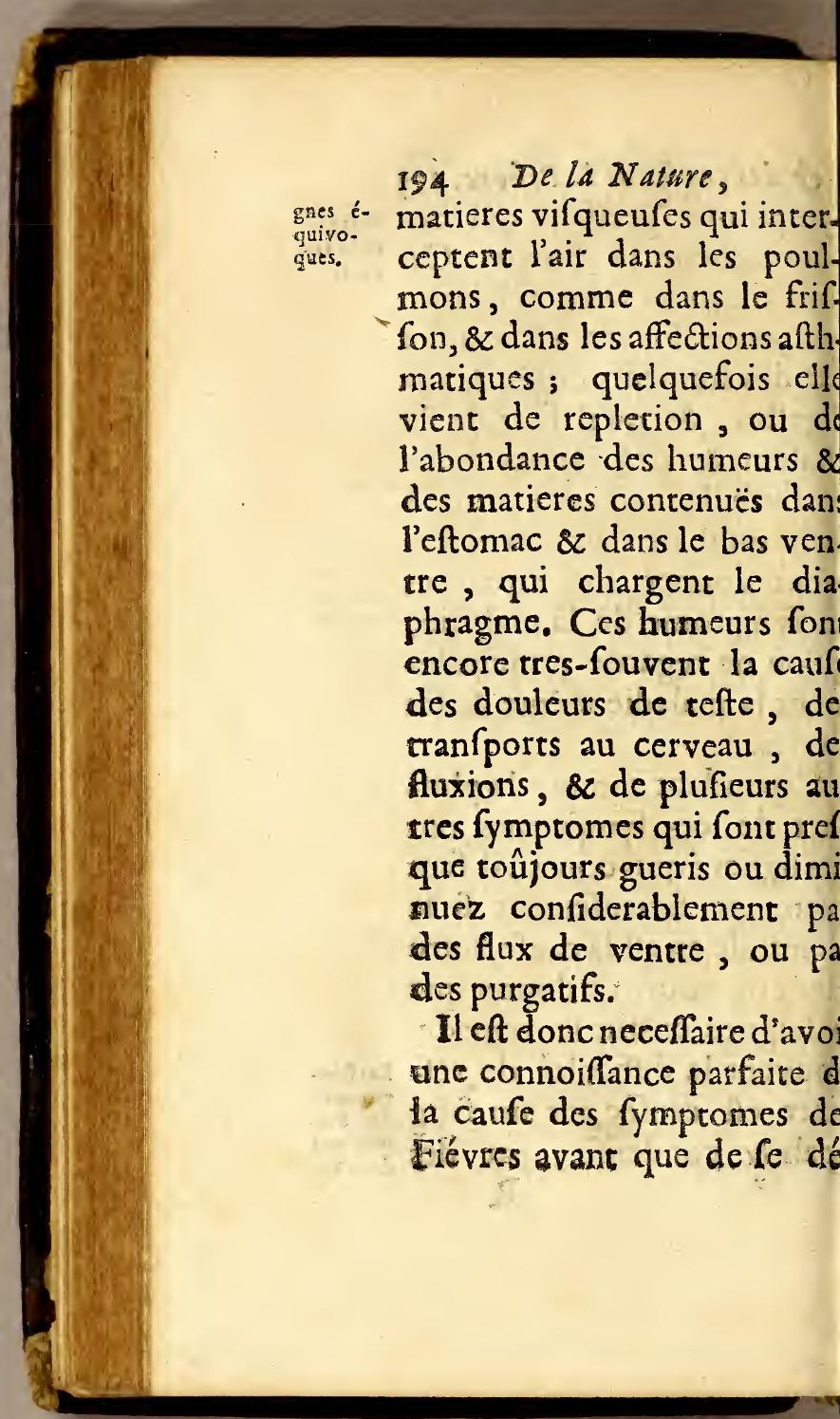


$\rightarrow$ des caufes de la Fiéure. I9s miner à la faignée; \& rés avoir bien fait des réxions fur tout cela, on fe- uniqueconvaincu que la neceffité mentàla faigner fe tire feulement de, \& il la plenitude, en faut la plenitude, \& que peu peu pour faignées avec les dietes faire, 'on fait obferver aux maa les, fuffiront pour fatisfai. à cette indication.

On dira, n'y a - - - il point utre raifon de metrre la gnée en ufage, que celle qu'on

- l'on tire dela plenitude; chaleurs ardeurs d'entrailles, ces les $\&$ des rens de feu qui coulent foufres rens de feu qui coulent allumez,
hs nos veines, ces foûfres font des
raifons imez \& cette chaleur étran- pour \{ai j e fi dévorante qu elle conae plus d'humide radical fept jours, que la chaleur urelle n'en confume en xante \& dix ans, comme explique un celebre $\mathrm{Me}$.

$\mathrm{R}$ ij 


\section{De la Nature,}

decin de Paris : Tout ce ne demande-il pas des rem des rafrîchiffans, \& pat co fequent la faignée qui eft plus rafraîchiffant de tous.

J'avouë que fuivant cet hypothefe on pourroit fai couler des ruiffeaux du fas des malades, \& mettre d feaux d'eau auprés de le lit pour éteindre tous feux ; mais $\&$ ces idées de tc rens de feu, cette chale étrangere \& ces foufres lumez n'ont rien de réel, ne font que des termes el phatiques qui impofent $\&$ donnent que des notions $\mathrm{Cr}$ fufes \&z embaraflantes de Nature des Fiévres. Tou les faignées \& toutes les bc fons rafraîchiffantes ferc rans fondement ; peu gens ignorent, \& nous 
\% des ganfes de la Fiévre. 197 ons dic, que ces fenfations - chaleur fone l'effer de la iévie, \& qu'elles n'en font oint la caufe. Et nous avons iit voir aflez clairement ce ie femble, qu'un chyle acie cru \& $x$ indigefte excicoir ans le fang des fermentaons.

On fçait d'ailleurs que s matieres graffes \& fulfuufes moderent les fermentions, parce qu'elles lient s efprits, \& adouciffent Lies fou: fres ne sentiama ment poins dansles Fífres, acrimonie des fels, \& qu'on s employe fouvent pour cer rage dans les operations de hymie; que files foufres de oitre fang s'enflammoient uclquefois, ce feroit appaLes fou. fos cal. ment les fermentations. mment en Elté, comme je ay dit cy-devant : nous ne oyons pas cependant qu'il - faffe de ces incendies dans

$R$ iij 
98 De la Nature; les plus grandes ardeurs cette faifon. L'on peut $\mathrm{m}$ me avancer icy une propo tion qui peut-eftre pafferc pour paradoxe, fi elle n'étc confirmée par l'experienc Les plus cicft que les plus grand chaleurs ne pro. duifent pas les. plus grandes fermentations. chaleurs ne produifent $p$ dans nos corps les plus gra des fermentations. En Eft par exemple, \& $z$ dans les $c$ mats chauds, la chaleur diffolvante, parce que la $\mathrm{m}$ tiere etherée eft dans, mouvement fi rapide qu'el ne trouve point d'obftacle fon paffage, \& les pores tous les corps font fi ouvert que les efprits fe diffipen d'où procede la langueur l'accablement dans lequel fe trouve alors.

Cependant on eft fans $\mathrm{Fi}$ vie, \& tant s'en faut que ? 
of descaufes de la Fiévre. 199 liqueurs chaudes \& piritueu-

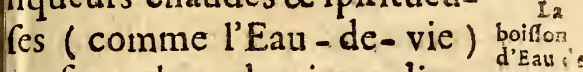
caufent alors des incendies, vie ne des inflammations, ou le donne pasta moindre fentiment de Fié- fiteryes en vre, qu'au contraire elles dé- fait corfilerent \& reparent les for frm ter ces; ceux qui vont à la Chaf- faurs les fe ou à l'Armée, en font coyas gouss perfuadez par leur propre experience ; ceux qui ont voyagé dans les pais chauds \& paffé fous la ligne, nous affurent la même chofe, \& que la boiffon-d'Eau-de-vie les conferve \& les défaltere, a lieu que l'eau fimple les jette dans des langueurs mortelles.

En effet, la raifon \& l'experience ne nous apprennentlles pas que les chaleurs cx- leurs at

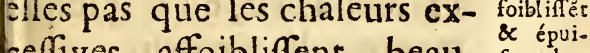
ceffives affoibliffent beau- eent les Eoup la chaleur naturelle par $\begin{gathered}\text { efprits } \\ \text { ifs ne is }\end{gathered}$

$\mathrm{R}$ iiij 


\section{0 \\ De la Nature,}

reparent des extrémes diflipations d'el cue par des cho. fes fpiritueufes. prits, \& que ces diffipation ne fçauroient eftre reparé que par des choles chaude \& fpiricueufes : \& nous avon remarqué que l'on n'a pas 1 Fiévre en Efté pour avoi bû du vin d'Elpagne ou de liqueurs chaudes, mais qu'e] le ne vient guere qu'apré avoir uf'e d'alimens cruds \& indigeftes, ou de boiffons ra pretves fraichiffantes. On void tou
sirces de la pleu. les jours des Porrefaix échau fez \& épuifez de fatigues re prendre de nouvelles force en beuvant du Vin ou d l'Eau de-vie : au contrair s'ils boivent de l'eau fraîche ou quelqu'autre boiffon ra fraîchiffante, on les porte l'Hôtel-Dieu, où la plufpar meurent de pleurefie.

Cependant le vulgaire in 
odes caufes de la Fiéure. $20 \mathrm{r}$ locile ne fçauroit compren- Erreuti Ire qu'il eft dangereux d'ufer fur leale boiffons rafraîchiffantes, chiffes juand on eft fort échauffé. II eft fi prévenu que la Fiére eft un feu devorant qui e confume, \&z qui ne fçauoir eftre éteint que par des afraîchiffemens, quil donbe tête baiffée dans tout ce qu'on luy propofe. Pour fe afraîchir, il fe laiffe tirer fout le fang des veines; il sexpes avale à longs traits le lait pour clair, les émulfions, \& la ti- certe est fanne; \& il fe rafraîchjt fi reur. fort, qu'il affoiblit \& éteint fa chalcur naturelle : de forte qu'au lieu d'une Fiévre forte, vigoureufe, \&\& capable de confumer toutes fes mauvaifes humeurs, il lay refte une Fićvre lente \& tue hydropifie, qui font des 
202 De la Nature, maux bien plus dangereu que le premier.

Il me femble que ce qu j'ay dit de la Fiévre, \& qu les rélléxions que je vien de faire, devroient être fut fifantes pour defabufer 1 Exemple Public de cette erreur. J pour faire voir l'abus des ra. core quelques exemp fraichif. rendre la chofe plus fenfible femens. Prefque tous les Auteur ont remarqué qu'il y a un analogie aflez jufte entre 1 fang \& le vin, \& qu'ils fon à peu prés furceptibles de mêmes alterarions.

Voici une experience faite fur le vin, qui pourra être de quelque utilité. Lorfque le vin fermente, fi le tonneau eft plein, il faut neecf fairement en ôter, de crainre qu'il ne rompe le tonneau: 
¿d descaufes de la Fiévre. 203 mais fi on continuë à tirer le vin, parce qu'il fermente roûjours, \& que l'on y fubftituë de l'eau, il eft certain qu'il ne fe fera qu'une fermentation imparfaite, \&z que le vin fera de mauvaife qualité. La même chofe arrive prefque toujours, lorfque l'on s'opiniâtre à vouloir guérir la Fiévre par des faignées \& par des boiffons rafraîchiffantes ; les faignées épuifent une partie des efprits ; les boiffons rafraîchiffantes noyent \& étouffent le refte, \& rempliffent les veines d'humiditez, tellement qu'il ne fe fait point de crife; le fang devient de mauvaife qualité, \& peu propre à nourrir les parties ; le Malade tombe dans une Fiévre lente, \& devient le plus fou- 
204 De la Nature, vent hectique ou hydropique Cét évenement eft fi com. mun, qu'il n'a pas befoin do preuves.

On peut encore affez: Autre
exemple propos, ce me femble, pro

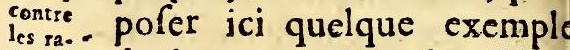
frấchir de la vegetation des Plan. femens née. idée affez vrafi-femblable des effers de la Saignée \& des boiffons rafraîchiffantes par rapport à ce qui fe paffe dans les Plantes. Chacun fçair qu'il s'y fair une circu. lation de la feve, \& qu'elle eft portée à roures les parties de la Plante pour fa nour. riture, par des tuyaux qui font analogues aux veines $\&$ aux artéres, de la même maniere que le fang eft porté à toutes les parties de l'animal pour fa fubfiftance: 
- Oo des canfos de la Fiéure. 20 it il eft aifé de remarquer tue les Plantes proficent \& ¿ portent bien, lorfqu'il ombe une pluie douce \& haude, \& qu'elles font expof'ées au Soleil ; de même que les animaux jouilfent D'une fanté parfaite, lorfgu'ils ufent de bonne nourfiture, \& qu'ils refpirent un bon air. Mais fi on prenoit une Plante, un Rofier par exemple, lorfqu'au Printems 1 commence à pouffer des feuilles \& des boutons, \& que $f_{2}$ feve eft en grand mouvement; qu'on le mît à l'ombre, qu'on empêchât la pluie de tomber deffus, $\& \subset$ enfin que l'on eût grand foin de l'arrofer de belle eau fraiche ; il y a bien de l'apparence que ce Rofier léertitoit, que fes feuilles per= 


\section{De la Nature;}

droient leur verdure, \& de. viendroient jaunes, \& qu'il pafferoit fon Printems fans rofes. Nous remarquons auffi que quand il tombe des pluies froides, nos vignes ont la jauniffe, \& qu'il n'y a que les pluies chaudes qui leur rendent cette agreable verdure, qui nourrit l'efperance des Vignerons.

Il me femble que lion peut faire une jufte application de cette remarque à ce qui fe paffe parmi nous. Combien voit-on de gens traîner une vie languiffante, être pâles, avoir la jauniffe, à caufe des faignées frequentes, \& de l'ufage continuel des rafraîchiffemens. Si au Printems le Soleil remuë un peu la maffe du fang, \& en fait fortir quelques parties terreftres 
Z des caufes de la Fiévre. 207 falées, il paroît quelques uggeurs au vifage; c'eft un ye échauffé, dira-on, faut promtement le ra aîchir. On coure à la faihée, aux eaux de veau \& de buler, au lait clair, au lait Afneffe, quelquefois à ceQuil ne faut point é: i de Vache; mais il faur le lait cremer, c'eft-à-dire, le époüiller de fa fubrtance ouce balfamique \& f pirileufe ; enfin de tout ce qu'il de bon. Voilà comme on affe la plus belle faifon de année dans l'efclavage de la 1edecine. Mais il feroit ai- de voir que toure cette onduite n'eft pas reguliere, eue on vouloit la compater à qui nefe elle qui lui eft oppof'ee, \& $\&$ fot point on confideroit que ceux fe porté ui n'ufent ni de faignées, frent plus ii de rafraîchiffemens, font reux que 


\section{De la Nature;}

Eeùx qui forts \& vigoureux, \& joüil faigner. fent d'une fanté parfaite.

On dira encore, fuppof qu'il y ait de l'abus dans l't fage trop frequent des fai gnées, il faut fe rendre à l'ex perience à l'égard des boil fons rafraîchiffantes, pour 1 guérifon des Fiévres, puit que chacun fçait qu'en Lan guedoc \& en Provence of s'en guérit en beuvant à 1 glace.

in queis cas les safraîchiffemens có viennent dans les ciérres.

Je conviens du fait, quo qu'il ne foit pas toûjour conftant; \&z javouë que le rafraîchiffemens guériffen quelquefois la Fiévre. J'el ai dit ailleurs la railon; c'el quil y a des Fiérres dans lef quelles les acides font for divifez, \& les efprits en 1 grand mouvement, qu'ils $f$ diffipent : de forte qu'il n'? 
\& descaufes de la Fiévre. 209 pas de peril à les r'allier par les boiflons rafraîchiffantes, ur tout en Efté \& dans les limats chauds, où l'air réare en peu de tems les imreflions froides que ces biffons auroient faites.

Il y a Gependant beaucoup le précaution à prendre dans 'ufage des rafraîchiffemens; $x$ il en faut éviter l'excés, de l'empêcher les crifes, chiffeeur d'empêcher les crifes, mens, i que les humeurs qui font

a caufe des Fiévres, ne oient fonduës \& diffoutes. Far il eft conftant que s'il y a peaucoup de mauvais fucs lans les premieres voyes qui ntretiennent la Fiérre, \& gue d'ailleurs la maffe du fang bit dépourveuë d'efprits, les oiffons rafraîchiffantes fe. ont tres-dangereufes', parce quelles affoibliront les ef-

Précalltion à prendre dansliufage des safrât$S$ 


\section{IO De la Nature,}

prits : Et cela ne contred point à ce que nous avor remarqué touchant l'urag des boiffons fpiritueufes chaudes dans les pais chaud lorfque l'on eft épuifé $\& z$ dar une diffipation d'efprits. Air cetre obfervation ne donn point d'atteinte à nôtre hy pothefe : au contraire, ell fert à la rendre plus intelli gible, \& à faire voir (com me nous l'avons dit) que le faignées \& les boiffons ra fraîchiffantes ont leur ufag dans les Fiévres, \& font tres utiles en de certaines conjon Etures.

Erreur L'on peut dire ici, qu fieursyl- c'eft fans fondement qu'ur vius de
Dublin, Auteur moderne qui a donn' g'si $2 \mathrm{~m}$ is la Sail'exclufion aux Remedes ra. gné càs frâichiflans, a mis la Saigné
'indiference. dans l'indifference, parce qu'i 
do des caufes de la Fiévre. 2 II ze paroîr pas (à ce qu'il dit) qu'en France $\&$ en Efpagne, pù l'on faigne rous les Febriitans, il en meure davantage qu'en Italie, \& dans les putres pais où l'on ne faigne point. On pourroit oppofer certe remarque la fupputa. tion d'un curieux Anglois, qui fair voir qu'il meure oroportion la moirié plus de Malades dans l'Hôtel - Dieu de Paris, que dans les Hôpiaux de Saint Thomas \& de Saint Barthelemy, qui font es plus chetifs de Londres, pù l'on faigne beaucoup moins qu'à Paris. D'aillcurs, on ne fçauroit doriter que la Saignée \&z les Remedes qui lui font oppofez, n'ayent des effets tres-differens.

Tout le monde convient que depuis que le 2uingring Quinqui$S$ ij 


\section{De la Nature,}

afage, il eft en ufage, -il meurt moin uneurt moins de Febri. de Febricitans ; \& l'on el citans.

convaincu que cetre écorc falutaire guéric en moins d huit jours des Fiévres, con tre lefquelles on avoit $\mathrm{cm}$ ployé inurilement pendan plutieurs mois les faignées \& les boiffons rafraîchiffantes Ainfi la Saignée ne fçauroi être un Remede indifferent.

Ce même Auteur a pro pof'́ un paradoxe affez nou veau ; c'eft Monfieur Sylviu de la Societé des Phyficien: de Dublin, dans un Trait qu'il a donné au Public. C Traité a pour titre, Nouvell idée de la $N$ ature ds Fiévres Cette idée eft aflez confor. me à nôtre hypothefe : mai comme le paradoxe y eft op. pofé, \& qu'il combat l'ex. plication que je donne des 
\&o des caufes de la Fiévre. 213 mptomes qui arrivent dans ; chaud de la Fiévre; je roy qu'il ne fera pas inutile e l'examiner icy, afin de aire voir la nullité des preues que l'Aureur avance pour foûtenir, \& d'établir plus plidement la verité de nôtre ypothefe.

Monfieur Sylvius prétend ue le fang circule moins îte pendant l'ardeur de la Paradoxe de Mófieur Sylvius. iévre, que dans les autres ms. La raifon qu'il en done, c'st qu'alors les partics biritueufes font liées $\& \mathrm{~cm}$ araffées par les acides: d'où s'enfuit que le fang tombe ans une confufion qui raentit fon mouvemeñt. Il eut aufi que les arteres ouffent le fang par la conaction de leurs fibres, $8 c$ ue torfqu'il eft grofier \& $S$ iij 
$2 i 4$ De la Nature, vifqueux, il n'obeiffe pas preflement des arteres : c'e pourquoy les arteres ne fa fant plus leur dilatation leur contraction dans to lefpace qu'elles prendroie fi le fang circuloit plus vîte elles les renouvellent en $r$ compenfe plus fouvent, qu lors que chaque retour $f^{2} \mathrm{~d}$ do faire de plus loin. Ainfi lo battemens du pouls plus fr quens, font une marque qi le fang circule moins vîte.

Monficur Sylvius ajoute que la chalcur ne donne p aux corps un mouvemer progreffif: Il donneplufieu exemples pour prouver cett propofition, entr'autres luy de l'eau prefque bouii lante dans un chaudron $q$ eft fur le feu; \& il dit qu cetre eau n'acquiert pas pl 
odescaufes de la Fiérve. 215 de volume par la chaicur.

Pour répondre à ce para- Réponfé doxe, je conviens d'abord au para: que dans les Fiévres le fang eit groflier, vifqueux, chargé de cruditez \& d'acides, $8 *$ qu'cftant confideré comme tel, il devroit couler plus entement, qu'un fang bien flair \& tres-pur. Mais fi on ait réflexion que ce fang a cquis plufieurs degrez de nouvement par la fermentaion, on n'aura pas de peine comprendre qu'il doir cirfuler plus vîte qve dans fon tat naturel, \& lorfqu'il ne fermente point. On fera conraincu de cette verité fi on reut fe reflouvenir de ce que ay dit, que dans le friffon cs efprits \& la matiere fubile étoient enveloppez, que e mouvement du cour étoir 
De la Nature,

fufpendu, \& que ces efpri enveloppez, \& ce mouv ment du cour fufpendu toient la caufe du friffon, que dés le moment que accidens ceffent, l'on fet le mouvement du cour $r$ tabli \& recoublé, \& que chaleur fe fair fentir à to le corps. D'où il eft évide que les efprits \& la matie fubtile étant développez ont imprimé un mouvemes rapide \&z extraordinaire roure la maffe du fang, ont porté la chaleur à tout les parties les plus éloignées.

Car enfin l'état du fang different dans le friffon, dans le chaud de la Fiévre $\&$ fi dans celuy-là toutes lo parties du corps font froide Géetries \&e tremblantes, que dans celuy-cy ces même partic 
\& descaufes de la Fiévre. 217 parties deviennent chaudes, gonflées, agitées \& fuantes, be faur-il pas conclure que cela ne s'eft fait que par un nouvement plus vîte du fang? $x$ peut on douter que la chaeur ne donne au corps un nouvement progreflif, puirque la chaleur eft le principe liv mouvement. Nous pourions donner plufieurs exemles pour en convaincre $\mathrm{M}^{\mathrm{r}}$. fylvius; celuy qu'il a propo'e nous fuffic: $\&$ il n'y a pas enfé lorfqu'il a dit que l'eau l'un chaudron qui eft fur le eu, n'augmente pas de voume; fi lon y prend garde on verra qu'elle s'étend feniblement, \& qu'elle fe répandra par deffus les bords i on augmente le feu.

A l'égard de ce que $M^{8}$. iylvius pretend que le fang

Que la
chaleur dóneaux corps in $n$ mouiemét pro. greffif.

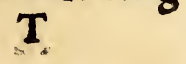




\section{De la Nature,}

groffier \& vifqueux n'obeit pas au preffement des arteres, ( ce quiles oblige à redoubler leur mouvement) \& luy donne occafion de conciure que les battemens du pouls plus frequens, font une marque que le fang circule moins vîte : je réponds que le mouvement du cœur $\&$ des arteres eft un mouvement paffif , \& Que le dépendant du fang; c'eft à mouve.: dire des efprits, \&z de la mades arte-
res $\& \mathrm{du}$ res $\& \mathrm{du}$, un mouvement palfit.

tiere fubtile, de forte que lors que les efprits \& cette matiere font en grand mouvement, elles communiquent ce mouvement aux parties groffieres \& vifqueufes, les rendent fouples \& pliantes, les font Qu'un pafter avec rapidité dans toufăg groffier $8 x$ vifqueux tes les parties du corps, \& caler à reiterer leurs dilatations $\&$ forcent le cour $\&$ les arteres 
\&u des caufes de la Fiévre. 219 leurs contradions. Et cela fuf- plusvîte fit, ce me femble, pour faire qu'un comprendrequ'un fang grof- \& épuré. fier \& chargé de cruditez, peut circuler plus vîte qu'un fang pur \& clair, felon les degrez de mouvement qu'il aura reçû.

L'exemple fi fouvent alle: gué de la fermentation du vin, eft démonftratif en cette occalion : dans le mouft qui fermente les parties groffieres du vin, font pouffees \& agi-ées en tout fens par les plus fubtiles, \& le volume de la iqueur s'augmente de telle orte, qu'un tonneau qui fermente paroift plein, quoyque juelquefois il ne foit pas à deni, quand la fermentation it celfée.

Ce paradoxe de $M^{5}$. Syliius a interrompu nos réfle. 
xions fur la faignée; majs je croy que ce que nous en avons dit, eft fuffifant pour donner une idée affez certaine du temperament qu'on doit apporter dans l'ufage de ce remede : il elt fans contredit, des meilleurs \& des plus neceffaires de la Medecine; il produit mille bons effers, \& quoyque nous en ayons dit une partic, j'avouë qu'il eft impolfible de les décrire tous. Et c'eft apparament ce qui a donné occafion de le porter jufqu'à l'excés où il eft aujourd'huy, c'eft pourquoy j'ay effayé d'y apporter quelque moderation, \& je croirois avoir rendu un fervice confiderable au public, \& fair un Ouvrage digne de la porrerité, fi je pouvois mettre la Saignée dans fes juftes bornes. 
Qu des caufes de la Fiévre. 221

$\mathrm{Ne}$ fera-on jamais réflexion fur les fâcheux évene. mens de ce Remede ? Et n'elt. ce pas une chofe criante que le premier petit Frater qui va voir un malade, le faigne impunément en quelquétat qu'ille trouve, dans un friffon, dans un redoublement, dans une crife? c'eft fans dourte une licence qui merite reforme, mais c'eft un fait de Police qui n'eft pas de ma competence : Il fuffit que j’aye la liberté de dire icy mes fentimens, le public y aura tel égard qu'il jugera à propos.

Il s'agit maintenant de parler des purgatifs. Il n'eft pas facile de démontrer la maniere dont les purgatifs agiffent fur les humeurs quils reneontrent dans nos corps, ni

Réflexió
fur les effets de la faignée.

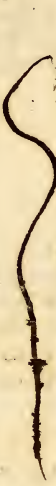

$$
\mathrm{T} \mathrm{ij} \mathrm{i}
$$




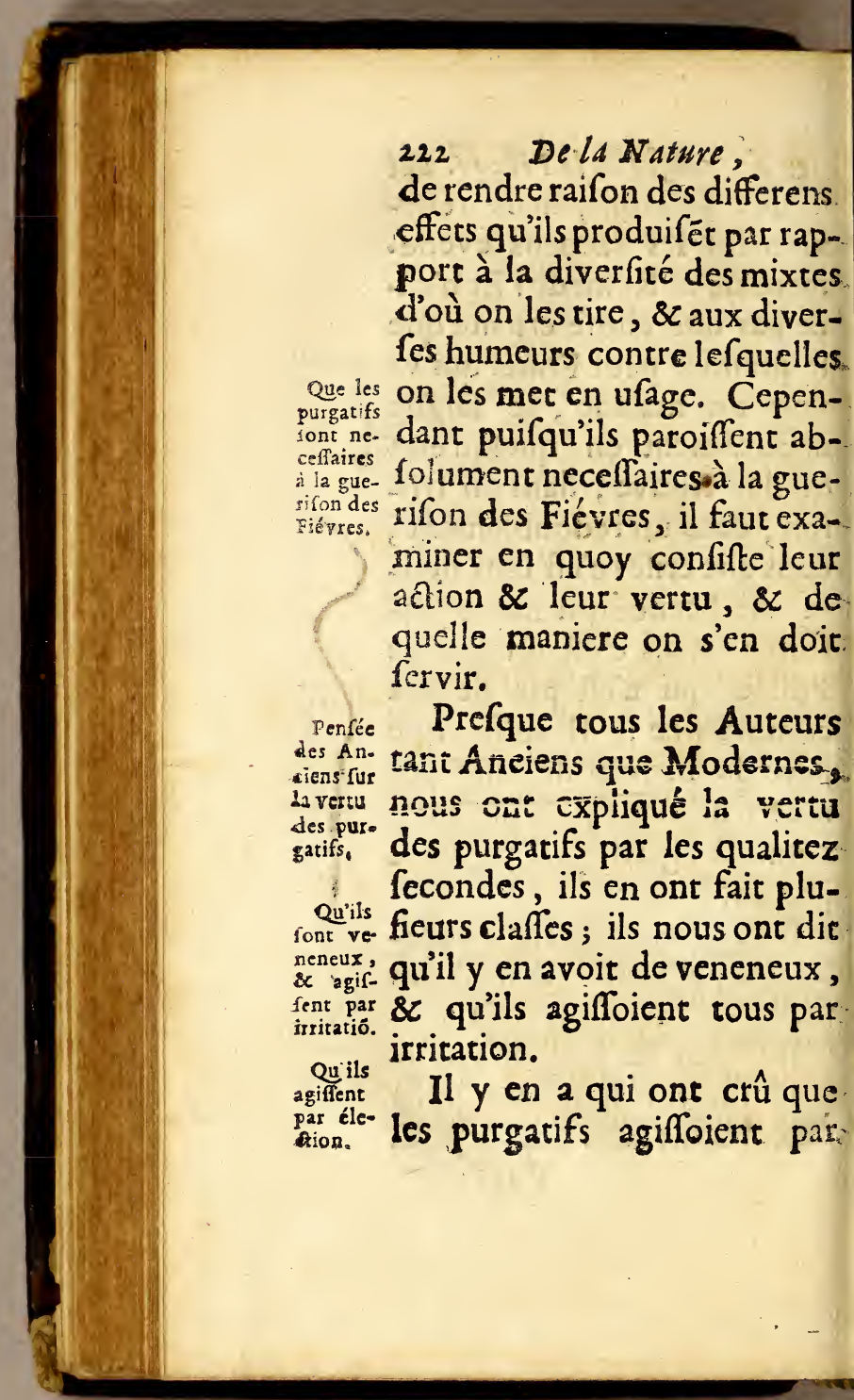


\& des caufes de la Fiérre. 223 élection, qu'ils étoient deftinez ou affectez à certaines humeurs \& à certaines parties, à la bile, à la mélancolie, au foye, à la race, \&zc. \& que ces purgatifs alloient chercher dans le fang \& dans les vifceres les humeurs vicieufes, \&Z les faifoient dégorger parles glandes, \& par les arterioles dans. les inteftins pour eftre évacuées.

Mais comme ces opinions ne me paroiffene pas vrai- Moder. femblables, j'ay crû́ qu'il $f_{2}-$ font ferloit avoir recours ì d'autres vis pour moyens pour connoître \& trelaver moyens pour connoitre \& tu des expliquer la vertu des pur- purgatifs gacifs.

Quelques Modernes fe Ils $\mathrm{fe}$ font fervis du mélange des vis du liqueurs, afin de juger par le des lia refultat de ce mélange, des ef- queurs, fets que tels ou tels remedes

$$
\text { T iiij }
$$


2.2 De la Nature, pourroient produire fur no humeurs.

Quelques autres ont con fulcé l'experience \& l'analy fe, ou refolution des mixtes \& c'elt à mon fens la mecho ils ont de la plus aflurée \& la plu sonfulté l'experience \& I'analyfe facile pour découvrir la ver tu des purgatifs, \& pour e connoiftre 'l'ufage. L'expe $\mathrm{Ce}$ moyen paroitt le meil. teur. rience m'a appris que le $S e n$ né, la Rhubarbe, la Scam monée, \&ce, purgent; \& I'A lesprin. nalyfe me démontre que ce
sip:s dapts purga. tifs font compopurgatifs font compofez di parties alkulies, refineufes \& fezh. fulfurcufes. Aprés cela fi ir fais réflexion fur l'ufage au. quel on les deftine, \& $\mathrm{fi} j$ confidere quelles font les hu. ce que meurs qu'il eft neceffaire ds lest que purger, \& que je remarque meurs
qu'il faut wrges: meurs ne font autre chofe 
$\checkmark$ des caufes de la Fiévre. 225 ue des reftes d'alimens $\mathrm{mal}$ gerez, aigris \& corrompus, ui communiquent leur maudife qualité au fang, \& troulent l'œconomie naturelle - la fanguification, d'où dévent toutes nos maladies. - concluray fans peine que s fubftances alxalies, fulfueufes \& refineufes feront urgatives, parce qu'elles aiene à la digeftion, qu'elles ermentent avee les acides, ( que cout ce qui digere \& ermente, rarefie, augmente = volume \& le mouvement carte \& precipire.

Sur ce principe il eft ailé le juger que les humeurs inligeftes \& aigries qui fe troueront dans l'eftomac, ou lans les premieres voyes, feont neceffairement purgées on prend du Senné, de la 


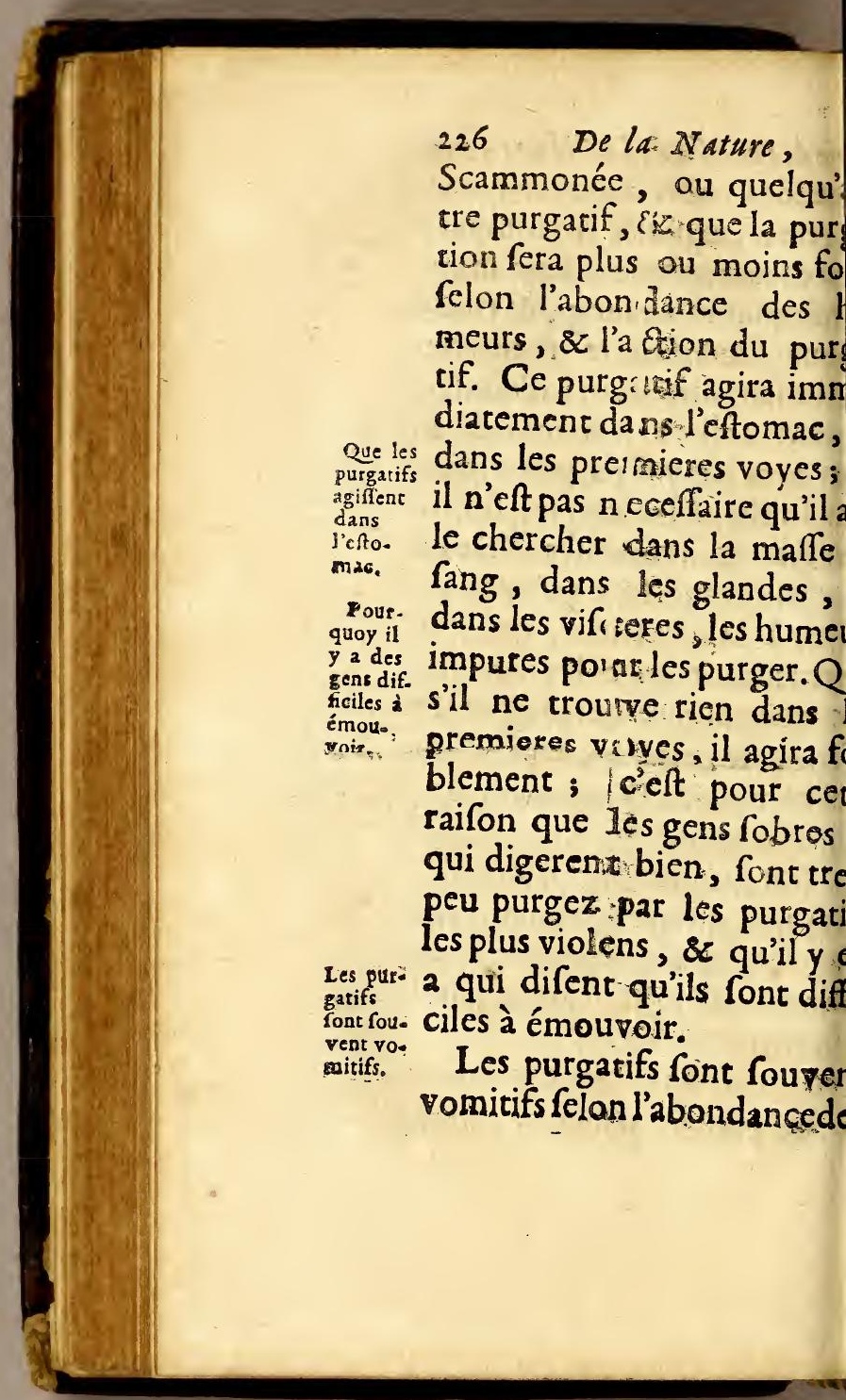


- des caufes de la Fiévre. 227 meurs, \& felon les degrez. fermentation : \& je comnds qu'un Remede n'eft quoy ils . mitif que parce qu'il fer-mitifs. nte, \& rarefie extraordirement les matieres conuës dans l'eftomac. En les purat cela il n'eft pas neceffai-- gatifs ne de fuppofer des qualicez venelignes, ni de l'irritation; 115 n'a $^{\prime}$ vinaigre picote \& irrite; $;$ githene caufe des naufées, mais il pass par it point purgatif: on $f e$ te vimême fouvent avec fuc- naigre de potions sổides poui \& is efter des vomiffemens \& $\begin{gathered}\text { purge } \\ \text { poin. }\end{gathered}$ s diarrhées; la Theriaque i eft un antidote, eft fount purgative \& vomitive lon les humeurs cruës \& ingeftes qu'elle rencontredans. ftomac. Mais on dira que fur cette pothefe on pourroit pre. 


\subsection{De la Nature;}

si tous tendre que tous les mix

les mix-

tes refineux \&

fulfureux.

font pur -

gatits,

qui ont des parties fulfur fes \& 2 alkalies, auront $v$ vertu purgative que faiv: la méme regle, les foufres les fels volatiles feront $p$ gatifs; ce quir n'eft pas cc firmé par l'experience.

Je réponds à cela qu'il vray qu'il y a un grand no bre de mixtes qui abond en refine $\&$ en fels volatil qui ont une vertu purgativ

com: Giayqu'ils ne foient pas ment les mixtes refineux cont purufage, \&z dans le Catalog des purgatifs; les potio gatifs. cordiales qui font compofe pour la plufpart d'eaux fpi tueufes $\& z$ volatiles purge tres-fouvent; les Sirops fo: purgarifs par la même raifos le Sucre \& le Miel qui abo dent en fels effentiels $\& z$ efprits, purgent \& aider 
des canjes de la Fiévre. 229 cion des purgatifs : que $\mathfrak{f}$ 5 les mixtes dont on tire raifines , des fels effen;, \&zc. ne purgent pas: peut penfer que la raifine es rels effentiels y font en -petite quantité, ou qu'ils if enveloppez dans les res principes, quils ne aroient fe manifefter.

L'Antimoine diaphoreti, par exemple, n'a per2 qualité vomitive, que ce que fes foulfres font fi. , \& enveloppez par les du nitre: Cependant ce me diaphoretique \& beauip d'autres remedes, qui n'aent ordinairement que par afpiration, ne laiffent pas rre fouvét purgatif, comme 'ay infinue lorfqu'ils renatrent beaucoup d'humeurs ns l'eftomac $\&$ \& quils y fe-

Les cor? diaux font for: vent purgatifs 
230 De la Nature, journent quel que tens. D' I'on peut raifonnableme conclure, ce me femble, que des remedes cordiaux \& 1 dorifiques, qui font comp fez de fubitances fulfureuf douces \& fpiritueufes fo purgatifs, ce n'eft point $p a$ Ce n'ent ce qu'ils irritent les partie point isritatió.

mais à caufe qu'ils mettent mouvement, \& qu'ils dig rent les humeurs cruës $\&$ ac des qu'ils trouvent dansl'eft mac. Qu'ily a J'avouë qu'il y a des dr gues qui purgent fi violemmét qu'on diroit que c'eft par irriquatiö, ou ont du venin. gues qui purgent fi violem ment, \& qui caufent de te déchiremens dans les entrai les, qu'elles pourroient dor ner occafion de penfer qu les purgatifs ont de la ma lignité, ou qu'ils purgent $p a$ irritation; la Gomme-gutt \& la Cologuinte font de c 
des caules de lat Fiévre. 231 re ; la Gomme gutte abon- comme en foufres malius \& cauries, c'eft pour cela qu'elle vomitive; la Coloquinte chargée d'un acide corrod'où vient qu'elle fermenpeu avec l'efprit de nitre, pme l'a remarqué un haAnglois, \& qu'on la coravec des alkalis; mais on doit pas conclure de-là que purgatifs en general ayent la malignité, \& agiffent irritation, puiffque tous autres qui forne dans l'ufaordinaire ont des qualitez ofée à ceux-cy, \&z qu'ils rcompofez de parties dou, volatiles \& fulfurcufes, mortifient $\&$ adouciffent acides.

Au fond, il n'eft pas rai- pournable de conclure que les qurgatifs gatifs ayent de la maligni-

la Gom12 Colon quinte

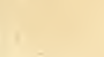




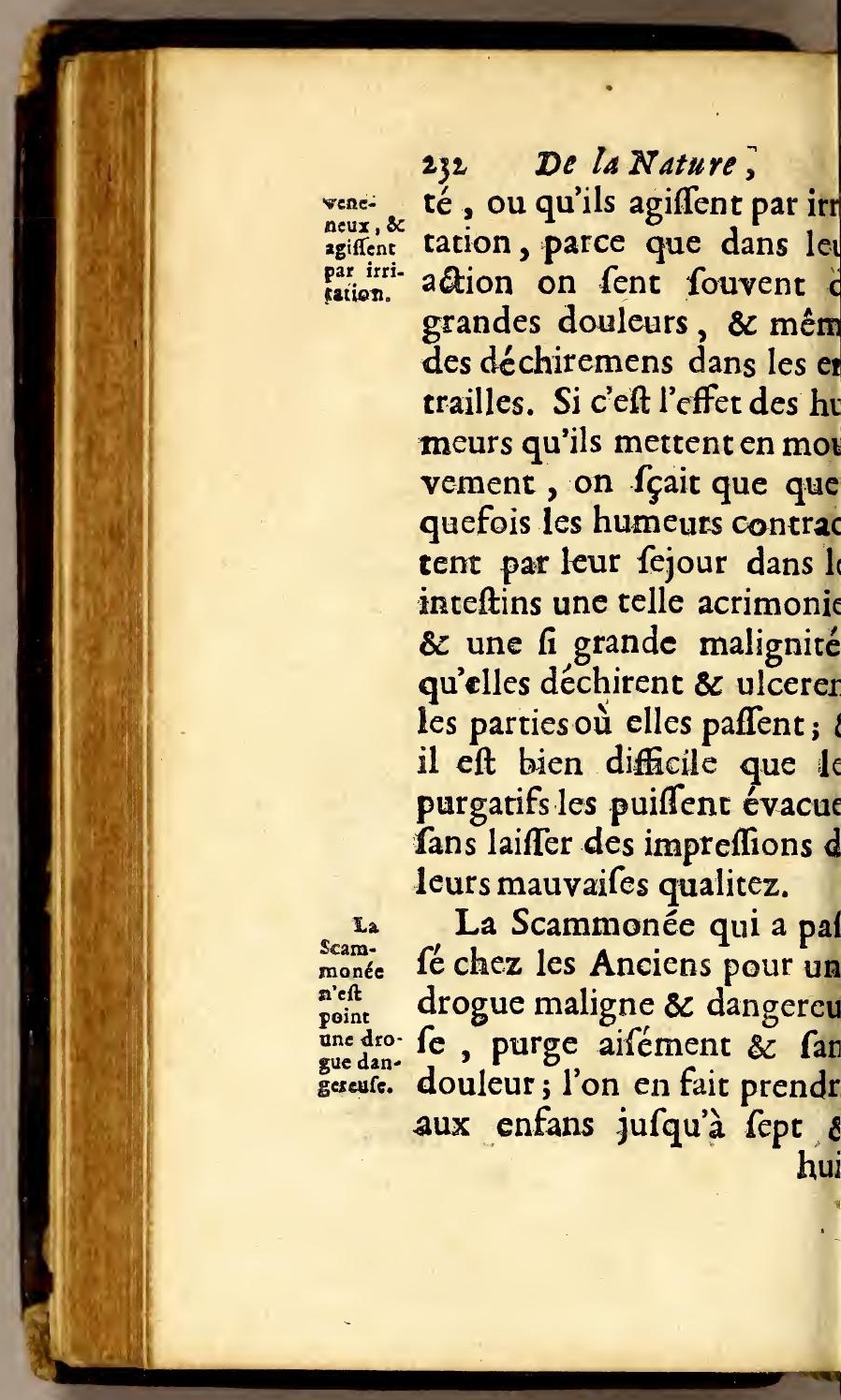


o des caufes de la Fiérore. 233 huit grains : \& l'experience m'a appris qu'on en peut donher jufqu'à trente fans rifque. Cependant il y a encore auourd'huy des Medecins qui erient au feu, lors qu'on deaye dans une infulion de enné deux ou trois gros de liaphoenic, ou de diaprun foutif, parce qu'il entre dans etre dofe quatre ou cinq rains de Scammonêe; cela air bien voir que l'on n'a pas xaminê les Remedes à fond our en connoître les vertus, $\angle$ qu'on s'en eft feulemenc enu à la tradicion.

La Caffe qui eft dans le Ia $_{\mathrm{C}}$ ang des plus foibles purga- puro

fs, purge quelquefois vioemment, \& caule des granles coliques, fur tout quand Ile n'eft pas recente, parce tlle dois u'elle s'aigrit aifément, $c^{\prime} e \mathbb{t} c^{\prime} s_{*}$ 


\section{De la Nature,}

Precar- pourquoy on la choifit douce. prendse \& du Levant, \& on la mêle dans l'ufage des purgatifs avec du fucre pour la confer. ver. Ainfi il ne faut toûjours s'étonner de la difference des effets dans l'action des purgatifs, mais on doit avoir principalement égard dans l'adminiftration de ces Reme. des, à la Nature des maladies, au temperament du malade, aux faifons, \&c. En Efté, par exemple, le ventre eft plus libre, les purgarifs les plus doux conviennent alors, parce que les humeurs ront plus en mouvement, les fruits, les herbes, l'eau de riviere, le Vin doux, le Cydre purgent ; \& on peut penfer que c'eft parce qu'ils excitent des fermentations dans l'eftomac.

Ces réflexions me paroif 
de des caufes de la Fiévire. 235 ent fuffifantes pour donner ne idée affez vrai-femblable e l'action \& de la vercu des urgatifs ; \& il me femble u'il n'elt pas neceffaire de - donner la gehenne, de uppofer des contractions de bres dans l'eftomac, ni d'aoir recours à l'irritation \& ax qualitez malignes pour écouvrir la vertu des purgafs; \& je penfe que cela purra lever tous les fcrupu$s$ dans lefquels le public a 'é jufqu'icy à l'égard de ces emedes, \& qu'il fera peradé qu'ils ne font pas in ingereux qu'on a voulu luy ire croire, puifque la plufirt ont beaucoup de rappore ec-nos alimens.

Aprés ces réflexions gene- ment Apres ces reflexions gene- de certe les fur le legirime ufage de $\begin{gathered}\text { pratique } \\ \text { iné de } \\ \text { l'bre }\end{gathered}$ Caignée, \&z fur la vertu des l'hypo. 
236 De ls Nature;

Remedes purgatifs; il m $\simeq$ fen ble qu'il ne fera pas diffici. $d^{2} e n$ faire l'application à Pratique par rapport à no principes. Si donc noftre hy pothefe eft vraye, comm je croy l'avoir fuffifammer prouvé, \& que les Fiévre foient caufées par des hu meurs cruës \& indigeftes, q1 Deux paffent de l'eftomac \& d indicarions pour la guerifon des Fiéries. inteftins avec le chyle dar le fang. Je trouve qu'il y at ra deux indications pour guerifon des Fiévres, à fç purgatio voir la purgation \& la tran 8 tranfyiration. piration; la purgation regai de les humeurs cruës $\&$ ir digeftes qui font dans lespre mieres voyes , \& qui trou blent l'œeconomie du chyle ? du fang.

Dans cette veuë $\dddot{j}$ établ pour maxime cerraine qu' 
\& des caules de la Fiévre. 237 fuut purgér, ou faire vomir e plûtoft qu'il eft poffible; c'eft à dire dés le commencement des Fievres, afin d'em- menr. pêcher le mauvais commerce de ces matieres cruës qui s'introduifent dans le fang, $8 z$ entretiennent les fermentations fiévreufes. La feconde indication m'en fournit deux faignor. autres, c'eft la Saignée, \& les Remedes diaphoretiques \& fpecifiques; la faignée fe rapporte à la plenitude, tellement que s'il y a trop de fang, il ne circule pas aifément, c'eft un obftacle'à la tranfpiration: il y a des fignes effentiels de certe plenitude, nuent la necefité je les ay remarquez ailleurs; de fai-: il faut donc faigner pour remedier aux fymptomes pref- $\mathrm{L}_{\mathrm{a}} \mathrm{rat}^{\mathrm{O}}$ fans, pour faciliter la circu- gnée fé lation, \& pour fatisfaire à la re d'a= 
plenitude, deux, trois ou qua tre faignées au plus fuffifent ce me femble; à toutes ce: indications; Et comme tou: les fympromes qui deman. Trois ou dentla faignée, fe manifeften quatre :

principalement au commen. cement des Fiévres, c'eft auff dans ce tems-là qu'elle doit eftre mife en ufage.

Ies Re. Les Remedes diaphoreti-

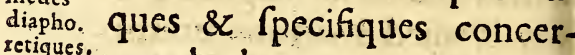
xetiques. nent les humeurs cruës $\&$ indigeftes qui font dans le fang, Leur \& y caufent la Fiévre; ils font ufage. inftituez pour cuire, digerer Idée ge. \& diffoudre ces humeurs. Voifon des là en general une idée de la Fiévres. guerifon des Fiévres. Mais avant que d'entrer dans le détail des chofes neceffaires à cette guerifon, j'ay deffein Explica- d'expliquer des difficultez qui
eion des difficu. fe prefentent, \& de prévenis 
¿o des caufes de la Fiévre. 239 es objections qu'on pourroit iire contre cette Methode.

On m’objectera d'abord tezquife prefentét contre cette Methoue je commence par où l'on de. loit finir; que c'eft une Prati- Qu'il ne ue generalement reçû̈ë de ne ger qứa-. urger dans les Fiévres qu'a- prós aprés rés le feptiéme jour, ou les de coces prés les fignes de coation; ue les plus experimentez $\mathrm{Me}$ - Quec'efif Iufage ecins font dans cet ufage: $z$ qu'il eft fi bien érabli dans - public, que lors qu'on dehande des nouvelles d'un ma. de, fi l'on dit il fera purgé emain; on répond, à l'inftant eft donc gueri. Que d'ailpurs c'eft une Pratique fonée fur l'autorité d'HippoQu'il eft: fondé fur l'alstorité d'Hippocrats: rate dans l'Aphorifme 22. u livre premier, Concocta redicari, atque movere, non uda, neque in principiis mo. à non' inrgeant, plurimum. 
240 De la Nature, verò non turgent. D'où il évident que je fuis bien meraire de propofer une m xime formellement oppofé à l'autorité d'Hippocrate, la Raifon \& à l'Experien ce.

J'avouë que c'eft Pufag Réponfe de ne purger dans les Fiévre qu'aprés le feptiéme jour, o aprés les fignes de coction; 8 je conviens que les Medecin qui ont le plus de reputatio font dans cette Pratique : ma je ne demeure pas d'accor quils foient fondez en raifo Que cet \& en experience; \& je ni Aphorifme n'au. corife point cet ufage.

que l'autorité d'Hippocrat dans l'A phorifme allegué fa. vorife leur conduite. Pou eftre éclairci fur cette matie. re, il faut examiner le fen: de l'A phorifme ; \& fi du tem: d'Hipposrate on traitoit le: febricitan: 
20 des caufes de la Fiévre. 248 ebricitans comme on fait aujurd'huy:

A l'égard dela Pratique des Anciens, il ne paroift dans ucun endroit d'Hippocrate, i chez les Auteuts contem- Les Anz orains, que pour guerir les ciens ne '́ iévres on fit des faignées point le ins nombre aux malades, \& 2 comme u'on les noyaft de lait-clair, on fair de boiffons rafraichiffanmear. $s$; \& 2 il y a bien de l'appance que fi certe Pratique roit efté bien receuë du tems Hippocrare, il ne nous auit pas laiffé cet Aphorifme, hifqu'il y eft fornellement ppolé, comme je feray voir ans la fuite.

Voicy le fens litreral de Aphorifme: Il faur purger s humeurs cuites, \& non

$s$ crues; non pas même commencement des, $\mathrm{ma}$ : $x$ 


\section{De la Nature,} $\frac{\text { ladies, pourveu que la ma. }}{\text { tiere ne furmonte, } 8 \alpha \text { nabon }}$ n'abonde pas, d'où je con. clus qu'il faut purger avant 1 : sens lit- coction, c'eft à dire dés 1 teral de l'A phor. 23.1. I,

commencement des Fiévres la matiere qui furmonce, or qui eft en trop grande abon dance, ou en trop grane mouvement ; jentends pa: cetre maticre les humeurs tu mulrucules de l'eftomac \& des inteftins, qui paffent dan le fang, \& entretiennent 1 : Fiévre. Au furplus, il fau cuire, ( $c$ 'eft à dire) digerer rarefier, 8 diffoudre les hu meurs qui one paflé dans li fang, \& font la caufe de li Qu'il a Fiévre : Ainfi cet Aphorifm parties.
a deux parties; l'une nous ap. prend qu'il faut purger dé: le commencemeat des Fié. 
or des caufes de la Fiévre. 23 res, les humeurs feditieues \& impures qui font dans eltomac \& dans les premiees voyes : \& l'aucre nous fait omprendre quil faut laifer aire la coction des humears ruës \& indigefes qui font ans le fang avant que de urger; \& elle nous infinuë a même tems, fi je ne me ompe, qu'il faut aider la aleur naturelle \& les efprits faire certe coction : à quoy s faignées reiterées, ni les biffons rafraîchiffantes ne auroient convenir, puifae les faignées épuifent les prits, \& que les boiflons fraîchiffantes affoibliffent chaleur naturelle, fans laielle il ne fe fait point de etion parfaite : Ainf jay fon de foûtenir que cette ethode eft formellement

$X$ ij 
244. De la Nature, oppofée à l'efprit de l'Aphorifme.

On doit done purger, $\mathrm{fe}$ lon la doctrine d'Hippocrate dans cet Aphorifme, les hufaut pur- meurs trop impetueufes, dés ger dés encement les humeurs abondantes. le commencement des Fiévres. Il y a plufieurs paffages dans ce fameux Auteur qui autorifent cette Pratique, dont les citations feroient fuperfluës. Il faut auffi faciliter la coction des humeurs qui caufent la Fiévre, apré! quoy la purgation eft necef. fautil pur- faire. Hippocrate en rend $l_{2}$ ger 21 a fin pour eviterles rechutes.

raifon, Aph. 12. liv. 2. 22d relinguuntur in morbis, reci. divas faciunt; sc cette pur. gation regarde principale. ment la précaution pour pré. Cotte venir les rechutes. De tour Metho- cela il refulte que ma $\mathrm{Me}$ fondée thode eft fondée fur la do. 
\& des caufes de la Fiérure. 245 Exrine d'Hippocrace, lorfque 'établis deux indicacions ge- d'Hip. pocrats nerales pour la guerifon des Fiévres; à fçavoir, la purgation \& la tranfpiration, \& que l'on doit purger le plûtoft qu'il eft poffible les humeurs impures qui abondent dans l'eftomac, \&z dans les nteftins, \&z faire tranfpirer celles qui font contenuës dans a mafle du fang, c'eft à dire, es digerer, les rarefier $\&$ difCoudre; \& cela fe rapporte - la doctrine des Auteurs; qui faifoient dépendre toues nos maladies du défaut de tranfpiration, ou de l'excés de condenfation.

Ces maximes generales étant ainfi établies, il faut entrer dans le détail des remedes qui puiffent fatisfaire toutes nos indications.

$X$ iij 


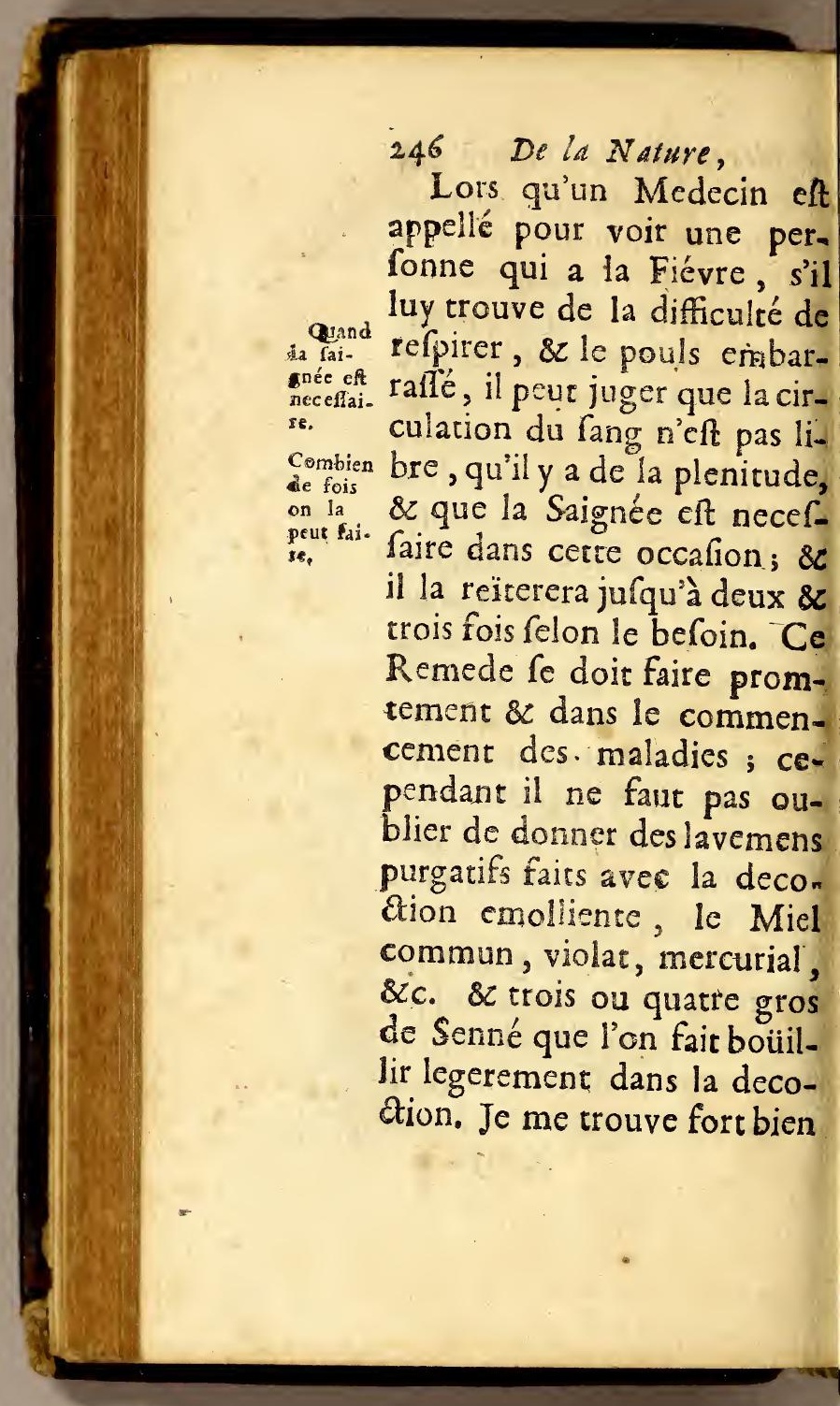


Co des caufes de la Fiéure. 247 ic l'ufage des lavemens pur- Iavemes gatifs; on doit pourtant con- $\begin{gathered}\text { purgatifs } \\ \text { tres uni- }\end{gathered}$ Hiter en cela le temperament les. des Malades. Il y en a qui En quite ont fujers à des douleurs de faus ab. coliques, à des vapeurs, \&zc. qui les lavemens fimples onviennent mieux que les purgatifs.

Que fi par l'effet des lave. mens, ou par d'autres fignes, I paroift qu'il y ait beaucoup g'humeurs dans l'eftomac \& lans les entrailles, on donne eurement cette potion pur- purgatijative.

Prenez du Senné, deux gros. Dufel Vegetal, un demi gros. De la Caffe fraîche mondée, une once.

Des fë̈illes de cichorée fauvage coupée menu, une poignée.

Iettex for le tout une chopine $\mathrm{X}$ iij 


\section{De la Nature,}

d'eau boüillante: pajjeze preffez, of le faites pren dre an Malade.

Cetre potion purge douce. ment \& fans rifque, elle peu eftre reïréée le lendemair felon l'effer \& le befoin Souvent même on faigne \& on purge tres-utilement dan un mếme jour. On donne aufi fort à propos des vomi tifs, ils font tres-utiles lorfque le malade a de frequen-

C'eft une bonne pratique de purser oude mir d'abord. tes envies de vomir, \& qu'i vomit aifément; le Tartre Emetique m'a toûjours paru le meilleur vomitif; jen fais prendre cing ou fix grains dans du boüillon ou dans quelqu'autre liqueur : \& ce Remede guerit tres-fouvent les Fiévres fans retour.

Il faut donc purger ou faire vomir le plûtolt qu'il eft 
$\checkmark$ des caufes de la Fiéure. 249 offible : c'eft aux Medecins examiner s'il n'y a point d'in. dications contraires, comme des tenfions douloureufes. lans le bas ventre, des difofitions inflammatoires, \& hurres fymptomes qui s'oppofent à la purgation. Mais e le repete : c'eft une bonne pratique de purger ou de aire vomir au commencement des Fiévres; \& il eft rare de voir un malade qui a vomi, ou qui a le ventre libre, avoir beaucoup de Fiéyre.

Aprés l'urage des purgatifs, c'eft une bonne methode de donner quelque porion cordiale \& fomnifere, pour calmer le mouvement de l'eftomac \& des humeurs. Voicy celles dont je me fers le plas ordinairement. 
sgo De la Nature,

Prenez de l'eau de Pavot trois onces.

DM Diacodissm, fix gros. Et de l'eau de Canelle, un gros

En voicy une autre qui n'eft pas moins bonne.

Prenez de l'eau de Meliffe, trois onces.

Du Sirop d'Oeillets, une once. Et de la teinture de Lauda. num faite avec l'e eprit volatil de Sel Armoniac, cing ou fix goutres.

La tein: La teinture d'Opium fe d'opium fair auffi avec la teinture de avec I'Efprit volatil de Sel Armo. niac eft la meilleure.

Safran tirée par l'Efprit de vin, ou avec l'Efprit de vin feul; mais celle qui eft faite avec l'efprit volatil de fel $\mathrm{Ar}$ moniac me paroift la meilleur.

Ces potions ou Juleps peu- 
odes fues de la Fiévre. 251 ent eftre aromatif'es, \& endus plus agreables par uelques gouttes d'Effences olariles, comme de fleurs Oranges, de Canelle, de hin, de Macis, \&zc.

Quelquefois on donne pour même deffein un demi gros - Diafcordium, un demi gros u un gros de Theriaque nouelle; \& fouvent j'y ajoúte $n$ grain de Laudanum.

Je pourrois donner icy hufieurs formules de juleps - d'opiates qui conviennent ans cette occafion, mais les ivres en font pleins, je n'ay as deffein de les tranfcrire our grofir ce volume : on eut y avoir recours." Je proofefeulement ceux dont je he fers, \& qui me paroiffent uffifans pour remplir les inications qui fe prefentent 
252 Dela Nature, dans la guerifon des Fiévres. Voilà en peu de mots $m$ methode de traiter ies Fié

Si les? Eiévres ne gueriflent? point pas $12 \mathrm{fai}-$ gnée $x$ par la purgatió. ionmet en ufage les diaphoretiques \& les $f_{\text {peci- }}$ figues.

vres lorfqu'il y a plenitude repletion, ou abondanc d'humeurs dans les premie res voyes; que fi aprés la fai gnée faite felon les preflan befoins, \& aprés l'ufage de purgatifs la Fiévre perfevere jay recours à la tranfpiratio $\&$ à la coation, \& j'employ pour cela les remedes diapho Ie 2rin. retiques : je n'en ay point d quine que af. furé pour 12 gueriSon des Eitevres. plus affuré que le Quinquina jen fais diverfes preparations Voicy celle dont je me trou. ve le mieux.

Preparai tion du 2uingus: na tres. ytilos.

Prenez une once \& demie di bois de Saffafras rapé : faitesla boüillir legerement pen. dant un quart-d'heure dans un vaiffeau couvert, ou au bain Marie dans deux pintes 
$\therefore$ des caufes de la Fiévre. 253 d'eau, aufquelles vous ajoûtercz quatre ou cinq onces de bonne Eau-de-vie; Aprés cela vous y jetrerez une once \& demie de bonne poudre de Quinquina, \& laifferez encore boüillir le tout enfemble pendant un quart-d'heure, \& y ajoûterez fur la fin deux ou trois pincées de fleurs de $\mathrm{Pa}$ vot rouge, avec trois oul quatre onces de fucre.

Cette boiffon guerit feu- ' $v$ 'on ex ement les Fiévres continuës guerit les intermittentes : L'on fortes de n ufe en tout tems, dans Fiévres.

es accés, dans les intermifons, dans les redoublemens. on la prend chaude comme $s$ bouillions; fil'on veur on pour 12 boit froide, elle eft excel- pleurefie? ente dans la pleurefie fi on meillewn ufe chaudement. Et c'eft se prife a meilleure methode en tou- ment, es fortes de Fiévres où se 
254

De la Nature, remede eft en ufage; c'eft dire où la tranfpiracion elt ne. celfaire.

Je protefte icy que je m'en fuis toûjours fervi avec fuccés, \& je fuis perfuadé que ceux qui s'en fervirone $s^{3}$ en trouveront bien. Mais il ne faut point avoir de frupules fur l'ufage de ce remede, $\&$ te 2 win. on fe doit metrre dans l'efquina sieft. point un remede dangereux.

Il guerit en digerant les hunieurs 8 en for tifiant les par. prit qu'il n'ef point dangereux, que l'on n'en fçauroit trop prendre, qu'il guerit promeement \& feurement en facilitant la tranfpiration, la digeftion des humeurs cruës, $\&$ en fortifiant l'eftomac. J'y mêle quelquefois fept ou huit goutres de teintures d'Opium pour une prife, \& cela faic fort bien. Il eft inutile de dire qu'il faut donner quelques bouillons par intervalle, 8 
\&u des canfes de la Fiévre. 255 nir le malade chaudement; eux qui fuivront cette $\mathrm{Me}$ lode feront confirmez dans oftre hypothefe, \& verront u'il y a peu de Fiévres qui e foient parfaitement guees en moins de huit jours ar l'urage du Quinquina.

Le Quinquina Ce donne en- Diverfes pre en fubftance en opiate; manieres n en fair des boles avec la oudre ; il eft excellent infuner le 2uinquip?

- dans le vin; on peut en ire de la Tifanne, du Sipp, de laConferve, \&zc. Il y a lus de douze ans que jen fis aire des Tablettes pour un ntrepreneur du Pavé de la pute d'Orleans, qui ayant ne Fiévre double tierce ontinuë, fur mandé par feu $1^{\mathrm{r}}$. de Colbert pour rendre uelques comptes; il falut beir, \&z partir avec la Fié - 


\section{De la Nature,}

vre; Le malade mangea do fes tablettes en chemin fai. fant, \& revint vigoureux \& fans Fiévre. J'ay donné de ce remede à plufieurs perfonnes

destage qui eftoient obligées de monblettes' irescom. mode. ter à cheval tous les jours \& d'aller à la Campagne, quoy qu'elles euffent la Fiévre, \& qui en ont efté parfaitement gueries.

Je ne fçaurois pafler icy rous filence que quelques Medecins, par un efprit de contradiction, ou parce qu'ils ne connoiffent pas la Fiévre ni la vertu du Quinquina, ont condamné ma methode de le faire infuler avec du vin nouveau, affurant qu'il faloit du vin vieux, apparammene parce quil échauffois moins; car ces $\mathrm{M}^{\mathrm{r}}$. ne fçauroient comprendre qu'on gue. riffe 
\&u des caufes de la Fiéure. 257 riffe la Fiévre avec des remedes chauds. Mais comme je fuis perfuadé que fi le 2 uirquisa n'eftoit chaud, it ne gueriroit pas la Fiévre, \&z qu'il le fait en mortifiant les acides, \& que d'ailleurs le vin nouveau eft plus fpiritueux que le vieux; ainfi il eft meilleur pour tirer la verru du 2uinquina. C'ett pas ectre raifon que $M_{*}^{2}$ de Monginot en faifoit faire avec du mouft dans le rems des vendanges; \& l'experience m'a appris que cette preparation eft des meilleurs.

Voicy d'autres febrifuges pour ceux qui ne s'accommodent pas du Quinquina.

Plufieurat febrify: sti.

Prenez de l'eau de chardonbenit, quatre onces. De l'Esprit de vin, deux onces.

$$
\text { צ }
$$




\section{De la Nature, Mêlez é prenez de cette po- tion deux on trois fois le jour.}

\section{A UTRE.}

Prenez de l'eau de Meliffe quatre onces, avec huif ou dix gouttes d'Efprit de Sel volatil Armoniac. Il en faut ufer comme de la precedente.

Le Sel Armoniac purifié pris jufqu'à douze grains dans un bouillon, deux ou trois fois par jour, eft un bon febrifuge.

La boiffon amere des An. glois faite avec la racine de Gentiane, la petite centaurée, ou le chardon-benit, \& le genievre, eft febrifuge.

Cequi

Monfieur Sylvius vante le in eqirizueux or fulfureur eft febrifuge camphre comme un excellent febrifuge. En general tout ce qui elt fpiritueux \& fulfu. 
do descaufes de la Ficure. 259 eux \& qui facilite la digerion, \& la tranfpiration eft ebrifuge. Mais comme je 'en ay point trouvé de plus firé que le 2uinquina, je n'y attache, \& je cherche les noyens d'en rendre l'urage greable fans diminuer fa

\section{yertu.}

Il faut auffi remarquer qu'il 11 y a des a des Fiévres où il n'eft pas où les heceffaire de mettre d'abord faignées en ufage les purgatifs ni la fai- purganée, comme celles où il n'y a font pas oint defymptomes preflans; necorias point de lymptomes preflans; pù les humcurs ne font pas dans un mouvement trop vioent; \& où la tranfpiration cft aifee:alors on donnebeaucoup alla Nature, on fe concente de faire obferver une diete exaate aux malades; on les nourrit peu dans les commence- palliati: mens ; on fait ufer de lave.

Elles fe gueriffent par une men thode 
260 De la Nature, mens fimples; on donne la nuit des Juleps cordiaux tels que nous les avons propolé on fait boire de l'eau pure avec quelque Sirop : celle de Ra ki- la Riviere de Seine eft purviere de Seine bonne dansles Eiévies. gative, \& principalement au Printems \& en Efté ; \& je Pour- tive vient de la diffolution quoy elle des fels contenus dans les sative. bois qui flottent continuellement fur cette Riviere. Cette diffolution fe fait mieux lors que l'éau eft un peu échauffée, \& elle s'en trouve plus chargée en Efté qu'en Hyver, parce qu'en Hyver le lit de la Riviere eft plein d'eau de neige $\&$ de glace qui diminuë la vertu des fels effentiels des Plantes. Peuteftre fera-on confirmé dans cette penfée, fi on fait réles 
$\checkmark$ des canfes de la Fiévre. $26 \mathrm{I}$ ion que les cendres des bois ortez ont beaucoup moins e fels que les cendres des utres bois ; c'eft pour cette aifon qu'on ne s'en fert pas. ans les lexives.

Quoy qu'il en foir, j'ay obervé que l'eau de la Seine it une boiffon excellente ans les Fievres fi on y mêle u Sirop violat; quelques ueillerées d'Eau-de-vie ajoûées à une pinte d'eau de Rin iere font encore une bone boiffon; le vin \& l'eau vec une rôtie fe peuvent ermettre, \& l'ufage m'en paru tres-utile prefque dans butes les Fiévres. Par cette nethode palliative, on gueit feurement les Fiévres qui e font pas accompagnées de ymptomes preffans, \& elles e terminent par une tranfpis

Y iij 


\section{De la Nature,}

- racion heureufe : aprés quos on purge pour éviter les re. cheutes, felon le confei d'Hippocrate; \& cette pra. tique fe rapporte au precepte de l'Aphorifme, il faut purger aprés la coction.

Mais afiri de faire voir d'une Nouvel- maniere plus fenfible que la les refle- coction des humeurs, dont 12. 1.1, il eft parlé dans l'A phorifme, regarde principalement les mauvais fucs qui fe font introduits dans la maffe du fang; Il faut encore faire quel. ques réflexions qui feront le dénouëment de cette difficulté, comme je l'efpere.

Hippocrate nous apprend Iorigine que toutes nos maladies vien-
de toutes nos maladies vient de l'air ou des alimens, nent de l'air ou des alimens, fi bien que celles où l'air n'aura point de part, fe rapporteront uniquement aux mau. 
бo des caufes de la Fiéure. 263 is fucs qui dérivent des aliens. Si donc quelque pernne tombe malade d'une évre aprés avoir trop man-. \& trop bû, je comprends el'eftomac \& les inteftins de tte perfonne font farcis de atieres indigeftes, \& qu'une rtion la plus fubtile de ces atieres fe mêle avec le chy, lequel eftant porté dans fang y excite la Fiévre, \& l'aucre refte dans le fonds l'eftomac, dans lesreplis, dans les cellules des intefis ; \& je penfe qûe ces auvais reftes communiquent continuellement au chydes vapeurs $\&$ des fucs imIrs qui augmenteront la évre, \& cauferont tous les mptomes fâcheux qu'on y pid paroiftre tous les jours. ans cette conjoncture fi je 


\section{De la Nature,}

confulte Hippocrate dans fo Aphorifme, le fens commu fuffira pour me faire voir qu certe matiere contenuë dar l'eftomac \& dans les inteftin eft en orgafme; c'eft à di qu'elle furabonde, qu'elle e fuperfluë, qu'elle caufe do fermentations vicieures, que cet homme divin m'er feigne qu'il faut l'évacue promptement, qu'on n'en do point attendre de coation Et cela fe confirme par l'ex perience qui nous fait voi tous les jours que cette ma tiere, au lieu d'acquerir que que coation, contracte $\mathrm{pa}$ le fejour qu'elle fait dan l'eftomac \& dans les inteftin une puanteur $\&$ une corrup. tion extréme : fi bien qu'i n'y a perfonne de bon fen gui ne convienne qu'il ef plus 
ordes caufes de la Fiévre. 265 lus expedient \& plus avan- Qu'il of ageux à un malade d'eftre ${ }_{\text {pediérde }}^{\text {plus ex- }}$ romtement purgé de ces purger aatieres, que de les laiffer prement; roupir dans fon ventre où que de, lles deviennene tô̂jours corrom: lignes \& $x$ dangere les alignes \& dangereufes : \& maties ow n'Hippocrate n'a point vou1 dire qu'il faloir attendre u'elles euffent acquis toutes es mauvailes qualitez pour fre purgées.

Je n'ay pas deffein d'exafiner icy toutes les explicaons que les Auteurs ont onnées de la coction des umeurs, \& comment les lus éclairez, \& Fernel même, nt pretendu que la coction es humeursmorbifiquesétoir Ce qree es humeurs morbifiques étoit les Auo ne converfion en pus ou enteurs on: uelque chofe d'approchant ia cocuelque chofe d'approchant. tion dea - fuis perfuadé que l'idée bugeus une pareille coction feroic 
266

De la Nature,

plûtoof refoudre un malad

à prendre cinquante medecines, que d'attendre qu'il of fut formé dans fon corps de abrés ou du pus.

Je m'attache au fens litte. ral de l'Aphorifme allegué qui veur dire parla coction sens lit- une digeftion ou une matu. l'A phe. irsne, 2. ta.

ration, par rapport à ce qn fe fait dans.les fruits quan ils meuriffent. Mais cette ma turation ne fçauroit conve nir aux matieres qui croupif fent dans l'eftomac \& dan les intertins; ta chalcur na curelle y elt fuffoquée, les le vains y font corrompus, \&z oc matieres font comme les ca davres qui empoifonnent l'ai

ater dos humeurs corrom. pués dis lettoans. quiles environne, les bouil. lons $\&$ les meilleures nour ritures s'y corrompent; 8 ceft ce qui a donné lieu 
$\circlearrowleft$ des caufes de la Fiéure. 267 et Axiome fi celebre dans 1 Medecine, plus on nourrit $n$ corps impur, plus on le leffe. Je penfe donc que cetcoction \& maturation d'hu- Qu'il 's peurs fe fait principalement ans la maffe du fang par les prits, \& par la matiere fubfait une coction dins la maffe dy le qui agiffent continuelleent fur les cruditez, en adou. frant les acides groffiers, en faifant tranfpirer ceux ai font infociables; de la hême maniere que dans les uits, les fucs acerbes $\&$ grofors font adoucis, fubtilifez meuris par la chaleur. Il t donc vrai - femblable 'Hippocrate a voulu nous prendre dans fon Apho- qu' quip $_{\text {pocrate }}$ fme qu'il faloit attendre $\&$ a entent der la coction des humeurs cotion corla ii eftoient introduites dans des has: fang, \&z qui en troubloient 
268

De la Nature,

l'aconomie, \& purger enfu re les fuperfluitez qui refter decetre coction pour prév nir les rechutes, comme je l': remarqué , \&z que l'on d voit purger promtement ce les qui eftoicnt abondantes tumultucufes dans l'eftom: $\$ z$ dans les inteftins.

Mais on dira, cela ne d Objec- cide pas en voltre faveur, éé de I’Aphosiome. ne vous autorife point aff pour introduire une maxin nouvelle dans la Medecin de purger dés le commenc ment des Fiévres. On col vient qu'Hippocrate ordon de purger d'abord, lorfquel humeurs font rumultueuf \& abondantes; mais il ajo re daus fon Aphorifme qu'e les le font rarement, \& $p$ là il vous impofe filence f les purgarifs, \& vous défen 
co des eanjes de la Fiévre. 269. le les mettre fouvent en ufae, fur tout dansle commenement des maladies.

A cela jay deux chofes à lire : I a premiere eft, que fi os purgatifs avoient efté aufi ommuns \& aufii connus di ems d'Hippocrate qu'ils le jection. ont aujourd'huy, il y a bien c l'apparence quili eût efté hoins refervé fur leur ufage. pa ne fe fervoir de fon tems ue d'Hellebore, de Conombre fauvage, de Colouinte, $\&$ d'autres drogues gocrate iolentes $\&$ dangereufes; \& $\&$ ous avons maintenans dela Jaffe, de la Manne, des Ta. arins, de la Rubarbe, du enné. Nous avons encore es électuaires purgatifs, com, ze le Diaphœnic, le Diaprun plutif, le Diacarthami, la oudre Cornachine compo-

$\mathrm{Z}$ iij

Purgá tifs e:l usage du tems
d'Hip. 
270

De da Nature,

fée avec parties égales

Tartre vitriolé, de Scammo née, \& de poudre de Jalap dont on donne depuis ving jufqu'à trente grains dans d vin blanc, ou en bole, \& une infinité d'autres purgatif que l'on peut mettre en ufa ge felon les occafions.

La feconde chefe que j'a

Differé- cesentre bes habirans du Nord 8 ceux du Levant. appofer, fe tire de la diffe rence qu'il y a entre les ha bitans de la Grece \& ceux d Nord; ceux-cy font voraces mangent \& boivent beau coup, \& tranfpirent peu, 8 c'eft là la fource de toutes no maladies; ceux-là au con traire font fobres, mangen peu, \& font dans une trant piration continuelle : $8 z$ cett difference, fi je ne me trom pe, impofe la neceffité d purger promtement dans ke 
ó des caufes de la Fiévre.27! limats froids, oǹ l'on void les re: eu de Fiévres qui ne foient fouvens recedées de vomiffemens, pées de le naufées, ou enfin de quel- somifo: fue dévoiement : ce qui eft ine marque évidente de l'or; afme, \& du tumulte des huheurs, \& par confequent une aifon de purger dés le compencement des maladies.

Mais au fonds fuppoft u'Hippocrate ait pretendu fu'il falut actendre ou profurer la coztion des marices abondantes $\&$ tumultueues contenuës dans l'eftomac 2 dans les inteftins; comment s'y prend - on aujour'huy pour fatisfaire au preepre de ee Grand homme propofons quelque exemple.

Un Medecin vient voir un malade qu'il trouve fort op- Exerts: prefl'e, ayan beaucoup de le pour

Z iiij 


\section{De ia Nature,}

ăne la Fiévre, avec des envies dk ordinaire de guerirles *iévres n'sit pas fordée fur l'aucorité d'Hipposrate. vomir ; ce malade a mang amplement $\&$ bû à la glace au refte, c'eft un bon fujet, le Medecin parle élegammen de la maladie, car il y a de? maurais Medecins qui fon fort éloquents, \& ç'en eft la fatalité : cela impofe au pu. blic, quelle apparence qu'un homme qui parle fi bien gucriffe mal Le Medecin donc dit qu'il faut s'affure de la Fiévre, en éteindre le feu, \& calmer le mouvement rrop imperueux des humeurs par des rafraîchiffemens : I ordonne des faignées, des émulfions; il fair boire de la Limonade, du peric lait ; fait prendre des lavemens faits de lait-clair, de decoction, de laituës $8 \alpha$ de Miel de $\mathrm{Ne}$ nuphar, il reitere les faignées: 
$\checkmark$ des caufes de la Fiévre. 273 Enfin tant eft procedé qu'aprés quinze ou feize faignées, (on va fouvent plus loin;) le malade a des tranfports au cerveau, des mouvmens convulfifs, \& d'autres fymptomes caufez, fi je ne me rrompe, par l'épuifement des elprits, \& par la corruption des humeurs contenuës dans le bas ventre. Dans cer embaras on demande du confeil, on fait venir des Medecins qui ne manquent pas de dire que la procedure a efté bonne, mais que la maladie eft grande. On s'informe de l'evenement, toute la famille eft intriguée : le malade a des Charges, des affaires, des enfans; les Medecins répondent comme les Oracles toûjours obfcurement : on delibere fur les remedes, on pro- 
274 De la Nature, pofe des faignées au pied, à Ee qui a la gorge, des applications de

duit dàs

1. Mede-

cine les

Charla-

tans, les

Moines, pigeons fur la tefte, à la planre des pieds : tout cela fe fair inutilement, le malade s'en \&ce

trouve plus mal. Enfin un voifin produit un avanturier un Moine, une femme qui donne du vin Emetique, ou quelqu'autre potion purgative, qui fait vuider des baffins pleins de mauvais reftes. d'alimens, de falades, de legumes, \& d'autres matieres tres-puantes, par où le malade fe trouve extrémement foulagé ; \& avec le fecours de quelques liqueurs fpiritueufes \& cordiales, \& de bons ali. mens, il eft parfaitement gueri.

Mais fi ce malade guerit; il a couru de grands rifques, \& il eft certain que plufieurs 
du descaufes de la Fiévre. 275 y fuccombent, Voilà cependant la methode avec laquelle on traite les febricitans, \& l'on void aif'ement fi elle eft fondée fur la doctrine d'Hippocrate : car enfin s'il y avoit dans les entrailles de ce malade des matieres abondantes \& en orgafme, il eft conftant quil faloit les purger d'abord pour fatisfaire au precepte de ce Grand hom. me : l'on auroit prévenu tous les fymptomes qui font arrivez au malade, \& tous les hazards qu'il a courus. Que sil faloit attendre, ou procurer la cotation des humeurs, c'eft agir contre l'efprit d'Hippocrate, \& contre le bon fens, d'ordonner des faignées frequentes, des émultions \& des boiffons rafraichiffantes, qui au lieu de far 


\section{De la Nature,}

Ia caufe clliter cetre coction, l'em-
des fié-

vreslen- pêchent formellement, \&

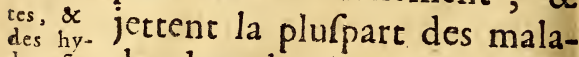
dropifies des dans des langueurs mortelles, dans des Fiévres lentes, des hydropifies, \& dans plufieurs autres accidens dont ils ont bien de la peine à revenir.

C'eft donc une bonne methode, \& conforme à la doatrine d'Hippocrate, de purger promtement toutes les matieres impures, qui ne deviennent pas plus traitables par le rejour qu'elles font dans l'eftomac $\&$ dans les inteftins; au contraire il eft conftant qu'elles y acquierent une corruption \& $z$ une malignité tres-dangereufe. Si aprés l'ufage des purgatifs la Fiévre continuë, j'ay recours aux remedes Diaphoretiques 
Oudescaufes de la Fiévre. 277 tels que je les ay propolé. Cetre methode eft non. feulement fure contre toutes les Fievres intermittentes, mais encore contre les continuës, \& principalement contre celles où il y a du friffon, $\&$ où la tranfpiration n'elt pas libre, comme dans l'Automne, dans l'Hyver \& dans le Printems.

Il faut remarquer icy que le 2urnquina eft encore un remede excellent contre les Fiévres hediques, \& contre les Fiévres lentes; dans cel- guina eft les-cy la faignée du bras $\&$ du un bon pied doit fouvent preceder l'ufage du 2uinquina, principalement aux filles qui ne teat - $^{\prime}$, font pas reglées; les vomitifs leur font auffi tres-neceffaires, parce qu'clles ont ordinairement l'eftomac chargé contre les Fié: vres lenques, 


\section{De la Nature,}

de cruditez vifqueufes; apré quoy l'ufage du Quinquin. en boiflon avee le vin, ol avec le Saffafras, comme jc l'ay propof'é, eft tres-conve. nable; on fait en même tems ufer de cette opiate hyfterique.

Opiate hayfterisucs
Prenez du Quinquina en pou dre tres-fine, demi-once.

Du Mars preparé à la rofée, of mis es poudre fubtile, deux gros.

Du Macis, trois gros.

De l'extrait d'aloès, un gros. De l'Effence antibyfterigue, demi-dragme.

En voicy une autre.

Prenez du Quinquina en poudre, demi-once.

De la Contrayerva, deux gros. Des Sels de Tamarifo, de Mars, d'Abfinthe, de chas cun un gros. 
\&o des caufes de la Fiévre. 279 Ces Opiates faites arec le Sirop d'Ármoife, \& prifes à a quantité de deux gros par jour, foir \& matin, avec la boiffon de 2uinquina, font de tres-bon ufage dans les giévreslentes; la Fiévre hecique n'elt pas fi facile à gueir, fur tout quand elle a fair peaucoup de progrés, \& que e malade eft tombé dans une naigreur extréme. Il faut qut it lonc y remedier autant qu'il lessese fft poffible dans fa naiffance; ette Fiévre eft caufée par un cide âcre \&\& coagulant qui lomine dans le fang, c'eft ourquoy le lait eft prefque oûjours nuifible dans cette naladie, parce que les acides e coagulent \& luy fervent de refure : rien ne convient donc mieux que les remeder qui morcifient les acides com. 


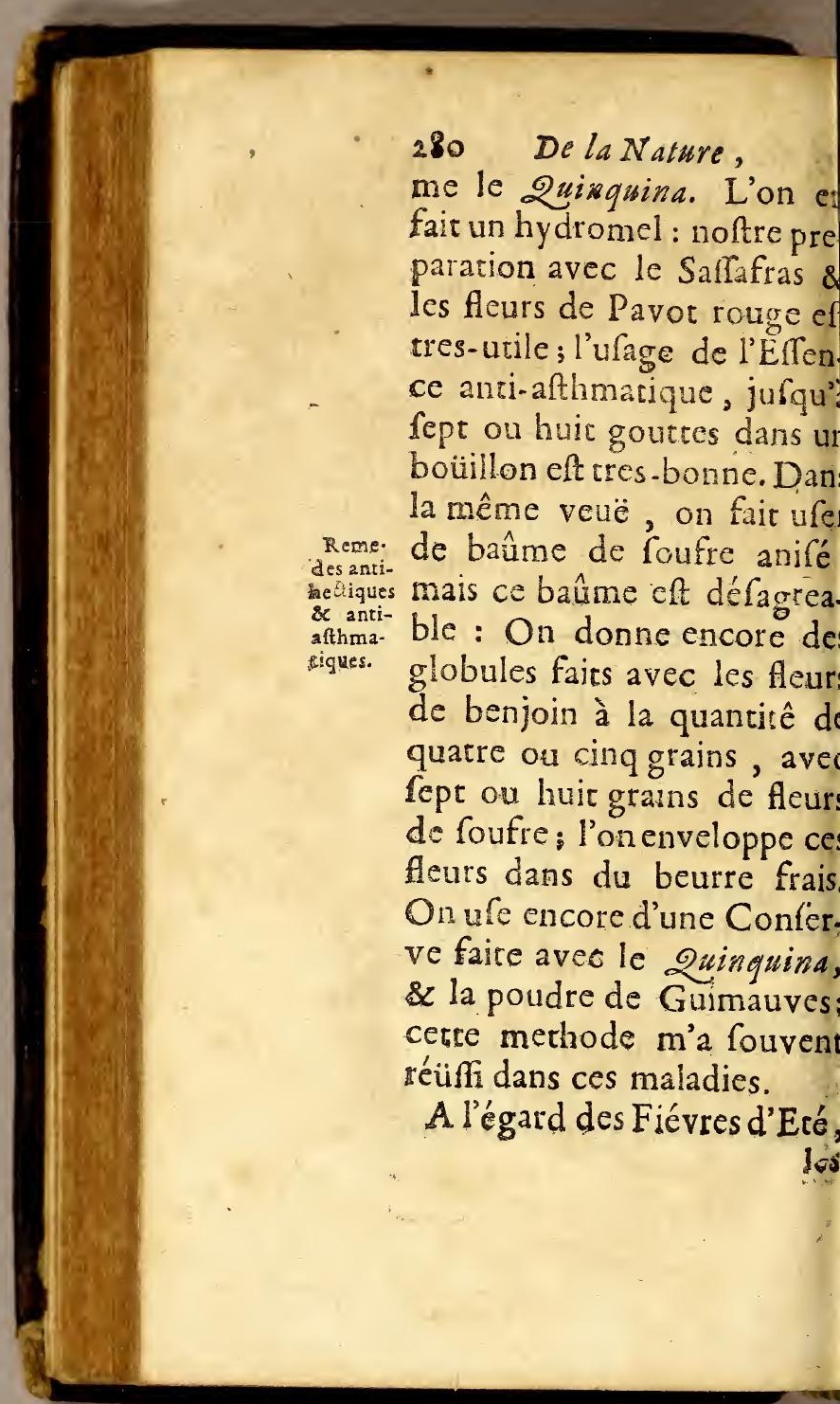


du des caufes de la Fiévre. 28 in os remedes diaphoreciques 'y font pas coûjours neceffaies, fur tout lorfque la tranfiration eft for libre, \& que is humeurs font en grand louvement, les plus legers urgatifs fuffilent; l'eau de Dans los Fiévres d'Eté les diaphoretiques peu neJaffe, ou la Caffe diffoute ans du petit-lait purgent aiment, la Manne \&z la Caffe puiillies enfemble legereent purgent fort bien; les hux de veau $\&$ de pouler font ors fort utiles, parce qu'els tiennent le ventre libre, quielles ont une onctuofité fi émouffe la pointe des hueurs bilieufes \& piquantes. ans cette même veuë on onne des émulfions faites ecles femences que l'on apU? 28 \& 83 effet des multón :lle froides; on farcit fort opos le corps d'un poulet ; ces femences; elles on

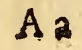


282 De la Nature, une huile douce qui calme 1 noze. mouvement trop impetueu - vec le des humeurs, les rend cou Melow lantes, les precipite \& les em pêche qu'elles ne s'élevent Ia tefte : au lieu de quatre fe mences froides, dans la fai fon des melons, jemplis corps du poulet, de la grain $\&$ de la chair de ce fruit, $e^{\prime} e$ une efpece d'apozeme laxati qui fait fort bien dans les Fís vres bilieufes.

11 faut remarquer qu'il y desFiévresoù la rranfpiratio eft quelquefois i forte, qu les efprits \& les foulfres s'es halent \& fe diflipent: c'e pourquoy il eft neceffaire $d$ les retenir par des boiffons ac vlage des, comme la Limonade, I monade eaux de cerifes, de verjus, l 2. des Doiflons rafrầshidătes

potions faites avec les aigr de foulfre \& de virriol. 0 
do des canfes de la Ficoure. $28 \mathrm{~g}$ doic cependant ufer de précaution dans l'ufage de ces remedes, de peur d'cmpêcher les crifes \& les fontes. des humeurs qui caufent les. Fiévres.

Il faut encore obferver que fi l'ufage des acides eft utile pour calmer le mouvement trop imperueux des humeurs qui s'élevent à la tefte \& y caufent des douleurs importunes, \& pour déterminer le cours de ces mêmes humeurs par les voyes inferieures; fou. vent il eft incommode par les befanteurs d'eftomac, par les mastersis. gonflemens \& par les coliques dont les acides font la caufe : ces mêmes acides produifent auffi quelquefois des tenfións dans la veffie, c'eft pourquoy il eft necellaire de les adoucir : Voicy une pas des Ací: dess.

des.

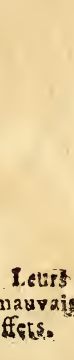




\section{Dela Nature,}

tion qui m'a paru fort conve. nable dans ces occafions.

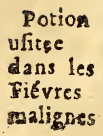

Prenez de l'eau d'Alleluya, deux onces.

De l'eau de Chardon-benit, deux onces.

Du Sirop viclat, une once. Du Seld'Abfinthe, demi-gros. Sur la fin j'y ajoûte quelgues gonttes d'esprit de Soulfre on de vitriol, pour donner une legere acidité.

Je donne deux fois le jour cetre potion, \& par le different mélange de ces fels, la fermentation eft avancée, \&z la Fiévre terminée par une legere tranfpiration.

Ainf l'art de guerir les Fié. vres confifte principalement dans la methode de procurer Ia tranfpiration quand elle n'eft pas libre, \& de la calmer quand elle cft violente 
ódes caufes de la Fiérure. 285 Pendant les grandes chaleurs de l'Efté, \& dans les climats chaud's, Jes boiftons rafraîchiffantes font fouvent utiles, \& on gueric les Fiévres en beuvant à la glace, parce que ces boiffons arreftent la fermentation, \& calment le mouvement trop imperueux des humeurs, \& l'on ne doic pas craindre que les efprits foient fixez ou condenfez, parce que la chaleur de l'athmofphere eft affez forte pour conferver leur mouvement, \& entretenir la tranfpiration; Mais il faut prendre garde préass que dans l'ufage des boiffons rafraîchiffantes l'eftomac \& les premicres voyes foient dé. gagées d'humeurs impures, prendre dansl'us: rage des boiffons rafrâेchilätes. autrement ces boiffons cauferoient des coliques, des gổntemens, des indigeftions, \& A 2 iij. 
286 De la Nature, beaucoup d'autres accident tres-dangereux, comme je l'ay cy-devant remarqué.

Il eft donc neceffaire d'ufer de grande précaurion dans l'adminiftration des boiffons

Torfque la tranf. piration n'eft pas excesinve acides $\&$ rafraîchiffantes. Voicy à mon fens ce qui peut fervir de regle; Si la tranfípiration n'eft pas excoflive, s'il paroift qu'il y ait beaucoup d'efprits dans la mafle du fang, ce que l'on connoiftra par l'étar du malade, le pouls fera fort, les fonctions feront libres, alors on peut fe fervir feurement de boiffons acides telles que nous les avons propolées: \& il y auralieu de croire queles premieres voyes ne communiquant point à la maffe du fang de mauvais fucs, les efprits qui y auront efté recenus par les boiftons 
ódes caules de la Fiévro. 287 acides, digereront aif'ement les humeurs cruës \& indigeftes qui eftoient la caule de euand la Fievre. Mais fi la tranfpi- elle effive ration eft trop forte, s'il y a des diffipations d'efprits, ee qui fe maniferte par la foiblef: fe du pouls, par l'étar languirfant du malade, quelquefois par des taches livides 8 pour- Eieres prées qui paroiffent fur la malignos peau, ceft là le caractere des Fiévres malignes: alors les. boiffons acides \&z rafraîchiffantes font tres-dangereures, \& les potions cordiales \& $\mathrm{f}$ piritueufes font de neceflité abfoluë.

Les eaux de Scorfonaire, de Reine des Prés, de Mille-pertuis, de Scordium, de Melifle font tres-bonnes; on en fait des potions avec les Sirops d'cillets, de grenade. 
288 De la Nature,

\&c. Les confections d'Hiacinthe \& d'Alkermes, l'eau Theriacale, l'Eau-de-vie, l'eau de Canelle, avec les fels volatiles de Vipere ou de corne de Cerf mếlez à la quantité de fept ou huit grains, dans quatre ou cinq onces d'eau de Scorfonaire, \& fept ou huit gouttes d'efprit de Que le Soulfre ou de Vitriol, font mélange des ef. prits acides a vec les fels volatiles eft utile dans les Fiévies malignes un tres-bon effet dans les Fiévres malignes, fi on reïtere la potion deux ou trois fois le jour. Le mélange de ces efprits avec les Sels Volatiles paroiftra peut-eftre fe contredire, parce qu'ils. font oppo$\mathrm{fez}, \& z$ excitent une fermentation; mais il eft fort utile dans cette occafion, parce que les efprits Acides donnent aux Sels Volatiles une qualité de Sels effentiels, par laquelle 
do des canfes de la Fiévre. 28 , laquelle ils deviennent plus doux , \&z portent moins à la refte; de tous les Sels Volatiles, celuy de fel Armoniac me paroift le meilleur.

On fait auffi des potions avec les eaux Cordiales, comme de Scorfonaire ou de Meliffe;

$\&$ avec les eaux f piritueufes, comme l'eau Theriacale ou de Canelle, \& le Sirop d'œillets: Ces potions données fre. quemment \& à cueillerées, font un tres-bon effet dans les Fiévres malignes. On y ajoûte fouvent, \& fort à propos, a teinture d'Opium.

Voicy une potion qui m'a paru forr utile. Ie donne qua- Potiars re ou cing grains de Tartre urile dás Emetique fur huit onces d'eau vres ma te ligats de Scorfonaire. J'en fais prendre des cueillerées d'heure op beure : ce remede punge 


\section{De la Nature,}

doucement les matieres impures qui entretiennent les Fiévres malignes, \& détruic par là les fermentations vicieufes; Il eft fort convenable aux enfans qui ont des vers; on leur fair encore boire de l'eau de Mercure. Voicy une boiffon que j'ay crouvée tresbonne dans ces occalions.

Pour les entars gui ont

des ress.

On fait une decoction de raclure de corne de Cerf qu'on mêle avec un tiers ou un quart de vin blanc, \& quand on veut donner à boire à l'enfant, on trempe un feru dans de l'huile diftilée de petites Oranges vertes, $\&$ on en met deux ou trois gouttes. Ce Cataplafime eft encore excellent contreles vers.

Cetapla:- ceufité contre les rers

Prenez un gros oignon rouge ou blanc, creufez-le \& mertez dans le creux un gros d'a; 
du des caufes de la Fiéure. 291 nis, un gros de graine de $T_{2}$ naifie qu'on appelle dans les Difpenfaires femen contra; Aprés y avoir ajoûté vingtquatre grains de bon fafran en poudre, recouvrez le creux de l'oignon avec la piece que vous avez ôtée, \& l'enveloppez de papier ou d'étouppes pour le faire caire dans les cendres chaudes, \& quand il fera cuit vous le tirerez; ôtez les groffes peaux, \& pilez le refte dans un mortier : quand il fera bien pilé, mettez-le dans une petite terrine fur un feu moderé, \& y mêlez demi-once de beurre frais, un gros \& demi de bonne Theriaque, \& autant de Therebentine de Venife: Da tout bien mêlé enfemble pendant un peu de tems fur un petit feu, vous en ferez un Cataplafme que vous appliquerez fur le nombril de la largeur de la pomme de la main, \& le ecnouvellerez tous les jou: $\varsigma_{\text {. }}$

$\mathrm{Bb}$ ij 
29. De la Nature,

La Theriaque, le Diafcordium, les poudres de Viperes \& de la Comteffe de Kent, fonc encore de tres. bons remedes dans les Fié. vres malignes.

Qiic les remedes fyiritueux ne font point dangereux dăs les Fiévres maNignes.

Les vins de Bourgogne, d'Erpagne, de Canaries, \&zc. font auti de tres-bon ufage; \& il ne faut pas dire avec le peuple, ni comme les Medecins vulgaires, que ces re medes font chauds, qu'ils donnent rop de mouvement aux humeurs, \& caufent des tranfports au cerveau, puifque, comme nous l'avons dit ailleurs, l'épuifement des efprits $\&$ les forces diflipées ne çauroient eftre reparez que par des chofes fpiritueufes; \&z l'experience m'a appris que les remedes fpiritueux, au lieu d'augmenter le mouve 
¿ des canfes de la Fiérre. 293 ment des humeurs 82 les fermentations, les calment, s'ils font difpenfez \& adminiftez, de forte qu'ils deviennenc fupericurs $\& z$ dominans dans la maffe du fang; nous fçavons que lorfqu'un Acide \& 2 un Alkali fermentent enfemble, fi on ajoûte de l'Alkali, la fermentacion ceffera bientoft, parce que l'Acide fera abforbé par l'Alkali; la même chofe arrivera fi on augmente l'Acide, mais il fe fera une coagulation dangereufe : d'où il eft évident que les Fiévres ne fe gueriffent que lorfque la chaleur natu. relle ou les efprits ont digeré, ou diffout les matieres cruës \& indigeftes.

Dans l'hypothefe commu ne l'on aura peine à croire qu'un homme óchauffé qui

$\mathrm{B} b$ iij 
294 De la Nature,

boit à la glace, puiffe tomber dans une pleurefie ou dans une Fievre ardente, \& l'on fe perfuadera aifément que fi cet homme boit de l'Eaude-vie, il fe brûlera les entrailles \& s'attirera une Fiévre chaude. Cependant tout Exem- le contraire arrive : j'ay veu
ples pous confirbons ef- aprés de longues marches, fe fers des: trouvant dans un épuifement
semedes, fpititheux. extréme, \& mourane de foif, arriva fur le bord d'un ruiffeau bourbeux, rempli de cadavres; l'eau de ce ruiffeau luy ayant fait horreur, il demanda de l'Eau-de-vie, \&c en beut une chopine d'un feul rrair, aprés quoy il s'endormit, \& $s^{2}$ 'eveilla auff frais $\&$ aufi vigoureux que s'il s'étoit repofé toute fa vie. Mr. de Monginot m'a af- 
od des caufes de la Fiévre. 295 furé qu'il avoit veu un homme ayant la gangrene fi fore à la jambe, que fuivane l'avis des Medecins \& des Chirurgiens on devoit lay couper le lendemain. Er pour le difpofer à fouffrir cette operation, \&z afin de calmes les humeurs, on luy avoic ordonné un Julep ou une émul. fion qu'il devoit prendre la nuit; mais la garde s'étant endormie, \& enfuite éveillée en furfaut fe méprit, \& donna au malade une phiole pleine d'Efprit de vin, au lieu de fon émulfion: il eft vray qu'il fentir beaucoup de chaleur pendant la nuit : mais lors qu'on vine pour luy couper la jambe, les chairs gangrenées fe trouverent feparées des chairs vives, \& enfin le malade guerit.

Bb iiij 


\section{De la Nature,}

Nos Livres font pleins d'hifoires qui nous apprennent que plufieurs malades de Fiévres malignes $8 z$ de pelte, ont efté gueris par des boiflons chaudes \& fpiritueufes. Il faut donc convenir que les remedes fpiritueux \& vo. latiles font tres-necefraires dans les Fiévres malignes $8:$ dans les épuifemens, \& qu'il ne faut pas eftre timide à s'en fervir. Souvent les meilleures remedes font infructueux $\&$ inutiles, parce que l'on eft rop refervé fur leur ufage.

Il y a encore des Fiévies malignes qui viennent du défaut de tranfiration, comme celles qui accompagnent Fes de la la Rougeole \& la perice V $\mathrm{V}$ ero. petite verole, ac. 1e. Quelques Aureurs croyent que ces Fiévres font caufées par les impurerez ou du fang 
\&o des caufes de la Fiévre. 297 menftrual, ou de la nourriture que l'enfant reçoit dans le ventre de fa mere; ce fenciment ne paroîtra peut être pas mal fondé fi on fait réflexion que la plûpare des femmes groffes ont prefque toûjours l'appetic déreglé, qu'elles fe nourrifient mal, \& que d'ailleurs ciles n'ont pas la refpiration fort libre, c'elt-à-dire que l'air \& la matiere fubtile font trop embarraffez, \& n'ont pas le mouvement neceffaire pour bien rarefier tous les fucs nourriciers qu'elles fourniffent à leurs enfans: Ainfi ces enfars font nourris $\&$ formez de fucs groffiers \& vifqueux qui ne laiffene pas un com. merce libre à la chaleur ras turelle, \& à la matiere fubtile. A quoy il faut ajoûter que les enfans vivent de laj. 


\section{De la Nature;}

tage qui épaiffit le fang, \& le rend tres-fufceptible de coagulation.

Pour confirmer ce raifonnement, j'ay obfervé $1^{\circ}$. Que les enfans qui ont mangé peu de boüillie, qui boivent un peu de vin, \& qui font beau-

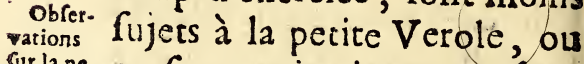
coup d'exercice, font moins sur la pe. en font moins incommodez, sole. que ceux qui vivent d'une maniere oppofée; $\&$ je fuis perfuadé que fi on rafraîchic trop les enfans en Efté, on les prive du benefice de la faifon, en interceptant les humeurs fuperfluës qui croupiffent dans leurs veines, \& les parens ont fouvent le chagrin de les voir mourir de la petite $V$ erole en Hyver. $2^{\circ}$. Que les enfans qui ont beaucoup de gale font moins 
¿d descanfes de la Fiévre. 299 fujets à la petite Verole, $\&$ quil y a fouvent du peril à guerir la gale aux enfans.

$3^{\circ}$. Que les femmes grolfes qui fone vigoureufes, qui fe nourriffent d'alimens chauds \& fucculens, \& qui accouchent en Elté, ont des enfans moins incommodez de 1 petice Verole.

$4^{\circ}$. Que ceux qui font d'un temperament chaud, qui font beaucoup d'exercice, \& qui ufent d'alimens \& de remedes chauds, font peu fujets à la petite Ve. role.

Je croy que l'on fera convaincu que ces obfervations font juftes, fi l'on fait réfexion que la petice Verole eft rare \& peu dangereufe dans les climats chauds; que les enfans courent les ruës 
hemede contrela petite Tonit.

300 De la Nature,

en Efté avee cette maladie \& qu'en Hyver elle eft fou vent mortelle; qu'elle ef tres-commune 22 tres-funefte dans les paîs froids, \& beaucoup plus en Angleterre qu'en France.

Cela fuppofé, il y a bien de l'apparence que la tranfpiration eft le meilleur remede à ces maladies; dans cette veuë on fait des potions cordiales avec des eaux fpiritueufes données fouvent $\&$ aे cueillerées, comme nous avons dit cy-deffus; Et il ne faut pas s'imaginer qu'il $y$ ait icy une indication contraire à celle des Fiévres malignes qui font caufées par l'excés de tranfpiration, puifque dans celles-là fi les efprits font diflipez, il fawt les reparer.au lieu que dans celles: 
o des canjes de la Fiérure. 301 cy eftant enveloppez dans des matieres craffes, \& liez par des acides dominans, il faue développer les efprits en détruifant les acides: ce qui ne fe peut faire qu'arec des remedes fpiricueux. La faignée eft un excellent remede contrela perite $V$ erole lorfqueles puitules ne fortent pas faci- En quet ment, qu'il y a beaucoup de casla fai. Fiévre avec difficulté de ref- vientà pirer, mais elle eft dange- verite reufe \& fouvent mortelle aprés l'éruption. Les poudres de Vipere, \& de la Comtelfe de Kent font encore d'un bon ufage.

Les Anglois donnent fouvent de l'Opium dans cette maladie jufqu'à trois ou qua- Anglois fois par jour, \& avec fuccés; dans ces parce que ce remede donne du repos, \& facilivel'éruption

Opisa ufité? majadice 
302 De la Nature,

Cette methode pourroit fur. prendre ceux qui croyent que l'Opium fufpend le mouvement des humeurs, mais on ne doute plus qu'il ne foit fudorifique. Dans cette penfée je croy que la Tifanne de 2uizaquina feroit tres-utile; javouë que je ne l'ay pas experimenté, mais comme ce remede mortifie les acides \&z rarefie le fang, je ne fçaurois m'empêcher, dans la prevention où je fuis pour le

Eifanne. de Quinquina bonne dans la petite Korole.

2uinguina, de penfer qu'il feroic tres-utile en cette occafion, fil'on en faifoit une Tifanne avec l'eau de Scorfonaire, la raclure de corne de Cerf, sz le faffafras.

Il faut remarquer que les Fiévres malignes font prefque toûjours accompagnées de vomiffemens ou de nau- 
du des canfes de la Fiéure. $3^{\circ} 3$ f'ées, \& qu'alors on ne doic pas eftre timide à faire vomir ou à purger. En cela je fuis tres-oppofé à $\mathrm{M}^{s}$. Deffe, qui donne pour regle infaillible, de faire toûjours preceder les fudorifiques aux purgarifs dans les maladies aiguës; \& il me permettra de luy dire contre l'infaillibilité defa regle, que iy trouve deux inconveniens affez remarquables : Le premier eft, que Incos: veniens contre la pratique de Mr. Deffe lorfque l'on donne des remedes fudorifiques, s'il y a dans l'eftomac $\&$ dans les premieres voyes des maurais fucs, les fudorifiques refteront dans l'eftomac, y cauferont des naufées ou quelques vomiffemens imparfaits qui fatigueront le malade : Ce fait eft confirmé par l'experience. L'autre inconvenient eft que 
304 De la Nature,

fi les fudorifiques paffent, ils feront affoiblis \& alterez par les fucs impurs qu'ils rencontreront, \& ils en introdui. ront une partie dans la maffe du fang; ce qui y caufera de nouveaux troubles.

Il êt donc préalable de netoyer les premieres voyes, afin que les fudorifiques y puifient paffer fans rien perdre deleur vertu., \& qu'ello foit portée toute pure dans la mafle du fang : Cette pratique eft fondée, à l'égard des purgatifs, fur l'autorité d'Hippocrate, qui nous ap. prend dans l'A phor. I0. liv. 4 . qu'il faut purger dés le premier jour dans les maladies aiguës, 2 qu'il y a du peril differer.

Je diray en paffant que la rerenue dans laquelie on a efté jufqu'icy. 
dos desufes de la Fiévre. 305 jufqu'icy, a introduit dans la Medecineles Avanturiers, les Charlatans \& les Moínesipendant que les Medecins temporifent \& deliberent fur dess regles incercaines, un Avancurier donne l'Emetique, \& le malade guerir, \& cela donne à l'A vanturier un titre de $\mathrm{Mc}$ decin qui le met au deffus de toutes les Facultez.

La pleurefie eft une maladie aiguë toûjours accompagnée d'inflammation, ou de difpofition inflummatoire de poitrine ; ce font des fymptomes qui paroiffent incompatibles avec les purgatifs \& avec les vomirifs; cependant il y a des conjonctures où ils font de neceffité abfoluë dans cette maladie, \& ceux qui donnent d'abord des fudoriGques le font tres-fouvene

C e 


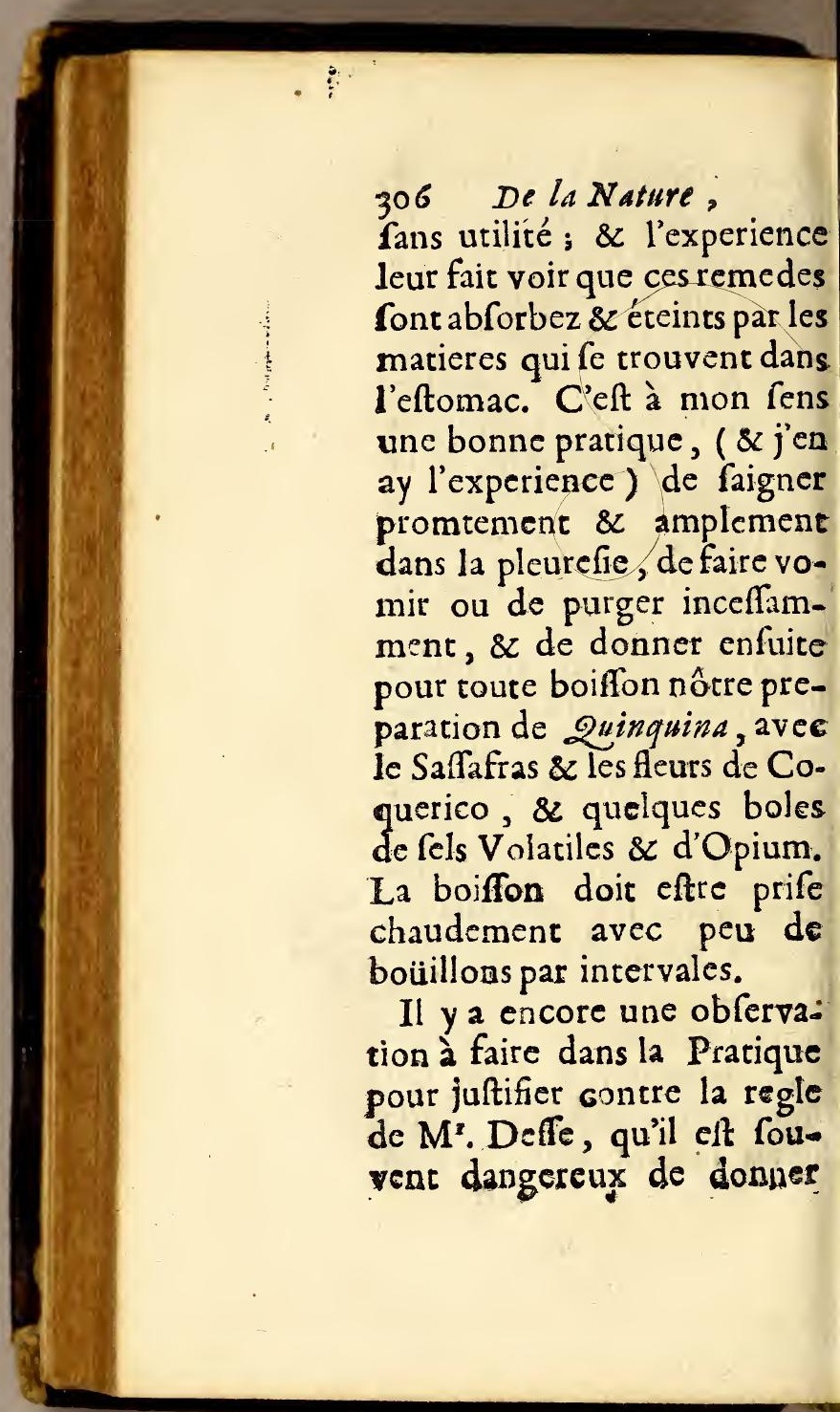


ordis caufs de la Fiérre 307 des remedes fudorifiques lans avoir fait preceder les purgatifs; C'eft que on donne de l'Opium en Opiate ou en teinture, avec les efprits ou fels volatiles, qui fans contredit font fudorifiques, \& qu'il y aic dans l'eftomac $\&$ dans les premieres voyes une bile impure ou d'autres mauvais fucs, on caufe prefque toûjours des delires \& des tranfports au cerveau. A peu prés comme fi l'on donnoit deux ou trois verres de vin Mr. Dese

pur à une perfonne à demiyvre, ce qui acheveroit de l'enyvrer. Or je pole en fait, que fi cette perfonne avoic $l^{2} e$ ftomac bien net, deux ou trois verres de vin ne feroient pas capables de luy troubler le cerveau jufqu’à le mettre en defire.

$$
\text { C c ij }
$$




\section{De lo Nature,}

J'ay doncrairon de m'éton. ner de ce que $\mathrm{M}^{\mathrm{r}}$. Defle qui a tane veu de malades, \&\& fur tout dans les Hôpitaux des places de Guerre, n'ait pas remarqué que les fudorifiques ne devoiene pas toûjours prececeder les purgarifs dans les maladies aigues. J'avouë que j'avois eu du plaifir de voir dans les Ouvrages de cet Auteur quelque conformité avec nofte bypothefe, \& même avec nos expreffions; mais comme il s'écarte de nos principes, il me pardonnera fi je ne m'accommode pas de fes maximes, \& fi je prends la iberté de donner icy quelques avis generaux pour la guerifon des malades des Armées \& $z$ des Hộpitaux.

Premierement je regarde zous les Hôpitaux en general, 
¿o des caufes de la Fiérre. zo9 à l'egard des malades, comme des Temples confacrez à la pefte où à la mort; \& je conçois que rien n'eft plus préjudiciable à l'état que de ramaffer dans un feul lieu rout ce quil y a de puant, de fale, d'infirme 82 de corromObretpu dans une Ville \& dans une Armée. D'ailleurs on ne fçauroit difconvenir qu'il ne foit tres-dangereux à un malade d'efte parmi des malades; \& fi la fupputation d'un: curieux Anglois qui a remarqué qu'il meurt à proportion: tous les ans trois mille malades dans l'Hôtel-Dieu de Paris, plus que dans l'Hôpital de la Charité, eft jufte, n'y a-t'il pas lieu de croire que ces 3000 . malades ne mew rent qu'à caufe du mauvais air, 8c de l'incommodité qu'ils 
310

De la Nature,

fouffrent à l'Hôtel-Dieu, \& que pour fauver la vie à ce malheureux, il faudroit mettre cetce Maifon à l'inftar do l'Hôpital de la Charité; la chofe n'eft peut-être pas fi dif. ficile à executer qu'on pour. roir s'imaginer ; \& je fuis perfuadé qu'elle n'augmenteroit pas la dépenfe de la Maifon, fans parler de ce qu'on doit faire pour fauver la vie à 3000 perfonnes dont la perte regarde l'Etat; \& va à prés de trois millions, à lés évalüier feulement fur le pied quon évaluë les Efclaves d'Alger. J'ay dit que cette reforme n'augmenteroit pas la dépen. fe de la Maifon, \& je crois même qu'elle en feroir diminuée confiderablement; il eft vray qu'il feroir neceffaire d'augnenter le nombre des 
ou des caufes de la Fiévre. $31 \mathrm{I}$ Medecins \& des Chirurgiens, mais la dépenfe qu'il faudroir faire pour cela feroit bien compenfée par la prompte guerifon des malades : car il y en a peu qui ne gueriffent en huit jours s'ils font bien fecourus, au lieu que ceux qui meurent, languiffent quelquefois des années entieres, ce qui produit une dépenfe infinie.

A l'égard des malades des. Armées, j’ay remarqué qu'on abus eđé: les envoye prefque tous à cernant l'Hôpital d'où il n'en revient dies gueres; car il eft certain que més. les petites maladies y deviennent grandes, tant à caufe du mauvais air, que de la mauvaife adminiftration des remedes $\&$ des alimens. Il y a des Chirurgiens dans les Regimens qui encore qu'ils 


\section{2 \\ De la Nature,}

foient payez par les Officiers; n'en ont pas plus de foin des Cavaliers \& des Soldats; ils les font conduire dans les Hôpitaux des Villes prochaines pour la moindre indifpoficion. Il faut encore obferverque les Chirurgiens, quoy que tres habiles à pancer des playes oz à faire des operations, ne font pas fort intelligens dans la connoiffance des maladies internes: cepiendant elles font fort frequentes dans les Armées, par les fatigues continuelles que fouffrent les Troupes, $8 z$ par

Caltes la mauvaife nourriture dont
des maladies d'As. ¿née. elles ufent; elles boivent au premier ruifteau, à la premie$x \in$ fontaine, au premier puits qu'elles rencontrent, \& man. gent tous les fruits qu'elles trouvent de quelque qualité qu'ils 
¿d des caufes de la Fiévre. 313 qu'ils foient, c'eft là la fource de tous leurs maux : ainlí le vray moyen de les guerir, eft de leur netoyer l'eitomac \& de le fortifier. J'ofe affurer que dans la derniere Campagne d'Allemagne, \& $\mathrm{M}^{\mathrm{r}}$. l'Intendant le cerrifiera, vois l'honneur de loger chez liiy, j'en ay empếché un grand nombre d'aller à l'Hôpital, \& méme de la Maifon du Roy; je les ay rous gueris en tres-peu de tems dansleurs tentes: Ils y font beaucoup mieux que dans les Hôpitaux, \& les décampemens ne font pas fi incommodes qu'on penfe ; une Armée ne fait gueres plus de deux ou trois lieuës, $\&$ on guerit un malade en chemin faifant avec du Quinquirsa, du Vin, de l'Eau-devie, de la Theriaque, \&c. On le

Dd 
314 De la Nature, purge avec du Diaphonic, on le fair vomir avec du Tar: tre Emetique, on a encore Reme- des electuaires purgatifs fort les ma- commodes dans ces occaladies d'A $A$ frans; Pap cette methode, avée. a la bonne nourricure \& le repos, un Soldat eft bientoft rétabli : au lieu que fi on l'envoye à l'Hôpital, fa Cam. pagne eft faite, il y meurt, ou il y mene une vie languiffance. Il eft vray que fur la fin du mois de Seprembre, \& pendant le mois d'Octobre les Troupes font fort incommodées dans le Camp à caufe des mauvais tems; mais il vau. droit bien mieux, s'il eftoit poffible, répandre les mala des dans les Villes frontieres que de les amaffer dans un Hôpital. Je le repete, les Hôpitaux font des Temples con- 
od des caules de la Fiévre. 3is facrez à la pefte ou à la mort: l'on y faigne les malades, \& on leur donne des Tifannes rafraîchiffantes comme à de bons Bourgeois, fans faire réflexion que prefque toutes leurs maladies viennent de fatigues, d'épuifement ou de mauvaife nourriture, \& $q$ que le repos \& les bons alimens leur font plus neceffaires que les remedes rafraîchiffans.

Certe digreffion m'a un peu écarté de mon chemin, je prie $M^{*}$. Deffe qui en 2 efté l'occafion, d'eftre perfuadé qu'il n'entre point d'efprit de Cririque dans la liberté que jay prife de l'apoftropher: jofe même efperer que s'il trouve peu de folidiré dans mes raifons, \& qu'il n'y ait pas affez de certitude dans mes experiences, il me fera

D d ij 


\section{De la Nature,}

l'honneur de m'en avertir.

Voilà fuccinatement ma methode de guerir les Fiévres, elle eft fondée fur deux indications generales qui fe rapportent à la purgation $\&$ à la tranfpiration.

Par la purgation la matiere de la Fiévre elt évacuée.

Jay érabli pour maxime certaine de purger dés le commencement des Fiévi'es autanc qu'il eft polfible; cette Abregé maximefe doic pratiquer dans de ma Methode. toutes les Fiévres, mais principalement dans les continuës \& en Efté, parce qu'alors les humeurs eftant en plus grand mouvement, elles font portées avec rapidité dans les veines où elles gâtent le fang: d'ailleurs les efprits fone diffipez par la tranfípiration exceffive, c'eft pourquoyil eft ne- 
do des caufes de la Fiévre. 317 ceffaire de netoyer les premie. res voyes, afin de pouvoir mettre en ufage les acides \& les boiflons rafraîchiffantes pour calmer le mouvement trop impetueux des efprits.

Car enfin fi des humeurs qui croupiffent dans les entrailles font la matiere qui compofe toutes les Scenes tragiques d'une maladie longue, dangereufe \& fouvent mortelle, peut-on difconvenir que ce ne foit une précaution heureufe \& neceffaire d'évacuer promtement ces humeurs par des purgatifs bien concerrez? J'ofe affurer que cette pratique m'a toûjours paru feure $\&$ facile.

Il y a moins de peril à differer la purgation dans les Fiévres intermittentes. A l'égard de la tranfpira. $\mathrm{Dd}$ iij 
318 De la Natare, cion,j'ay propolé deux moyens pour la procurer à fçavoir, la faignée \& les remedes dia. phoretiques.

Par la faignée la circulation du fang eft aidée, le reffort de l'air eft plus libre : de forte que la matiere fubtile \& les efprits agiffant fur les hu. meurs, les digerent, les rarefient \& font tranfpirer les fuperfluitez.

Les remedes diaphoretiques fourniffent à la maffe du fang des parties fpiritueufes \& fulfureufes, qui eftant affociées à la chaleur nazurelle ou aux efprits, agiffent de concert pour cuire, digerer $\&$ diffoudre les maticres in digeltes.

Les diaphoretiques font neceffaires, lorfque par la faignée \& par la purgation les Fiévres ne font point gueries, 
o des caufes de la Fiérre. 3 I \& qu'il ne s'eft pas faic de tranfpiration fans laquelle is n'y a point de guerifon parfaite.

Les Remedes diaphoretiques confirment noftre divifion des Fiévres, \& démontrent quil y en a qui dépendent de la difpofition peu fpiritueufe du fang : car comment deviner d'où vient une Fiévre quarte à un homme qui a efté beaucoup purgé , à qui on a donné des vomitifs, $\&$ qui d'aitleurs mange \& digere bien, \& qui a les entrailles en bon étar, fi on ne fuppofe avec nous, que le fang de cet homme eft dan une ques fon difpofition acide $\&$ peu fpiri- ge tueufe, puifque les remedes diaphoretiques qui mortifiene \& chaflent les acides, \& qui rétabliffent la chaleur \& les ef

D d iii). 


\section{De la Nature,}

prits dans la maffe du fang, lont febrifuges; \& qu'enfin ceux qui s'en fervent, avoüent quils en deviennent plus forts \& plus vigoureux. Er comme le Quinquina eft le febrifuge dont je me fers principale ment, il faut à prefent parler de ce remede, $\&$ des experiences que j'en ay faites, afin de le difculper de tous les maux dont on l'accufe, \& de délabufer le public, s'il eft polible, de cette erreur groffiere, qui eft encore reçû́e de quelques Medecins, que le 2 uinquina fixe les humeurs qui caufentes Fiévres.

$\mathrm{M}^{\mathrm{r}}$. de Monginot m'en a ouvere le chemin dans fon - 2uin- Traité de la guerifon dss Fiémortifie vres par le Quinquina : car
les aci. des. cet Auteur mayant fait voir que ce remede gueriffoir les 
ou des caufes de la Fiérure. 32 I Fiévres en mortifiant les acides, j'en ay tiré cetre conclufion, que les acides dominans dans le fang ou dans le chyle, devoient eftre neceffairement la caufe des Fiévres; \& pour efte pleinement convaincu que le $Q$ uinquisa mortifie \& détruic les acides, bien loin de les fixer, j'en ay fait de nouvelles experiences fur du fang, \&z fur des liqueurs analogues au chyle : pour cela j'ay pris deux phioles de verre que j'ay échauffees mediocrement, jay receu dans Exper riences qui jufti: fient qus le Quinquina ne fixepoint les acidos. chacune de ces phioles environ quatre ou cing onces de fang de cochon fortant des veines; dans l'une j'avois mis deux cueillerées de vinaigre, $\&$ dans l'autre j'avois mis environ autant de vin de 2 win2uina tel qu'on le donne au. 


\section{De la Nature,}

Ie 2uin- febricitans; j'ay plongé à quina avec lo fang,

l'inflant ces deux phioles dans un pot d'eau chaude, afin d'avoir une chaleur proportionnée à celle du fang; j’ay remarqué peu de tems aprés, que le fang de la phiole dans laquelle $j$ 'avois mis le vinaigre eftoit entierement coagulé d'un rouge fort brun tirant fur le noir, \& que le fang de la phiole où j'avois mis le 2uinquina eftoit fluide $\&$ d'un beau rouge, approchant de la couleur du fang des arteres. J'ay reitieré cette experience plufieurs fois

- fur le fang d'autres animaux, \& même fur du fang humain, en y mêlant l'infufion du 2uinquina avec les mêmes précautions, \& jay toûjours remarqué les mêmes effets.

J'ay encore eu la curiolité 
eor des caujes de la Fiévre. 323 de faire ces experiences fur du lait, voici comment : J'ay lait, pris du lait fortant du pis de la Vâche, j'en ay mis dans trois écuelles; dans la premie. re j’ay délayé de la preffure, j'en ay délayé auffi dans la feconde écuelle, mais j'y ay ajoûté du vin de 2 uinquina: $\&$ dans la troifieme j'ay mis du vin de Quinquina tout feul. J'ay à l'inftant mis ces trois écuelles dans un four mediocrement chaud: peu de tems aprés j'ay trouvé dans 12 premiere écuelle un fromage blanc\& mol, avec quantité de petit-lait; dans la feconde, j'ay remarqué que la feparation des parties du lait fe faifoit plûtolt que dans la premiere, mais qu'il y avoit peu de fromage qui eftoit plus fec \& plus ferme, \& $\mathrm{da}=$ 
324 De la Nature;

vantage de petit-lait; $\&$ dans la troifiéme, je n’ay apperçû aucune apparence de coagulation.

Le 2uin- Je ne me fuis pas contenté quina
ges ếche de voir par ces experiences
les ca. les coa- que le Quinquina empêchoit la coagulation, jay voulu effayer s'il pourroir diffoudre celle qui feroir déja faite: Pour cet effet j'ay mis dans la premiere écuelle du vin de Quin. quina, le fromage en a efté diffous en partie, \& eft devenu comme celuy de la deuxiéme écuelle : certe experience m'a fait nâ̂tre le deffein d'examiner l'effet que le Quinguina pourroit faire fur le fang coagulé; pour cela j'ay mis du vin de Quinquine dans la phiole où eftoir le fang coagulé avec le vinaigre, le fäg n'en a reçû aucune alteration, 
¿o des caufes de la Fiévre. 325 \& j'ay retiré le vin de 2 uinquina avec le goût \& la couleur qu'il avoit auparavant. J'arois encore receu du fang dans une phiole, lequel je laiffay coaguler à l'air fans aucun mélange;j'ajoûtay tout de mê. me à celuy-cy du vin de 2 uinquina, il y perdic quelque chofe de fon goût, \& parut plus broüillé que celuy que Javois mis fur le fang coagulé par le vinaigre.

Je tire de-lì cette confequence, que le 2uinquin qui tient le fang \& le lait dans un état de fluidité, doit produire le méme effet dans nos corps \& fur nos humeurs; $8 z$ que fur ce principe il elt ai- dértuifé de conclure qu'en guerif fant les Te de conclure qu'en guerif - acides. fant les Fiévres, il ne le fait que parce qu'il rarefie le fang \& le rend plus tluide, en dé 


\section{\$26 De la Nature,}

truifant les coagulations que les acides fuperflus y avoient produites, \& que puifqu'il diffout les coagulations, il ne faut pas douter qu'il n'ait la vertu de corriger \& $\angle$ de détrulre les levains acides en quelqu'endroit qu'illes trouve.

De-là on peur conclure, pour le dire icy en paffant, que le Quinquina n'eft pas feulement un remede excellent contre les Fiévres, mais de plus qu'il peut eftre tresurile dans les indifpolitions qui procedent de l'abondanbeft un ce des humeurs; par exemple dans la Faim-c3. pine. dans cette maladie qu'on ap. pelle Faim-canine, dans laquelle les fucs acides font fi abondans, qu'ils picotent \& ir. ritent inceffamment les membranes de l'eftomac, qu'ils coagulent le chyle, \& em. 
dos caufes de la Fiévre. 327 pêchent la digeftion \& la diftribution des alimens, d'ou s'enfuivent les vomiffemens, la maigreur de tout le corps, $\&$ les autres accidens de cette maladie; Il eft indubitable que le Quinquina en détruifant tous ces mauvais fucs, en préviendra tous les effets dangereux. Je pourrois en dire autant de plufieurs autres indifpoficions qui dépendent de l'acidité des humeurs, mais je fortirois de mon fujet.

Je ne fçaurois cependant m'empêcher d'ajoûter encore icy que le 2uinquina eft un tres-bon remede contre les Rhumatifmes, \& contre les Gouttes; Ces maladies 2uinquas ront caufees par des humeurs na bon froides $\& 2$ condenfees qui ne les'sours circulent pas aif'ement, de Rhumas les autres $\operatorname{ma}$ ladies caufées par les 2cides.

$$
\text { . }
$$




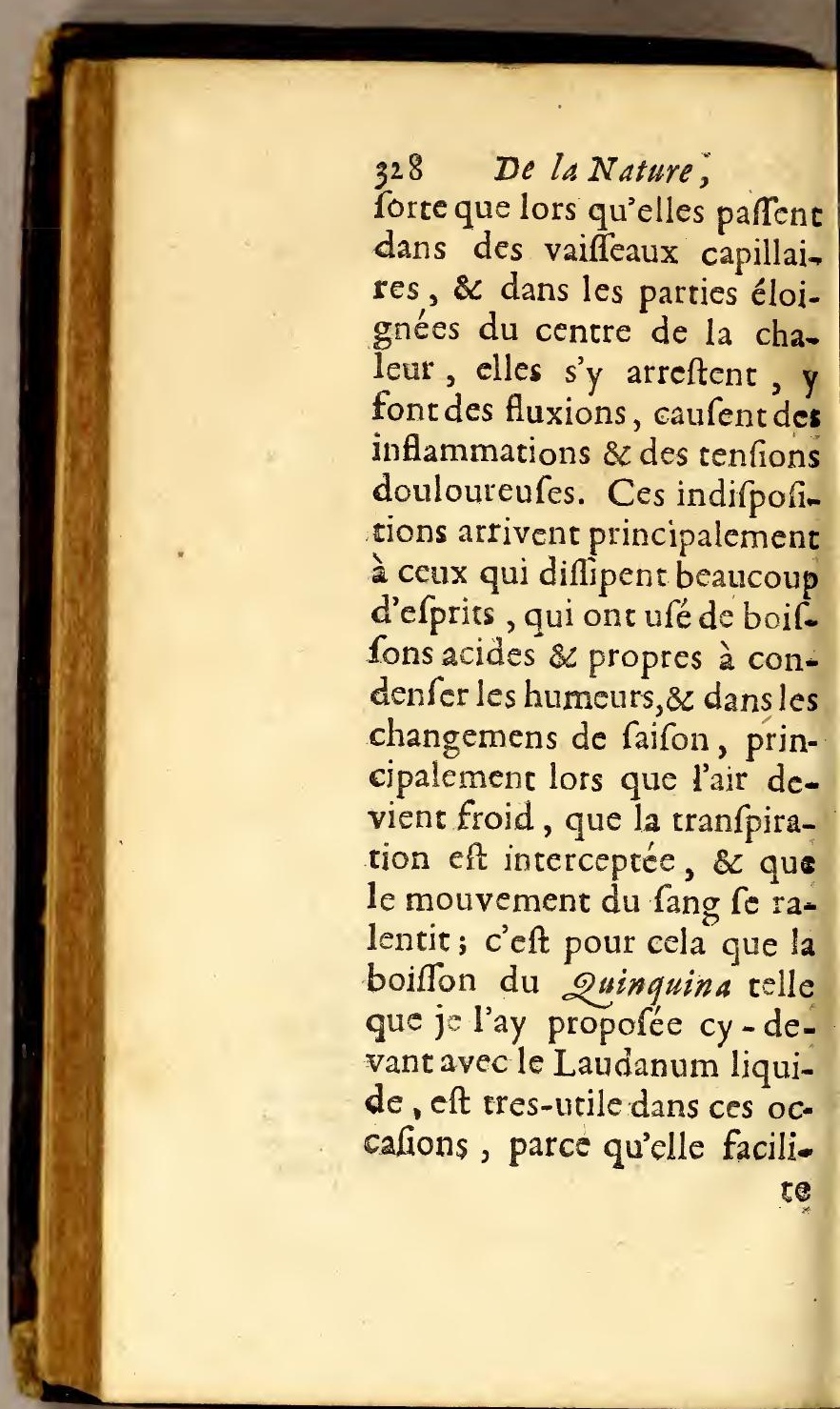


é descanfes de la Fiévre. 329 te la tranfpiration, qu'elle adoucit l'acrimonie des humeurs \& les rend plus fuides \& coulantes : Dans certe mî́me veuë on employe tres-à propos les fudorifiques, je me fuis fervi avec fuccés de fomentacions d'hyebles, de fauge \& de perficaria maculata, ou poivretre. Certe plance eft tres-bonne, elle abonde en $A l_{K}$ ali : les fomentations produifent des fueurs favorables, aprés quoy on froteles parties avec l'onguent Marciacum, auquel on ajoûte l'Efprit de vin $\&$ la liqueur de Laudanum.

Pour revenir à mes experiences, il y a encore uneréflexion à faire qui me paroift de trop grande utilité pour la paffer fous filence. Jay remarqué que bien que le vin de E e 


\section{De la Nature,}

Quinquina ait empêché la coagulation du farg \&z du lait, \& qu'il ait diffout une re 2 in. bonne partie du lait recemguina ne ment tourné en fromage ; il jas toû- n'a point fait d'impreffion fur coagula- la coagulation du fang faite par le vinaigre, \& qu'il n'en a guere fait non plus fur le rang coagulé à l'air. Ce qui fait voir quel'action de ce remede n'eft pas toûjours d'égale force, \& qu'elle dépend fouvent de la difpolicion du fujet : D'où je conclus que fi le 2 singuina n'a pas la vertu de détruire les acides qui caufent les fortes obltructions, \& de guerir par exemple une hydropifie accompagnée de fchirres invererez, de ratte ou d'autres parties: on ne doit pas s'en prendre à ce remede, ni dire quill en 
or des caufes de la Fiéture. $33 \mathrm{I}$ foit la caufe; au contrairc on peut affurer que s'il ne guerit pas des maux incurables II lles prévient

il pourra du moins les prévenir, \& les guerir dans leurs commencemens lors qu'on s'en fervira avec methode , \& qu'on en donnera une quantité fuffifance pour corriger les mauvaifes qualitez du chyle \& du fang.

Ce que je viens de dire de l'action du Quinquina, peur eftre encore confirme par l'experience : fi on mêle du Quinquina dans le vinaigre, il affoiblira à la verité fon aigreur, mais il ne fçauroit la détruire entierement; que fi on le mêle dans le vin il le confervera tres - long-tems fans s'aigrir. J'en ay veu qui ayoir efté plus de fix mois dans une boutcille fans ac-

$$
\text { Ee ii }
$$




\section{De la Nature,}

querir la moindre aigreur.

De ces mêmes experiences on peut enfin conclure que bien que le $\mathscr{Q}$ uinquina foit un remede excellent contre toutes les Fiévres, il eft pour-

Qnil ent meilleur pour les mirtétes que pour les con\$nuës.

tant plus fpecifique pour les intermirtentes que pour les continuës. La raifon en eft, que dans la plufpare des Fiévres continuës, les acides font trop diffous \&z trop divifez, $\&$ que les humeurs font en fi grand mouvement qu'on eft obligé quelquefois de quitter l'ufage des remedes qui rarefient \& diffolventla maffe du fang, comme fait le 2 wnquina, pour avoir recours à ceux qui la condenfent \& l'e. paififfent comme font les acides; au lieu que dans les Fiévres intermittentes il y a toûjours des levains aigres qui 
o des canfes de la Fićvre. 333 condenfent le chyle \&zle fang, $\&$ font oblacle à leur mouvement; \& c'eft pour cela que le Quinquina eft un remede tres-affuré pour ces fortes de Fiévres.

Remarquez pourtant que le 2 uinguina ne guerit pas fi promement les Fiévres dans toutes les faifons, \& que les effers de ce remede font beau-

coup moins heureux en Hyver qu'en Efté. En voici la raifon, c'eft que les acides qni avoient efté diffous \& dérruits par le Quinquina érant renouvellez par le froid excerieur, fervent aifément de levain à une nouvelle fermentacion, \& produifent des re. chutes: au lieu qu'en Efé les mêmes acides ayant efté une fois corrigez par le Quinqui. 27 s'exhalent \& fe diffipear Ec iij 
334. De la Nature, facilement par l'ouverture des pores; c'eft pour cela que les Medecins qui connoiffent parfaitement les vertus du Quinquina, font tres-rigides à faire garder à leurs malades toutes les précautions neceffaires pour faciliter la tranfpiration; \& c'eft dans cet efprit qu'ils leur doivent défendre de s'expofer à l'air froid, \& leur faire continuer l'ufage du remede pendant plufieurs jours, \& plus dans un tems qu'en un autre, afin de rendre le fang affez fpiritueux pour pouvoir refifter aux impreffions de l'air , 82 pour diffiper entierement les acides.

Obfervez encore qu'il ne faut rien ajoûter au Quinquina qui puiffe empêcher ou diminuer fon action; le més 
ou des cares de la Fiévre. 335 lange des acides produiroit précreti indubitablement cet effet, ton mé: puis quils augmenteroient lange, ceux qui dominent dans le d'autres. fang, \& qu'ils affoibliroient la vertu de ce remede : Sur quoy je ne fçaurois m'empêcher de blâmer la pratique de ceux qui ajoûtent au Quinquina des jus de Citron ou des jus d'Oranges; affuré. ment ils confultent moins en cela la raifon que le goût des malades.

Aprés ces experiences, \& ce que je viens de conclure, il femble qu'on ne devroit pas douter des bons effets du Que lé शrinquisna ne fice Quinquina. Cependant il fe trouve encore des gens qui le décrient comme une drogue pernicieufe; mais parce qu'on ne fçauroir difconvenir qu'it ne foit un feprifuge afturé, xe point. 
336 De la Nature,

ils foûtiennent que s'il guerit les Fiévres ce n'eft que par la fixation des humeurs qui les caufent, \& que cette guerifon eft plus dangereure que le mal, puifque par ce moyen on enferme le loup dans la bergerie, comme on le dit vulgairement.

II eft vray que ceux qui ne jugent des chofes que par les apparences, peuvent bien simaginer que le 2 üinquina ne guerit les Fiévres qu'en fixant les humeurs. Mais fans m'arrefter aux rermes de fixer or de fixation, qui ne conviennent proprement qu'aux chofes qui font renduës folides $\&$ immobiles; il me fem. ble que les gens de bon fens doivent efre perfuadez que ces fixations d'humeurs corrompuës, comme on les fuppore 
or des canfes de la Fiérre. 337 pofe dans les Fiévres font abfolument imporfibles \& conreaires a la parfaice fanté dout ve parla traires à la parfaite fanté dont raifon $\&$ jouilfient ceux qui ont efté par l'ex. gueris par ce remede. D'ailleurs fi on fait réfexion que le 2 singuina agiflant immediatement dans l'eftomac, s'il cftoir capable de produire des fixations, on s'appercevroit apparamment de quelque tenfion, dureté ou pefanteur à cetre partie, \& enfuite lorfqu'il te mêlcroit dans le fang il ne manqueroir pas de produire des oppreflions, des fuffocations, des palpications, $\&$ une infinité de maladies qui font les fuites ordinaires de la fixation, \& de la condenfation des humeurs.

Si le Quinquina pouvoit produire tous ces effets, ce feroit fans doute lorfqu'on le $\mathrm{FE}$ 
338 De la Nature, mêle immediatement dans le fang, puifqu'il ne manque. - roir pas de le coaguler; ce. pendant j'en ay feringué dans les veines d'un chien qui n'en a reffenti aucune incommodité. On fçait pourtant que fi* on faifoit la même chofe avec du vinaigre ou avec quelqu'autre liqueur acide $\&$ coagulante, le chien mourroir prefque dans un inftant, \&z on luy trouveroit du fang coagulé dans les veines \& dans le cour. Il faut donc conclure de tout se que je viens de dire, 8 z conformement à nos experiences, que le Quinquina ne coagule ni ne fixe point les humeurs; quau contraire il rarefie \& purifie le fang, \& le rétablit dans fon mou. vement libre \& naturel. 
\& des canfes de la Fiéure. 339

Je connois un Medecin,

homme de merite d'ailleurs, qui eft tellement prévenu, que le Quinquina fixe les humeurs, qu'il me foûtenoit l'année derniere qu'un Officier qui eft fujet à des vapeurs mélancoliques, en ayant eu quelques atteintes qui s'étoicnt manifeftées par une maniere d'afthme qui decincur l'incommodoit principale- par le ment la nuit, étoit tombé 2uinquäs Entêtement d'un me. dans cette indifpofition, parce quil avoit pris du Quinquina pour fe guerir dune Fiévre qu'il avoit euë à la fin d'Avril, \& que ce remede ayant fixé les acides qui cauloient la Fiévre, ils avoient produit une oppreffion, $\&$ une efpece d'afthme à la fin de Juin; \& fur ce que je dis que cer althme n'avoir

$F f i j$ 
$34^{\circ}$ De la Nature,

rien de commun avec la Fié-

vre du mois d'Avril, il ne me paroifloit pas vrai-femblable que des acides qui avoient efté la caufe d'une Fiévre parfaitement guerie il y avoit prés de deux mois, fuffent fixez \&z reftez dans le corps; que cette fixation jetteroit dans de grands inconveniens ; qu'il étoir bien plus raifonnable de croire que le Quinquina en gueriffant la Fiévre avoir détruit les acides qui en étoient la caufe; que $j^{3}$ en avois donné des raifons affez convaincantes dans mon petit Traité ; qu'à l'égard de rindifpofition de cet Offcier l'on en pouvoit attribuer la caufe à quelque défaut dans le regime de vie, comme de fouper tard, \& als 
or des caufes de la Fiévire. 34 r froid de la nuit, car nous étions dans l'Alface affez prés des montagnes, où il faifoit une chaleur exceffive le jour. Ainfi je penfois que les vapeurs de l'eftomac \& du bas ventre appefantiffoient le diaphragme, \& que l'air condenfé par le frais de la nuit ne circulant pas aifément dans les poulmons, la refpiration ne devoit pas eftre af$\mathrm{fe}_{\mathrm{z}}$ libre; mais cette raifon n'eftant pas de fon goût, il perfifta à foutenir que les acides qui avoient efté fixez par le Quinquina étoient la caufe de l'indifpofition dont je viens de parler. Il ajoûta que mes raifons n'étoient pas affez fortes pour le faire changer de fentiment, \&. qu'il étoit autant pofirble de détruire les acides que F f iij 


\section{De la Nature,}

d'aneantir la création.

J'avouë que je fuis bien fâché de voir un fi honnefte homme dans une fi étrange prévention, \& puifque les experiences que jay faites fur le Quinquina, \& les raifons que j'ay alleguées ne font pas fuffifantes pour le convain. cre, j'ajoúteray de nouvelles preuves pour effayer de le défabufer, \&z tous ceux qui font dans fon erreur.

Ie confidere dans les Fiévres deux fortes d'acides qui en font les differences, \& d'où j'appelle les unes chyleufes \& les autres fanguines.

Deux Ainfi il y a les acides du chyfortes d'acides fiévres. acides du chyle font grofle $\&$ les acides du fang; les fiers, ils font contenus dans les maticres cruës \& indi. geftes qui excitent dans le 
or des caujes de la Fiéure. 343 fang des fermentations fiévreufes. Je compare ceux-cy au verjus, ou au fuc des fruits qui ne font pas meurs.

Les acides du fang fonc plus déliez, plus purs \& plus afinez; ils refultent de la diffipation des efprits lorfque la maffe du fang contracte une difpofition acide de la maniere que je l'ay cy-devant expliqué. Je compare ces acides aux acides du vinaigre; Or que le 2uinguina change, détruife \& chaffe tous ces acides en gueriffant les Fiévres, il eft manifefte; car il digere $\&$ rarefic un chyle cru \& épais en purifiant le fang, \& par une efpece de maturation il convertir les matieres cruës \& indigeftes en fang pur \& capable de nourrir les parties.

Ff iiij 


\section{De la Nature,}

Un raifin qui n'eft pas méur, que l'on appelle verjus au commencement du mois d'Aouft, a fans doute perdu fon acidité, \& elle eft détruite \& changée en liqueur dauce lorfquil eft devenu raifin meur à la fin du mois de, Septembre, \& l'on ne f̧̧auroit dire raifonnable. ment que la chaleur en meuriflant ce raifin ait fixé les acides du verjus. Ainfi lorfque le 2uinquina guerit une Fiévre, il porte dans le fang des parties fpiricueufes \& balfamiques, qui en détruifant les coagulations, rarefient les humeurs indigeftes \& les acides gropiers, \& challent les plus exaltez par des fueurs \&z par une rranfpiration douce ; \& l'on ne fçauroit difconvenir que les 
od des caufes de la Fiévre. 345 acides ne foient chaffez \& détruits, puifque les fueurs fentent fouvent l'aigre, qu'il y a fur la peau des demangeaifons \&z des petites pultules qui font des effets fenfi- bles de l'eruption des acides. Mais au fonds les Medecins \& les Chymiftes con- tout ce noiffent-ils quelque chofe qui coza dans la Nature qui fixe \& Gxe eft coagule qui ne foit acide? acide.

Comment donc peut-on comprendre qu'un remede qui guerit une maladie cauf'e par des acides, faffe les mêmes effers que les acides? $\&$ eft - il poffible qu'on foic tombé dans cetce erreur, fans prévoir les abfurditez quien refulcent :

Il n'y a point de Philofophe qui ne f̧̧ache que nô. tre vie \& noltre fanté dépen- 


\section{De la Nature,}

dent de la jufte difpenfation $\&$ diftribution des fucs nourriciers, \& du bon temperament de ces fucs; que ce bon temperament procede du jufte mélange des principes; que les efprits y doivent eftre fuperieurs pour tenir les acides dans un état de fluidité \& les empêcher de faire des coagulations; que les acides y doivent eftre proportionnez pour lier les efprits, de peur qu'ils ne s'évaporent. On fçait auffi qu'il fe fait un écoulement $\&$ une diffipation continuelle de ces fucs par l'infenfible tranfiration, \& qu'ils font reparez par les alimens pour la confervation de noftre machine : tellement que s'il étoit poffible de concevoir que tous les acides refteroient 
\&. des caufes de la Fiévre. 347 dans noftre corps, \& que les autres principes fe diffipe. roient par la tranfpiration infenfible, ou par les autres voyes : on pourroit s'imaginer en mêmetems que nous ferions bien-toft petrifiez, ou du moins remplis d'obftructions de fchirres.

A penfer naturellement, Effets de l'abondance des ac: des. l'on auroir de la peine à croire autre chofe d'un amas continuel d'acides; car il y a bien de l'apparence qua fi les acides qui caufoient la Fiévre font retenus, ils s'affocicront à tous les autres qui feront dans les alimens. Quels defordres ne peut - on pas concevoir d'une teile idée ! $\&$ comment l'ajufter avec la tranquillité \& la fanté parfaite dont joüiffent ceux qui ont efté gueris d'une Fié 
348 De la Nature; vre intermittente par le 2 win quina pendant l'intervalle de retours, qui eft quelquefois $\mathrm{d}$ deux mois \& plus, comme : eft arrivé à cet Officier qui cu l'atteinte d'althme.

$S i$ aprés que le Soleil a Printems, en Efté \& en Au. tomne a changé les nitres do l'air en mille figures differen. tes pour la production de: mixtes, on difoit lors que l'Hyver revient, le Soleil avoil fixé les nitres de l'air, ils n"étoient pas détruits, parce qu'il eft autant facile de détruire les acides, que d'aneantir la création. Je penfe qu'il n'y a perfonne de bon fens qui voulut recevoir une telle propofition; tout le monde comprend qu'en Hyver les frimats, la glace, la neige \& les nitres ne regnent dans l'air 
or des caufes de la Fiévre. 349 que par la foiblelle du Soleil, \& parce qu'il n'a pas affez de chaleur pour les fondre \& pour les diffoudre : \& l'on fçait que la plus grande partie des nicres qui font entrez dans la compofition des mixtes y font encore, comme dans les fruirs, dans le $\mathbf{V}$ in, dans le Cidre, \&c. On peut ce me femble, raifonner de la même maniere à l'égard des remedes chauds \& f piritueux que I'on a mis en ufage pour guerir les Fiévres. Ces remedes ont rarefié, fondu \& diffipé les acides groffiers \& les humeurs cruës qui en étoient la caufe, de forte que fi les Fiévres reviennent aprés qu'on s'eft fervi de ces remedes, doit-on conclure que les humeurs cruës \& que les acides aroient efté fixez? 
350 Dela Nature,

N'eft-il pas plus raifonnable de penfer que le fang s'eftane refroidi, il eft retombé dans une difpofition fiévreufe, parce que l'on a difcontinué l'ufage des remedes chauds \& du Quinquina.

Mais on dira pourquoy done certe Fiévre revientelle aprés l'ufage du 2 uinquina? Il en faut chercher la raifon: que fi je ne fuis pas affez heureux pour la trouver comme $j$ e ne m'en flatte pas, aura-on droir de conclure de-là que les acides fixez par le quinquina foient la caufe des retours des Fiévres?

J'attribuë la caufe des re-

Quie les rechutes ne font pas une preuve de fixation par le Quinginas chutes aprés l'u fage du Quinquina, au mépris que lon fait du regime de vie, ou aux alimens rafraîchiffans \& acides qui effacent les bonnes 
\&u des caufes de la Fiérre. $35^{\mathrm{I}}$ impreflions du Quinquina, ou à ce qu'on n'aura pas continué d'en prendre pendant plufieurs jours, ou enfin à ce qu'on fe fera expofé à l'air froid, \& qu'on n'aura pas pris toutes les précautions necerfaires pour prévenir les fuires de ces mauvaifes difpofitions, peut-être fera-on perfuadé que c'eft - là la vraye caufe des recours des Fiévres fi l'on fair réflexion fur ce que j’ay déja infinué, que les Fiévres qui ont efté gueries en Efté par le Quinquina ne reviennent point, ou que les rechutes font moins frequentes en cetre faifon; que quelquefois elles ont des retours au Printems, parce qu'alors la faifon eft fouvent froide, ce qui n'eft pas propre à rétablir le fang dans fa qualicé fpiri- 


\section{De la Nature,}

Ies Fié. tueufe. Si d'ailleurs on con-

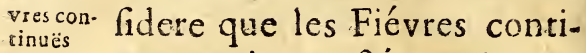
qui ont nüës qui ont eftè gueries par
efté gueefté gue-
zies sar
le $2 u i n q u i n a$
ne reviennent le givin- jamals; fi on fait encore ré$\underset{\substack{\text { revien- } \\ \text { nent ja- }}}{\text { flexion fur ce que nous avons }}$ mais. dit, que les impreffions de l'air fur la maffe du fang étoient plus fortes que celles du chy. le, \& qu'un fang qui avoit efté dans une difpolition acide, la reprenoit aifément lorfque l'on difcontinuoit l'ufage des remedes qui avoient changé cette difpofition, fur tout fil l'on fe trouve dans une faifn froide.

Remarquez auffi que ceux qui one efté gueris en Hyver de quelque Fiévre intermittente par d'autres remedes que par le 2uinquina, retombent facilement s'ils s'expofent au froid; ce n'eft pas gu'en 
\& des caufes de la Fiéure. 353 qu'en Efté la Fiévre ne revien. ne quelquefois, mais cela n'arrive quà ceux qui fe rafraîchiffent trop.

L'on n'a donc pas raifon de pretendre que fi le guinquina ne fournit pas affez de fubftances chaudes à la maffe du fang pour refifter longtems aux atteintes de l'air froid, \& empêcher les retours des Fiévres, il fixe les humeurs qui caufent ces Fiévres.

Cependant c'eft fur ce faux préjugé de fixations d'hu. meurs par le 2uinquina qu'on Erreurs a foûtenu publiquement qu'il populaicaufe des fchirres de foye $\&$ chant le de rate, qu'il confume l'hu- 2riagus: mide radical, qu'il tarit les fources de la fecondité; $\&$ enfin que c'eft un poifon qui coagule le fang dans les veines. Que des Aureurs ont

$$
\text { G g }
$$


354. De la Nature; écrit qu'il caufe des Rhumatifmes, des Afthmes, des hydropifies, des fuppreffions de mois, \& ont pretendu qu'il s'eft trouvé des malades, qui de peur de tels accidents, ont fouhaité de retomber dans la Fiévre dont ils avoient efté gueris par l'ufage de ce remede.

Il eft aife de voir que ceux qui ont de tels fentimens ne connoiffent gueres le $\mathscr{2}$ winguina, ou quils font dans une étrange prévention; mon hypothefe, \& ce que j'ay avancé fur l'action de ce remede, a fait voir clairement qu'ils ne font fondez ni fur la raifon, ni furl'experience. J'ajoûteray à cela cette petite réflexion; Je prie le public d'examiner fi ceux qui Conr heatiques \& bydropi- 
Qu des canfes de la Fiévre. 355 ques, ou qui fone morts de ces maladies; \& fi ceux qui meurent tous les jours à la fleur de leur âge pour de fimples Fiévres, \& je l'interpelle de declarer fi ces malades ont pris du Quinquina, \& s'il n'eft pas vray qu'ils onc été beaucoup faignez, qu'ils ont abondamment ufé de Tifannes $\&$ de boiffons rafrầchiffantes. Il eft vray que l'on a quelquefois recours au Quinquina, mais c'eft aprés avoir mis en ufage tous les autres remedes, \& s'il ne fait pas les effets que l'on en devroit naturellement attendre, c'elt la faure de ceux qui en ordonnent l'ufage.

Voilà les réflexions que les experiences fur le Quinquina m'ont fait faire; javouë que l'action de ce remede m'a

$\mathrm{Gg}$ ij 
356 De la Nature, donné d'autres idées de Is caufe des Fiévres que celles que j'avois auparavant, \& que je n'ay pû̀ la rapporter fimplement à l'intemperic chaude, ou à la pourriture des humeurs : jay veu qu'il n'agiffoit pas en éteignant la chaleur, mais qu'ayant la proprieté de rarefier, de fondre $\&$ de refoudre les coagularions, il faloir que la Fiévre fût caufée par des humeurs épaiffes \& coagulées, dont le Quinquina procuroit la fonte \& la diffolution. Dans cette vouë j'ay crû que je pouvois m'écarter de la route ordinaire pour expliquer la Nature \& la caufe des fiévres, \& me prévaloir de cette liberté de fentimens établie entre les Philofophes, comme un droit imprefcriptible. J'ay en cel? 
¿े des caufes de la Fiérre. 3it pour garand de ma conduite le grand Hippocrate, fes écrits nous font voir qu'il n'eftoir pas fi jaloux de fes penfées, ni fi fcrupuleufement attaché à fes dogmes, qu'il ne fut preft de les abandonner, s'il trouvoit ailleurs plus de certitude.

Le f̧̧avant $M^{r}$. Menjot a remarqué qu'Hippocrate, aprés avoir expliqué dans le Livre de la Narure humaine, la doatrine des élemens qu'A. riftote trouva fi belle qu'il en tira les fondemens de $\mathrm{fa}$ Phyfique, n'avoit pàs laifle de nous donner plufieurs traitez fur les principes de Démocrite, ce qui fait voir qu'Hippocrate ne prenoit point d'aurre parti que celuy de la verité ; \& comme il étoit de l'illuftre famille des

$$
\text { Gg iij }
$$




\section{$35^{8}$ De la Nature,}

Afclepiades, on ne doute point qu'il n'eut puif'e dans les Regiftres du Temple d'ECculape la plufpare des chofes qu'il nous a laiffées. Les Prêtres de ce Temple étoient les dépoficaires de ces Regiftres qui contenoient les fecrets de la Medecine, puifque tous ceux qui avoient efté gueris de quelque maladie, alloient y dépofer les Memoires des remedes dont ils s'eftoient fervis.

Aprés Hippocrate, la Medecine a demeuré long. tems comme hereditaire à la maifon des Afclepiades; mais dés qu'elle en eft fortie, elle a beaucoup perdu de fa dignité \& de $\int_{2}$ premiere fplendeur. Je n'ay pas entrepris d'examiner les differentes fectes par lefquelles elle a palté, par 
Lo descaufes:de la Fiévre. 359 quels degrez elle eft parvenue au point où on la void aujourd'huy, ni commene les Medecins qui fe piquene d'eftre le plus fcrupuleufement attachez à l'Antiquité, ont une conduite peu conforme à l'efpric d'Hippocrate.

Il me fuffit de faire comprendre que la Medecine tire fon origine des Experiences; que les Experiences doivent eftre la regle de nos raifonnemens; \&2 que fi le Quinguina preparé avec du vin ou de l'Eaude-vie guerit feurement les Fiévres, ceux qui entreprennent de les guerir par des remedes oppofez à celuy-là, n'ont point de principes cercains \& folides. Ainfi je croy qu'on ne fçauroit m'ac:- 
360 De la Nature, \&c. cufer de nouveauté, finon en ce que je renouvelle l'ancien ufage, \& que je rappelle le ficcle des Experiences. Quoy qu'il en foit je fouhaire que mes nouveautez puiffent donner occafion à ceux qui font plus éclaircz que moy, de penetrer plus avant dans une matiere auffi difficile $\&$ aumi peu connuë que celle des Fiévres.

\section{F I N.}




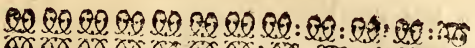

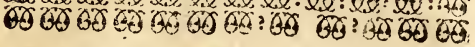

\section{T A B L E}

DES MATIERES.

Ordre \& divifion de ce Traité; page 2.

PREMIERE PARTIE.

Examen de la doctrine des Anciens fur la Fiévre.

Efinition de la Fiévre felon les Anciens page 3 . Examen de cette définition, 4. Quela Fiévre n'eft pas une chaleur étrangere, 5.Ce qui fe prouve par la vegetation des plantes, ibidem. Et par l'analogie qu'ily a entre cette vegetation, \& celle des Animaux, 6 . Examen de la divifion generale des Fiévres, 9. Que la Fiévre Ephemere $n^{\circ}$ eft pas une inflammation des efprits, ibid. of fuiz. Mais une legere fermentation de toure la maffe du fang, II. Quéla Fié. $\mathrm{Hh}$ 


\section{T A B L E}

vre continuë fimple ne confifte pas dans l'inflammation du fang contenu dans les grands vaiffeaux, ibid. Quela Fiévre hectique ne réfide pas dans les parties folides, I3. qu'elle dépend de l'épuifement des efprits, I4. \& du défaut des fucs nourriffiers,

Examen des Fiévres putrides, I7. $\mathrm{Ce}$ queles Anciens ant entendu par la pourriture du fang, I8. Cette pourriture ne peut eftre dans les grands vaiffeaux fans paffer dans les petits, 2c. Si elle étoit dans le fang toutes les Fiévres feroient mortelles, 2I. Et les Fiévres intermittentes ne fe-

- roient pas les moins dangereufes, 22. Que le mouvement du fang empéche qu'il ne fe corrompe,

preuves dont on fe fert pour établir la corruption du fang, $24 \cdot 1^{\circ}$. Les puntules \& les abfcés qui arrivent dans les Fiévres, $25.2^{\circ}$. La couleur du fang des febricitans, ibideme $3^{\circ}$. Les vers qu'on a 


\section{DES MATIERES.}

trouvez dans le fang, ibidem. Que les puftules ne font pas une marque de corruption, 26. Non plus que la couleur du fang, 27. Raifons de differentes couleurs dans le fang, 28. Rétléxions fur ces differences, 30. Pourquoy le fang paroift beau dans les Fiévres malignes, ibid. Pourquoy il paroift corrompu dans les autres Fiévres, 32. Qu'il ne paroift pas toûjours également beau dans ceux qui fe portent bien, 33. Pourquoy le fang n'eit pas de même couleur dans la palette que fur le bord, $\quad 36$ Que les vers quion a trouvez dans le fang ne font pas une marque de corruption, 39. puifqu'ils viennent de femence, 40. Que les infectes ne s'engendrent pas de corruption, 43. Experience fur ce fujet, 44. Remarques fur la generation des Abeilles, ibid. D'où vient que les infectes naiffent fi promtement, \& en fi grand nombre, 45. Si les plantes viennent fans avoir efté

H h ij 


\section{T A B L E}

femées, $4^{6}$. Loy generale de la Nature pour la production des Animaux \& des Plantes, ibid. Qu'il n'y a point d'Animaux imparfaits,

Autre divifion des Fiévres, 49.

Dans laquelle les Auteurs prennent les effets pour les caufes, 50

\section{SECONDE PARTIE.}

Hypotbefe fur la caufe des Fiévres.

CE que c'eft que la Fiévre, 52. Ce que G'eft que fermentation, 53 . Que ce qui excite cette fermentation dans les Fiévres eft le chyle ou le fang mal difpolez, s5. Ces mauvaifes difpofitions dépendent de l'air \& des alimens, 56 . dont les bonnes qualitez font la fanté, 57 . de même que les mauvaifes la déreglent,

ibid.

Ce que c'eft quel'air, $58 . \&$ comment il change nôtre conftitution dans les differentes faifons. 59. En Hyyer, ibid. Au Pria- 


\section{DES M ATIERES.}

tems, 60. En Efté, 6i. Et dans l'Automne,

Quelle eft la difpofition du fang dans les Fiévres, 64. De quelle maniere le fang devient aigre, 65. Comment le chyle acquiert la même qualité, 67. vue le fang tient de l'aigre dans les Fiévres, 68. Comment cette aigreur du fang excite la Fiévre, 69. Auffi bien que l'aigreur du chyle, 70. Quand on fe porte bien le chyle fe convertic en fang fans aucun trouble, 7 I. Au lieu que l'un \& ' 'autre eftant mal difpofez, caufent la Fiévre par leur mélange, 72. Explication des Fiévres continuës, 74. $\&$ des Fiévres intermittentes,

-ibidem.

Explication des fymptomes qui paroiffént dans le frifton, 86. Des douleurs vagues \& pefan. tes, 87. Des bâillemens, 88. Des extenfions, \& des mouvemens convulfifs, 89 . De la difficulté de refpirer, 9r. Dela foif, ibid, \& de la frequence du pouls , 92. $\mathrm{H} \mathrm{h}$ iij 


\section{T A B L E}

Que tous ces fymptomes ne viennent point de l'irritation des parties membraneufes, 93 Explication des accidens du chaud, I0O. Des douleurs de tefte, $i b i d$. Et du delire, ibid. Raifon de la difference de tous ces fymptomes,

Ios retours des pitvres ror tentes font tres-difficiles à comprendre, 102. Ces retours viennent de ce que la maffe du fang n'a pas été rétabliẽ , ibid. Et leur difference vient de ce qu'il y a plus ou moins d'acide, 104. Et plus ou moins d'efprits dans le fang, Ioj. Que dans la Fiévre quarte il y a plus d'acide \& moins d'efprits, que dans $I_{a}$ Fiévre tierce, I06. Comment les Fiévres tierces ou quartes deviennent doubles tierces, ou doubles quartes,

Nouvelle divifs, 107 108. en chyleun des Fiévres, guines, Iro. Conclufion de toute I'hypothefe, 


\section{DES MATIERES.}

TROISIE'ME PARTIE.

Réponses aux Objections.

I. Bjection, que fi la Fiérre dépendoit du mélange da chyle, \& du fang, on auroit toûjours la Fiévre, \& qu'on la gueriroit par la diete, \& par l'abltinence, 113. Réponfe, II 4 .

2. Objection, que l'impureté des humeurs eft la même chofe que la pourriture, I2I. Réponfe, ibidem.

3. Objection, que le fang ne fçatroit s'aigrir, 122 . Diverfes raifons la-deffus, ibid. Réponfes à toutes ces raifons, I23. Exemple de l'aigreur du fang dans l'hydropifie,

4. Objection, que les acides font le remede des Fiévres, \& non pas la caufe, 130. Réponfe, ibidem, Précautions fur leur rage, 133. Qui eft bon dans Hh iii 


\section{T A B L E}

de certaines Fiévres, plûtôt que dans d'autres, 5. Objection, que les acides ne font pas differens dans le chaud, de ce qu'ils eftoient dans le froid, 136. Réponfe, ibid.

6. Objection, que fi les impref. fions de l'air fur le fang étoient plus fortes que celles du chyle, on ne verroit point de Fiévies au Printems, 138. Et que routes les Fiévres devroient fe guerir dans les changemens de faifons, 139. Réponfe

7. Objection, que les difpoltions bilieufes font la caufe des Fiévres, \& non pas l'aigreur du fang, r43. Réponfe, ibid. Que la bile ne peut pas caufer la Fiévre, I44. D'où vient que les alimens chauds caufent la Fiévre ? 146. Et pourquoy les hydropiques \& les forbutiques n'y font pas fujets? ibidem.

8. Objection, que fi les Fiévres venoient de l'aigreur du fang, elles feroient toutes incurables, 148 . Réponfe, 


\section{DES M A TIERES.}

9. Objection, que la Fiévre étant une fermentation, elle dépend du mélange d'un acide avec un alkali, \& non pas feulement de l'action des efprits, igo. Réponfe, III. Queles acides \& les alkalis donnent occafion à la fermentation, mais qu'ils n'en font pas les caufes,

10. Objection, que la divifion des Fiévres en chyleufes \& fanguines n'eft pas jufte, puifque les qualitez du fang ne peuvent dépendre que du chyle, I54. Réponfe, ibid. L'action de l'air fur le fang, isga Que l'air eft le principal agent de $\mathrm{T}$ a fanguification, 157. Qu'il ent le principe du mouvement inteftin du fang, I59. \& même, fuivant quelquesuns, le principe du mouvement du cœur, 160. Que tout cela fert à prouver que les impreffions de l'air fur le fang font plus fortes que celles du chyle, 164. Et à confirmer la divifion des Fiévres en chyleufes \& en fanguines, 


\section{TA B L E}

QUATRIE'ME PARTIE, Contenant la Piatique.

Avec des Experiences of des $R \epsilon_{\text {. }}$ flexxions fur le Quinquina.

Comment on faifoit la Medecine dans les premiers tems, 168. La faignée en ufage chez les Anciens, 169. Methode de $\mathrm{M}^{\mathrm{r}}$. Courtois fçavant Medecin de Paris, 170. Sa penfée fur les Plantes,

ibidem.

Refuntion de la Differtation de $M^{r}$. Bayle fur la faignéé, 172. Rém fléxion particuliere de $M^{5}$. Bayle, 775 . Que par rune raifon conrraire au fentiment de $\mathrm{M}^{\mathrm{x}}$. Bayle, il ne faut pas faigner pour guerirles Fiévres, I78. Que $I_{2}$ machine de $M^{\mathrm{r}}$. Papin ne démontre point la neceffité de fajgner, 180 . Que les obfervations de $\mathrm{M}^{\mathrm{r}}$. Bayle tre prouvent point qu'il faut faigner, $\quad 8_{2}$

$\mathrm{Ce}$ que c'eft que la faignée, 185. Sentimens des Aureurs 
DES MATIERES.

fur l'effer de la faignée, ibidem. Pour quelle raifon les Anciens ont établi la faignée, 187 . Les Auteurs ont établi deux fortès de pletore, ibid. Seconde pletore mal fondée, \& ne prouve pas la neceffité de la faignée, 188. \& 189 .

Que la faignée n'eft point le remede des Fiévres, mais feulement des. fymptomes qui les accompagnent, $189 . \&$ 190. Le legitime ufage de la aaignée dépend. de $l_{a}$ connoiffance des fympromes de ces maladies, I9r. En quel cas la faignée eft utile, 192. Rélexion que l'on doit faire dans l'ufage de la faignée, ibid. \& 193 .

Les fympromes des Fiévres ont des fignes équivoques, ibid. \& 194. Que la faignée fe rapporte un:quement à la plenitude, \& qu'il faut peu de faignées pour y $\mathrm{fa}-$ tisfaire, igs. Si ce qu'on dit des chaleurs d'entrailles \& des foufres allumez, font des raifons pour figigner,

ibidem. 


\section{T A B L E}

Les foufres.ne s'enflamment point dans les Fiévres, 197. Les foufres calment les fermentations, $i b i d$. Les plus grandes chaleurs ne produifent pas les plus grandes fermentations, 198. La boiffon d'Eau-de-vie ne donne pas la Fiévre; c'eft un fait confirmé par les Chaffeurs \& par les voyageurs, 199. Les chaleurs affoibliffent \& épuifent les efprits, ils ne fe reparent que par les chofes Ipiritueufes, ibid. \& 200. Preuves tirées de la pleurefie, ibid. Erreur vulgaire fur les rafraîchiffemens, 20I. Raio fon \& experience pour corriger cetre erreur, ibidem. Exemple pour faire voir l'abus des rafrấchiffemens, 202. Autre exemple contre les rafraîchiffemens \& la faignée, 204
Qiilil ne faut point écremer le lait, 207. Que ceux qui ne fe fone point faigner fe portent bien, \& font plus vigoureux que ceus qui fe font faigner, ibid. \& 208 . En quels cas les rafraîchiffe. 
DES MATIERES. mens conviennent dans les Fiévres, ibid. Précaution à prendre dans l'ufage des rafraîchiffemens, 209 Erreur de Mr. Sylvius de Dublin, qui a mis la Saignée dans l'indifference, 210. Depuis que le Quintruina eft en ufage, il meurt moins de Febricitans, 2II. \& 212. Paradoxe de $\mathrm{M}^{\mathrm{r}}$. Sylvius, $2 \mathrm{I} 3$. Réponfe au paradoxe, 2ij. Que la chaleur donne aux corps un mouvement progreffif, $217 \cdot$ Que le mouvement des arteres $\&$ du cœur eft un mouvement paffif, 218. Qu'un fang groflier \& $\&$ vifqueux peut circuler plus vîte qu'un fang clair \& épuré, ibid. \& 219. Cela eft démontré dans la fermentation du vin, ibidem, Réflexion fur les effets de Ia faignée,

Que les purgatifs font neceffaires à la guerifon des Fiévres, 222. Penfée des Anciens fur la vertu des purgatifs, ibid. Qu'ils font veneneux, \& agiffent par irrication, ikid. Qu'ils agiffent 


\section{T A B L E}

par élection, ibid. Moyens done fes Modernes fe font fervis pour connoître la vertu des purgatifs, 223. Ils fe font fervis du mélange des liqueurs, ibid. Ils ont confulté l'experience \& l'analy $f_{e}, 224$. Ce moyen paroift le meilleur, ibid. Les principes dans les purgatifs font compo$\mathrm{fez}$, ibidem. Ce que c'eft que les humeurs qu'il faut purger, ibidem.

Que les purgatifs agiffent dans l'eftomac, 226. Pourquoy il y a des gens difficiles à émouvoir? ibid. Les purgatifs font fouvent vomitifs, ibidem. Pourquoy ils font vomitifs? 227. Les purgatifs ne font pas veneneux, ibid. Ils n'agiffent pas par irritation, ibidem. Le vinaigre irrite, \& ne purge point, ibid. Si tous les mixtes refrneux \& fulfureux font purgatifs ? 228. Comment les inixtes refineux font purgatifs? ibid. Les cordiaux font fouvent purgatifs, 229. Ce n'elt point par irritation. 
DES MATIERES.

Qu'il y a des drogues qui purgent fi violemment qu'on diroit que c'eft par irritation, ou qu'elles ont du venin, 230. Comme la Gomme-gutte, la Coloquinte, 23r. Pourquoy les purgatifs font eftimez veneneux, \& agiffent par irritation? ibid. \& 232 . La Scammonée n'eft point une drogue dangereufe, ibidem. La Caffe purge quelquefois violemment, 233. Elle doit être douce, ibid. Précaution à prendre dans l'ufage des purgatifs,

\section{$234^{\circ}$}

Fondement de cette pratique tiré de l'hypothefe, 235. Deux indications pour la guerifon des Fiévres, 236. Purgation \& tranfpiration, ibid. S'il Eaut purger au commencement, 237. S'il faut faigner, ibid. Symptomes qui marquent la neceffité de faigner, sbidern. La faignée fe doir faire d'abord, ibidem. Trois ou quatre fuffifent, $23^{8}$ Les Remedes diaphoretiques, $23^{8}$. Lexur ulage, ibidem, Idée gene 


\section{T A B L E}

rale de la guerifon des Fiévies; ibid. Explication des difficultez qui fe prefentent contre cette Methode, ibid.\& 239. Qu'11 ne faut purger qu'aprés le fep. tiéme, ou aprés les fignes de coat on, ibid. Que c'eit l'ufage, ibid. Qu'il elt fondé fur l'autorité d'Hippocrate, ibid. Réponfe, 240. Que cet Aphorifme n'autorife porat cet ufage, ibidem.

Les Anciens ne traitoient point les Fiévres comme on fait prefentement, 24I. Sens litteral de l'Aphor. 22. liv. 1. 242. Qinil a deux parties, ibid. Quil faut purger dés le commencement les humeurs abondantes. 244 . Qu'il faut purger à la fin pour éviter les rechutes, ibid. Cette Methode eft fondée fur l'autorité d'Hippocrate, ibidem. \& 245.

Quand la faignée eft neceffaire, 246. Combien de fois on la peut faire? ibid. Lavemens purgatifs tres-utiles, 247. En quel. 
DES MATIERES.

cas il s'en faut abftenir ? ibid. Potion purgative, ibidem. C'eft une bonne pratique de purger ou de faire vomir d'abord, 248 . La teinture d'Opium avec l'keprit volatil de Sel Armoniac eft la meilleure,

250

Si les Fiévres ne gueriffent point par la faignée \& par la purgation, 252. On met en ufageles diaphoretiques \& les fpecifiques, ibid. Le Quinquina fpecifique affuré pour la guerifon des Fiévres, ibidem. Préparation du Quinquina tres-utile, ibidem. Lon en guerit toutes forres de Fiévres, 253. Bonne pour la pleurefie, ibid. Elle eft meilleure - prife chaudement, ibidem.

Le 2uinquina n'eft point un remede dangereux, 254. Il guerit en digerant les humeurs, \& en fortifiant les partics, ibidem. Diverfes manieres de donner le 2ninquina, 255. L'ufage des Tablettes tres-commode, 256 . Plufieurs febrifuges, 257 . Ce 


\section{T A B L E}

equi eft fpiritueux \& fulfureux eft febrifuge,

Ill y a des Fiévres où les faignées ni les purgations ne font pas d'abord neceffaires, 259. Elles fe gueriffent par une methode palliative, ibid. La Riviere de Seine boune dans les Fiévres, 260. Pourquoy elle eft purgative ?

ibidem.

Nouvelles réflexions fur l'A phor.

22. liv.1. 262. L'origine de toutes nos maladies vient de l'air ou des alimens, ibid. Qu'il eft plus expedient de purger promtement, que de laiffer corrompre les matieres, 265. Ce que les Auteurs ont penfé fur la coction des humeurs, ibid. Sens litreral de l'Aphorifme 22. liv. I. 266.

Effet des huneurs corrompuës dans l'eftomac, 266. Qu'il fe fait une coction dans la maffe du fang, 267. Ce qu'Hippocrate a entendu par la coction des humcurs, ibid. Objection tirée de l'Aphor. cité ,268. Réponfé 


\section{DES MATIERES.}

à 'l'objection,

Purgatifs en ufage du tems d'Hippocrate, 269. Differences entre les habitans du Nord \& ceux du Levant, 270. Les Fiévres font fouvent précedées de vomiffemens, 271. Exemple pour prouver que la methode ordinaire de guerir les Fiévres n'ett pas fondée fur l'autorité d'Hippocrate, ibid. \& 272.

Ce qui a introduit dans la Medecine les Charlatans, les Moines, 2xc. 274. D'où vient le peril dans les maladies, 275. La caule des Fiévres lentes, \& des hydropifies,

276

Le 2 uinguina eft un bon remede contre les Fiévres lente \& hectiques, 277. Opiate hyfterique 278. La Fiévre hectique eft plu; difficile à guerir que la Fiévre lente, 279. Remedes anti-hectiques \& anti-althmatiques, 280.

Dans les Fiévres d'Eté les diaphoretiques peì neceffaires, $28 \mathrm{r}$. Uiage \& effet des emulfions,ibid.

$$
\text { I i ij }
$$




\section{F A B L E}

Apozeme fait avec le Melon, 282. Ufage de la Limonade \& des boiffons rafraîchiflantes, ibid.

Utilité des Acides, 283. Leurs mauvais effets, ibid. Potion ufrtée dans les Fiévres malignes, 284 . Précaution à prendre dans l'urage des boiffons rafraîch: fantes, 285 . Lorfque la tranfpiration n'eft pas exceflive, 286 . Quand elle eft exceflive, 297 . Caractere des Fievres malignes, ibidem.

Que le mélange des efprits acides avec les fols volatiles eft utile dans les Fiévres malignes, 288. Potions cordiales, 289. Potion: urile dans les Fiévres malignes, ibid. Pour les enfans qui ont des vers, 290. Cutaplafme ufité contre les vers,

ikidem.

Que les remedes fpiritueux ne Tont point dangereux dans les Fiévres malignes, 292. Exemples pour confirmer les bons ef fets des remedes fpiritueux, 29. Les caufes de la petice Ve- 
DES MATIERES. role, \& c. 296. Obfervations fur: la petite Verole, 298. Remede contre la petite Verole, 300. En quel cas la faignée convient à la perite Vcrole, zor. Opiun ufité chez les Arglois dans ces maladies, ibidem. Tifanne de Quinguina bonne dans la perite: Verole,

302 Inconveniens contre la pratique de $\mathrm{M}^{\mathrm{r}}$. D fle, 303 . Remarque fur la pleurefie, jos. Obfervation fur l'ufage des fudorifiques contre $\mathrm{M}^{\mathrm{r}}$. Deffe,

Obfervation fur les Hôpituux 309 . Abus coneernant les maladies d'Armées, $3{ }_{1}$. Caufes des mala.lies d'Armées, 312. Remedes pour les maladies d'Armée, 314. Abregé de ma Methode, 316. Les. diaphoretiques font febrifuges 2 3I.9.

Le $Q$ uinquina mortifie les acides, 320. Experiences qui juftifient que le Quinguina ne fixe poine les acides, 321 . Le Quinguina. mêlé avec le fang, 322. Avecle lait.

Ii iij

$32 j$. 


\section{TA B L E}

Le Quinquina empêche les coagulations, 324. Il guerit les Fiévres en détruifant les acides, 325. C'eft un bon remede dans la Faim-canine, 3z6. Et dans les autres maladies caufées par les acides,

Le 2 uinquina bon contre les Gouttes \& les Rhumatifmes, 327 . Il ne détruit pas toûjours les coagulations, 330. Il les prévient, 33 r. Qu'il eft meilleur pour les intermittentes que pour les continuës, Réflnues, $3 j \geqslant$. na, 333. Précaution fur fon mélange, avec d'autres remedes, 335. Que le Quinguina ne fixe point, $i b i d$. Ce qui fe prouve par la raifon $\&$ parl'experience, 337 . Entêtement d'un Medecin fur la fixation par le Quinquina, 339 . Tout ce qui coagule \& fixe eft acide, 345. Effets de l'abondance des acides,

Que les rechutes ne font pas une preuve de fixation par le 2 uinquina, 350. Les Fiévres conti- 
DES MATIERES. nuës qui ont efté gueries par le Quinguina ne reviennenc jamais, 352. Erreurs populaires touchant le Quinquina, 353.

Fin de la Table des Matieres.

\section{EXTRAIT DV PRIVILEGE du Roy.}

DAr Grace \& Privilege du Roy 1 donné à Paris le 29. d'Aouft 1691 . Signé par le Roy en fon Confeil CARPOT : Il eft permis à |ACRins Minot Dockeur en Medecine, de faire imprimer partel Imprimeur qu'il voudra choifir, un livre intitulé, De la Nature $\mathcal{E}$ des caufes des Fiévres, \&c. pendant le temps de fix années confecutives, à commencer du jour que ledir livre fera achevé d'imprimer 
pourla premiere fois en vertu du prefent Privilege : Et deffences font faites à tous autres Imprimeurs \& Libraires, de l'imprimer, faire imprimer, vendre \& debiter, fans le confentement de l'Expo: fant, ou de ceux qui auront droit de luy, à peine de trois mille livres d'amende, de confifcation des Exemplaires contrefaits, \& de tous dépens, dommages \& interefts, ainfi que plus au long il eft porté par ledit Privilege.

Ledit Sieur MrNot a cedéfon Privilege à L A URENT D'Houry Marchand Libraire, fuivant l'accord fait entr'cux.

Regiftré fur le Livre de la Communauté des Imprimeurs $\mathrm{Li}$ braires de Paris le 3. Septembre 1691 .

Achevé d'imprimer pour la: premiere fois en vertu du prefent Privilege le 4. Novembre 159 . 


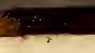




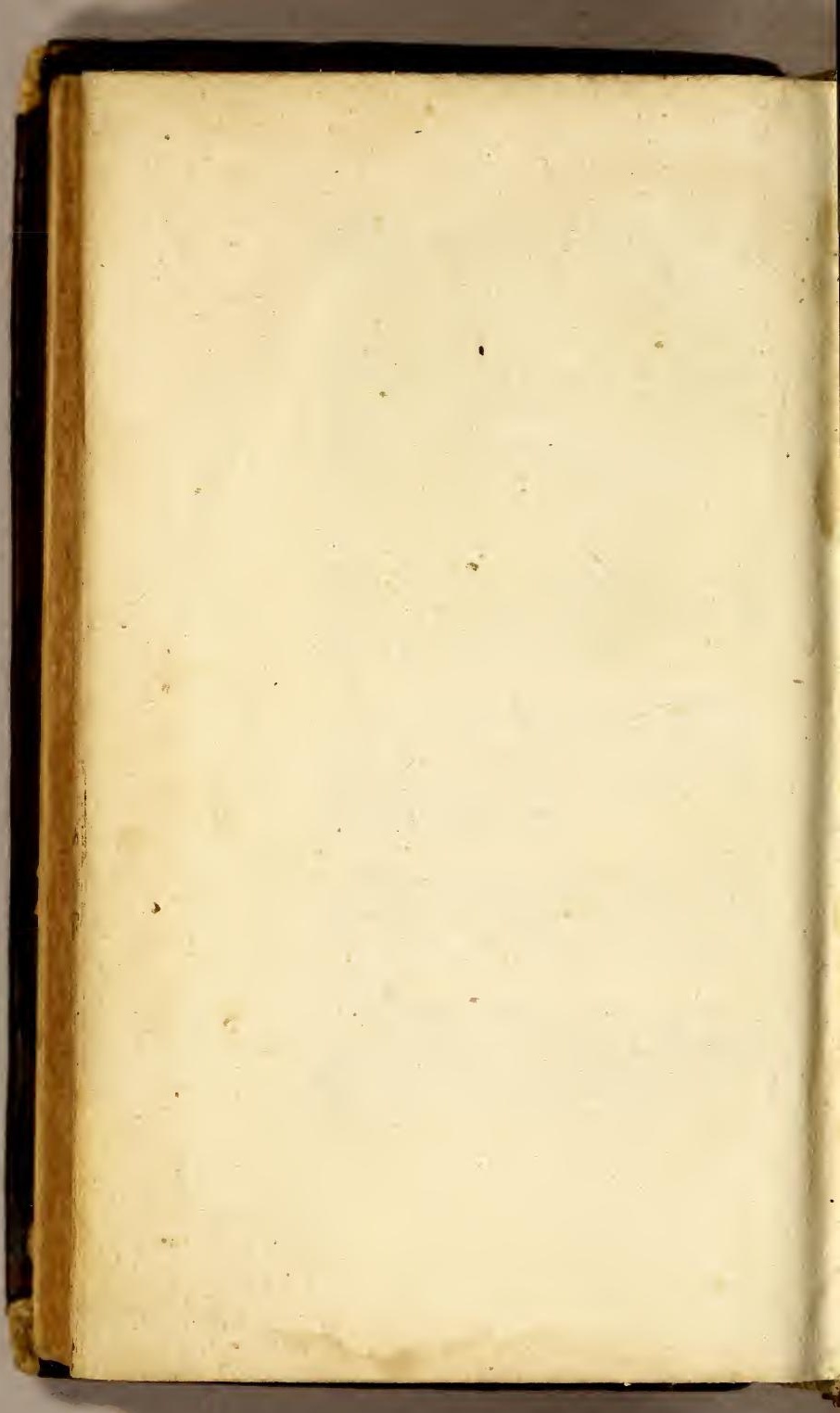




\section{$E 69$} Mnowd

है 


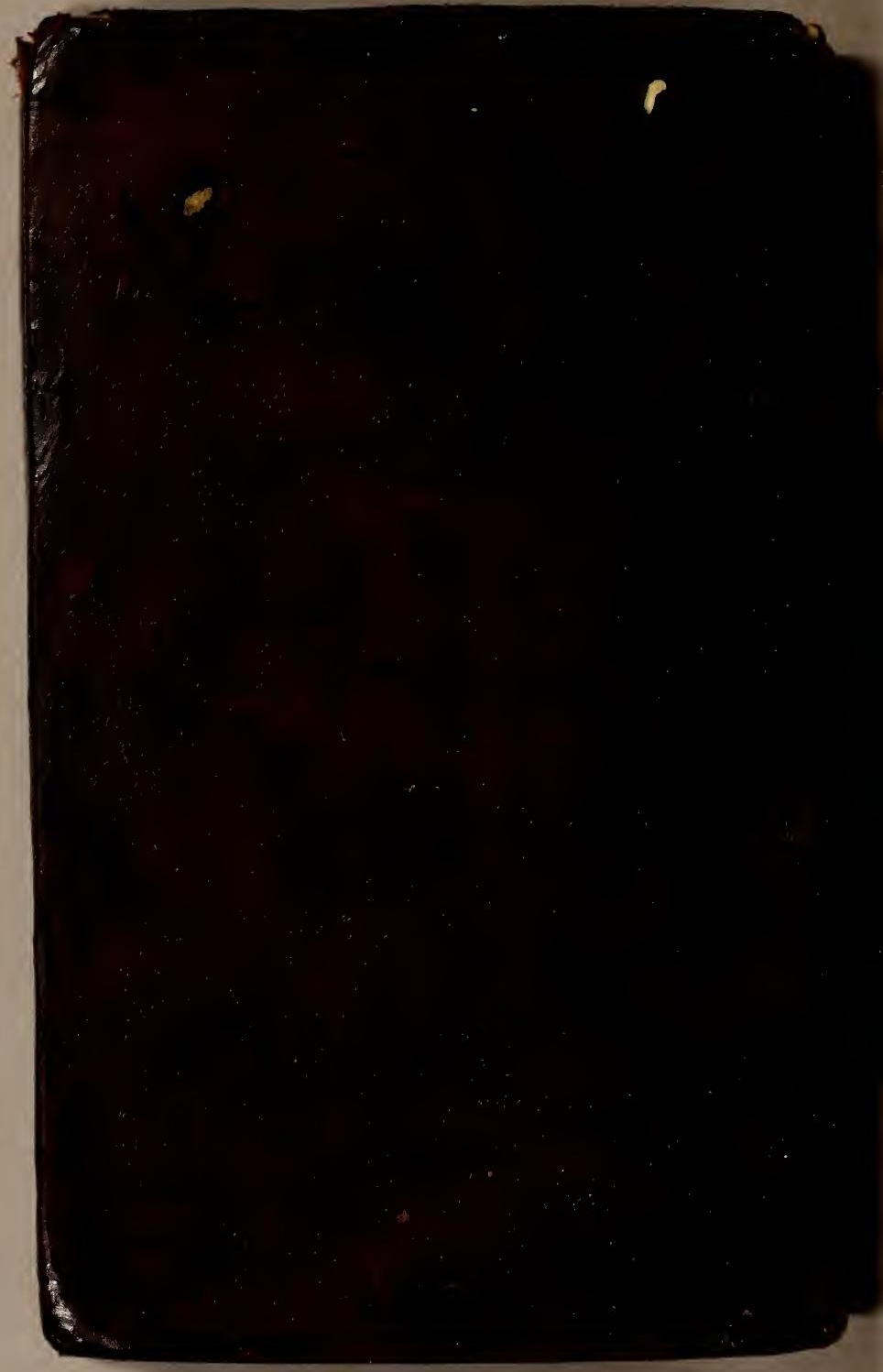

